
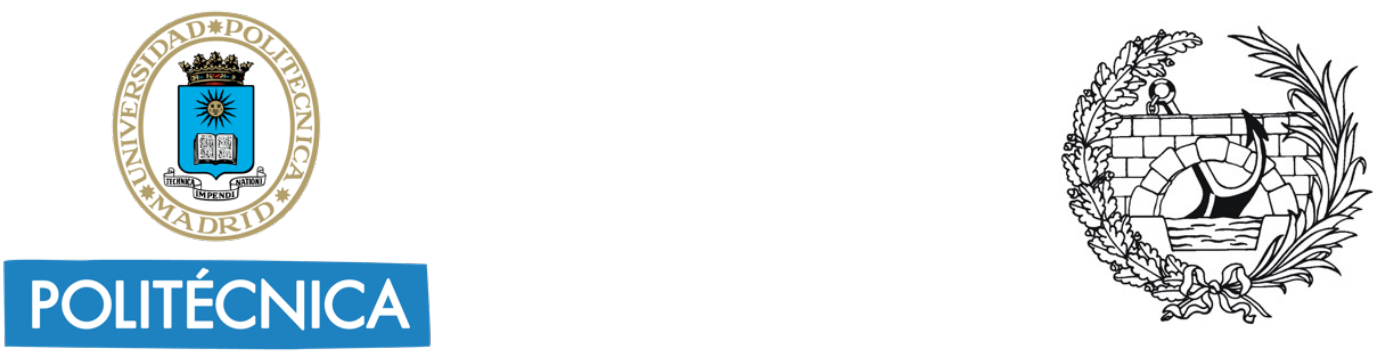

UNIVERSIDAD POLITÉCNICA DE MADRID

ESCUELA TÉCNICA SUPERIOR DE INGENIEROS DE CAMINOS, CANALES Y PUERTOS

DOCTORADO EN SISTEMAS DE INGENIERÍA CIVIL

\title{
BEHAVIORAL FACTORS UNDERLYING THE ADOPTION OF SMART MOBILITY SOLUTIONS
}

DOCTORAL THESIS

\author{
GUILLERMO VELÁZQUEZ ROMERA \\ M.Sc. Civil Engineering \\ M.Sc. City Sciences
}

\begin{tabular}{l|c} 
SUPERVISOR & CO-SUPERVISOR \\
Prof. ANDRÉS MONZÓN & Prof. SIGAL KAPLAN
\end{tabular}

Madrid, 2019 
Behavioral factors underlying the adoption of smart mobility solutions

(This page has been intentionally left blank) 


\section{POLITÉCNICA}

Tribunal nombrado por el Mgfco. y Excmo. Sr. Rector de la Universidad Politécnica de Madrid, el día de de 2019.

Presidente:

Vocal:

Vocal:

Vocal:

Secretario:

Suplente:

Suplente:

Realizado el acto de defensa y lectura de la Tesis el día de de 2019 en

la E.T.S. de Ingenieros de Canales, Caminos y Puertos de la U.P.M.

Acuerda otorgarle la calificación de:

Madrid, a de de 2019.

EL PRESIENTE

LOS VOCALES 
Behavioral factors underlying the adoption of smart mobility solutions

(This page has been intentionally left blank) 
"The isolated man does not develop any intellectual power. It is necessary for him to be immersed in an environment of other men, whose techniques he absorbs during the first twenty years of his life. He may then perhaps do a little research of his own and make a very few discoveries, which are passed on to other men. From this point of view the search for new techniques must be regarded as carried out by the human community as a whole, rather than by individuals."

Alan Turing 
Behavioral factors underlying the adoption of smart mobility solutions

(This page has been intentionally left blank) 


\section{AGRADECIMIENTOS}

El desarrollo de esta tesis doctoral ha sido posible gracias a la colaboración de muchas personas e instituciones. Todos ellos han aportado su granito de arena - ya sea de manera directa o indirecta; ya sea en el plano intelectual, emocional o material- para hacer más fácil su desarrollo.

Empiezo por agradecer al Banco Europeo de Inversiones y a la Comisión Europea su apoyo a través de la financiación de proyectos de investigación. Así, también quiero agradecer a la UPM el que ofrezca una educación pública de calidad. Ojalá estas dos cosas únicamente vayan a más en el futuro.

También quiero dar las gracias a mi director, Andrés Monzón, y a mi co-directora, Sigal Kaplan, por su exigencia y empeño en sacar lo mejor de mí. Por darme múltiples oportunidades de aprender y por su paciencia al enseñarme, orientarme e impulsarme. Muchas gracias.

Esta etapa ha sido también un periodo de mucho crecimiento personal. Se lo debo a mis compañeros del Master in City Sciences con los que compartí un año fantástico y aprendí multitud de nuevas ideas. Me siento en especial deuda con Fiamma, Vicky y Javi con los que ASCIMER se convirtió en un verdadero lujo. Espero poder trabajar de nuevo en el futuro con tantas ganas, con tan buen equipo y en un proyecto tan social, creativo e innovador.

Quiero dar las gracias también a Andrés, Andrea, y András, por acompañar discretamente mi avance como investigador y guardar los mejores ánimos para mí; a Carmen y María Eugenia por cuidarme y aconsejarme en mi paso por TRANSyT; a Iria, Laura y Javi por acompañarme de manera especial en la recta final, aprendiendo mutuamente y riéndonos cada día; y a Juan, mil gracias por tus aportaciones y comentarios a la tesis.

También forman parte de esta tesis Dr. Bhat, que me abrió las puertas a su centro de investigación en Austin; Patricia y Felipe, gracias a los que mi estancia realmente dio sus frutos; y Adam y Parit que hicieron que lejos de casa fuese casa también.

Quiero darle las gracias a Madrid por ser una ciudad en la que todo es posible, incluso el albergar un cambio radical en la movilidad de la ciudad que ha posibilitado este trabajo. De igual manera, merecéis mención todos mis amigos y amigas que habéis aguantado mis ausencias en este proceso. Por último, quiero daros las gracias a mi Madre, mi Padre y mis hermanos Juancho e Inés. Sois lo mejor que tengo. Me gusta pensar que todos vosotros constituís las variables latentes con las que habría que modelizar la consecución de este resultado. Gracias de corazón.

Guillermo 
Behavioral factors underlying the adoption of smart mobility solutions

(This page has been intentionally left blank) 
Today, cities are home to more than half of the world's population and hold a preeminent position in both human activity and global economy. Yet, their growth, which is expected to continue in all world regions in the near future, is posing massive sustainability challenges. These challenges bring up the need for innovative urban solutions that help to reduce inefficiencies and externalities, while retaining the benefits of urban surge.

At the same time, Information and Communication Technologies (ICTs) have undergone swift progress, constantly generating new solutions and business models. These innovations are rewriting the ground rules for multiple economic sectors, including the urban services field as they are being deployed in cities around the globe.

Smart Mobility solutions arise from the transposition of these technologies and disruptive models to the urban mobility field. These new solutions are expected to solve several urban challenges through an optimization of city services while enhancing social, economic and environmental sustainability and the quality of life of the citizens.

This doctoral thesis is framed in the context of the popularization of the Smart City concept and of the massive eruption of IT-based urban mobility solutions in our cities. It is aimed at expanding the body of knowledge in the transport behavior field by understanding how certain behavioral traits present in the population are aligned with the choice to adopt and use new IT-based sustainable transport solutions and services.

With this aim, the users of Madrid's transport network have been searched for the propensity to adopt and use three different smart mobility solutions linked to the three main transportation options (active modes, public transportation and private car). Three behavioral studies are developed in this work in the city of Madrid, each including a specific data collection process through online surveys. The hypotheses and the executed analysis are focused on the role of both traditional transport-related and more novel technology-related attitudinal factors; obtaining an answer to the research question of which behavioral traits underly the decision to adopt smart mobility solutions. Results show that the factors of "green values", "social norms", "technophilia" and "privacy concerns" do play relevant roles in the users decision to adoption and use these solutions.

The objective of this thesis is to improve public policy by focusing on how said attitudinal factors can be exploited to leverage a new, more sustainable future of urban mobility. In this sense policy recommendations are provided in its conclusions. 
Behavioral factors underlying the adoption of smart mobility solutions

(This page has been intentionally left blank) 


\section{RESUMEN}

Hoy en día, más de la mitad de la población mundial vive en áreas urbanas. Las ciudades ocupan una posición preeminente tanto en la actividad humana como en el conjunto de la economía mundial. Sin embargo, su crecimiento imparable, que se espera que continúe en todas las regiones del mundo en un futuro próximo, está planteando enormes desafíos de sostenibilidad. Estos retos plantean la necesidad de encontrar soluciones urbanas innovadoras que ayuden a reducir las ineficiencias y las externalidades, garantizando al mismo tiempo los beneficios de las aglomeraciones urbanas.

En paralelo a este proceso, las Tecnologías de la Información y la Comunicación (TIC) han experimentado un rápido avance, introduciendo de forma continua nuevas soluciones y modelos de negocio. Estas innovaciones están reescribiendo las reglas más básicas para múltiples sectores económicos, incluyendo el área de los servicios urbanos a medida que se despliegan en ciudades de todo el mundo.

Las soluciones de movilidad inteligente surgen de la transposición de estas tecnologías y modelos disruptivos al campo de la movilidad urbana. Así, se espera que estas nuevas soluciones resuelvan varios retos urbanos a través de la optimización de los servicios de la ciudad, mejorando al mismo tiempo la sostenibilidad social, económica y medioambiental y la calidad de vida de los ciudadanos.

Esta tesis doctoral se enmarca en el contexto de la popularización del concepto de Smart City y de la irrupción masiva en nuestras ciudades de soluciones de movilidad urbana basadas en TIC. Su objetivo es ampliar el conocimiento en el campo de los estudios de la conducta del usuario en materia de movilidad mediante la comprensión de cómo determinados rasgos de comportamiento presentes en la población se alinean con la elección de adoptar y utilizar nuevas soluciones y servicios de transporte sostenible basados en TIC. Con este objetivo, se ha estudiado entre los usuarios de la red de transporte de Madrid la propensión a adoptar y utilizar tres soluciones de movilidad inteligente vinculadas a las tres principales opciones de transporte (modos activos, transporte público y vehículo privado). En este trabajo se desarrollan tres estudios de conducta en la ciudad de Madrid, cada uno de los cuales incluye un proceso específico de recogida de datos a través de encuestas online. Las hipótesis y los análisis realizados se centran en el papel tanto de factores de conducta tradicionalmente relacionados con el transporte como factores más novedosos relacionados con la tecnología; obteniendo así una respuesta a la pregunta de investigación del presente estudio, centrada en qué rasgos de comportamiento subyacen a la decisión de los usuarios de adoptar y utilizar soluciones de movilidad inteligente. Los resultados muestran que los factores de "valores ecológicos", "normas sociales", "tecnofilia" y "preocupaciones sobre la privacidad" desempeñan un papel importante en la decisión de los usuarios de adoptar y utilizar estas soluciones.

El objetivo último de esta tesis es mejorar las políticas públicas, centrándose en cómo se pueden explotar los factores de conducta mencionados para impulsar un futuro más sostenible de la movilidad urbana. En las conclusiones del trabajo se formulan recomendaciones en este sentido. 
Behavioral factors underlying the adoption of smart mobility solutions

(This page has been intentionally left blank) 


\section{TABLE OF CONTENTS}

$\begin{array}{lr}\text { PARTI-INTRODUCTION } & 1\end{array}$

$\begin{array}{ll}\text { 1. INTRODUCTION } & \mathbf{1}\end{array}$

1.1 RESEARCH MOTIVATION \& RELATED RESEARCH ACTIVITIES 3

1.2 THESIS STRUCTURE

2. MOBILITY IN THE FRAME OF INTELLIGENT CITIES \& THE ROLE OF THE DIFFERENT MODES 9

2.1 URBAN GROWTH, SMART CITIES AND THE SMART MOBILITY PARADIGM

2.2 SMART MULTIMODAL MOBILITY \& HUMAN BEHAVIOR 27

2.3 BEHAVIORAL FACTORS FOR SMART MOBILITY 28

2.3.1 GReEN VAlues/Green Lifestyle

2.3.2 SOCIAL NORMS/COMMUNITY RESILIENCE

2.3.3 TECHNOPHILIA/TECH-SAVVINESS

2.3.4 SAFETY/PRIVACY CONCERNS

2.4 RESEARCH QUESTIONS 32

3. OBJECTIVES AND RESEARCH FRAMEWORK 35

3.1 GENERAL OBJECTIVE

3.2 SPECIFIC OBJECTIVES

$\begin{array}{lll}3.3 & \text { RESEARCH FRAMEWORK } & 37\end{array}$

$\begin{array}{ll}\text { PART II - ANALYSIS METHOD } & 41\end{array}$

4. METHODOLOGY $\quad 43$

4.1 SURVEY DEVELOPMENT AND DATA COLLECTION

4.2 STATISTICAL MODELS FOR DATA ANALYSIS

4.2.1 EXPLORATORY FACTOR ANALYSIS

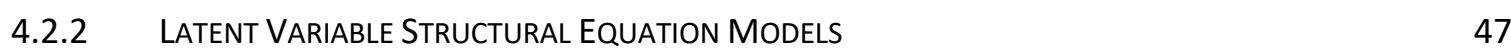

4.2.3 Integrated Choice And LATENT Variable Models 48

5. MADRID SMART MOBILITY LAB $\quad 49$

5.1 POPULATION AND TRANSPORTATION NETWORK IN MADRID

5.2 MOBILITY PATTERNS IN MADRID 49

5.3 URBAN CHALLENGES AND SMART MOBILITY SOLUTIONS IN MADRID

PART III - BEHAVIORAL MODELS FOR THE ADOPTION OF SMART MOBILITY SOLUTIONS IN MADRID 61

6. APPLICATION OF THE METHODOLOGY TO MADRID 59

7. BEHAVIORAL MODEL FOR THE ADOPTION OF BIKESHARE 67

$\begin{array}{lll}7.1 & \text { OVERVIEW OF BICIMAD } & 67\end{array}$

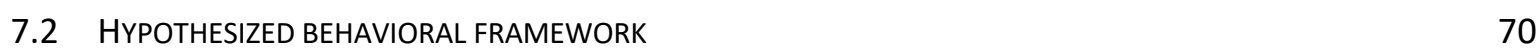

7.3 DESCRIPTION OF THE EXPERIMENT DESIGN AND EXECUTION 72 
$\begin{array}{lll}7.4 & \text { SAMPLE DESCRIPTION } & 76\end{array}$

$\begin{array}{lll}7.5 & 77\end{array}$

$\begin{array}{llr}7.6 & \text { MOdEL ESTIMATION RESULTS } & 80\end{array}$

8. BEHAVIORAL MODEL FOR THE ADOPTION OF A MULTIMODAL TRANSIT APP 83

8.1 OVERVIEW OF “MiTRANSPORTE” APP 85

8.2 HYPOTHESIZED BEHAVIORAL FRAMEWORK 86

8.3 DESCRIPTION OF THE EXPERIMENT DESIGN AND EXECUTION 88

$\begin{array}{lll}8.4 & \text { SAMPLE DESCRIPTION } & 93\end{array}$

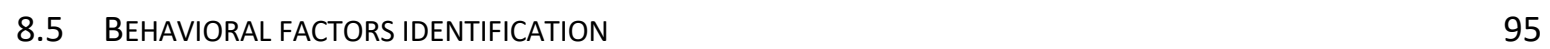

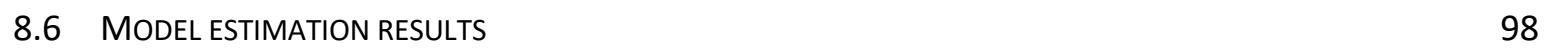

9. BEHAVIORAL MODEL FOR THE ADOPTION OF CARSHARE 101

9.1 OVERVIEW OF CARSHARE IN MADRID 101

9.2 HYPOTHESIZED BEHAVIORAL FRAMEWORK 103

9.3 DESCRIPTION OF THE EXPERIMENT DESIGN AND EXECUTION 105

$\begin{array}{llr}9.4 & \text { SAMPLE DESCRIPTION } & 114\end{array}$

$\begin{array}{llr}9.5 & \text { BEHAVIORAL FACTORS IDENTIFICATION } & 118\end{array}$

$\begin{array}{lrr}9.6 & \text { MOdEL ESTIMATION RESULTS } & 120\end{array}$

10. DISCUSSION \& CROSS SOLUTION ANALYSIS 125

PART IV - CONCLUSIONS

11. CONCLUSIONS AND FUTURE RESEARCH

$\begin{array}{ll}11.1 \text { CONCLUSIONS } & 133\end{array}$

$\begin{array}{lr}11.2 \text { POLICY RECOMMENDATIONS } & 147\end{array}$

$\begin{array}{ll}11.3 \text { LIMITATIONS AND FUTURE RESEARCH } & 145\end{array}$

$\begin{array}{lr}\text { 12. REFERENCES } & 149\end{array}$

$\begin{array}{ll}\text { PART V - ANNEXES } & 161\end{array}$

ANNEX I-SURVEYS

ANNEX II - RESEARCH ACTIVITIES THAT SUPPORTED THE THESIS 


\section{LIST OF TABLES}

Table 1. Urban Mobility challenges as identified by the ASCIMER project

Table 2. Taxonomy of Smart Mobility solutions grouped by areas ....................................................23

Table 3. Main characteristics of the three developed surveys ............................................................46

Table 4. Bikeshare Survey Sample Description Summary .............................................................76

Table 5. Output of rotated factor analysis (exploratory) for the Bikeshare study ................................78

Table 6. Structural Eq. relating LV to Bikeshare use and intention to renew subscription ...................81

Table 7. Survey items included in Mi Transporte research study questionnaire .................................91

Table 8. Technological capabilities of the sample by age, \% of device ownership ..............................94

Table 9. Output of rotated factor analysis (exploratory) for the mobile APP study ............................96

Table 10. Structural equations relating latent factors to app use intention and adoption...................99

Table 11. Offers characterization by different Carsharing services in Madrid ...................................103

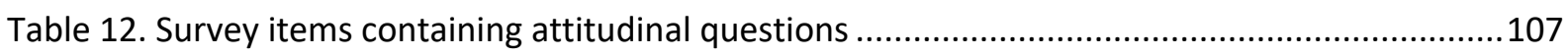

Table 13. Carshare Survey Sample Description Summary..............................................................114

Table 14. Users vs. non-users of Carshare, for different levels of car access ...................................115

Table 15. Frequency of use of the private car by type of trip (Carshare non-users) ...........................115

Table 16. Frequency of use of Carshare by type of trip (Carshare users) ........................................116

Table 17. Choices of the sample by age group (Carshare) ….........................................................117

Table 18. Output of the rotated factor analysis (exploratory), for the Carshare study....................119

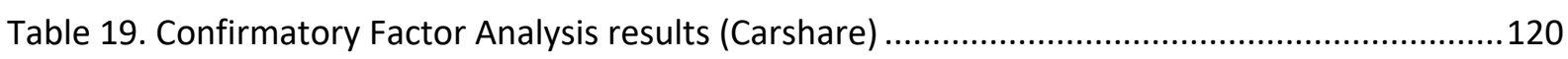

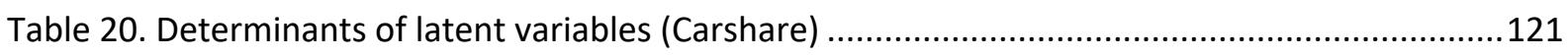

Table 21. Measurement equation of use of shared services and choice model of Carsharing use ....122

Table 22. Comparison of results in the three solutions 
Behavioral factors underlying the adoption of smart mobility solutions

(This page has been intentionally left blank) 
Figure 1. General structure of the Doctoral Thesis

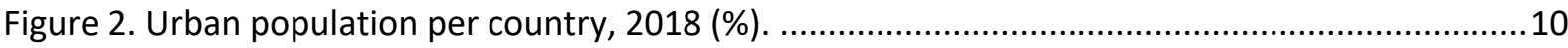

Figure 3. Urban Challenges in developed and developing regions, by City Dimension. ......................11

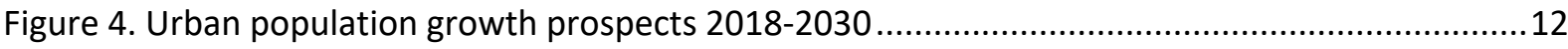

Figure 5. Population with broadband mobile subscription per country (\%), 2012-18 .........................13

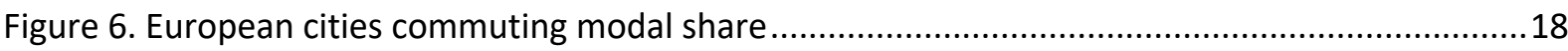

Figure 7. Key improvements for the different modes, multimodality as a common enabler...............24

Figure 8. Relative $\mathrm{CO} 2$ emissions for each mode $\left(\mathrm{g} \mathrm{CO}_{2} /\right.$ pax-km) .................................................26

Figure 9. Research questions linked to the adoption of smart mobility solutions................................33

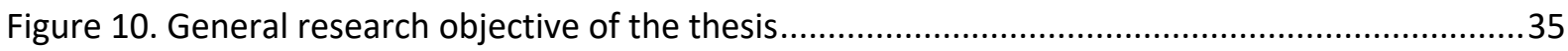

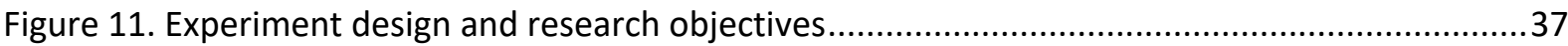

Figure 12. The three smart mobility solutions selected for the doctoral thesis research....................38

Figure 13. Overview of the methodological procedure of the thesis..................................................43

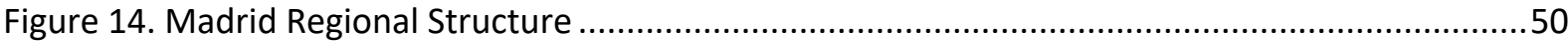

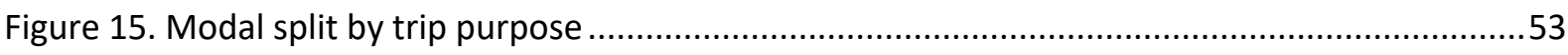

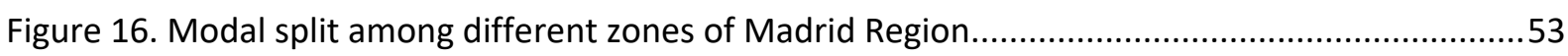

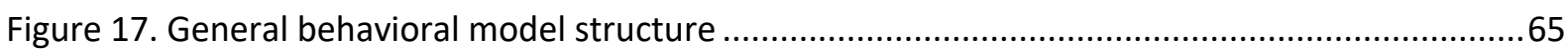

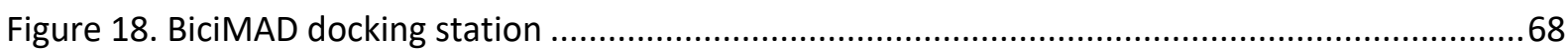

Figure 19. Distribution of BiciMAD docking stations in Madrid .......................................................68

Figure 20. Evolution of registered users in BiciMAD (2014-2019) ....................................................69

Figure 21. Hypothesized Behavioral model for the adoption of BiciMAD .........................................71

Figure 22. Surveyed area and zone split for the ex-ante survey phase of BiciMAD .............................73

Figure 23. Bikeshare model results: relation among variables and latent variables............................82

Figure 24. Mi Transporte outlook. Configuration and Map screens. ................................................86

Figure 25. Hypothesized behavioral model for the adoption of a Multimodal Transit APP ................87

Figure 26. Location of the Avenida de America interchange station within Madrid city.....................89

Figure 27. Panel Survey Evolution through the three waves (Mi Transporte) .....................................90

Figure 28. Multimodal APP model results: relation among variables and latent variables ...............100

Figure 29. Infographic with the three main existing Carsharing systems in Madrid ...........................102

Figure 30. Area coverage for the three main existing carshare systems in Madrid...........................102

Figure 31. Hypothesized Behavioral model for the adoption of Carshare .......................................105

Figure 32. Location of the two institutions where the sample was obtained...................................108

Figure 33. Carshare model results: relation among variables and latent variables ...........................123 
(This page has been intentionally left blank) 


\section{LIST OF ACCRONYMS AND ABREVIATIONS}

\begin{tabular}{|c|c|}
\hline CFA & Confirmatory Factor Analysis \\
\hline CFI & Comparative Fit Index \\
\hline CRTM & Consorcio Regional de Transportes (Regional Transport Authority of Madrid) \\
\hline EC & European Commission \\
\hline EEA & European Environmental Agency \\
\hline EFA & Exploratoty Factor Analysis \\
\hline EMT & Empresa Municipal de Transportes (Local Transport Company of Madrid) \\
\hline ETAM & Extended Technology Acceptance Model \\
\hline FP7 & 7th Framework Programme \\
\hline ICLV & Integrated Choice and Latent Variable Model \\
\hline ICTs & Information and Communication Technologies \\
\hline INE & Instituto Nacional de Estadística (Spanish National Statistics Office) \\
\hline ITU & International Telecommunications Union \\
\hline KMO & Kaiser-Meyer-Olkin \\
\hline LOS & Level Of Service \\
\hline LV & Latent Variable \\
\hline NFC & Near-Field Communication \\
\hline OECD & Organisation for Economic Co-operation and Development \\
\hline PT & Public Transportation \\
\hline PWC & Price Waterhouse Coopers \\
\hline R\&D & Research and Development \\
\hline RMSEA & Root Mean Square Error of Approximation \\
\hline RQ & Research Question \\
\hline SEM & Structural Equation Modelling \\
\hline UITP & Union Internationale des Transports Publics \\
\hline UN & United Nations \\
\hline UPM & Universidad Politécnica de Madrid \\
\hline WEF & World Economic Forum \\
\hline WTP & Willingness To Pay \\
\hline
\end{tabular}


(This page has been intentionally left blank) 
PART I - INTRODUCTION 
Behavioral factors underlying the adoption of smart mobility solutions

(This page has been intentionally left blank) 


\section{INTRODUCTION}

\subsection{RESEARCH MOTIVATION \& RELATED RESEARCH ACTIVITIES}

Cities are the primary hubs of human activity. Their growth has been constant over the last few decades worldwide with economic activity, cultural offerings and services acting as attraction elements for families and businesses. Cities offer a wide array of opportunities to their inhabitants; however, they also pose great challenges to both social and environmental sustainability.

In recent times, the outstanding progress of Information and Communication Technologies (ICTS) as well as their wide deployment around the globe have brought some of the biggest changes to human life in all of history. This change, which has fundamentally affected the way we communicate and how we handle information, has had an undeniable effect on how individuals interact and on how societies manage their activity. ICTs have rewrote the ground rules for multiple economic sectors, including the transportation and mobility fields.

As of today, it has never been easier to reach your friends and relatives, your clients, or your service providers. It has never been easier to obtain and share information, to contract, or to pair supplier and demander for any good or service imaginable. This wave of change and of adaptation to new technologies is still ongoing in most sectors of the economy, introducing improvements worldwide at different speeds and with different geographical distributions.

On the downside, the turmoil of digitalization has also unveiled relevant challenges. Some of them are new, like the overflooding of the users with information due to the democratization of the power to communicate and the disappearance of physical distance barriers in communication terms. Other examples include the difficulties of adaptation of the elderly to digital platforms and technologies or the collection of personal data without sufficient guarantees for the technology users. Some others are preexisting challenges that have been strengthened by technology, like social inequality mechanisms or the widening of gaps in regulation. 
The transportation sector, and more specifically the urban mobility sector, is one of the fields where this transformation is having a wider impact, with even greater changes expected to come soon. The proper integration of these changes in our cities has the potential to create a more livable and sustainable reality. Conversely, they could generate further exclusion, widening the gap between population groups. These impacts are dependent on the implementation process, the pace of social adaptation and, most importantly, the public policies adopted.

This doctoral thesis is framed in the context of the popularization of the Smart City concept and the massive eruption of ICT-based urban mobility solutions. It is aimed at improving public policy by understanding which behavioral traits present in the population are aligned with the choice to adopt and use new ICT-based sustainable transport solutions and services. With this information in hand, the thesis suggests how said attitudinal factors can be exploited through policy to leverage a new, more sustainable future of urban mobility.

Alongside the elaboration of this work, a wider set of research activities -parts of which are included in this document- have been developed. These projects include (i) "ASCIMER" (Assessing Smart City Initiatives in the Mediterranean Region) a three-year project funded by the European Investment Bank under its EIBURS program; (ii) "OPTICITIES" a research project aimed at Optimizing Citizen Mobility and Freight Management in Urban Environments, funded by the European Commission under its 7th Research Framework Programme and (iii) "Transforming Transport" a 2,5 year project focused on testing the effects of Big Data on Transportation and funded by the European Commission under its Horizon 2020 research program. Also, two research stays have taken place in relation with this work at the Hebrew University of Jerusalem and at the University of Texas at Austin. For more information on these activities we ask the reader to refer to ANNEX II - RESEARCH ACTIVITIES THAT SUPPORTED THE THESIS. 


\subsection{THESIS STRUCTURE}

In order to ease comprehension, this doctoral thesis has been structured in four differentiated parts that contain a total of twelve chapters. Each of these parts groups a set of chapters that have a common ground within the global research process. Within them, every chapter presents one of the different steps of the research process as depicted in Figure 1 on page 6 . The structure for the thesis then results as follows:

\section{PART I - INTRODUCTION}

The first part acts as an introduction to the studied topics, prior to the development of the main body of the thesis. It contains a general introduction chapter (Chapter 1), a literature review chapter (Chapter 2), and a description of the main research objectives of this work (Chapter 3).

- Chapter 1 introduces the work, explaining the motivations that led to its development and gives a general overview of its structure.

- Chapter 2 contains an overview of the main literature, which is divided in three sections: the first one presents the diagnosis of the current state of cities, and the smart city and smart mobility concepts; the second section presents the use of behavioral models in smart mobility and the state of the art of latent factors used in research of smart mobility; the third and final section identifies the research questions, linked to better understanding how certain behavioral factors inform the adoption of new mobility solutions.

- Chapter 3 concludes the literature review by establishing the overall research goal of the thesis, as well as its specific research objectives. This chapter also explains the research approach that has been followed including how and why three smart solutions are to be studied to achieve those objectives. 


\section{PART II - ANALYSIS METHOD}

The second part of the thesis contains two chapters related to the chosen research methods. The first

(Chapter 4) describes the methodology of analysis selected for this research, the second one (Chapter

5) characterizes the city of Madrid, where the analyzed solutions are located, as a smart mobility lab.

- Chapter 4 describes the methodology that has been applied in order to guarantee a faithful analysis of the influence of the selected behavioral factors on the adoption and use of three different innovative ICT-based mobility solutions.

- Chapter 5 presents the Madrid case study, home to the three smart mobility solutions analyzed in this thesis. The chapter describes the city's demographic and economic characteristics as well as reports main transportation infrastructures and services that exist. A characterization of the mobility of Madridians is also presented. To close the chapter, urban mobility challenges that take place in the city of Madrid are explained; helping to understand why the adoption of smart mobility solutions in Madrid is necessary.

\section{PART III - BEHAVIORAL MODELS FOR THE ADOPTION OF SMART MOBILITY}

The third part of the thesis holds the principal body of research, containing the three concrete studies developed in this work, with papers either published in scientific journals, presented at scientific transport conferences, or undergoing the publication process. Chapter 6 links the chosen methodology and the previously described case study, introducing the three main research studies which constitute Chapter 7, 8 and 9; with Chapter 10 summarizing their main results in a cross-compared analysis.

- Chapter 6 acts as an introduction to the case studies in the three subsequent chapters, defining how the broadly described methodology and research objectives are applied to the case of Madrid and structured in the three research works.

- $\quad$ The research study presented in Chapter $\mathbf{7}$ is centered on better understanding the adoption mechanism for a smart mobility solution linked to an active mode: biking. The work presents 
the results of a process of experimentation (with ad-hoc data collection and the development of a behavioral model) carried out to analyze the factors that influence the decision to subscribe to the public bikeshare system in the city of Madrid.

- The research work presented in Chapter 8 studies the intention to adopt, actual adoption and usage of a smart mobility solution linked to transit: a Real Time Multimodal Public Transport APP. Again, through a process of experimentation, including the execution of a data collection campaign and a statistical model, the behavioral factors influencing the decision to use the app are analyzed. This research was published in the Transportation Research Record in 2018.

- The research study presented in Chapter 9, is centered on behavioral factors informing the adoption of a smart mobility solution linked to the private car mode: fully electric carshare. Once more, through an ad-hoc process of experimentation, which included the execution of a data collection campaign and a procedure of statistical modelling, different behavioral factors influencing the decision to adopt carshare are analyzed. This piece of research was recently submitted for publication.

- Based on the outputs obtained, Chapter 10 summarizes the main results, making a comprehensive argument through a cross-discussion.

\section{PART IV - CONCLUSIONS}

The fourth part of the thesis includes the main conclusions and future research lines generated by the overall research work (Chapter 11) and the compiled references (Chapter 12)

- Chapter 11 summarizes the main conclusions and contributions of this work. It also includes future research lines complementing and reinforcing this thesis and the policy recommendations that can be derived from it. Chapter 12 contains, in alphabetical order, the references consulted for the development of the thesis. 


\section{ANNEXES}

Finally, the fifth part includes two annexes containing (I) the surveys employed for data collection in the three research experiments and (II) information on the related research activities that have been undertaken in parallel to the development of this thesis.

In order to help understanding the link between the structure and the concepts included in this work, Figure 1 below displays the overall structure of the doctoral thesis, with all 11 chapters developing step by step the research process.

Figure 1. General structure of the Doctoral Thesis

\section{LITERATURE REVIEW (Ch.2)}

SMART CITY \& SMART MOBILITY

NEW ICT-BASED SOLUTIONS

BEHAVIORAL STUDIES \& FACTORS

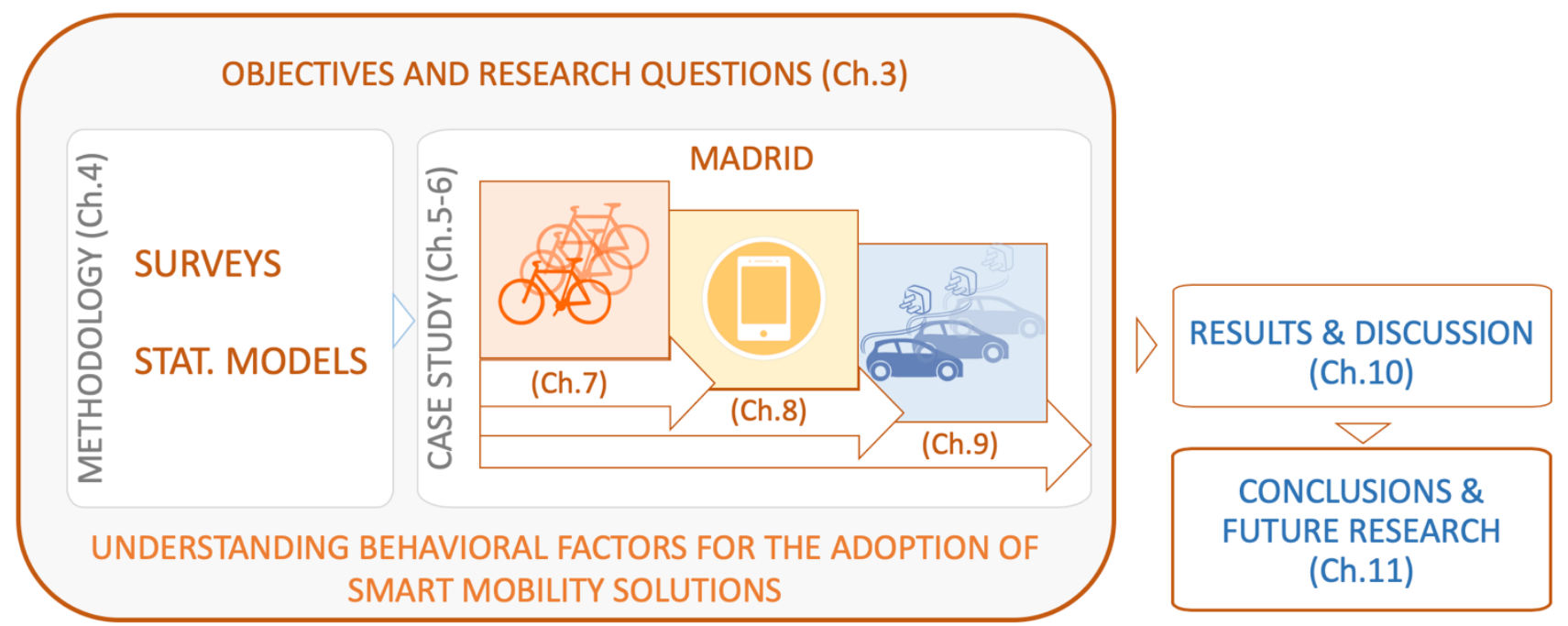




\section{MOBILITY IN THE FRAME OF INTELLIGENT CITIES AND THE ROLE OF THE DIFFERENT MODES}

\subsection{URBAN GROWTH, SMART CITIES AND THE SMART MOBILITY PARADIGM}

\section{GLOBAL URBAN GROWTH AND CHALLENGES}

According to the Merriam Webster dictionary, cities characterize as compactly settled areas of greater size, population, or importance. However, the concept has further evolved and nowadays it transcends the merely physical dimension of the settlement combining it with its indissociable human layer. This is, that now the concept also integrates the social and economic activities that at the same time emanate from and fuel the complex reality of the modern city. In their 2014 work, Neirotti et al. (2014) formulate: "current cities are complex systems, characterized by massive numbers of interconnected citizens, businesses, modes of transport, communication networks, services and utilities."

Along history, cities have constantly embraced technical advancements, gradually improving their functioning and proving to be an outstanding solution capable of boosting the quality of life of their inhabitants (Glaeser and Gottlieb, 2009). As a result, over the last century urban areas have gradually concentrated population, economic activities and social and cultural interchanges, adopting a prominent role in nowadays societies. Today, world cities are home to approximately $54,3 \%$ of the planet's population (World Bank Open Data, 2018), as well as they cluster 70\% of the World's economic activity (UN-Habitat III, 2017).

Urbanization levels are heterogeneous in geographic terms, with the most urbanized regions being North America (with $82 \%$ of its population living in urban areas in 2018), followed by Latin America 
and the Caribbean (81\%), Europe (74\%) and Oceania (68\%). The level of urbanization in Asia -although lower- is rising fast, now approximating $50 \%$. In contrast, Africa remains mostly rural, with only $43 \%$ of its population living in urban areas.

Figure 2. Urban population per country, 2018 (\%).

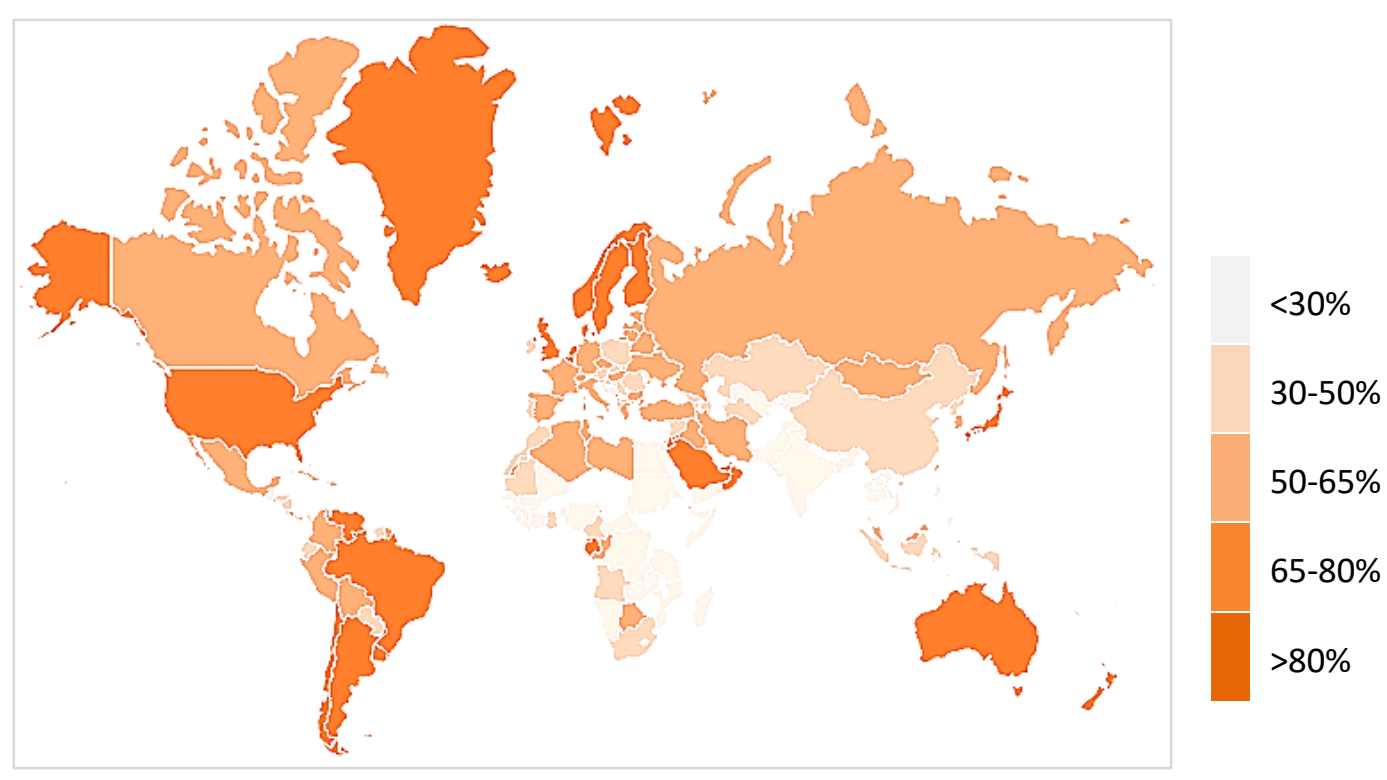

Source: Own elaboration based on UN data

This rise of the urban can be seen as an opportunity. The OECD points out on its Competitive Cities in the Global Economy review (2006) that agglomeration economies allow cities to offer a wide range of choice in resources and to concentrate more specialized business services and infrastructure. Such agglomeration economies are confirmed by an initial positive correlation between the cities size and the average household income (Zheng, 2007). Urban areas provide both the advantages of specialization and of diversity, as well as they tend to have greater endowments of capital (human and physical). They also hold the capacity to concentrate R\&D activities and to generate innovation (more than $81 \%$ of OECD patents are filed by applicants located in urban regions).

Conversely, the growth of cities has also started to create massive sustainability challenges (UNHabitat III, 2017). As a matter of fact, cities are the places where inequalities are larger and, unless adequately managed, negative externalities can surpass the positive economies of scale that the concentrated urban scheme generates (European Commission, 2011a). Some examples of these negative effects are thoroughly described also by the OECD; like the concentration of large and persistent pockets of unemployment, exclusion and poverty or like the exponential increase of negative externalities like air pollution, noise and congestion. 
With the aim of presenting the reader with a general perspective, Figure 3 graphically shows the result of a systematized analysis carried out by the ASCIMER project ${ }^{1}$ in 2016 summarizing the most relevant challenges of urban areas today. In the figure each challenge is linked to the different urban areas that constitute the city according to that same study. The analysis is unfolded in two sets of challenges, the inner ring-colored-corresponds to the challenges of cities in developing countries (in the specific study the analysis was conducted for south Mediterranean cities). The outer ring -grey- displays the challenges identified for cities in developed regions (in the study: European-Mediterranean cities).

Figure 3. Urban Challenges in developed and developing regions, by City Dimension.

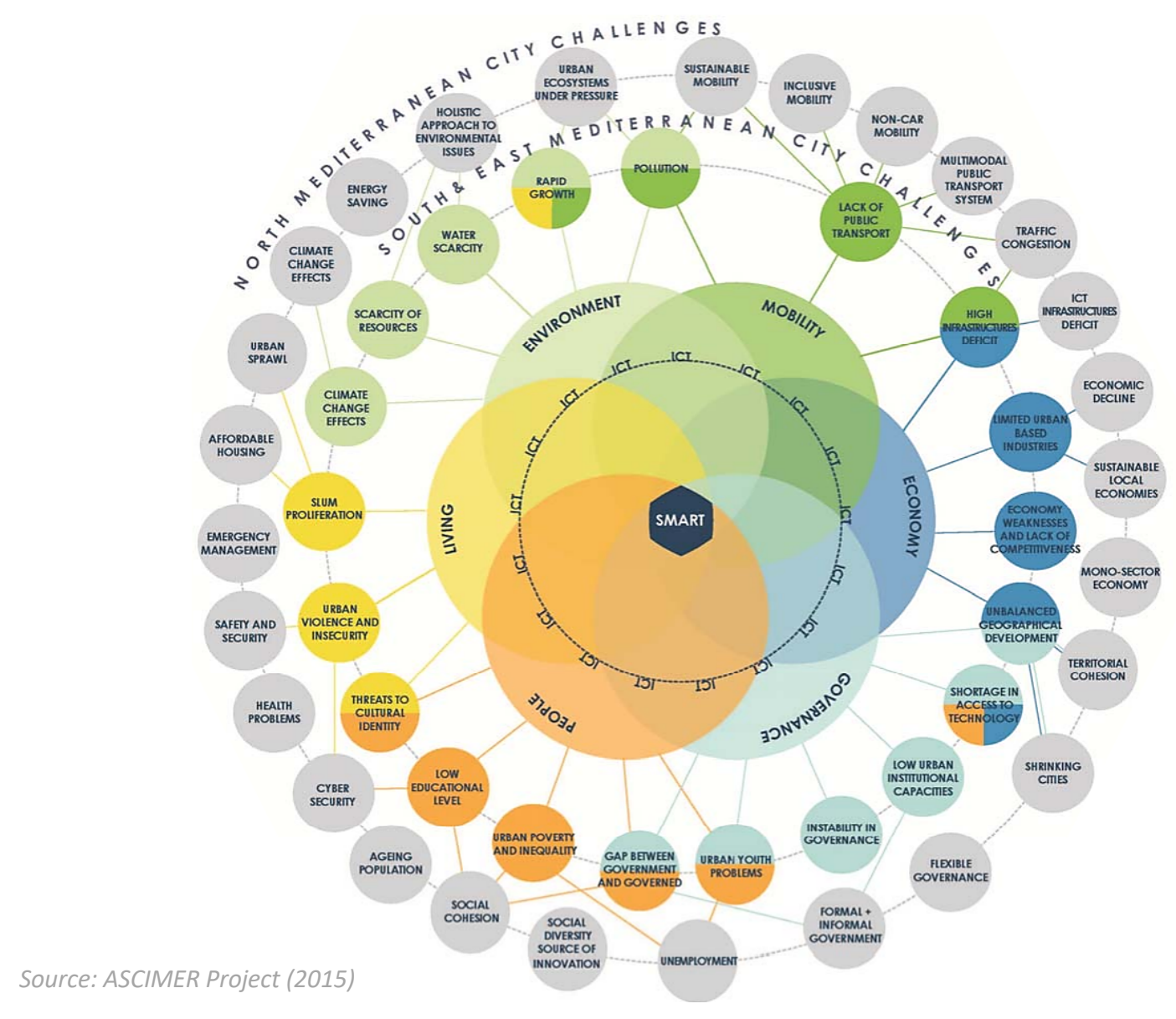

\footnotetext{
${ }^{1}$ ASCIMER is a three year research project funded by the European Investment Bank under its EIBURS program. Its main objectives are to develop a comprehensive framework to help public and private stakeholders to make informed decisions about Smart City investment strategies and to build skills to evaluate and prioritize these kinds of projects. (http://www.eiburs-ascimer.transyt-projects.com/) (accessed 02/05/2019)
} 
The figure includes twenty-seven challenges identified by the ASCIMER project for developed cities, and twenty challenges identified for cities in the developing regions. Each challenge is located near the area of the city that it affects more broadly, as well as it shares the color with that area -or those areasrelated to it. Challenges in developing cities are connected also with the challenges of developed ones that they are likely to turn into unless adequately solved.

Among those challenges, we can see some that are directly related to just one action field. These onefield challenges are identified with the same color as the action field to which they belong. In a second group, we can see multi action field challenges which are multi-colored in relation to the action fields they are affecting to. This representation gives an idea of how todays challenges are multilayered and how they need to be addressed in a multidisciplinary way (Fernandez-Anez et al., 2018). The initiatives taken to overcome each of these challenges may affect directly or indirectly more than just one action field, avoiding silo approaches.

To close this section we can conclude that regardless of its potential drawbacks, there is a generalized forecast that urban growth will continue in the next decades. As shown on Figure 4, the United Nations estimates that another 2.5 billion inhabitants will be added to the cities of the planet by 2050 . This means that by the late $21^{\text {st }}$ century, over $70 \%$ of the world population will be growing, living and working in cities. Hence, is appears as very likely that urban areas will keep on gaining importance as targets of environmental, economic and social policies in the near future.

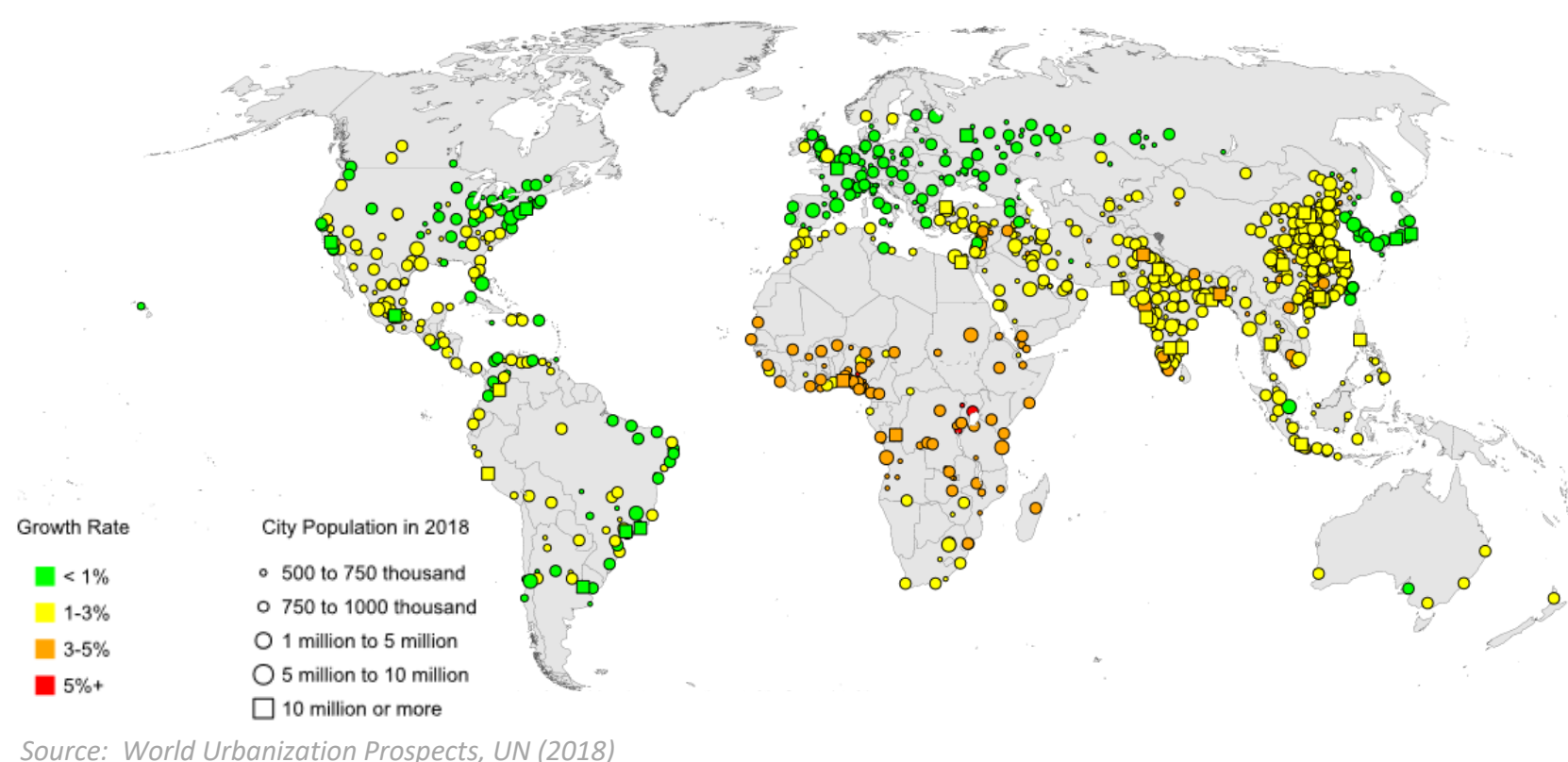

Source: World Urbanization Prospects, UN (2018) 


\section{THE RISE OF TECHNOLOGY (ICT)}

During the last decades, the progress of Information and Communication Technologies (ICTs) as well as their wide deployment around the Globe has brought some of the biggest change to human existence. ICTs are present in almost every aspect of our daily lives (especially in developed economies), with new sensors, electronic appliances and devices reaching the consumer market every day.

As an example, in 2018 smartphone penetration rates reached $80 \%$ in almost every region of the World, but for Africa, that reached $40 \%$, with a perspective of even further increase in the near future (especially in Africa that is expected to reach $80 \%$ in 2020). The figure below shows data provided by the International Telecommunications Union (2018) on the evolution of broadband mobile subscription coverage as a percentage of the total population.

Figure 5. Population with broadband mobile subscription per country (\%), 2012-18

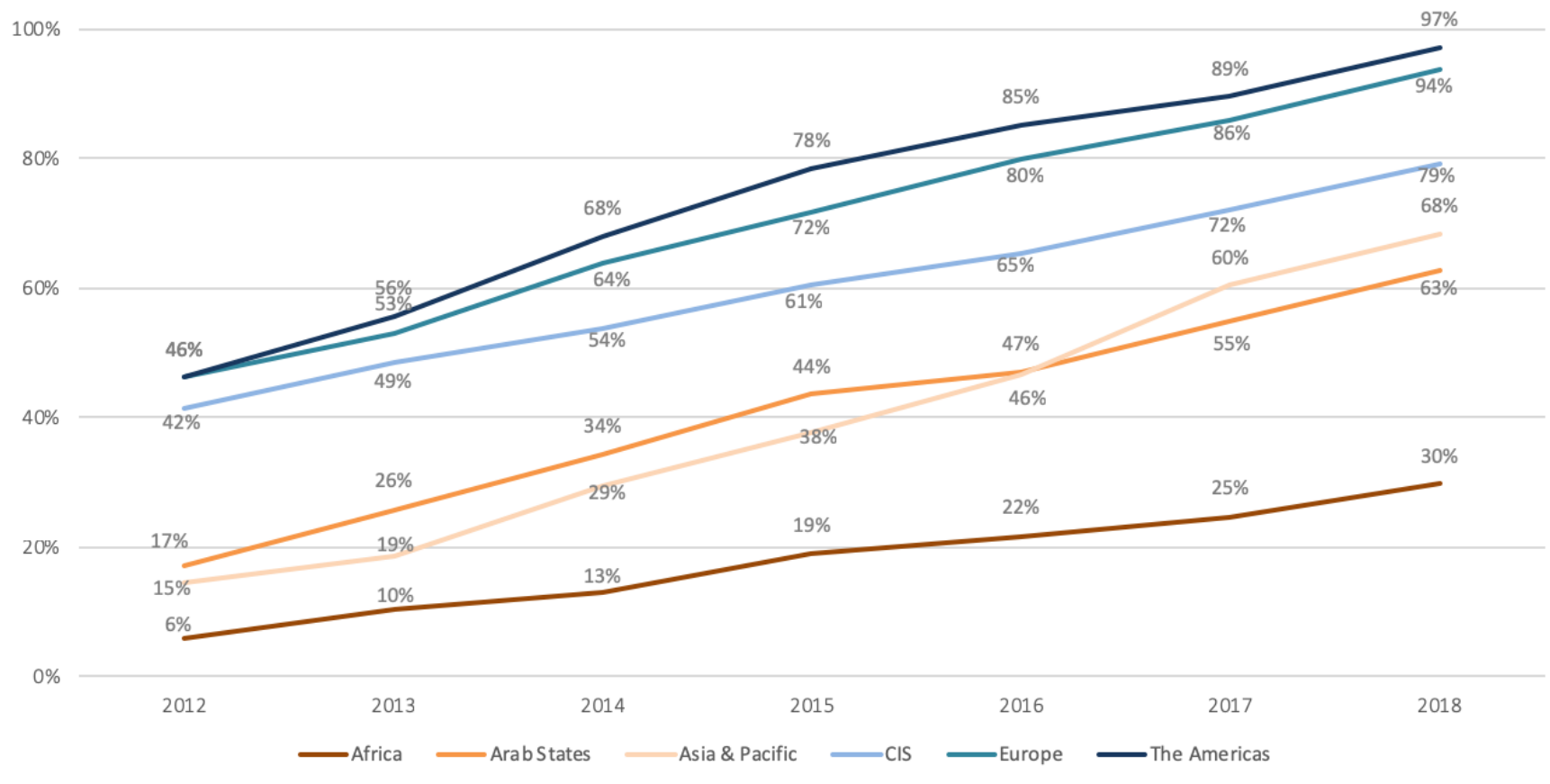

CIS - Commonwealth of Independent States, it includes Armenia, Azerbaijan, Belarus, etc.

Source: ITU (2018) and Own elaboration

In the same line as smartphone ownership, the increase in broadband access is generalized worldwide (Figure 5) and trend for the near future can also be ventured to continue on the rise. As of today, it has 
never been easier to reach your friends and relatives through social networks ( 29 million messages are sent every minute through Whatsapp according to the WEF, $\left.2018^{2}\right)$ contacting your clients $(146.000$ Skype calls take place per minute) or your service providers (186 million emails are sent every minute). Today, the internet has 4 billion users worldwide and Google processes over 50.000 searches every second. It has never been easier through all of history to obtain and share information, to contract, or to pair offer and demand for whichever good or service.

These changes, intrinsically affecting the way we communicate and how we handle information, have had an undeniable effect on how individuals interact and how we manage our activities, rewriting the ground rules for multiple economic sectors, including the mobility field. The wave of change and adaptation to new possibilities is still undergoing in most of the economic fields, introducing improvements worldwide at different speeds and with different geographical distributions.

In this framework, a new concept of city arises to solve the composite set of problems that urban settlements are facing: the Smart City. This concept, described in the next section, is spreading worldwide as a synonym of an innovative and new sustainable model of city that relies on ICT technology to address urban challenges.

\section{THE SMART CITY CONCEPT}

The Smart City concept appeared as a direct consequence of the two realities described in the previous sections. With the initial idea coming from the industry side; at first it appeared as if technological solutions were about to instantaneously solve all of the rising problems of our cities. However, despite several years of elaboration and inmplementation of Smart City plans -with considerable amounts of public funds being dedicated to lever the smarter management of urban areas and services- the ultimate impacts of the Smart Cities are still unclear, as well as the adequate procedures for their implementation.

\footnotetext{
${ }^{2}$ World Economic Forum, Global agenda March 2018. Available at: https://www.weforum.org/age nda/2018/03/internet-minute-whatsapp-facebook-emails. Accessed 02/05/2019
} 
In the academic field, and despite multiple efforts, there is no scientific standard for the concept of Smart City. This means that the concrete reality that the Smart City idea envisions still remains unclear. Several scientific approaches have suggested that an essential part of the concept lies in the combination of different aspects of the city in a holistic approach (Chourabi et al. 2012; Lombardi et al. 2012; Caragliu, Del Bo, and Nijkamp 2011). This concept of holistic smart city is applied by many authors in their research proposals (Alawadhi et al. 2012; Caragliu, Del Bo, and Nijkamp 2009; Chourabi et al. 2012; Fernández-Güell et al., 2016 ; Giffinger et al., 2007; Leydesdorff and Deakin, 2010). Also the existence of ICT-based urban solution keeps a more or less central place in the definition of the concept. Monzon (2015) proposed a definition with an integrative approach of the above:

"A Smart City is an integrated system in which human and social capitals interact, using technology-based solutions. It aims to efficiently achieve sustainable and resilient development and a high quality of life addressing urban challenges on the basis of a multi-stakeholder, municipality based partnership".

This definition sets technology as the basis of the Smart City, but focuses on the goals of the concept: efficiency, resiliency, sustainability and high quality of life.

As it has been observed, Smart Cities are not usually built from scratch (there are exceptions), but rather leveraged through the execution of projects and the implementation of solutions that are strategically inserted in a Smart City Strategy (Angelidou, 2014; City of Vienna, 2014).

The 2017 UN Habitat conference on Housing and Sustainable Urban Development highlighted the importance of understanding cities as a tool to give solution to challenges. It also highlighted the importance of facing these challenges from a multi-dimensional and multi-scalar perspective. (UNHabitat III, 2017). This multidimensionality is indeed a key element as described by Fernandez-Anez et al. (2017) and should be taken into account in the analysis of any smart solution regardless of its primary classification in one of the Smart City Areas defined by Monzon et al. (2015): Governance, Economy, People, Living, Environment or Mobility.

Also, smart solutions introduce new social challenges, e.g. exclusion of the poor if they cannot access the required technologies, or exclusion of the elderly if they cannot learn to use the new systems (Helsper, 2009). The role of policy is proving to be essential in the correct deployment of the Smart City concept in all its dimensions, including the urban mobility one. (López and Monzon, 2018) 


\section{URBAN MOBILITY EVOLUTION AND CHALLENGES}

In the described scenario of decades of continuous urban growth, the nature of urban mobility has also undergone relevant change. The European Commission, in its 2001 and 2011 Whitepapers on transportation, refers to the transport sector as one of the fundamental elements for the functioning of modern economies, and hence, of modern cities. Today, $64 \%$ of all kilometers traveled take place in urban environments and it is expected that the total number of urban kilometers traveled will triple by the year 2050 (UITP, 2014).

In today's cities, mobility is increasingly characterized by more diffuse mobility patterns, longer travel distances and, in most of them, a continuous rise of the motorization level. However, this tendency has started to peak in some -mostly European- developed economies for reasons still under study. As stated by Van der Waard (2013), "although much quoted in publications on reduced car mobility, a significant change in the attitude of young adults could not be determined through existing research". Regarding urban mobility challenges, urban transport is a source of great externalities that have a negative impact on the city's environment, generating challenges such as road congestion, air pollution, noise, occupation of the -generally scarce- public space or accidents.

In that sense, it is noticeable that the transport sector represents almost one quarter of greenhouse gas emissions in the European Union (European Commission, 2016). Also, urban transport is the main cause of noise and air pollution in EU cities ( $70 \%$ of pollutants), causing many of them often to be in breach of the established air pollution limits (European Commission, 2017).

As shown in Figure 3 in the previous section, todays cities are subject to various kinds of pressures, mostly deriving from urban sprawl: excessive use of the private vehicle, congestion, pollution, relocation of jobs or lack of integration of new transportation modes; but also challenges due to the growing demand for individual mobility or to an increasing exigence in terms of the quality standards of public services from the citizen side ${ }^{3}$. Table 1 below summarizes and details the main urban challenges linked to the Urban Mobility dimension identified in the ASCIMER research project.

${ }^{3}$ PWC Research Centre for Public Sector (2007). 


\begin{tabular}{|c|c|}
\hline \multicolumn{2}{|c|}{ Urban Mobility Challenges } \\
\hline Sustainable mobility & $\begin{array}{l}\text { There is a global need of changing the mobility model worldwide towards } \\
\text { a more sustainable one that involves energy-efficient private and public } \\
\text { transport, the proliferation of soft mobility modes and a multimodal } \\
\text { connected network available for all citizens. }\end{array}$ \\
\hline Inclusive mobility & $\begin{array}{l}\text { A successful mobility network needs to be affordable and accessible to the } \\
\text { whole population. Mobility systems play a key role in avoiding spatial } \\
\text { polarisation by facilitating the access of all the city inhabitants and visitors } \\
\text { to all parts of the urban fabric. }\end{array}$ \\
\hline $\begin{array}{l}\text { Multimodal public } \\
\text { transport systems }\end{array}$ & $\begin{array}{l}\text { Public mobility needs to work as a fluent network where a citizen can be } \\
\text { able to change from one kind of transport system to another, making an } \\
\text { efficient use of each kind. }\end{array}$ \\
\hline Non-car mobility & $\begin{array}{l}\text { Within the new transportation models, non-car mobility has to be made } \\
\text { more attractive, while private car use has to be made socially and } \\
\text { economically less attractive. }\end{array}$ \\
\hline Traffic congestion & $\begin{array}{l}\text { Traffic congestion has negative effects both for citizen's health and for the } \\
\text { environment conditions. It consumes energy, space and reduces the quality } \\
\text { of life of the inhabitants. It is necessary to provide an attractive variety of } \\
\text { transport systems that avoid the unnecessary overuse of the car. }\end{array}$ \\
\hline $\begin{array}{l}\text { Pollution and Green } \\
\text { House gas emissions }\end{array}$ & $\begin{array}{l}\mathrm{CO}_{2} \text { emissions are one of the main sources of pollution. Reducing the fuel- } \\
\text { dependent mobility would allow decreasing the pollution level and } \\
\text { enhancing the environment quality. }\end{array}$ \\
\hline
\end{tabular}

Source: ASCIMER Project (2015)

Modal shares in modern cities vary enormously among geographical regions, making mobility challenges to also differ between them (ASCIMER, 2016). Figure 6 presents the modal split of different European cities with modes grouped into the three categories that will be used through this research work: Public Transportation modes (Bus, Tram, Subway, Train), Active Transportation modes (Walking and Biking) and Private Vehicles (private Car and motorbike).

On a prospective exercise, there is a consensus on the fact that with the increase in disposable income of households the number of daily trips per person increases (Schafer A., 2000), and that -even if global economic growth is slowing down- the disposable income of urban households is expected to rise on average across the Globe in the next decades (WEF, 2019). This combination of factors, together with (i) increasing quality expectations for urban mobility services (in terms of their comfort, commercial speed and predictability) (ii) greater demand of the users for more individualized service offer and (iii) higher requirements on sustainability terms, will require the diversification and modernization of the offer of urban mobility services. 
Figure 6. European cities commuting modal share

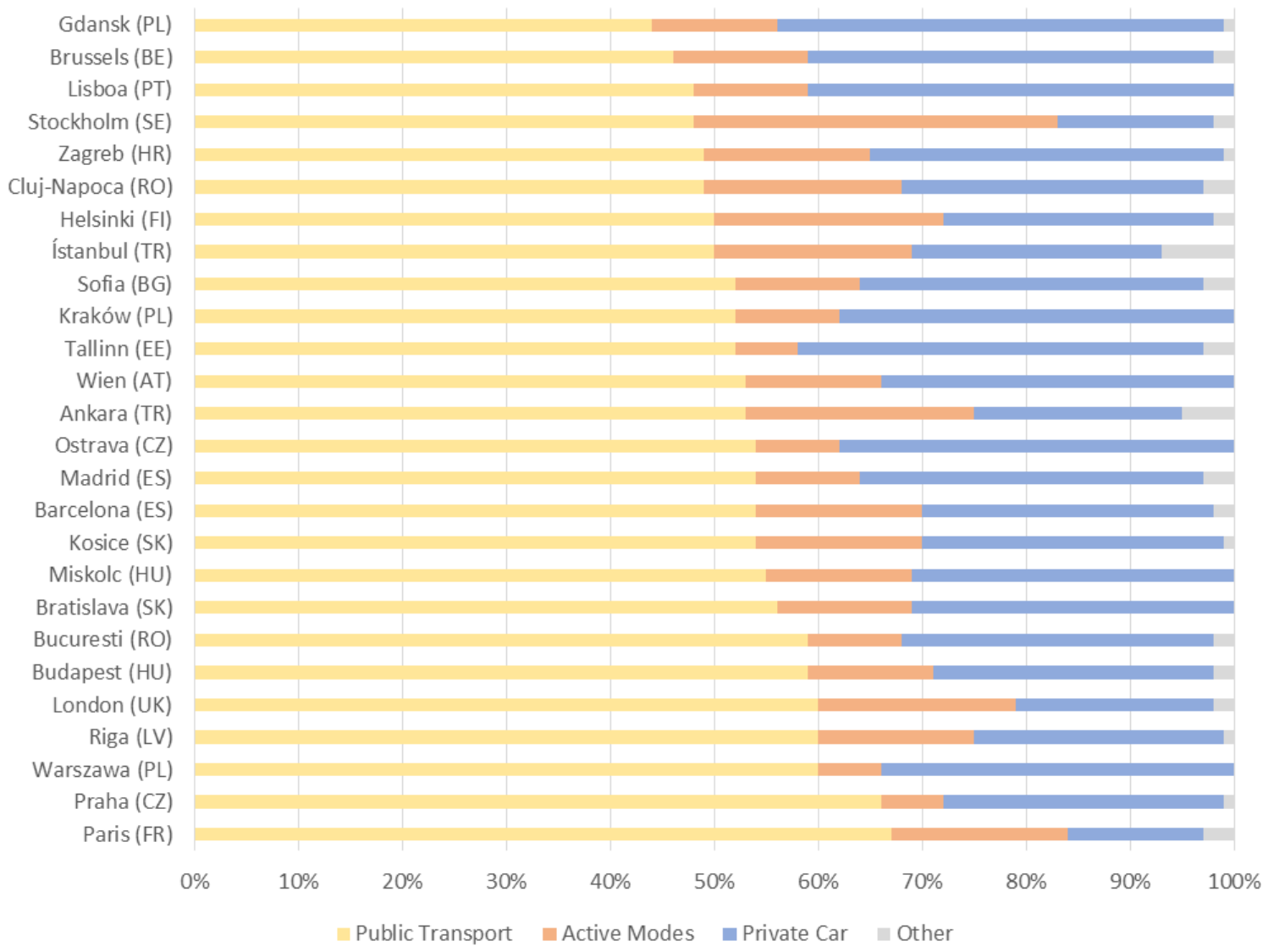

Source: Europe Environmental Agency (2016)

Hence, currently our cities have among their main objectives that of increasing the efficiency and quality of their transport systems, while reducing their related externalities. This need for improved urban mobility is widely acknowledged by leaders in governments, academia and the industry. In this regard, policy makers count with three different typologies of policy to make urban mobility more sustainable: (i) implement mechanisms that diminish both the average trip length and the need to travel (avoid strategies), (ii) promote the modal shift towards public transport systems or nonmotorized transport modes (shift strategies) and (iii) enhance the efficiency of the remaining travel activity through a more effective management of transport systems and networks or the improvement of vehicle design and fuel efficiency (improve strategies).

The European Commission suggests the combination of policies in all of the different typologies, and remarkably sets multimodality as one of the main objectives to seek in the future mobility of the EU's urban areas. Multimodality contributes to introduce resilience into the overall mobility system as it multiplies the combinations available to the user for a specific trip. This is highly desirable not only 
from the point of view of the flexibility and of the resilience of the system, but also from the point of view of efficiency, as the users are able to choose the most efficient mode in each situation and context of the everchanging urban reality. Evidence shows that multimodal trips have increased steeply in recent years, with generations $Y$ and $Z$ becoming strongly multimodal in several countries in Northern Europe (Kaplan et al., 2017), Germany and Britain (Kuhnimhof et al.,2011) or the US (Circella et al., 2017).

To enhance the efficiency of modern cities on the basis of the existing infrastructure, travelers must have the ability to combine different means of transport, adapting their choices to their circumstances as well as to the city context, and multi-modal transport systems need to operate as integrated, seamless networks. We can conclude at this point, therefore, that multimodality is a desirable future for the mobility of our cities, to face several city challenges not only in efficiency terms, but also with regard to urban sustainability and urban quality of life.

\section{THE SMART MOBILITY PARADIGM}

The concept of Smart Mobility makes reference to the implementation of innovative, sustainable and efficient solutions to provide the inhabitants of cities with cleaner, safer and fully accessible transport services. These intelligent systems aim to reduce the negative impacts of transport, at the same time that they fuel economic growth and improve the quality of life of the population (Chourabi et al., 2012; Neirotti et al., 2014).

In the urban mobility field, smart ICT-based solutions allow for the development of interconnected transport systems that integrate real-time information from multiple sources. These systems improve decision-making in both the user and the managerial sides of multiple transport modes, boosting system flexibility and adaptiveness as well as allowing to introduce a more active role of citizenship (Chourabi et al., 2012).

In the described context of (i) growth of the world's urban population, (ii) rise of the Smart City idea and (iii) urban mobility evolution; the paradigm for the provision of urban mobility services has changed deeply. Not only fleets and infrastructures are being improved with the introduction of new ICTs, but also completely new ICT-based solutions and business models are being created in our cities. These solutions aim to tackle urban mobility challenges by making mobility more sustainable, more inclusive, multimodal, active, efficient, resilient and sustainable on the basis of user and/or operator real time information provision. 
As a matter of fact, improved transit information has been proven to have a positive impact not only on urban mobility but also on the urban economy and environment, as it results in more efficient journeys for individual travellers and in improved satisfaction with the service (Skelley et al., 2013). Moreover, Ibraeva and Sousa (2014) pointed out that the lack -or the complexity- of information about routes and timetables acts as a powerful barrier for potential transit use. Thus, providing easily accessible and trustful information sources is essential for enhancing transit use. With the same idea being applicable to shared mobility as another low-carbon mode that reduces emissions and fuel consumption per passenger-trip (Nijland, Van Meerkerk and Hoen, 2015).

Objective measurable indicators have supported the existence of a positive relationship between information provision and transit ridership. However, information still plays a minor role in modal choice when compared to journey planning and execution for a chosen mode (Kenyon and Lyons, 2003). Today individuals still have to make their travel decisions under uncertain circumstances with respect to travel time; they are not able to predict the exact travel time or arrival time before starting their trips given a departure time (Li, Hensher and Rose, 2010). This uncertainty increases considerably in the case of multimodal chains. Yet, studies show the potential held by travel information systems to change travel patterns as a result of travel time savings (Toledo and Beinhaker, 2006), of reducing travel time variability (Fosgerau et al., 2008) and of increasing user satisfaction (Dziekan and Kottenhoff, 2007). While little research has addressed the link between information and transit use, some studies do show a positive relationship between transit information availability and transit ridership (Hou and Chen, 2013; Brakewood, Barbeau and Watkins, 2014; Dyrberg et al., 2015) the same is applicable to cycling (Navarro et al., 2013).

The utility of travel information provision becomes tangible in the users' willingness-to-pay for travel information, as demonstrated for example in Greece, the United Kingdom and China (Zografos, Androutsopoulos and Apospori, 2012). Users are willing to pay for information that provides added value compared to existing information services (Molin and Timmermans, 2006) and that the most valued features are the ones that include provision of real-time information (Dantan, Bulteau and Nicolaï, 2015).

However, while information technology is relatively cost-efficient and their use is spreading rapidly among transport users, the development of ICT solutions is rarely financially supported by transport authorities and operators, likely because the effective reach of mobile technologies as well as their impact on the travel patterns are yet unclear. Understanding the relation between real time 
information systems and improved mobility behavior could support public authorities in their decision to invest in advanced mobility systems supported by ICT technologies.

As it has been said, to enhance the efficiency of modern cities on the basis of the existing infrastructure, travelers must have the ability to combine different means of transport, adapting their choices to their circumstances as well as to the city context; multi-modal transport systems need to operate as integrated, seamless networks at both the physical and the information levels.

It is expected that in the next years greater budgetary efforts are to be dedicated in European cities to the introduction of smarter mobility systems. However, for cities to be able to retrieve all the potential benefits of these innovative systems it is important to understand the drivers that fuel their adoption and usage by citizens.

\section{SMART MOBILITY SOLUTIONS}

In the era of the digital revolution, urban mobility faces the challenge of identifying and making the best use of information technologies to process and enable the analysis of large volumes of data in a structured and integrated manner. In urban transport, it becomes essential to develop flexible information and decision-making systems to operate different modes of transport in real time, positively impacting users' time savings (Toledo and Beinhaker, 2006) and improving efficiency, economic savings and the reduction of emissions (Skelley et al., 2013). Smart mobility technologies and services have a wide range of advantages for travelers, transport service providers and for urban development planning.

- Travelers: improvement of the travel experience, reliability of time and costs, reduction of waiting times, reduction of traffic and congestion.

- Transportation Service Providers: better knowledge of demand and balance of supply to improve the functionality and the efficiency in the use of resources.

- Urban planning: improvement of future infrastructure planning and provision of transport services through the use of predictive models.

Given the increasing complexity in the implementation of new infrastructures at consolidated urban spaces, the efforts directed towards the optimization of the existing infrastructures gain strength. 
New ICT-based solutions allow for an optimization in the use of the existing infrastructure with a lower relative cost. Some examples of the multiple possibilities that these rising technologies introduce in the mobility field are:

- Access in real time to service information, allowing to share resources among users (cars, motorbikes, bikes, parking spots).

- Applications with access to information in real time for all the transport modes that is included into maps, price information, personal calendars, route planning and other services, allowing for an improvement of decision-making.

- Smart analytics used to study data coming from real service functioning, searching for patterns that generate insights (Machine learning) that allow for the optimization of the system (minimization of traffic congestion, synchronization of traffic lights for optimal traffic flow)

- Collecting real time information from the user side: Dynamic management of public transport systems based on demand.

- Payments with mobile or NFC technology allowing for seamless transactions and also for an easier combination of modes with combined fares based on the identification of a single payment system.

- Initiatives that allow sharing information among users through Social Media platforms (accidents on the route, congestion, detours, etc.). 
Table 2 summarizes the main smart mobility solutions identified by the ASCIMER project for the different areas of urban mobility.

Table 2. Taxonomy of Smart Mobility solutions grouped by areas

\begin{tabular}{|c|c|c|c|c|}
\hline AREAS & \multicolumn{4}{|c|}{ SOLUTIONS } \\
\hline $\begin{array}{l}\text { Traffic } \\
\text { management }\end{array}$ & $\begin{array}{l}\text { Strategic corridor and } \\
\text { network management }\end{array}$ & $\begin{array}{l}\text { Incident } \\
\text { management }\end{array}$ & $\begin{array}{l}\text { Safety } \\
\text { enhancement }\end{array}$ & $\begin{array}{l}\text { Real time traveller } \\
\text { information }\end{array}$ \\
\hline Public Transport & $\begin{array}{l}\text { Real time traveller and } \\
\text { operator information }\end{array}$ & $\begin{array}{l}\text { Safety and } \\
\text { security } \\
\text { enhancement. }\end{array}$ & $\begin{array}{l}\text { Public transport } \\
\text { alternatives. }\end{array}$ & $\begin{array}{l}\text { Integrated } \\
\text { payment systems }\end{array}$ \\
\hline Logistics & $\begin{array}{l}\text { Improvement on the } \\
\text { traceability of goods }\end{array}$ & $\begin{array}{l}\text { Fleet tracking \& } \\
\text { management }\end{array}$ & $\begin{array}{l}\text { Stock } \\
\text { management }\end{array}$ & \\
\hline Accessibility & $\begin{array}{l}\text { Enhancing physical } \\
\text { accessibility }\end{array}$ & $\begin{array}{l}\text { Enhancing digital } \\
\text { accessibility }\end{array}$ & $\begin{array}{l}\text { Enhancing } \\
\text { socio-economic } \\
\text { accessibility }\end{array}$ & $\begin{array}{l}\text { Enhancing cultural } \\
\text { accessibility }\end{array}$ \\
\hline $\begin{array}{l}\text { Clean and non- } \\
\text { motorized options }\end{array}$ & $\begin{array}{l}\text { Clean energy in traffic } \\
\text { and parking. }\end{array}$ & Cycling options. & $\begin{array}{l}\text { Walking } \\
\text { options. }\end{array}$ & $\begin{array}{l}\text { Alternative } \\
\text { motorized options }\end{array}$ \\
\hline Multimodality & $\begin{array}{l}\text { Passenger } \\
\text { multimodality }\end{array}$ & $\begin{array}{l}\text { Freight } \\
\text { multimodality }\end{array}$ & Shared Systems & \\
\hline
\end{tabular}

The management of these smart mobility trends in cities implies either the adaptation of existing ICT infrastructures or the introduction of new ICT infrastructure for their operation. Systems for data collection, data communication systems and protocols (for example, between traffic control centers, between and from vehicles, or between vehicles, stations and passengers) and quality standards in data collection, referring to the accuracy of the data and its communication in real time. This introduces the possibility of the users to carry a more active role, which favors a more efficient mode choice and route selection in all of the different modes and the introduction of new business models in transportation, including those of the sharing economy which are further developed in the next section. 
The role of local governments, crucial in Smart City approaches, is also fundamental in this sense for smart mobility. Regarding active mode enhancement, public intervention is key to improve infrastructure availability and increase safety in the active modes, leveraging their adoption. Concerning Public Transport, coordination efforts amongst operators is a recognized good practice that relies on public intervention and that allows to provide the users with ad-hoc multimodal information, increasing transit use and intermodality. Finally, regarding the shift towards cleaner private vehicle technology is also highly reliant on public policy, either through the enhancement of the renewal of vehicles or through the restrictions to the access of the less sustainable models of car.

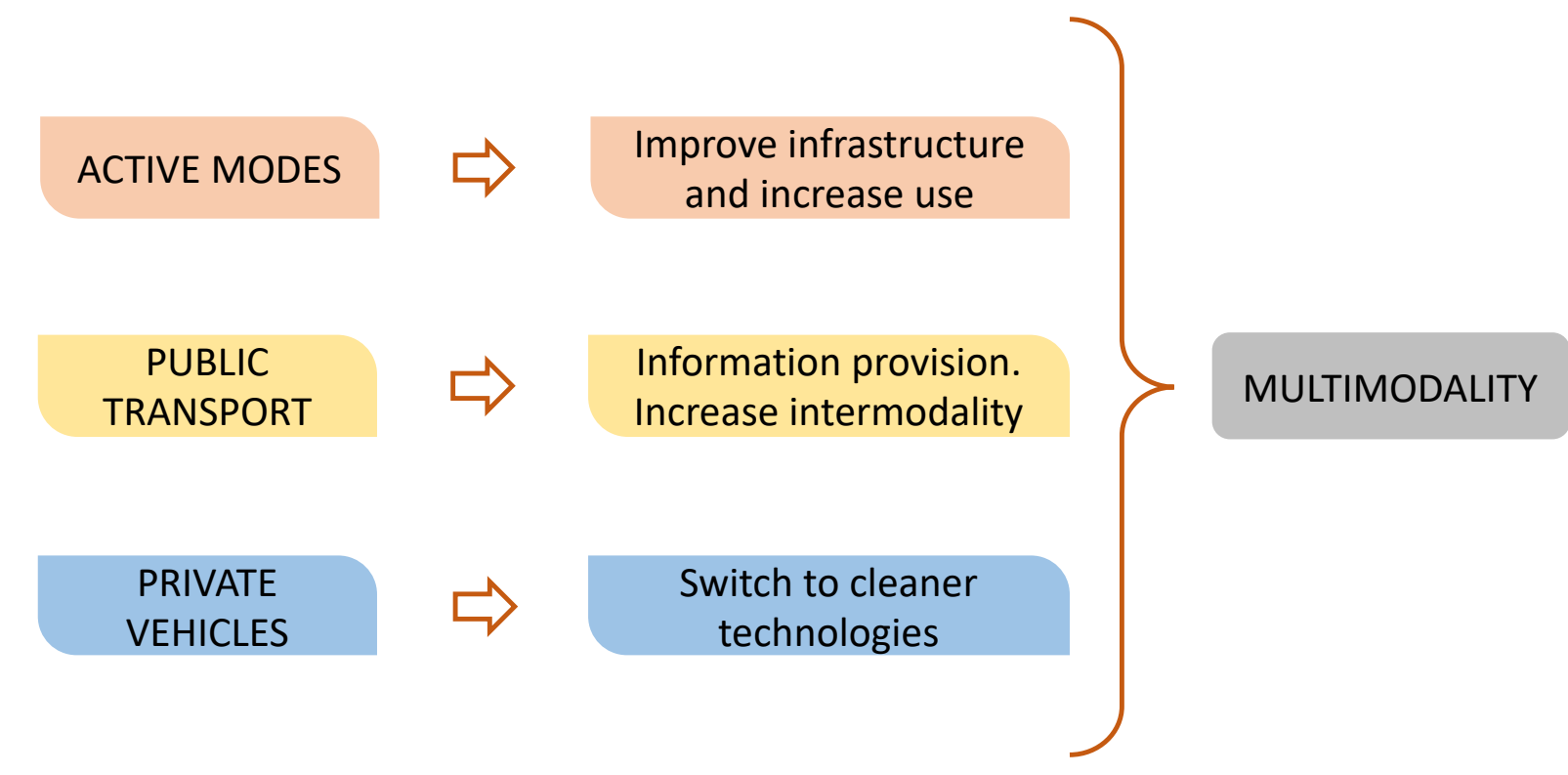

SHARED MOBILITY SOLUTIONS

Within smart mobility, there is a set of solutions that we would like to highlight in this work. They are urban mobility solutions that have reached our cities as a result of the transposition of the models and the mechanisms of the shared economy to the transportation sector. They are the so-called shared mobility systems, among which we can find fleets of different shared vehicles (cars, bikes, motorbikes, motor scooters...) that have been observed to reduce the use of the private car and which are already present in several Spanish cities. 
Traditionally, the mechanism that allowed to guarantee the coverage of diverse individual or family needs was the property. In the specific case of needs which, although temporary, have a relatively long lifespan, their coverage could be provided by leasing assets owned either by other individuals or by companies dedicated to it. This format, however, was inefficient in the case of very short-term needs or for certain markets with insufficient volume or characterised by their opacity.

Thus, the shared economy arises as a direct consequence of two factors: on the one hand, the existence of the aforementioned short-term demand for certain capital goods and, on the other, the emergence of new information and communication technologies (ICTs) that enable users for the first time to collect, process and exchange information simply and even automatically. The combination of these two factors introduces the possibility of combining this type of demand and its corresponding supply with ease, where previously both were not found or where the effort required to do so outweighed the benefit of the parties. This allows the use of property -real estate and real estateshared between several individuals in a dynamic way. For this purpose, a set of intermediary platforms arise in which private individuals/users can directly and temporarily share different assets.

These initial consumer-consumer loan schemes Airbnb (flats), BlablaCar (cars), etc., are rapidly evolving towards business models in which instead of direct loans between private individuals, a company lends its fleet of assets to users dynamically in the form of short-term rentals; thus, assimilating to existing businesses such as taxis, hotels or traditional car rentals. A variety of shortterm rental markets are therefore created, partly as a result of new previously unsatisfied demand and partly as a result of a substitution effect between ownership-based and service-based schemes.

There are also multiple business models to meet this demand. Specifically, in the urban transport sector, particularities such as the short average period of use of assets; the high initial investment involved; the demands for reliability and resilience on the part of the user; the growing multimodality or the need for an authorised driver make the number of existing solutions diverse and sometimes confusing.

The improvement in urban mobility that all these solutions will bring is set to be huge. Different studies have measured the impact that these technologies can have on the emission levels, the energy consumption or the quality of life of the citizens. 
Figure 8. Relative $\mathrm{CO} 2$ emissions for each mode (g $\left.\mathrm{CO}_{2} / \mathrm{pax}-\mathrm{km}\right)$

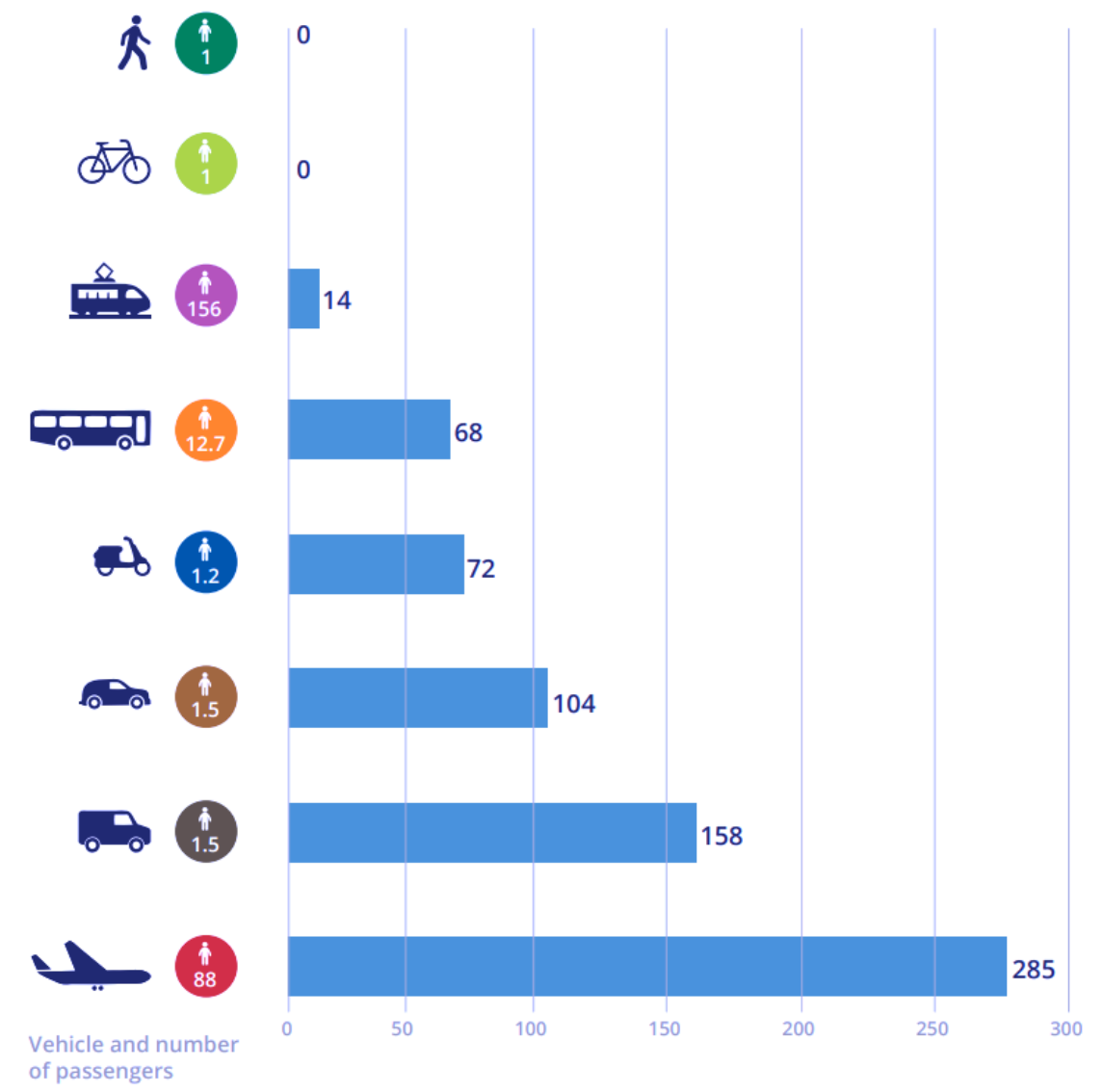

However, for these solutions to effectively generate the benefits that they intend, it is necessary not only their implementation by public authorities or private companies, but that users embrace them and exploit their advantages, which is directly related not only to their availability but also to social trends and to individual motivations. Also, the way in which they complement or compete with other clean transportation technologies can be determinant in the delimitation of their real positive impact on the mobility of the city. Hence, understanding the choice of the users to adopt and use these technologies becomes essential as a policy tool to enhance the transition towards sustainability in urban mobility. 


\subsection{SMART MULTIMODAL MOBILITY \& HUMAN BEHAVIOR}

In the mobility field, individual travel choices have been found to be conditioned to a large extent by both, the options available to the user, and the differential attributes that each option has, with the user choice being conducted in an interdependent way.

Most $20^{\text {th }}$ century studies on travel mode choice are focused mainly on modal attributes to explain the user choice. Individual-specific variables like age, gender, income or household size are often also included in these analyses to control for individual differences in preferences and unobservable modal attributes.

However, it seems reasonable that choices are also affected by individual-specific attributes, even to a higher extent that the simpler sociodemographic variables being taken into account; that is, attitudes and personal beliefs are likely to influence individual mobility decisions. (Ashok et al., 2002; Pendleton and Shonkwiler, 2001; Bhat and Dubey, 2014)

Attitudes refer to people's favorable or unfavorable evaluation of specific entities in their world (Eagly and Chaiken, 1993). These attitudes and beliefs will have a weigh in the consideration of the different modal options building the user's global utility of travel. As Choo et al. formulate, the utility of travel derives not just from the utility of reaching a desired destination (the traditional view of the utility of travel), but also from positive aspects of traveling itself (enjoyment of movement, exposure to the environment, skill in handling a vehicle, exploration and variety-seeking impulses, etc.), as well as from activities that can be conducted while traveling (relaxing, listening to music, using technology, working, etc.). All of these will generate different user utilities depending on the users traits.

The application of behavioral theories to travel behavior research has been reviewed by Golob (2003), and multiple studies have analyzed the effect of such behavioral constructs on modal choice in different context and for different modal options, obtaining results that prove their hypothesized influence (eg. Vredin et al. 2006 include multiple behavioral traits in their analysis of mode choice); for the specific transit mode, Kaplan et al. (2014) found that higher perceived service quality relates to higher perceived ease of payment for the service, which links to higher frequency of use; regarding active commuting Clark et al. (2016) presented that aiming for environmental protection favours change towards non-car; for the case of carpooling Kim et al. (2017) found that the intention to use a shared car is significantly influenced by pro-environmental attitudes while Homem de Almeida Correia et al. (2013) found that subjective perceptions (e.g. relationship with car mates, constraints to independence, status as a passenger or driver) are even more important for system adoption than the 
instrumental attributes of the carpooling system. Finally, Barberan et al. (2017) also confirmed the importance of such factors for understanding bicycle use likelihood and Waygood and Susilo (2015) studied the effects of safety perceptions on the decision to walk to school. We can conclude hence, that in today's study of mobility behavior, latent constructs are key to understand the choice process of the users.

\subsection{BEHAVIORAL FACTORS FOR SMART MOBILITY}

This section includes a revision of the main behavioral factors that either (a) have been studied for more traditional mobility solutions and are likely to inform the user decision to adopt and use innovative smart mobility solutions or (b) that are linked to the adoption and use of technological solutions in general, making them potentially relevant for the adoption of smart technology-based mobility services.

\subsubsection{Green Values/Green Lifestyle}

Nowadays concepts like sustainability, environmental responsibility or zero-emissions are unarguably influencing consumer habits in developed economies. The concept of environmental concerns can be understood as a multifaceted construct related to environmental attitudes and beliefs towards a combination of both local and global environmental problems. Empirical evidence suggests that proenvironmental behavior is a function of moral, altruistic and/or biospheric values (e.g., Guagnano, 2001; Joireman et al., 2001; Schultz et al., 2005) and that pro-environmental people evaluate altruistic and biospheric values as important (De Groot et al. 2007, 2009).

Since the 1970's, research has been investigating environmental concerns and their structure (Schultz, 2001) as well as their effects on human choices and human behavior. More specifically, their effects on transport behavior have been addressed in multiple research works (Dunlap and Van Liere, (1984); Buttel, (1987); Dunlap et al., (2000); Dunlap et al. (2002) or Han et al., (2017)) among many others.

Green Values have been studied as affecting the use of the private car mode (Lindgren, K. 2001), mode choice (Vredin et al. 2006). The factor has also been described to have a positive impact on the adoption of more efficient transport solutions like non-electric Carshare by Prettenthaler and Steininger (1999) Efthymiou, et al. (2013) or Kim et al. (2017). 
Consequently, it appears undeniable that such values -with proven influence on multiple aspects of behavior in relation to individual mobility decisions as well as on sustainable mobility solutions- should be included in the analysis when addressing the factors informing the decisions to adopt and use of smart mobility solutions.

In line with the findings of the above mentioned studies, the forecast of the effect that this variable could have on the adoption of the different solutions is positive in all cases. This is due to the fact that all of them are solutions which are eminently sustainable, and so, they align the effects that their use unfolds with those intended by a person with the aforementioned value in his or her profile.

\subsubsection{Social Norms/Community Resilience}

According to Schwartz (1977), a norm is defined as the self-expectations for specific action in particular situations that are constructed by the individual. This conception of norm parallels what Cialdini et al. (1990) refer to as an injunctive or prescriptive norm, meaning perceived social pressure, in the sense of how the individual senses the degree to which significant reference persons will approve his performance of an specific behavior.

Cialdini (1988) has also recognized that social norms have a descriptive meaning. A descriptive norm alludes to what most others are doing in a particular situation. It serves as a heuristic rule specifying how to behave. In this form the norm functions as a social convention.

Communitarian interests, studied as linked to personal norms are also an important determinant of pro environmental behavior, with problem awareness and perceived responsibility being cognitive preconditions for its development (Schwartz, 1977).

Social norms or community goals, then, reflect the mindset of considering peer decisions or communitarian interests which have been described as potentially relevant for making decisions in favor of community (Cialdini and Goldstein, 2004) (Leykin et al., 2013).

In transportation, social norms have been shown to increase sustainable transportation behavior (relative to private vehicle use) for commuting purposes, with users under the high social norm condition decreasing their commuting-related private vehicle trips (Kormos, Gifford and Brown, 2015). Communitarian interests, are also an important determinant of car-use reduction (e.g. Nordlund and Garvill, 2003). The same factors have been studied by Zhang et al., (2016) finding that they stimulate the intention to use public transport and increase actual public transport usage. 
Therefore, it seems reasonable to think that such a factor, with proven influence on multiple aspects of behaviour in relation to individual mobility decisions, may have relevant effects on choices regarding new sustainable mobility solutions. Our foresight of the effect that this latent construct could have on the adoption of the different studied solutions is also direct in all cases. This is due to the fact that all of the analyzed technologies are solutions which are understood to have a positive impact on the community where they are implemented (reducing emissions, reducing occupation of public space and preventing people from buying private vehicles). Also, social norms around them tend to enhance their adoption as they are seen as positive and modern solutions for the city's mobility. Hence, we can state that they too align the effects that their use unfolds with those intended by users with the abovementioned values in their profiles.

\subsubsection{Technophilia/Tech-savviness}

Seebauer et al. (2015) define technophilia as an attitude towards ICT, representing a sub-aspect of technology-related values, just as ICT are a subcategory of modern technology. Here the attitude describes the degree of positive or negative attraction to modern ICT. Seebauer et al. establish validity of a technophilia measure as a factor (valid construct) which can be distinguished from social norms and general technology-related values (discriminant validity).

Technophilia in different studies has been found to be more pronounced among men, younger people, individuals with higher education and persons who frequently use the Internet for travel information or who frequently use an in-car navigation system. The construct has also been studied by Astroza et al. (2017), which observed how smartphone ownership and use were found to increase the likelihood of using multiple modes of transportation. Lavieri et al. Found substantial and statistically significant effects of technophilia for sharing autónomous vehicles (2017a) and for the adoption of ride-hailing (2017b).

Given that the solutions on which the study focuses have an eminent technological base, it seems reasonable to take into account technophilia as a factor with a potential effect on their adoption. The perspective, in line with what has already been studied for the case of electric bikesharing by Munckacsy et al. (2017), is that higher levels of technophilia are correlated with higher rates of system adoption. 


\subsubsection{Safety/Privacy Concerns}

Research has shown that an individual with, say, a cautious "personality trait" performs more cautious behaviors than an individual without such a trait (Ajzen and Fishbein, 1980). In this sense, safety preferences have been described as an attitudinal factor for multimodal users choices (Vredin et al.) and for drivers (Martinussen et al., 2015), as well as identified as "Risk Averse" in the use of multimodal information by Dantan et al. (2015). In general terms, "Consumer privacy" refers to consumers' ability to control when, how, and to what extent their personal information is to be transmitted to others (Goodwin, 1991; Phelps, Nowak and Ferrell, 2000; Milne and Culnan, 2004).

The key is not the information disclosure per se, but rather the degree of control that is exercised by consumers over the collection of information and its subsequent use by marketers. Disclosing personal information online has been considered inherently risky in the online marketing context for several reasons as one of the key drivers of online trust, Bart et al. (2005).

Privacy concerns, has been described as an obstacle for the adoption of smartphones (Chin et al., 2012) smart homes (Courtney, 2008) e-commerce (Sheng et al., 2008) (Udo, 2018) and location-based services (Xu and Gupta, 2009), but has barely been studied in relation with the adoption and use of smart transportation solutions. As described, these smart solutions collect, process and store user information in their regular operation. In some cases the provision of credit card data is also required. Hence, in the same way that safety concerns are present for attitudes and decisions regarding general individual mobility, privacy concerns appear as potentially relevant in the user propensity to adopt and use these smart mobility solutions. 


\subsection{RESEARCH QUESTIONS}

After the literature review conducted in the previous sections, and as a consequence of social interest in the adoption of sustainable smart mobility habits by the inhabitants of urban areas, the following themes and research questions have been derived:

(1) We find a lack of understanding on how behavioral constructs like green values, communitarian attitudes or social norms -which have been studied for traditional transport modes- may inform and influence the choice to adopt and use innovative smart mobility services. Factors related to traditional mobility behavior like green values, communitarian attitudes or social norms may also inform the adoption and use of innovative smart mobility solutions. This brings us to our first research question:

The actual use of different transport modes is explained by a number of behavioral factors: green values, social norms and attitudes.

RQ1 - Are the behavioral factors for the adoption and use of smart mobility solutions similar to those relevant for explaining the use of traditional transport modes?

(2) Smart mobility solutions, for the case in which models to understand their adoption by the users have been developed, have undergone such study mostly in the light of mobility matters. However, these solutions have a strong technological character, heavily relying on ICTs to offer and manage their services. This attribute is in fact one of their competitive advantages in offer terms and consequently an aspect that differentiates them from other more traditional mobility solutions.

Concerning their adoption; potential users need to overcome technological barriers before they benefit from using them. They are also required to trust the firms that own and operate them, to which the legal framework in data protection policy becomes essential. As consequence, we find that there is a lack of scientific analysis of the effect of non-mobility behavioral factors, but of factors linked to the adoption and use of technology, which are potentially relevant for the adoption of these smart mobility technologies. We have focused for the study in the factors of technophilia and on the user privacy concerns. Technophilia however has already been studied by Munckacsy et al. (2017) and therefore is not included in the present study for the case of Bikeshare. This brings us to our second research question: 
The actual use of ICT-based tools depends on a number of attitudinal factors: technophilia, privacy concerns, etc.

RQ2 - Are the attitudinal factors for the adoption and use of smart mobility solutions similar to those relevant for explaining the use of ICT-based tools?

(3) As it has been described in previous sections, one of the main objectives to tackle in order to attain a more sustainable mobility is an increase in multimodal users and in intermodal trips. Hence, it becomes relevant understanding in a combined way how the evolution of behavioral traits in the population may affect in a differential way the adoption and use of smart mobility solutions in different modes. However, there is no evidence found in the revised literature in this topic. We find that there is a lack of information about if and how these factors may inform in a different way smart mobility technologies and solutions belonging to different modes. This brings us to our final research question:

RQ3 - Are there differences in the behavioral and attitudinal factors that explain the adoption and use of different smart mobility solutions?

Figure 9. Research questions linked to the adoption of smart mobility solutions

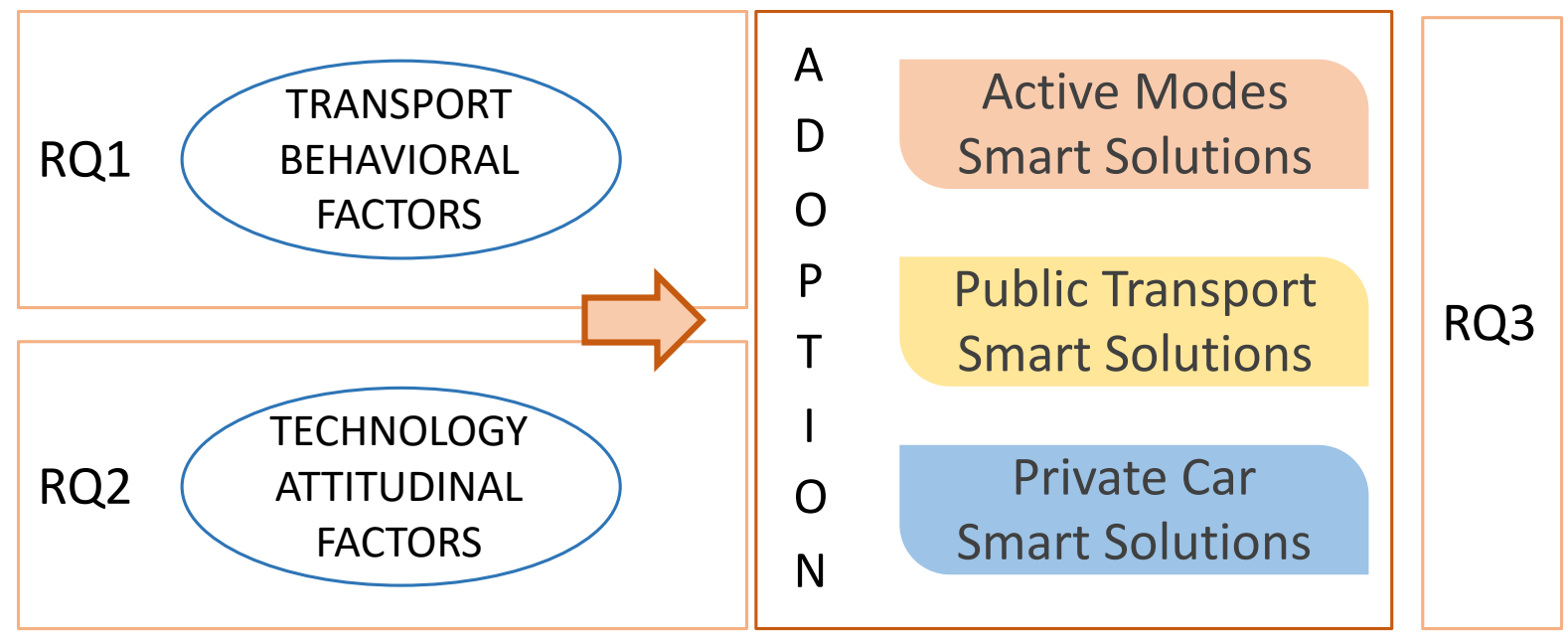


Figure 9 above shows how RQ1 is focused on understanding the effect of transport-related behavioral factors on the three smart mobility solutions, while RQ2 aims at understanding the effect of technology-related factors also on the three smart mobility solutions. RQ3 finally seeks the comparison among the three studied technologies. 


\section{OBJECTIVES AND RESEARCH FRAMEWORK}

According to the research background described above and to the state of the art on Chapter 2, the general and specific objectives of this research work are defined in this chapter.

\subsection{GENERAL OBJECTIVE}

The general objective of this doctoral thesis is to gain knowledge on the behavioral factors influencing the choice of the citizens to adopt Smart Mobility solutions as a necessary step to develop policies for enhancing their adoption, and thus, for achieving a more sustainable urban mobility. The goal is to understand and to compare the effects of these factors for technologies belonging to the three main categories of urban mobility (active mobility, public transportation and private vehicles) where the improvements to be made in order to obtain a more sustainable mobility vary as shown on Figure 7 .

This work will -presumably- also allow to understand also the strengths and weaknesses of these technologies and to derive design, policy or awareness measures that enhance their adoption. Helping to comprehensively improve the mobility of the city.

RESEARCH OBJECTIVE
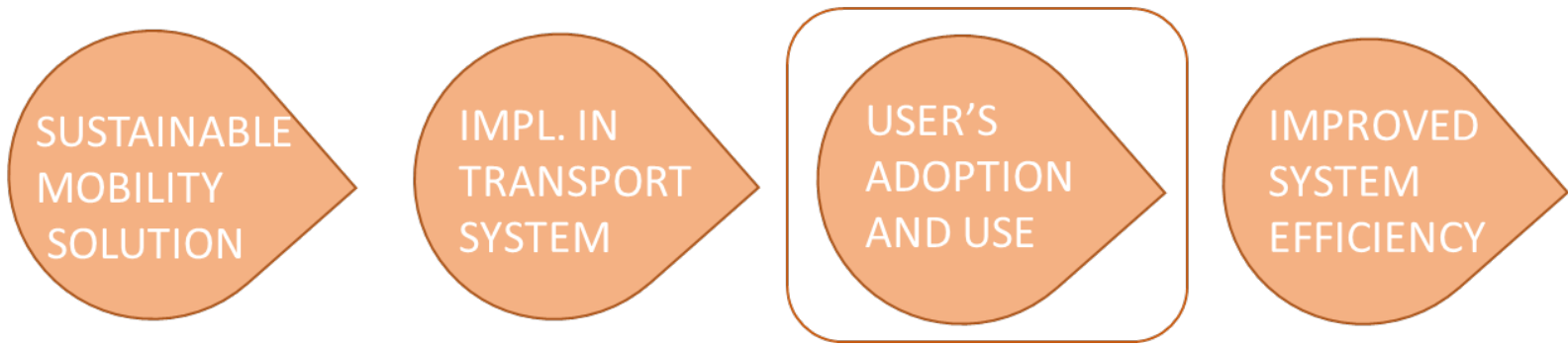


\subsection{SPECIFIC OBJECTIVES}

Given the general objective and the identified research questions, the following are the specific objectives of this research work:

Linked to RQ (1) and RQ (3):

- To explore the effects of latent constructs linked to urban mobility behavior like green values, social norms, etc. in order to validate them in three different innovative technologies (active mobility, public transportation, car mobility) implemented in the city of Madrid.

- Quantify the overall effect of each of the latent factors on the adoption and level of use of these newly introduced smart mobility solutions;

Linked to RQ (2) and RQ (3):

- like technophilia and privacy concerns; validating them in three different innovative technologies (active mobility, public transportation, car mobility) implemented in the city of Madrid.

- Quantify the overall effect of each of the latent factors in the adoption and level of use of these new smart mobility solutions;

Linked to the General research Objective:

- To develop guidelines and recommendations on the deployment of smart mobility solutions for policy makers, mobility service providers and transport operators, that help to increase the adoption of such systems. 


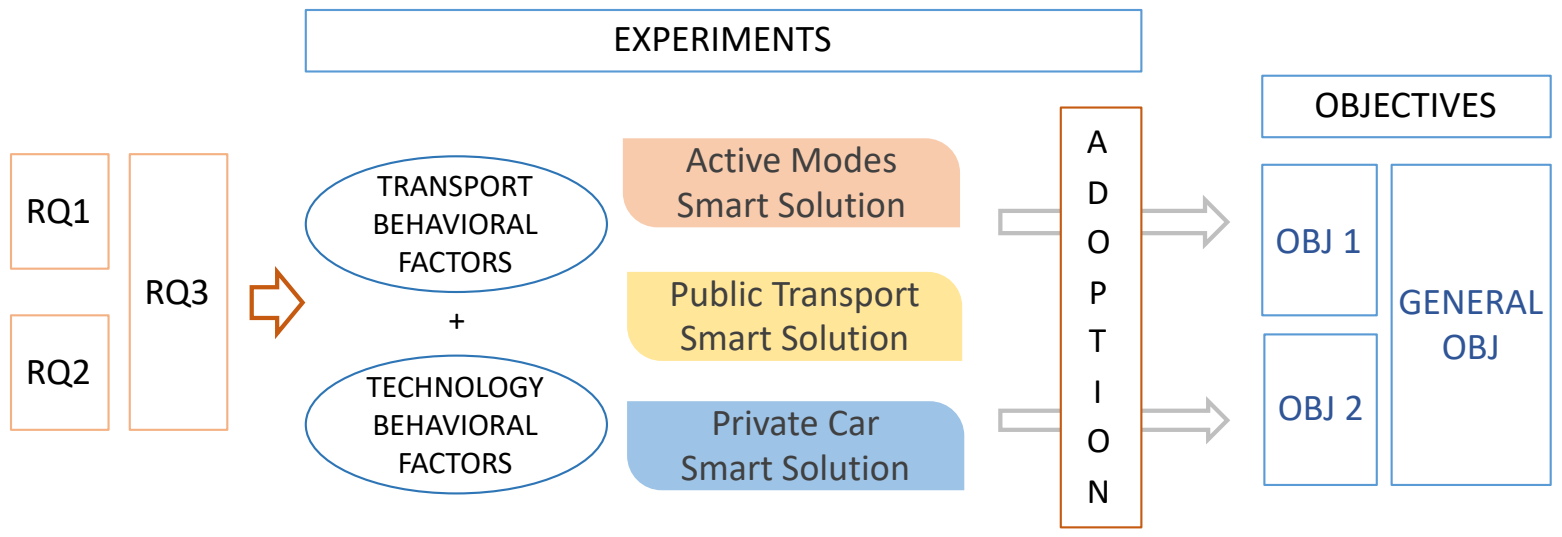

\subsection{RESEARCH FRAMEWORK}

To achieve the general objective of this thesis, a framework allowing to address each of the specific research objectives has been adopted. Thus, in order to achieve the first and second specific objectives, different experiments will be developed in which behavioral traits of the population as well as their effects on the adoption and use of the studied solutions can be carried out.

The case study method enables a researcher to closely examine the data within a specific context. It helps explain both the process and outcome of phenomena through complete observation, reconstruction and analysis of the case under investigation (Tellis, 1997; Zainal, 2007). Case studies are used for research purposes to develop a new theory through observation and testing, evaluating or improving existing theories through their implementation in practice. The method has been criticized for allowing wide generalization, subjectivity, and difficulties in documenting the acquired data in a unified manner. Nevertheless, in urban mobility planning, case studies are considered as an extremely useful tool to be used along with other research methods since the commons and similarities in relevant projects allow for transferability maintaining specific attributes of transport solution proposals. A case study also provides a communicative platform for transferring knowledge from the experts to the public and can inform the general public on complex features of scientific attributes (Bakogiannis et al., 2014).

With this aim, and as shown in Figure 12, three different solutions belonging to the three main categories of mobility, implemented in the city of Madrid, have been selected.

For the category of active mobility, a shared bike scheme introduced by Madrid city council. For the category of public transportation, a mobile app that provides real time information on the different 
PT modes, launched by the transportation authority of the city of Madrid. Finally, for the private vehicles mobility, services of $\mathbf{1 0 0 \%}$ electric shared car fleets. All three technologies are aligned with the goals set for the three urban mobility modes in Figure 7.

(i) Shared bikes increase the offer of biking infrastructure in the city. They invite non bike owners to approach this active mode as well as they allow users to combine biking with other modes along the day or in the same trip, enhancing multimodality.

(ii) For the case of the multimodal public transport app, this solution tackles the information provision challenge, allowing users to combine in a smarter and more efficient way public transportation modes, making this alternative more desirable and more competitive against the private vehicle.

(iii) Shared electric cars bring private mobility in Madrid one step closer to sustainability. In the same way as shared bikes, they allow users to combine their use with other modes along the day or in the same trip, enhancing multimodality. Also, they reduce the need for many user categories to own a private vehicle, reducing car ownership and hence, car misuse. Finally, although they indirectly cause the generation of pollutants and $\mathrm{CO} 2$ emissions in the production of the electric power that they run on, they clearly bring down the level of emissions in the city where they are most harmful.

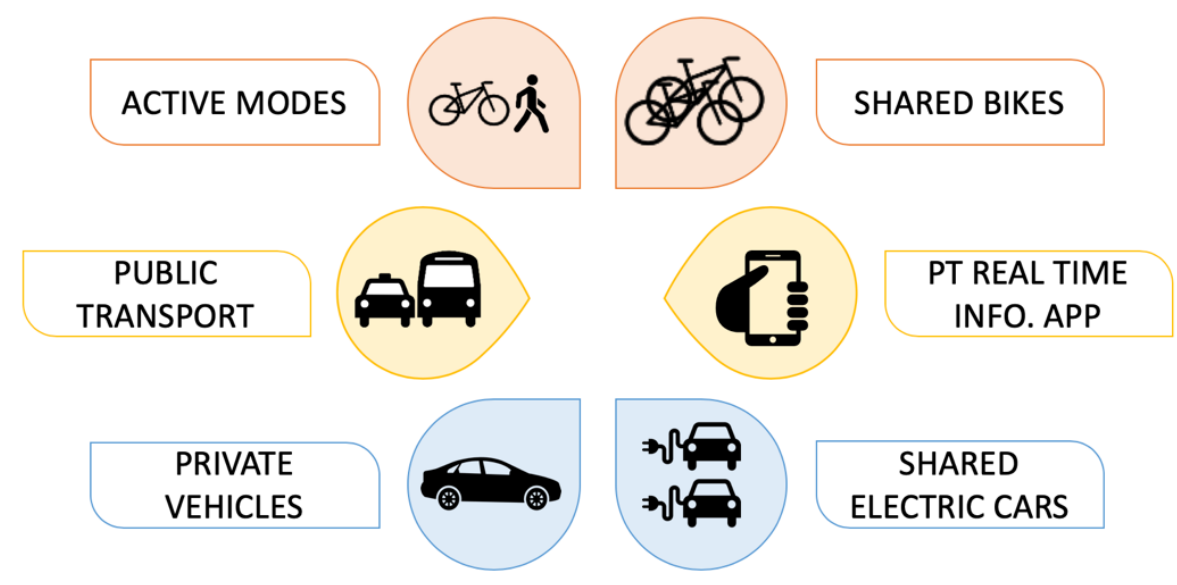

This triple-study research covers user perspectives on smart mobility solutions: At the top level, values relating to mobility and technology in general, including all modern industrial-scale and consumer- 
level technologies; at the intermediate level - the concept applied in this research - attitudes referring more specifically to smart mobility solutions as a part of modern transport technologies; finally, at the lowest level, the adoption and use of Smart Mobility Solutions as a subcategory within ICT and within transport solutions. The results of the analysis will allow understanding how the different behavioral traits affect the adoption of these technologies. The results could be used to develop strategies that contribute to achieve greener and cleaner cities through the enhancement of smart and sustainable transport options. 
Behavioral factors underlying the adoption of smart mobility solutions

(This page has been intentionally left blank) 
PART II - METHOD OF ANALYSIS 
Behavioral factors underlying the adoption of smart mobility solutions

(This page has been intentionally left blank) 


\section{METHODOLOGY}

The methodology employed in the development of this research has been consistently applied to the three studies that it contains. The experimentation process, as depicted in Figure 13 starts with the analysis of the smart mobility solution and the construction of a set of hypotheses on the behavioral model that underlies the adoption of such a technology. Taking these hypotheses as a reference, an experiment is designed, with a data collection campaign using surveys, and the application of a statistical model. The surveying methodology and the selected models for this work are further described in this chapter.

Figure 13. Overview of the methodological procedure of the thesis

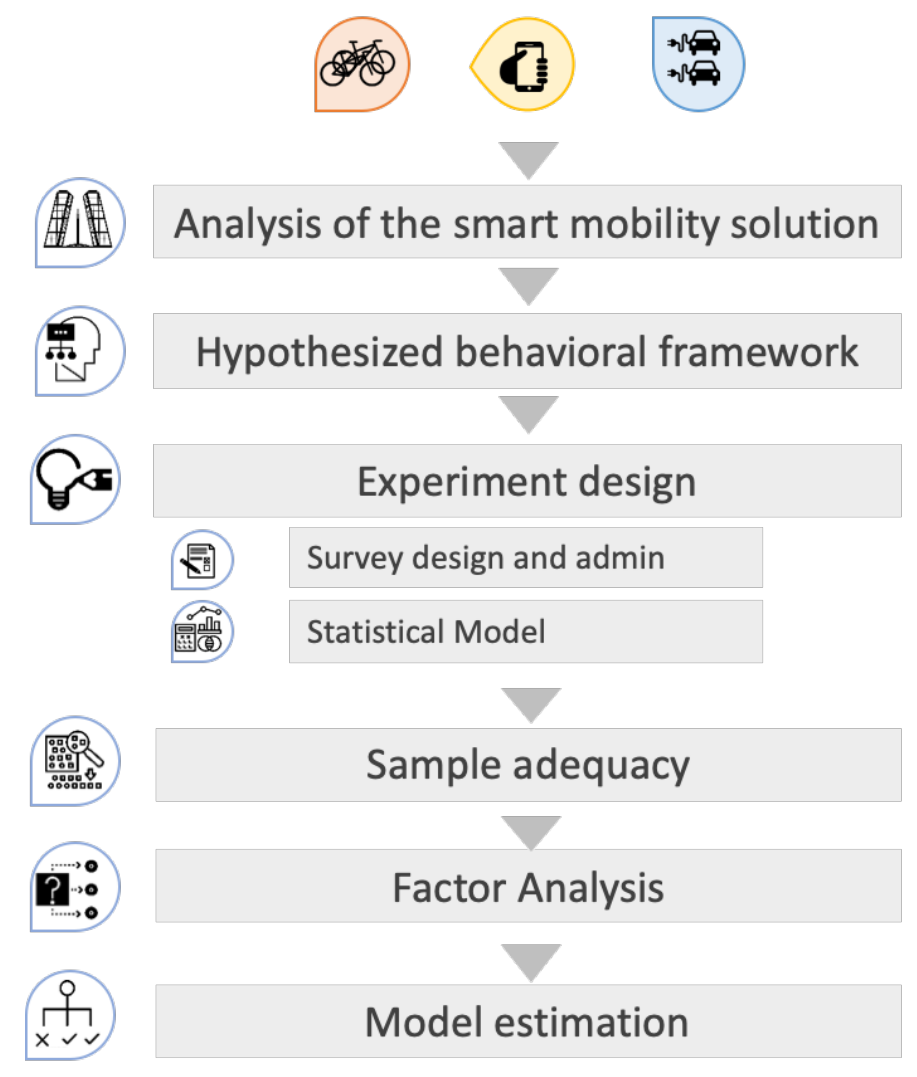




\subsection{SURVEY DEVELOPMENT AND DATA COLLECTION}

The surveying methodology employed in the development of this doctoral thesis is based on the one tested and described by Monzon et al. (2017) and applied in different research studies at the Transportation Research Centre of the Universidad Politécnica de Madrid (TRANSyT); consisting of a combined methodology of personal intercept interviews and online surveying to explore the opinion of potential or actual users of a transport service or infrastructure. This method, as described by Munckacsy (2017), synthetises the benefits of two methods described by Babbie (2010): (1) personal interviews: directness of the personal contact; the interviewer can keep records of observations about respondents and pursue the obtention of a more representative sample; and (2) online surveys: more confidential and honest due to anonymity and privacy; almost any type of question may be asked; and relatively cheap.

The methodology includes a series of steps in each survey phase. The first step is to define the survey objectives and to outline a proposal of the main topics and an initial survey plan. A draft questionnaire is then developed to fulfil the targeted objectives including the measurement of revealed and/or stated preferences, ranking questions, etc., and edited by a survey development tool. Actually, some companies offer a cloud-based development service, allowing prompt basic data analysis by charts and tables, as well as exporting options to data processing software. They also offer a friendly interface and an easy access to non-familiarised users to facilitate this task (e.g. Survey Monkey).

A pilot survey is carried before the definitive one to check whether the questionnaire is comprehensible and correct any possible drafting error, obtaining a pilot sample representing different age, gender, social background and transport habits. On the basis of pilot responses and recommendations, the questionnaire is refined in content and graphic design as well as adjusted to time limits. Once the final version has been fixed, cards with individual access codes (URL and/or QR code) to the web-based questionnaire are printed. To deal with the non-response rate, a prize was drawn among those respondents who completely filled the survey. Typical gifts can be Tablets, a gift voucher, or others related to the project (e.g. a smartbox).

The card delivering method is not limited to only giving the card to potential participants; the interviewer has to stop members of the specific target groups onsite and briefly explain (around 30 seconds) the points listed below:

- Name of the project and the institution responsible for implementation. 
- The objective of the survey.

- How to complete the survey. The cards delivered contain a link and a unique access code.

- The time needed to complete the survey. It is recommended not to exceed 10-15 minutes.

- The time period to complete the survey, usually around two weeks since the card is delivered.

- The prize in case participants complete the survey, and how they would be contacted if they were the winners.

Interviewers must also keep record of which user groups the cards had been provided to in order to balance and to ensure an initial adjustment of the sample. The data obtained while the surveying is ongoing is used to correct the sampling targets for the following days (e.g. stop delivering to young people when their quota has already been reached). This interviewer-participant interaction encourages and promotes the participation, and also prevents the card to be discarded. The advantages of this method are summarised in time and cost savings, response coding is automatic, and the database is online (stored data can be consulted at any time). On the other hand, older people may find it difficult to complete the survey and questions should be clearly understood. Participants could be also motivated to answer randomly (they save time and participate in the prize draw). Other methods should be considered (e.g. face-to-face surveys using tablets) in case that difficulties arise to complete the sample.

Finally, responses are stored in a database hosted on the same server as the questionnaire. They can be directly exported to an Excel or SPSS database for descriptive and advanced statistical analysis, first discarding any input errors and illegible responses. Duplication of responses and incomplete surveys can be monitored. Trompet et al. (2014) highlighted that due to the uncontrolled nature of an online user satisfaction survey, datasets should be cleaned for responses in patterns (e.g. $1,1,1,1,2,2,2,2,3,3,3,3 \ldots$ or $1,2,3,4,5,1,2,3,4,5 \ldots$ etc.) and responses in which the user statements are only very satisfied/very dissatisfied on all questions with them being answered quickly (control of overall response time).

The methodology was adapted to the specific circumstance of each study, evolving through them and tackling slightly differently the research objectives of each of them. 
Table 3. Main characteristics of the three developed surveys

\begin{tabular}{|c|c|c|c|c|}
\hline & & $\begin{array}{l}\text { BIKESHARE } \\
\text { SURVEY }\end{array}$ & $\begin{array}{c}\text { MULTIMODAL APP } \\
\text { SURVEY }\end{array}$ & $\begin{array}{l}\text { CARSHARE } \\
\text { SURVEY }\end{array}$ \\
\hline \multicolumn{2}{|c|}{ Type of experiment } & Panel & Panel & Simple \\
\hline \multicolumn{2}{|c|}{ Type of sample acquisition } & $\begin{array}{l}\text { Personal } \\
\text { incercept }\end{array}$ & $\begin{array}{l}\text { Personal } \\
\text { incercept }\end{array}$ & $\begin{array}{l}\text { Random } \\
\text { mailing }\end{array}$ \\
\hline \multicolumn{2}{|l|}{ Method } & Online & Online & Online \\
\hline \multicolumn{2}{|l|}{ Incentive } & Yes & Yes & Yes \\
\hline \multicolumn{2}{|l|}{ Date } & 2014-2015 & 2016 & 2017 \\
\hline \multicolumn{2}{|c|}{ Respondents } & 442 & 386 & 985 \\
\hline \multirow{6}{*}{$\begin{array}{l}\text { Addressed } \\
\text { Items }\end{array}$} & Green Values & $x$ & $\mathrm{x}$ & $x$ \\
\hline & Social Norms & & & $x$ \\
\hline & Technophilia & $x$ & $\mathrm{x}$ & \\
\hline & Privacy/Safety & & & $x$ \\
\hline & Service Quality & $x$ & $x$ & \\
\hline & Socio Demographic & $x$ & $x$ & $x$ \\
\hline
\end{tabular}

It is worth noting that due to the characteristics of the carshare system, in which the fleet of cars is freely distributed in the city, the surveying process was random mailing instead of personal intercept. These sampling methodologies have been described to potentially introduce biases related to survey non-response as well as to self-selection (Larose and Tsai, 2014). Self-selection mechanisms apply in procedures in which the sample is obtained within a predefined group that can have different characteristics from those of the population under study, introducing bias. In this case the predefined group are those users included in the mailing lists that were used for disseminating the survey. Regarding non-response the effects are inherent to online surveying and refer to the bias introduced by certain user profiles deciding not to take part in the study, introducing bias.

In sections 7.3, 8.3 and 9.3 a more detailed description of each of the surveys can be found, including the specific surveyed items and the administration process. 


\subsection{STATISTICAL MODELS FOR DATA ANALYSIS}

\subsubsection{Exploratory Factor Analysis}

Factor analysis is a multivariate analysis technique widely used in psychology and in the social sciences, according to Thompson (2007) "EFA dates back to the first decade of the 1900s, when Spearman (1904) conceptualized the method to address questions such as the nature of $1 Q$." The objective of this technique is to empirically identify latent constructs underlying a set of measured variables either to baldly provide insights on the existing latent construct structure or to validate a-priori hypotheses on those underlying data structures. (Comrey, Lee and Lee, 2013)

Latent Variables (LV) are theoretical constructs that cannot be perfectly measured by a single observable or declared indicator, but instead are indirectly measured through multiple indicators. Thus, a latent variable is expressed as a linear function of covariates that are proven able to reflect the variability of the latent construct among observations.

Their use, linked to Structural Equation Modelling was initially reviewed by Goldberger (1972) and has been evolving since, being widely-applied in modern social sciences where LV are used to measure the effects of abstract concepts like "intelligence", "social cohesion" or "political fairness".

In this research we make use of this procedure as a first step in the three experiments in order to analyze if hypothesized variables under study like green values, technophilia, social norms or privacy concerns have statistical ground to be included in the analysis.

\subsubsection{Latent Variable Structural Equation Models}

Structural Equation Modelling (SEM) is a well-established and method in behavioral and social sciences. SEM presents a general statistical approach for validating a multivariate correlation structure across latent and observed variables in a series of equations. SEM is used as confirmatory factor analysis and used to test whether the data fit a hypothesized latent variable measurement model. As Brown (2006) indicates:

"A fundamental feature of CFA is its hypothesis-driven nature. (...). CFA requires the researcher to prespecify all aspects of the model. Thus, the researcher must have a firm a priori sense, based on past evidence and theory of the number of factors that exist in the data, and of which indicators are related to which factors" 
SEM is a generalization of regression that holds an advantage in accommodating a correlation structure across multiple dependent variables, with the predefined set of latent constructs. SEM is commonly viewed as a combination of confirmatory factor analysis (CFA), representing the relationship between the latent constructs and the set of observed indicators, and a path analysis representing the dependency structure across the latent constructs (Pugesek, Tomer and Eye, 2003).

The analysis of behavioral variables in transport modelling is often linked to the use of SEM, with its application in travel behavior research being reviewed by Golob (2003).

In this research SEM is used in the first two studies (bikeshare and multimodal transit app), including the LV obtained in the exploratory factor analysis conducted, with the modelled dependent variables being the adoption of the two smart mobility solutions under study.

\subsubsection{Integrated Choice and Latent Variable Models}

The utility-maximizing framework of choice models, as applied in travel-behavior research, conceptualizes modal behavior as a discrete choice between a universe of options with the explanatory factors of the choice being the attributes of those options (J. Louviere and Hensher, 1982). These models allow to accommodate multinomial dependent variables in the choice side, those generally being the transportation modes. Later developments have introduced the user attributes as part of the modelling, including user behavioral constructs, relating them to the decision made by the user. (Bhat and Dubey, 2014)

In this research this modelling was employed for the analysis carried out in the third study, where we searched the propensity of individuals to adopt and use carsharing services. The searched choice was for the user to adopt, passively-non-adopt or actively reject the mobility solution, which consisted of a multinomial dependent variable. An Integrated Choice and Latent Variable model following (Bhat and Dubey, 2014) formulation has been used and is described in section 9.3.3. 


\section{MADRID SMART MOBILITY LAB}

\subsection{POPULATION AND TRANSPORTATION NETWORK IN MADRID}

Madrid municipality is the capital of Spain and the country's most populated urban area. It is a city of some 3.3 million inhabitants (INE, 2018), holding the third position in urban population terms within the EU (after London and Berlin), with its metropolitan area reaching 6.5 million.

Madrid has a relatively high population density, standing at 7,608 inhab. per square $\mathrm{Km}$ on average and reaching 27,000 inhab. per square $\mathrm{Km}$ inside the first ring road. The city is undergoing a rapid suburbanisation process, in which many population and jobs are moving out of the city center. Three ring motorways contour the city distributing a high number of trips between the 9 radial roads. In 2006 the city undertook a major urban renewal project that buried half of its first ring motorway $(6 \mathrm{~km})$ recovering the urban access to the river.

According to the Household Mobility Survey of Madrid Region, in the Metropolitan Area of Madrid which covers a developed area of $1.037 \mathrm{~km} 2$, close to 13 million displacements occur on a working day out of which 5.8 employ public transport. (CRTM, 2014) This fact gives an idea of the importance of public urban transport management in the municipality of Madrid.

The subway and bus networks are the two pillars on which the public transport offer is based in the city. The subway network is the third largest in Europe, only after London and Moscow, with $287 \mathrm{~km}$ and 238 stations. It has 12 regular lines and three light-rail lines which constitute the latest addition to the network. This network basically consists of a set of diametric lines, connected to each other by a circular line (line 6). It has a high degree of coverage in the municipality of Madrid (approximately 50\% of the population covered within a radius of 600 metres), especially in the central districts (Gutierrrez Puebla, 2013). 


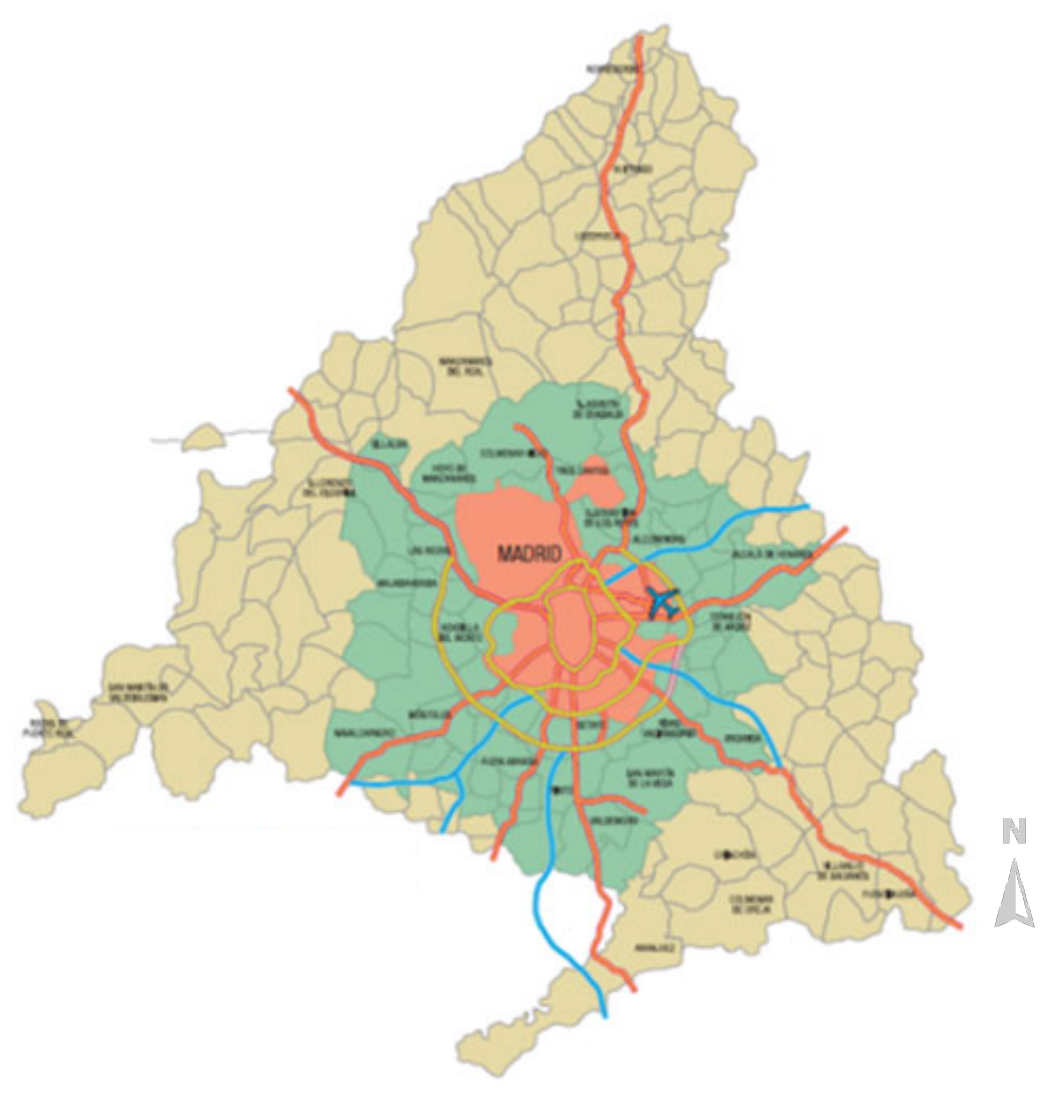

\section{Source: CRTM (2016)}

The municipal bus network is also very dense, with 212 lines and more than 10,500 stops distributed throughout the municipality (EMT, 2018). The great flexibility of the buses allows them to arrive where the metro service cannot. In fact, almost the entire population of the municipality of Madrid has a bus stop less than 300 meters from their home (Gutierrrez Puebla, 2013).

Public transport in the metropolitan periphery of Madrid is based mainly on the suburban railway and the interurban bus network, as well as on the subway whose network has already surpassed the municipal limits of Madrid. The suburban railway network has 10 lines and a total of 90 stations. In recent years new stations have been built, but improvements have focused on renewing the rolling stock, service frequencies and quality of service in general, the renewal of the two central stations is expected to come in the near future.

Another determining element to boost the usage of public transportation has been its proper conection with the road infrastructure through the construction of five fully operational (out of seven projected) multimodal interchange stations, which make connections between means of public transport faster and more comfortable in intermodal journeys, and hold park and ride facilities. 
Public transport is complemented by the intercity bus network, operated by 33 private companies, which operate under the coordination of Madrid Public Transport Authority (CRTM). This network also has a fundamentally radial structure, as the lines that connect Madrid with the surrounding municipalities along the main corridors predominate. Madrid Public Transport Authority (CRTM) coordinates all the public transportation operators in the region, for the city of Madrid this implies coordinating the services of the 700 regional bus lines, 212 urban bus lines, 10 railway lines, 12 metro lines as well as three light rail lines.

In Madrid, the strength and compactness of the central city and the existence of peripheral nuclei with medium and high densities favour the use of public transport and pedestrian movements (Cardozo et al. 2009). The weakest points appear in the new peripheral neighbourhoods, with low-density residential developments and fragmented travel attraction areas, which inevitably lead to the use of the car.

Even if much of Madrid's success from the point of view of sustainable mobility is due to its territorial model, in recent years Madrid is making a great effort to improve its mobility by enhancing greener mobility and multimodality. With this aim new plans for cyclist mobility, park-and-ride facilities or more sustainable bus fleets have been developed in the last years.

In this line CRTM is also working on new solutions that exploit their operation data in order to improve the information services provided to the users and to reduce user uncertainty associated to route planning and to disruptions in the service by unexpected incidents.

Regarding information provision the main public transport operators have launched in recent years information channels. Madrid city-bus (EMT) and Metro companies launched their real time information apps both available on the web from 2014 and for mobile devices from 2016 but they are not integrated. Also, in 2015-2016 EMT installed panels providing real time information about next services at each bus stop. Metro did the same at station entrances and platforms. At multimodal level, both Madrid City and CRTM launched their Open Data portals containing real time as well as historic transit data for developers to integrate such information in diverse solutions for PT users.

Another example of this will to improve transit services and to make them easier to use is the transport authority coordination center (CITRAM) that collects information in real time for all the different transport services and facilities, providing the users with real time information and warnings as well as allowing to coordinate in real time the decisions of the different transit services managers.

Also, on the policy side, Madrid has implemented different measures to drive a transition towards a cleaner and greener mobility in the city. Since 2017 the city has started to link air pollutant 
concentrations with bans to pollutant vehicles according to some predefined protocols. Also, since 2018 the city has introduced a limitation in the possibilities to park and drive in the central neighborhoods of the city that concentrate the highest population densities. The effectiveness of these recent measures is however yet to be demonstrated.

\subsection{MOBILITY PATTERNS IN MADRID}

Madrid is characterized by a highly integrated and well-structured multi-modal transit system, where over one third of total daily trips are carried out on public transit and with a user base with high technophile (Velazquez, Kaplan and Monzon, 2018).

As it occurs in other European cities, car ownership for the whole Madrid Region is higher than for Madrid City itself, standing at 0.505 and 0.455 cars per inhabitant respectively. Dispersed areas are characterized by higher car dependency, as the car is frequently the only practical alternative to typically inadequate, relatively and increasingly expensive public transportation systems (EEA, 2006). According to the 2004 Household Mobility Survey carried out in Madrid almost 13 million trips were made per day in the whole region. Therefore, each person made on average 2.5 trips per day. The trips lasted on average 29 minutes and have a length of $6 \mathrm{~km}$. The modal split was dominated by car use since $40 \%$ of these trips were done by car, $30 \%$ walking and $28 \%$ by public transport (Monzon et al., 2016).

These figures present considerable variations depending on the purpose or the area of the trip. Commuting trips are more based on motorized modes while people travelling for other purposes prefer to walk or cycle. On the other hand, trips done within Madrid City are based on public transport, walking and cycling, however trips made between the City and the rest of Madrid Region (i.e. Metropolitan Area) and among the different districts of the Metropolitan Area are basically made by motorized modes, especially by car (see Figure 15 and Figure 16). Nevertheless, a considerable percentage of these trips were also made on foot and cycling. Public transportation within the municipalities of the Metropolitan Area is the less preferred option due to the operational difficulties and lack of economic viability of quality public transport services to segregated areas (EEA, 2006). 
Figure 15. Modal split by trip purpose

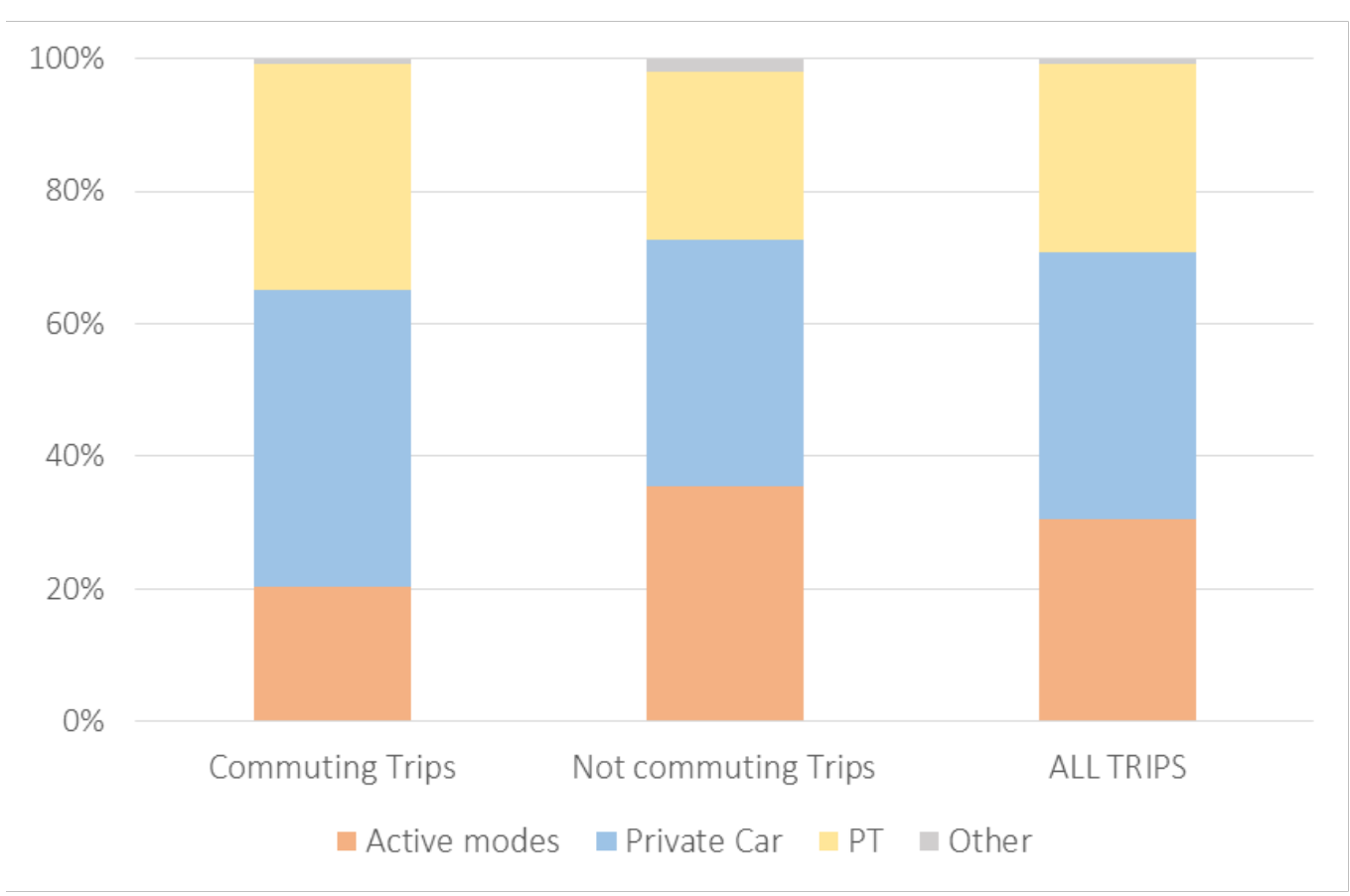

Source: Monzon et al. (2017)

Figure 16. Modal split among different zones of Madrid Region

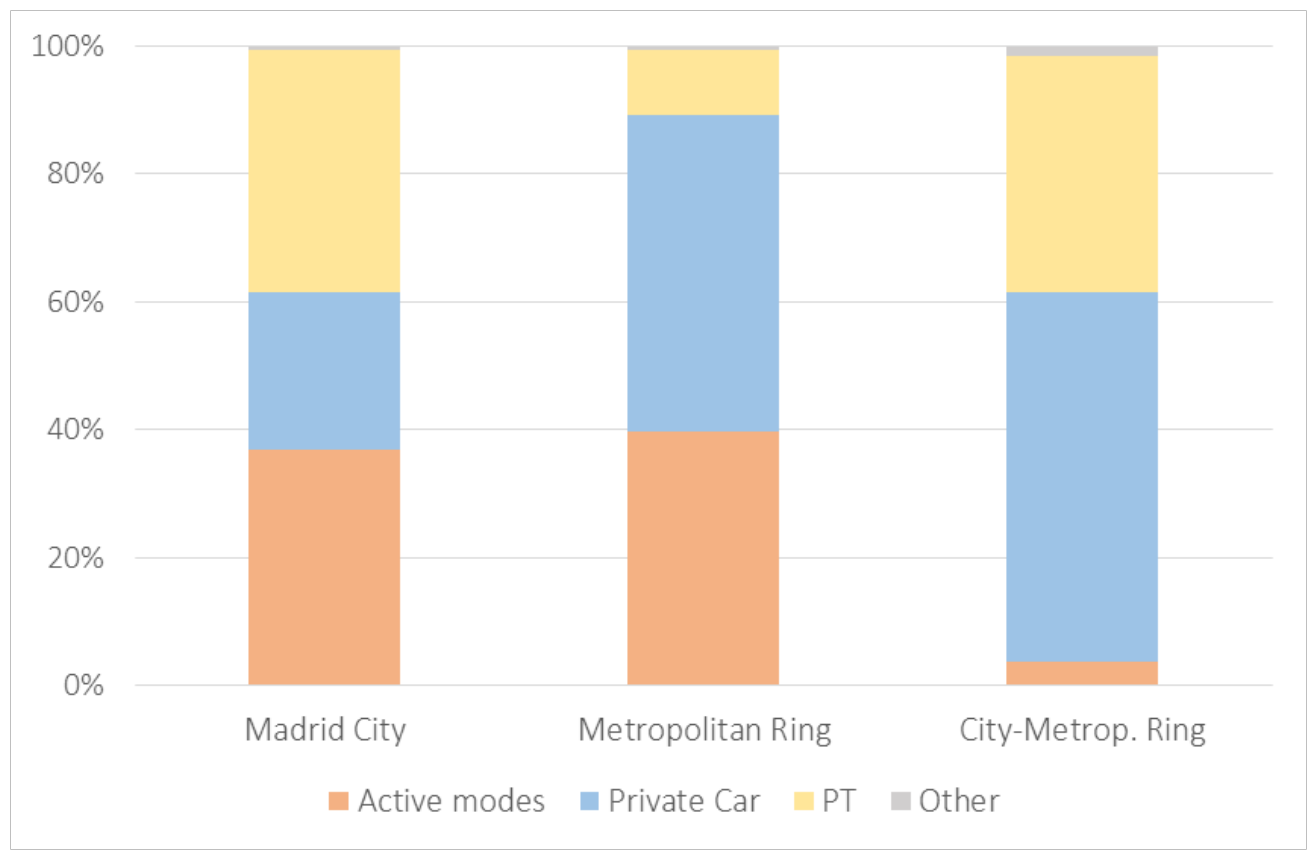

Source: Monzon et al. (2017) 
Finally, from the latest Synthetic Household Mobility Survey conducted in 2014, mode split in the Central District is dominated by soft modes, in particular by walking, achieving $57.7 \%$ of the trips while private cars are only chosen to make $10.1 \%$ of the trips within the Central District.

\subsection{URBAN CHALLENGES AND SMART MOBILITY SOLUTIONS IN MADRID}

In the last decades Madrid has seen an evolution in its mobility in line of that of many other European cities. Urban growth and sprawl have put pressure on the road system, leading to longer trips and greater car dependency, delivering increasing costs in road congestion for the citizens. Also, the accelerated adoption of diesel fuels has had an adverse effect on the air quality of the city.

Madrid consistently fails to meet the air pollutant limits set by European legislation. NO2 levels have exceeded the $200 \mathrm{mg} / \mathrm{m} 3$ limit on almost a monthly basis, with the winter period concentrating most of the events. In 2016 a new Protocol for High Nitrogen Dioxide Pollution Levels was implemented which considers four scenarios of pollution concentration levels. These scenarios add traffic restrictions as the level of alert increases. Measures range from forcing a limit of $70 \mathrm{~km} / \mathrm{h}$ speed in the $1^{\text {st }}$ ring road and some other arterial roads after one day of NO2 concentration levels over $180 \mathrm{mg} / \mathrm{m} 3$ in two measurement stations of the same area, to banning parking in the city center or partially banning traffic in the city center. This protocol was activated 28 times during 2017 and 2018. (Madrid, 2019)

Transport in the city of Madrid accounts for $47.3 \%$ of total CO2 emissions and $82 \%$ of NOx emissions, of which $85 \%$ and $83 \%$, respectively, come from road transport (Madrid, 2011). A wide variety of strategies have been considered to reduce both types of emissions, which included promoting the use of less polluting cars and fuels, public transportation and walking and cycling, the implementation of parking restrictions, the pedestrianization of historic areas, and the restriction of private vehicles in the city center (Madrid, 2011).

The last remarkable intervention in this regard is the pedestrianization of Plaza de España, an iconic venue in the center of the city that will turn into a green area and which is expected to enhance the use of transit, enlarge the spaces dedicated exclusively for active mobility, offer easily accessible park and ride and reduce car use in the area. 
Madrid is not a cycling-friendly city, according to Monzón and Rondinella (2010) in 2010 modal share of cycling was $0,3 \%$ in Madrid, more recent data shows a strong increase in the use of bicycles in the city, still remaining at a very low percentage in general trip share $(<2 \%)$.

Also, the city of Madrid shares some common problems of other European cities:

- Society: the weight of working-age population is decreasing due to the low birth rate, the increase in life expectancy and the migration of active population due to the lack of job opportunities. In addition, the socio-spatial segregation is growing, associated to socioeconomic inequalities. Urban transport systems are related to this trend, since they affect the livability of cities and provide accessibility (a concept linked to equity).

- Economy: a lot of problems associated with economic sustainability started appearing with the Eurozone crisis. The recent recession has been putting pressure over economic development and competitiveness.

To face these challenges, Smart mobility solutions have started to reach the streets of Madrid. In the last years Madrid has been home to the arrival of multiple innovative mobility solutions that at the present time constitute an incredibly wide set of options for the citizens.

In the block of active mobility we can find several bike-sharing systems. One of them -the public system- is the most popular and uses electrically assisted station-based pedaling bikes. However at least three other systems are running in the city with a free-float model totaling more than 5.000 bikes. In the field of public transportation several improvements have been introduced into Madrid's already well-functioning public transportation network. In this sense, the public transport authority introduced real time information on all subway and bus stops, as well as developed specific apps where these information could be obtained through the web or the use of a smartphone. Also, these data were made open so that other platforms like Google can integrate them in their offer of real time information. New tariffs are being explored by the transport authority with integrated payments and the offer of a mobility as a service scheme included in the upcoming improvements of the system. Finally in the block of private car mobility multiple alternatives have arisen. From shared electric vehicles that today add five different companies and more than 2.000 vehicles, to shared motorbikes and shared scooters that fill the parking areas in the city. Also two ridehailing systems are present in the city, with certain controversy regarding their regulation. Taxi services have adapted their offer including it in online booking platforms like Mytaxi. All these services have been adopted quickly by the citizens of Madrid, making the city a living smart mobility lab. 
All of these solutions are foreseen to improve some of the problems that Madrid is facing; reducing congestion, pollution and emissions while sustaining the accessibility and quality of life of the inhabitants of Madrid. Out of the described services, this section further details three relevant systems for the case of Madrid:

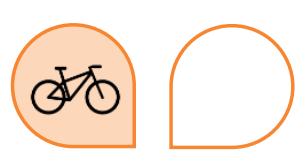

\section{BIKESHARE}

Cyclist mobility is gaining popularity worldwide as a sustainable and healthy mode of transportation capable of reducing traffic congestion and its associated emissions. Not only that, but also biking has been proven not only to be a sustainable transport mode, but the most competitive timewise for smallmedium distances (Romanillos and Gutierrez-Puebla, 2019).

In this line, public bicycle systems are conceived as an alternative mode of transportation, and as a bicycle promotion tool. In 2014 there were more than 600 public bicycle systems operating worldwide, a number that will undoubtedly continue to grow over the next few years (Wald, 2014).

Fishman et al. (2014) show that up to $20 \%$ trips in these systems come from the private car in cities such as Melbourne, Brisbane or Minnesota. In other cities, this percentage is below $10 \%$ (Washington DC and London). In these cities, an average reduction in the distance travelled by private cars of 252,844 kilometres has been achieved. From the environmental point of view the impact is remarkable as well, as a cyclist releases around 21 grams of CO2eq per passenger-kilometre, while a private car and a bus release around 271 and 101 grams of CO2eq per passenger-kilometre, respectively (Mrkajic et al., 2015).

In Spain most bicycle-sharing systems were inaugurated from 2007 on and in the last decade they have been in full swing, expanding their area of service and deploying new technical and operation models. These systems have acquired a tremendous importance as a tool for promoting bicycle use as well as offering an extra alternative within the public transport network in a city.

In June 2014, Madrid City implemented its own bicycle-sharing system (BiciMAD) with a variety of new technological innovations. The most important consisted on the inclusion of electric assisted pedalling, which mitigated one of the main obstacles when using a bicycle in the city: orography. BiciMAD also 
included an innovative system of bonuses, an advanced mobile application and was the first one in national scope to charge for use from the beginning.

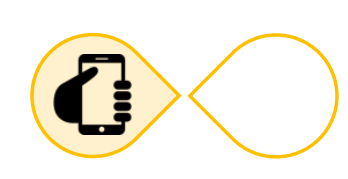

\section{MULTIMODAL TRANSYT APP}

Until recently, pre-trip information could either be gathered at home or on-route at designated locations (transit stops, vehicles etc.) now travelers carry their information source as they go along and the real-time information is continuously updated during the trip. Precise spatial-temporal information at any time, any place about every transport mode could be a game changer because it allows travelers to plan, change, re-schedule and chain trips spontaneously and 'on the go'. This advantage may greatly facilitate multimodal and sustainable travel modes. The general increase in market penetration rates of mobile devices from developing to the most advanced economies, equipped with user interfaces, suggests that smartphones could serve as global opportunity in user-operator communication. Transport authorities have nowadays the opportunity to better integrate transport modes, facilitate multimodal transport choices in an effective and cost-efficient way by a simple to use push-button app. Mobile applications appear as a new solution to tackle these information provision problems, presenting travelers with a personalized set of modal options that can include soft aspects like comfort or convenience, which can be determinant for a modal change (Kenyon and Lyons, 2003). Khattak et al. found that individuals are more willing-to-pay for travel information via the telephone when the information is customized, their trips are longer, and the trip is related with work. The actual adoption of these mobile travel information apps is crucial for their deployment and improvement. In situations involving new technologies, intentions to use form a rigorous measure of future use behavior.

Until recently Madrid had no single official channel integrating real time information from the various transportation modes available to citizens (urban bus, metro, interurban bus, railway, walking). In May 2016, Madrid implemented its first official Public Transport real-time information app Mi Transporte (http://www.crtm.es/atencion-al-cliente/area-de-descargas/apps/app-tiempo-real.aspx). Many cities have already done so, e.g. the apps developed by Transport for London, the Paris Region or Singapore on the public side, or the opening of data to the private sector that has developed apps in cities like San Francisco, Boston or London. Mi Transporte provides general information, such as the nearest 
stops, line routes, arrival times and trip disruptions, as well as the possibility for the user to obtain customized or automated information.

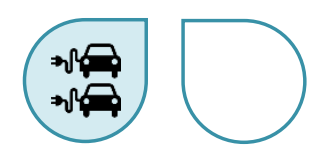

CARSHARE

Carshare systems consist of the shared use of a vehicle fleet by a group of users, who do not, however, share the same journey or the driver. In supra-neighbourly scales, this solution usually belongs to a company in which we find that ownership can adopt different schemes, from the most common business to a cooperative of the users themselves, or to their belonging to an institution (carsharing for employees, students, etc.).

And it is that from its origins carshare technologies have evolved enormously not only at the organizational level but also at the technological level. The first supra neighbourhood scale systems born in the 1980s in northern Europe and the USA consisted of a station or a set of fixed stations where users could rent vehicles for circular journeys. Later, the stations continued to be fixed but the routes became more flexible, becoming possible for them to be opened with start and end in different stations. With this approach comes what will be one of the main problems of station based systems, which is their rebalance to compensate for asymmetries in demand. Finally, with the advent of geolocation technologies, the free-float model is now available, in which users can locate vehicles via GPS and start and end the journey at any point within a predefined area of operation.

Today, more than 60 cities in 20 countries have carshare systems, mainly of business origin, with many of these companies present in multiple cities and countries, offering a global service. In Spain, the cities of Madrid, Barcelona, Bilbao or Seville have different systems of carshare, highlighting by variety and volume the city of Madrid.

The first Carsharing system landed within Madrid's central ring road in late 2015 with an initial fleet of 500 cars, all of them $100 \%$ electric. In this system, users need to register in the platform, get their documents and online payment method validated and then they are allowed start using short term leases.

It is important to highlight that regulation in the city of Madrid provides this model with a strong competitive advantage as it stablishes that zero emission vehicles can park for free in all the controlled 
parking areas (anywhere inside the first ring-road) and can move freely within the old city centre (only allowed to PT, taxis and residents of the area). This advantage, as well as assumedly other factors, has led for three other Carsharing companies to introduce their services in the city (totaling 2,100 vehicles), for four moto sharing services to introduce their services (totaling 2,000 motorbikes) and to a wide adoption of the systems.

Nowadays the city has the highest adoption rate of such services in the world and even intermediary booking platforms have been developed so that the user can easily book through a single APP the shared service that is most convenient for him at the time.

Carshare systems have advantages for both the user and the community. By reducing the number of vehicles needed to meet the same volume of demand, efficiency increases in terms of return on investment, maintenance costs, or parking space needed. In that sense, a study conducted at Harvard in 2010 focused on the use of carsharing in the form of circular trips estimated that each carshare vehicle in the city could eliminate between nine and thirteen private vehicles.

Carshare is therefore a great opportunity to optimise the scarce resource of urban public space with regard to the need for parking space. In the city of Madrid it has been observed that each shared vehicle serves about 10 users in substitution of the use of their private vehicle with approximately 810 rotations per vehicle per day ( $21 \%$ use). The occupancy of parking space for these users is therefore reduced by $90 \%$, to which should be added the additional efficiency by the more than reasonable choice of smaller vehicles on trips to areas of the city with less parking.

Other advantages include the rapid depreciation of assets and the fact that, from a regulatory point of view, it is relatively easy to impose restrictions on this type of vehicle on the basis of circulation or parking licences (requirement for electric vehicles...), which could have an impact on the type and technology of these vehicles, boosting the quality and modernity of the fleet. 
Behavioral factors underlying the adoption of smart mobility solutions

(This page has been intentionally left blank) 
PART III - BEHAVIORAL MODELS FOR

THE ADOPTION OF SMART MOBILITY SOLUTIONS IN MADRID 
Behavioral factors underlying the adoption of smart mobility solutions

(This page has been intentionally left blank) 


\section{APPLICATION OF THE METHODOLOGY TO MADRID}

For the development of the proposed work and the achievement of the objectives, the methodology is applied to three smart mobility systems in the city of Madrid. For each of them, an ad-hoc experiment has been designed based on the characteristics of the technology as well as on the specific behavioral model theorized.

The three technologies to be analyzed have similarities and differences between them. Chapters 7, 8 and 9 contain the description of the main work of the Thesis, which is materialized in the development of three experiments that will allow to analyze the behavior models that govern the adoption of new mobility technologies in the three selected smart mobility solutions: Bikesharing, Multimodal transport APP and Carsharing. In each chapter all the work carried out for a case study is collected, structuring the content in the following way:

X.1 A description of the intelligent mobility solution to be analyzed is provided.

X.2 Presents the hypothetical behavioral framework for the adoption of the innovative technology under study

X.3 Experiment design in order to test the hypotheses that have been defined.

X.4 The descriptive statistics of the sample obtained are presented and analyzed.

X.5 Process of identification of hypothetical latent factors

X.6 Results of the model.

As described in section 3.3 Research Framework, the research work carried out for the three studied solutions is interrelated. In this sense, the behavioral frameworks considered for each of them seek to reflect the different latent factors described in section 2.3 in the way in which they are most likely to inform the adoption and use of each of the technologies. 


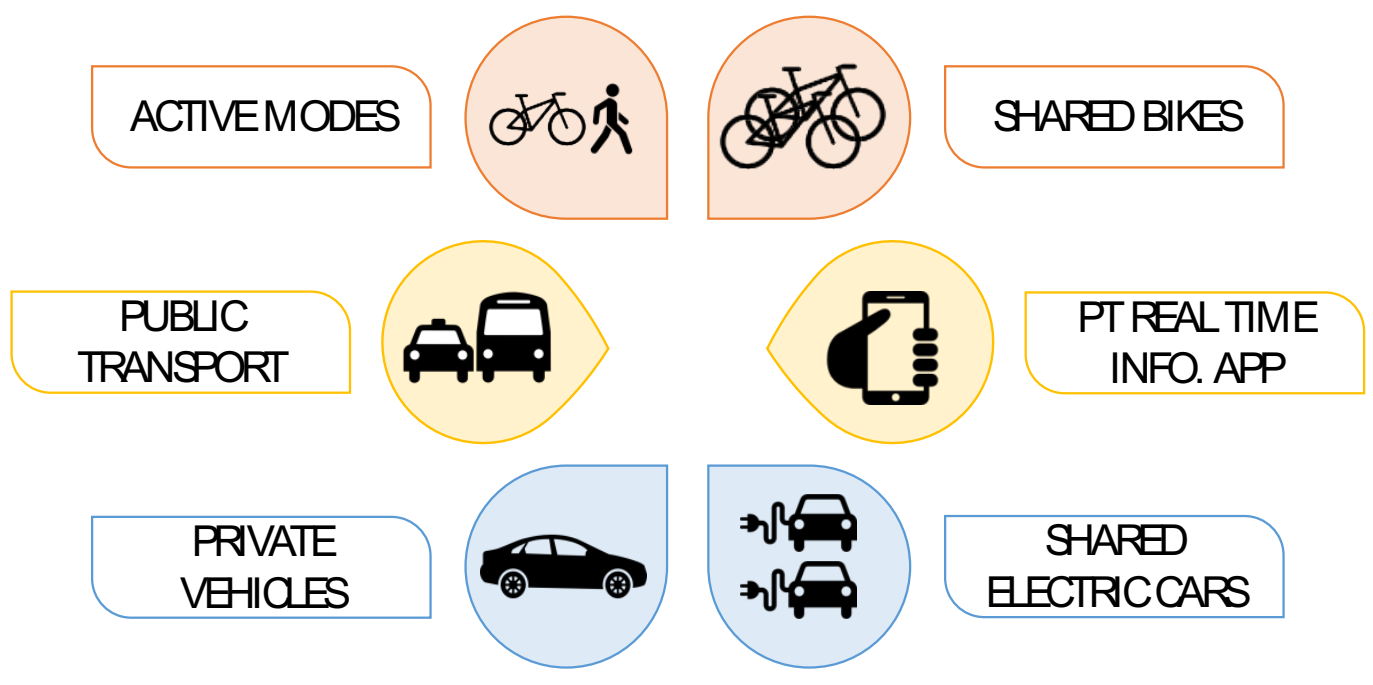

Broadly speaking, the methodological procedure used for the three studies begins with the development of research hypotheses on the behavioral framework underlying the adoption of the specific solution. A survey is then designed, taking into account the specific needs of the model we want to test.

The survey is distributed through channels designed to obtain a representative sample of potential users of the application and to collect this relevant information from them. Finally, the data are cleaned and processed, and the structure of the hypothetical behavioral model is statistically tested through a mathematical model.

Each of the three mobility solutions has its own hypothesized model based on the characteristics of the solution and previous information on the specific mode and studied latent constructs. The models respond to a general structure that is reproduced on Figure 17. In the figure we can see four different sets of variables; the first set of variables are the declared indicators used to build the latent variables (in Figure 17 represented in circular shapes) and that are generally not included in the representation of the models; the second set of variables are the latent variables, represented as ellipse-shaped forms that are hypothesized to inform the studied variables; these studied variables are represented as a rectangular shaped element; Finally, the user attributes are included and studied in their role to affect both the latent variables and the dependent variable. This graphic presentation of the models will be used through the three studies in the next sections. 
Figure 17. General behavioral model structure

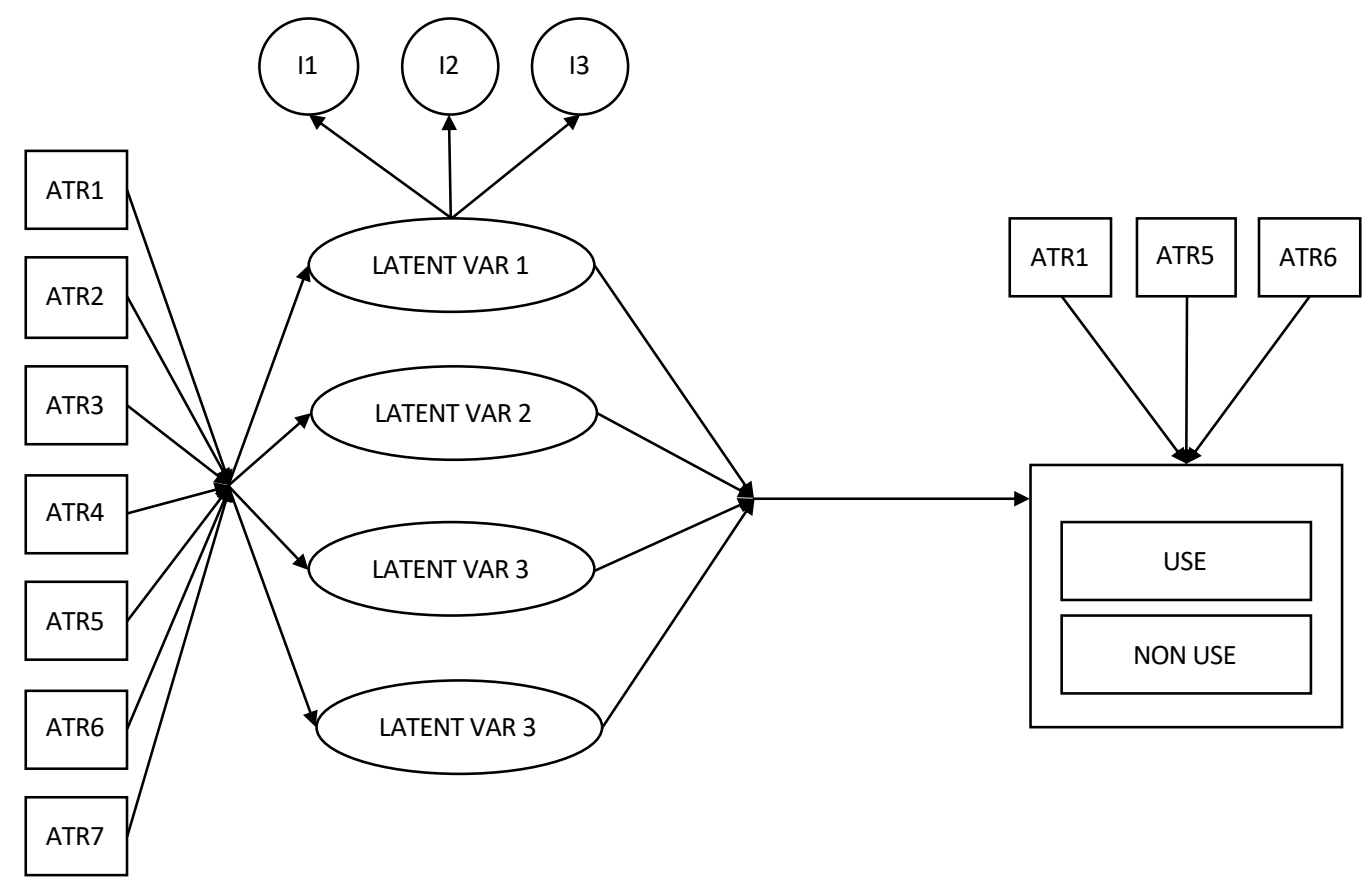

Through this process and the analysis of real solutions belonging to different types of mobility in Madrid we expect that comparability and cross analysis is easily understandable and solid enough, driving to more interesting conclusions. 
Behavioral factors underlying the adoption of smart mobility solutions

(This page has been intentionally left blank) 


\section{BEHAVIORAL MODEL FOR THE ADOPTION OF BIKESHARE ${ }^{4}$}

\subsection{Overview of BiciMAD}

In order to tackle the growing challenges of Madrid's urban mobility (e.g. disadvantages generated by motorised traffic) and particularly to promote active travel in a city centre characterized by a high level of walking and public transport use, the local government of Madrid implemented in early 2014 a public bike-sharing system.

The system was launched with a total of 1,560 bicycles and 123 docking stations. It was named "BiciMAD" and still now constitutes an example of the latest generation of bike-sharing technologies: (1) it is one of the very first large urban networks of pedelecs (electric pedal-assisted bicycles) in Europe, (2) it is a smart and eco-friendly scheme that encourages user-based redistribution through the offer of discounts and online information tools, and (3) it is a system that charges every user an initial fee in every ride in order to discourage modal shift from other sustainable modes (like walking, that is very strong in Madrid).

\footnotetext{
${ }^{4}$ The research included in this chapter has been sent for publication in the proceedings of the International Smart Cities Conference 2019 held in Casablanca, Morocco: Velazquez, G., Kaplan, S. and Monzon, A. (2019) 'Behavioral Factors influencing the adoption and use of an electric Bikeshare system: The case of BiciMAD'.
} 
Figure 18. BiciMAD docking station

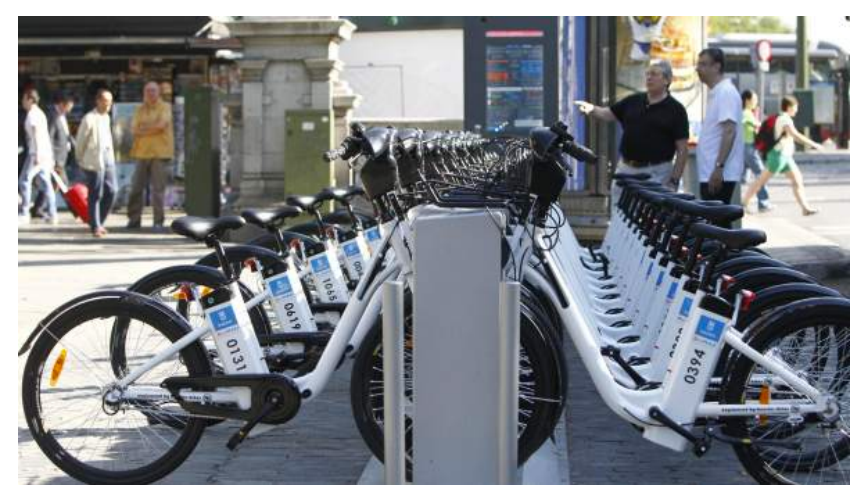

The system was introduced in the most central area of the city, home to around one third of the population or 800.000 inhabitants according to the last data released ${ }^{1}$, and reaching densities between 15 and 30 thousand inhabitants per square $\mathrm{km}$.

Figure 19. Distribution of BiciMAD docking stations in Madrid

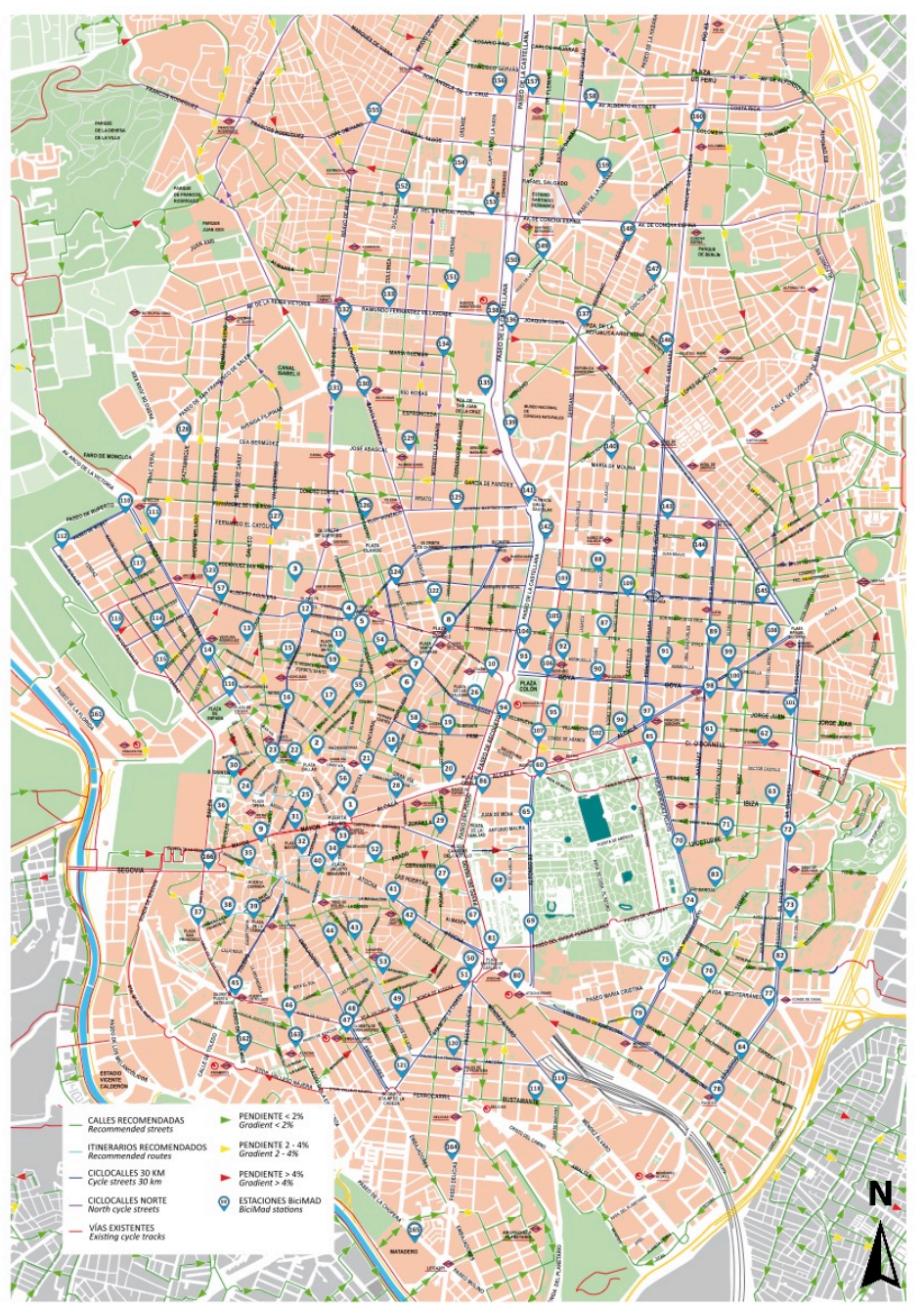


The current status of expansion of BiciMAD system is shown on Figure 19, where the colored area corresponds with the area inside the first ring road of the city. Today BiciMAD system has 166 functioning stations, with 2,000 electric bikes. The municipal government recently announced 45 new stations with an addition of 468 bikes to the system that will be introduced during 2019 , enlarging the coverage area to the south and the east of the city centre, as well as densifying the northern section.

Figure 20. Evolution of registered users in BiciMAD (2014-2019)

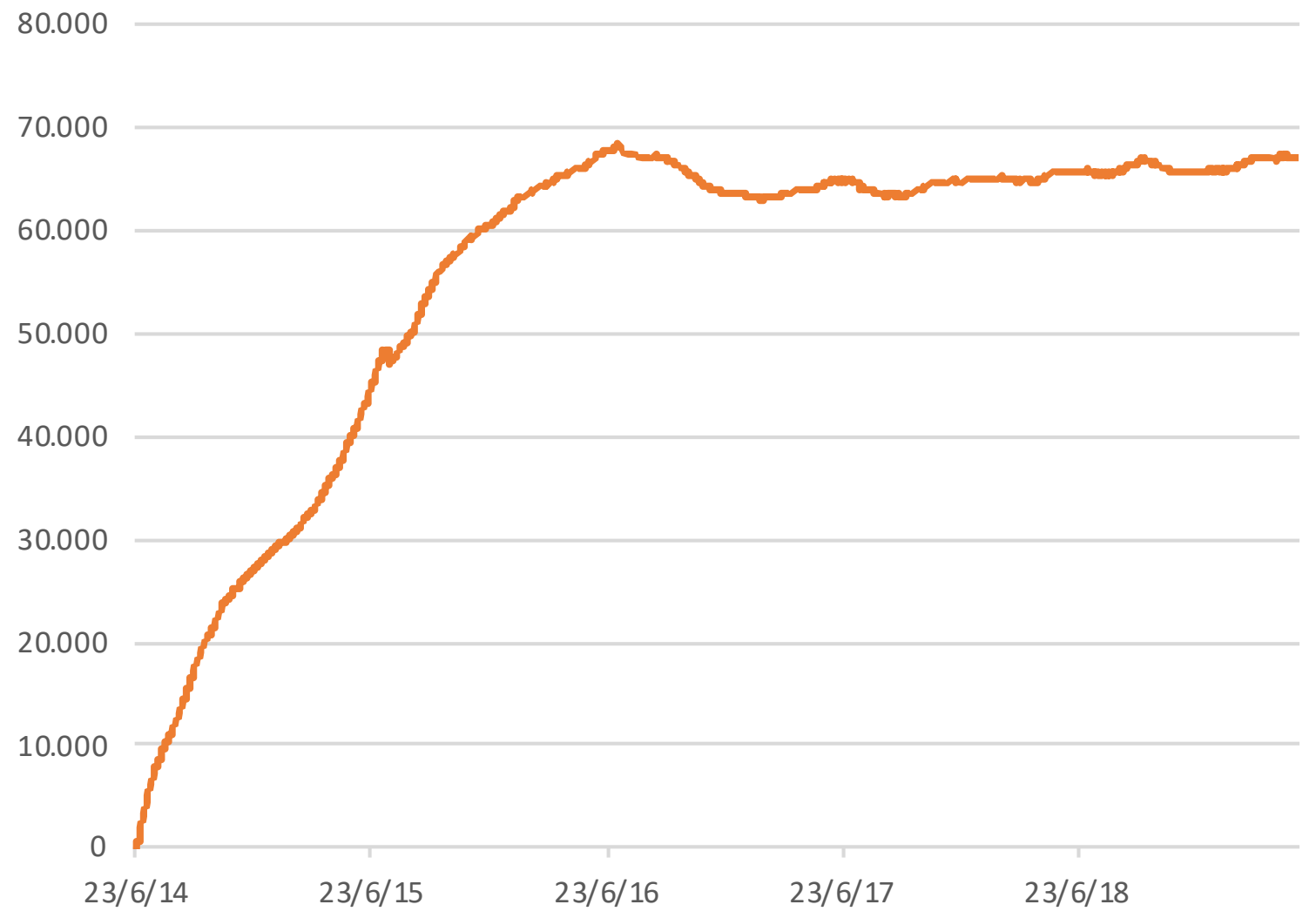

Source: EMT Open Data

New users can register through the BiciMAD webpage or at any of the docking stations. The evolution of the number of active users of the system is shown in Figure 20. There is a mobile app available to the users in which they can log in and check their trips, check their remaining pre-paid credit, add complaints, or check bike and docking spot availability in real time. Payments are pre-paid and can be conducted either online or with the user credit card at any docking station. 
Tariffs vary from regular users to occasional users. For regular users (over $90 \%$ of trips), the initial fee is $0,5 €$ for the first half an hour of use. The second half hour has the same price, while the next hour increases the price strongly as to discourage the use of the bikes for leisure purposes or keeping them on hold while performing some other activity.

\subsection{Hypothesized behavioral framework}

The methodological procedure for the study started with the development of a set of hypotheses, linked to the behavioral traits under study, that enlarged the state of the art with regard to the behavioral framework for the adoption and use of assisted pedaling bike sharing services.

In preliminary studies using these data statistical methods (factor analysis, cluster analysis, measures of correlation) have been used to identify and typify groups of (non-)users, understand the determinants and evolution of their willingness to use the service as well as to analyse changes of travel patterns (Munkacsy and Monzon 2017a; Munkacsy and Monzon 2017b; Munckacsy, 2017)

Concerning the latent constructs under study, we estimate that technophilia and green values are very likely to be included in the model, whilst social norms given the fact that the study was conducted mainly through an ex-ante survey is not likely to be relevant in this experiment. Given the risks related to biking in madrid, we assume that previous biking experience may act as a factor influencing adoption of BiciMAD. Privacy concerns on the other hand are not included as the use of BiciMAD can be conducted without the use of the mobile APP and without the provision of payment data.

We hypothesize thus, that the use of an assisted pedaling bikeshare system is related to the user satisfaction with the system itself, and to the user satisfaction with the vehicles. Green values of the user are related to his/her perception of infrastructure quality as well as to his/her previous experience in biking. This is motivated by personal technology affinity (importance of technology) and perceived importance of the level-of-service (LOS). All the elements were addressed in the questionnaire with specific sets of items. 
The proposed behavioral framework is based on these assumptions, adapted to the context of bikeshare use. Hence, the study will explore the following hypotheses:

H1: Bikeshare use is related to the user satisfaction with the system, user satisfaction with the bike and user satisfaction with the urban infrastructure for biking.

H2: User green values informs all three levels of satisfaction.

H3: Importance of technology influences satisfaction with the bikes and with the system.

H4: Previous biking experience informs satisfaction with the bikes and with urban infrastructure for biking.

H5: Covariates like age, income, familiarity with biking or access to a private bike will have an impact on frequency of use of BiciMAD services.

Figure 21 presents in a standardized graphic way this set of hypotheses to be tested in the model. Variables presented in a rectangular orange shape correspond to exogenous variables. Latent variables are represented in blue ellipse-shaped forms and finally dependent variables are presented in yellowfilled rectangular shapes.

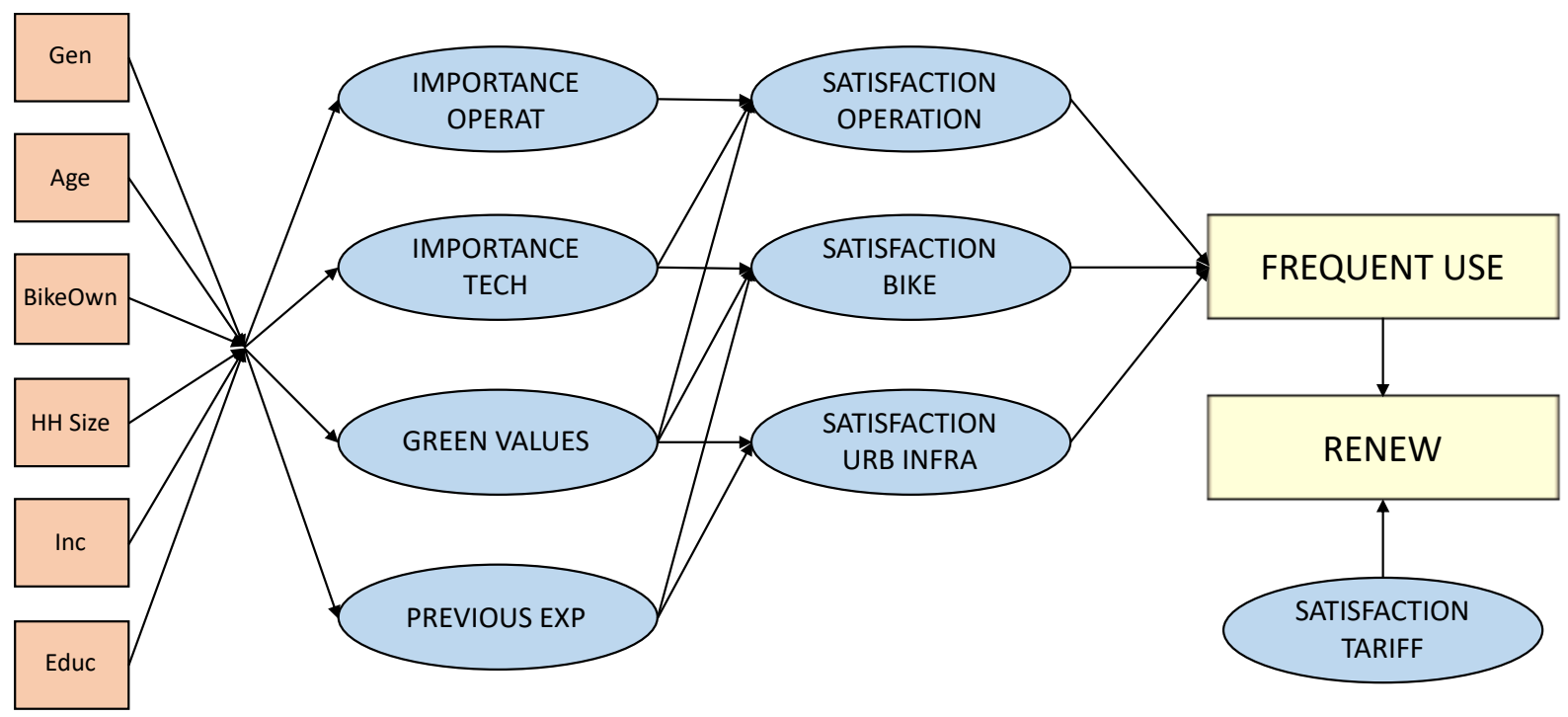




\subsection{Description of the experiment design and execution}

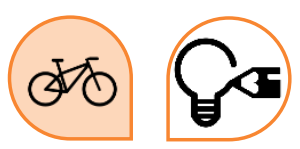

In early 2014 TRANSYT-UPM launched a self-financed research aimed at studying potential and actual users' intentions, perceptions, attitudes and behaviour of Madrid transportation network users on a new public electric bike sharing system being implemented in the city: BiciMAD. The experiment was conceived as a panel study, consisting of different survey waves, (1) before implementation, (2) right after implementation, and (3) after some time of the system being implemented. Given the size of the potential users for BiciMAD, estimated in the 3 million inhabitants of the city, the minimum sample size for a $95 \%$ confidence level and a $5 \%$ of confidence interval, is set to 384 persons.

Distributing a survey was selected as the option to gather the relevant information on a representative sample of potential users of Madrid's Bikesharing system taking into account the needs of the hypothesized model. Finally, the hypothesized behavioral model structure is tested and validated through the application of a Structural Ecuations Model.

Survey design and administration

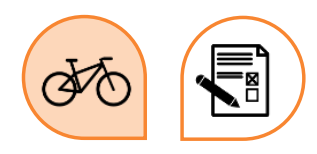

The data collection method was applied in three survey phases to reach all target groups and achieve a relevant number of complete responses (before implementation in 2014: 1,859 responses; after implementation in 2015: 442 and in 2016: 332). However, for the purposes of the study, only those surveyed after implementation were used for the analysis. 
All of the surveys had three main parts:

- 'You and the bicycle': the individual was asked about urban mobility and especially cycling patterns (bicycle use and evaluation of factors that influence cycling);

- 'You and BiciMAD': the user was asked about his intention to use bike-sharing (ex-ante survey), adoption of bike-sharing and motivation of use and non-use ( $2^{\text {nd }}$ and $3^{\text {rd }}$ survey phase), as well as appraisal of BiciMAD characteristics;

- 'Personal details': demographic and socioeconomic information of the individual.

In each survey, a pilot questionnaire was administered to survey development experts and frequent cyclists or bike-sharing users. Feedback was used to finalize contents, improve the questionnaire and eliminate internal logical errors of the online survey.

Interviewers distributed cards with access codes aimed at $50 \%$ on weekdays and $50 \%$ on weekends and holidays. The online questionnaire was open to responses from the first day of access card distribution until two weeks after all the access codes have been handed over. Prize draw took place within a few days after the survey had been closed.

Figure 22. Surveyed area and zone split for the ex-ante survey phase of BiciMAD

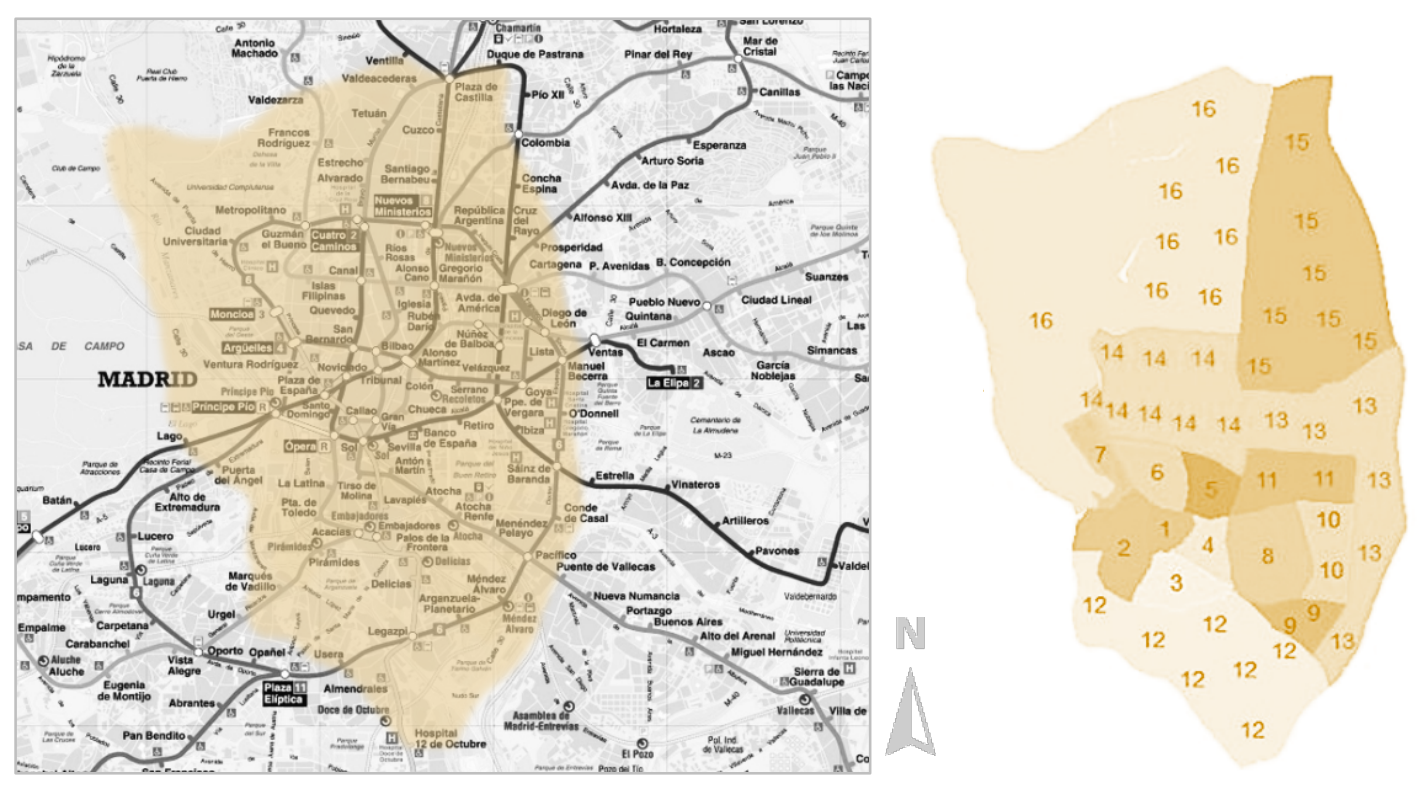


Access codes were distributed in the city core (city centre inside the $1^{\text {st }}$ ring road). In the ex- ante survey phase, interviewers covered the city of Madrid divided in 16 sample zones that the Transportation Research Centre of UPM has already used in previous research studies and that (see Figure 22 for more details).

Interviewers were instructed to address people of both sexes, all ages (youngsters below 25 years of age, middle-aged between 25 and 60 as well as the elderly), travelling by different transport modes (pedestrians, cyclists, car-drivers, public transport users) and different motivations within the survey area (residents, visitors, tourists, etc.). They had to stop people randomly in the survey site. In the second and third survey phases, they had to contact both actual users (75\%) and non-users (25\%).

BiciMAD is theoretically available for any people living, working or visiting its service area, the population of the survey is quasi-infinite. As the first survey aimed at identifying latent needs, samples of 1,000 responses in the first BiciMAD operational zone and 200 responses in other parts of the catchments area were the target.

These targets mean that the expected response rate was $10 \%$ (per access codes distributed), a reachable target on the basis of previous experience in applying similar survey techniques in Madrid. Consequently, 12,000 cards (1,000 per zone) were distributed in order to certainly cross the threshold of 1,200 responses in the ex-ante survey; 2,000 actual users and potential users were contacted personally in the next phases

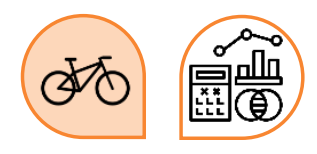

The methodology employed for the study was SEM. As already described in section 4.2.2, SEM presents a general statistical approach for validating a multivariate correlation structure across latent and observed variables in a series of equations. SEM is a generalization of regression that has an advantage in accommodating (i) a correlation structure across multiple dependent variables, and (ii) conceptual (latent) constructs that cannot be perfectly measured by a single observed indicator but require multiple indicators. SEM is commonly viewed as a combination of confirmatory factor analysis (CFA), 
representing the relationship between the latent constructs and the set of observed indicators, and path analysis representing the dependency structure across the latent constructs (Pugesek et al. 2003). A growing number of recent studies applied SEM to explore mode choice and mode switching intentions of adults (Chen and Chao, 2011; Kaplan, de Abreu e Silva and Di Ciommo, 2014; Kaplan et al., 2017). The methodology is thoroughly presented by Pugesek et al. (Pugesek, Tomer and Eye, 2003), and its application in travel behavior research has been reviewed by Golob (2003). In this study structural equations are used to explain the intention to use the app as a function of attitudinal factors and observed respondent characteristics.

In this study the SEM contains three sets of equations: (i) a set of measurement equations (eq. 1) relating the behavioral constructs to the indicators selected to measure them; (ii) a set of structural equations (eq. 2) linking the latent constructs to socio-economic characteristics, previous biking experience or PT subscription; a set of structural equations (eq. 3) relating bikeshare use indicators to the latent constructs and socio-economic characteristics.

$$
\begin{aligned}
& I_{r n}=Z_{l n}^{*} \alpha_{r}+v_{r n} \quad \text { and } v_{n} \sim N\left(0, \Sigma_{\nu}\right) \quad \text { for } r= \\
& Z_{l n}^{*}=X_{l n} \beta_{l}+\omega_{l n} \quad \text { and } \quad \omega_{n} \sim N\left(0, \Sigma_{\omega}\right) \quad \text { for } l=1, \ldots, L \\
& Y_{k n}^{*}=Z_{k l n}^{*} \gamma_{k Z}+T \gamma_{k T} \xi_{m n} \quad \text { and } \xi_{n} \sim N\left(0, \sigma_{\xi}^{2}\right) \quad \text { for } \quad k=1, \ldots, K
\end{aligned}
$$

where $I_{r n}$ is the value of an indicator $r$ of the latent construct $Z^{*}{ }_{I n}$ as perceived by respondent $n, Z^{*}{ }_{I n}$ is the value of latent construct $I$ for respondent $n, X_{I n}$ is a vector of the respondent's individual characteristics (i.e., socio-economic characteristics, bike ownership, PT subscription). $Y_{k n}^{*}$ is a vector of $k$ independent variables, namely the respondents' perceptions on BiciMAD system use frequency and renewal. The error terms follow a normal distribution with respective covariance matrices. The estimated parameter vectors are $\alpha_{r}, b_{l}, \gamma_{z}$, and $\gamma_{T}$.

The modelling of the adoption of BiciMAD is then conceived through a series of declared ordered variables, that are used to build the latent constructs. Those constructs are subsequently introduced in the SEM model in relation to a set of observed binary, ordered and categorical variables -that are used as covariates on both latent constructs and the dependent variables- and to the binary dependent variables of "level of use" and "intention to renew their BiciMAD subscription". 


\subsection{Sample description}

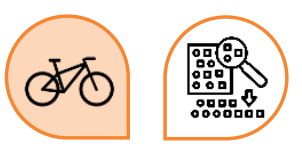

The obtained sample consisted of 442 potential users of the system of bikeshare, which is above the minimum sample size required. Table 4 summarizes the main data regarding the obtained sample for the study.

Male population is overrepresented, as female population in Madrid rises above $50 \%$ of the population, while in the sample women represent only 39 percent of the sample. Age groups are proportionally distributed. With Madrid's average age standing at 43.9 years in 2016 (INE). We expected however a certain bias towards younger respondents, as the type of survey that was executed tends to get more than proportional response rates from younger more technologicallyeager users.

Table 4. Bikeshare Survey Sample Description Summary

\begin{tabular}{|c|c|c|c|c|c|}
\hline Variable & Count & $\%$ & Variable & Count & $\%$ \\
\hline \multicolumn{3}{|l|}{ Age } & \multicolumn{3}{|l|}{ Gender } \\
\hline$<30$ & 109 & 25 & Male & 270 & 61 \\
\hline $30-40$ & 187 & 42 & Female & 172 & 39 \\
\hline$>40$ & 146 & 33 & Other & 0 & 0 \\
\hline \multicolumn{3}{|l|}{ Has his/her own bike } & \multicolumn{3}{|c|}{ Has a PT Subscription } \\
\hline Yes & 259 & 59 & Yes & 409 & 93 \\
\hline No & 183 & 41 & No & 33 & 7 \\
\hline \multicolumn{3}{|c|}{ Has a valid driver's license } & \multicolumn{3}{|c|}{ Previous experience with bikeshare } \\
\hline Yes & 375 & 85 & Yes & 170 & 38 \\
\hline No & 67 & 15 & No & 272 & 62 \\
\hline \multicolumn{3}{|l|}{ Access to a car } & \multicolumn{3}{|c|}{ Annual household income } \\
\hline Yes & 250 & 57 & Under $\$ 20,000$ & 73 & 17 \\
\hline No & 192 & 43 & $\$ 20,000-\$ 40,000$ & 167 & 38 \\
\hline \multicolumn{3}{|l|}{ Education level } & above $\$ 40,000$ & 201 & 45 \\
\hline High school graduate & 44 & 10 & \multicolumn{3}{|l|}{ Household Size } \\
\hline Vocational training & 28 & 6 & 1 & 80 & 18 \\
\hline Bachelor degree & 206 & 47 & 2 & 187 & 42 \\
\hline Graduate & 144 & 33 & 3 & 84 & 19 \\
\hline Post-graduate degree & 19 & 4 & 4 or more & 67 & 15 \\
\hline
\end{tabular}


Respondents with higher education degrees appear to be overrepresented when contrasted with the average educational level in Madrid, however it is important to keep in mind that both the service and the survey are focused in the inner city of Madrid, where income -and also educational level- stands above the average rates of the city. As it is further detailed in Chapter 11 - Limitations we recognize a potential bias due to the surveying procedure, as it requires the use of web or an ICT-device.

\subsection{Identification of behavioral factors}

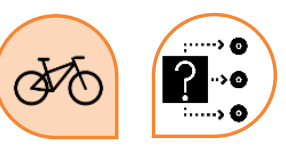

The data analysis for this first case study included the combination of both exploratory and confirmatory factor analysis followed by a structural equation model to empirically validate the proposed framework.

The objective of exploratory factor analysis is to identify a number of latent constructs underlying a set of measured variables in a situation without strong a-priori hypotheses, while confirmatory factor analysis is to test whether the data fit the hypothesized measurement model. The exploratory factor analysis in this study served to extract the existing latent constructs among different declared variables. Tests of internal consistency and sample adequacy constituted the necessary preliminary conditions for conducting factor analysis and obtaining meaningful results.

The items obtained in the survey demonstrate good internal consistency (Cronbach's alpha $=0.826$ > 0.8 ) and good sampling adequacy according to Kaiser-Meyer-Olkin measure ( $\mathrm{KMO}=0.892>0.8)$. The Spearman correlation matrix shows the existence of correlations without multi-collinearity.

The result of the Bartlett's test of sphericity rejects the null hypothesis that the correlation matrix is an identity matrix $(p=0.000)$. Exploratory principal axis factor analysis with varimax rotation (Kaiser normalization) produced seven or eight factors according to the Scree plot. 
Table 5. Output of rotated factor analysis (exploratory) for the Bikeshare study

\begin{tabular}{|c|c|c|c|c|c|c|c|}
\hline & F1 & $\mathrm{F} 2$ & F3 & F4 & F5 & F6 & F7 \\
\hline Importance of predictability & $-0,013$ & 0,423 & 0,213 & $-0,043$ & 0,162 & $-0,008$ & $-0,003$ \\
\hline Importance of sustainability & 0,109 & 0,420 & 0,435 & $-0,087$ & 0,005 & $-0,049$ & 0,133 \\
\hline Importance of flexibility & 0,088 & 0,268 & 0,364 & $-0,018$ & 0,116 & 0,016 & 0,056 \\
\hline Importance of enjoying & 0,008 & 0,351 & 0,404 & $-0,044$ & 0,062 & 0,058 & 0,221 \\
\hline Importance of street parling spots & $-0,114$ & 0,493 & 0,121 & 0,216 & $-0,095$ & 0,106 & $-0,037$ \\
\hline Importance of parking at buildings & $-0,106$ & 0,540 & 0,179 & 0,122 & $-0,122$ & 0,067 & 0,053 \\
\hline Importance of parking at job & $-0,070$ & 0,377 & 0,113 & 0,026 & $-0,097$ & 0,039 & 0,086 \\
\hline Importance of parking at public transport stops & 0,001 & 0,399 & 0,073 & $-0,005$ & $-0,140$ & 0,064 & 0,229 \\
\hline Satisfaction with specific lanes & 0,151 & 0,035 & 0,045 & 0,040 & 0,550 & $-0,156$ & $-0,025$ \\
\hline Satisfaction with shared lanes & 0,280 & $-0,037$ & 0,157 & 0,153 & 0,422 & $-0,052$ & $-0,013$ \\
\hline Satisfaction with parking availability & 0,135 & $-0,005$ & 0,005 & 0,038 & 0,806 & 0,047 & $-0,059$ \\
\hline Satisfaction with parking at buiildings & 0,166 & 0,003 & 0,003 & 0,034 & 0,811 & $-0,003$ & $-0,045$ \\
\hline Satisfaction with parking at job & 0,120 & $-0,135$ & 0,020 & $-0,026$ & 0,684 & $-0,005$ & $-0,015$ \\
\hline Satisfaction with parking at public transport stops & 0,133 & 0,036 & 0,001 & 0,076 & 0,637 & $-0,085$ & 0,134 \\
\hline Ease of use & $-0,023$ & 0,385 & 0,038 & 0,168 & $-0,005$ & 0,262 & $-0,242$ \\
\hline Comfort & 0,031 & 0,434 & 0,038 & 0,174 & $-0,038$ & 0,315 & $-0,228$ \\
\hline Bicycle maintenance & $-0,085$ & 0,148 & 0,163 & 0,058 & $-0,113$ & 0,436 & $-0,061$ \\
\hline Distance between stations & 0,100 & 0,213 & 0,060 & $-0,089$ & $-0,042$ & 0,455 & $-0,144$ \\
\hline Functioning of the totem & $-0,063$ & 0,209 & 0,060 & 0,006 & $-0,027$ & 0,534 & 0,003 \\
\hline How the anchors work & $-0,062$ & 0,095 & 0,161 & 0,094 & $-0,028$ & 0,625 & 0,020 \\
\hline Availability to park the bicycle & $-0,127$ & 0,249 & 0,014 & 0,068 & 0,069 & 0,601 & $-0,003$ \\
\hline Availability to take a bicycle & $-0,165$ & 0,202 & 0,084 & 0,093 & 0,003 & 0,615 & 0,000 \\
\hline Annual fee & 0,012 & 0,664 & $-0,119$ & $-0,139$ & 0,018 & 0,144 & $-0,002$ \\
\hline Enrollment Fee & 0,007 & 0,688 & $-0,074$ & $-0,100$ & 0,011 & 0,126 & 0,023 \\
\hline Tariff for occasional users & 0,213 & 0,522 & $-0,134$ & $-0,107$ & 0,026 & 0,024 & $-0,004$ \\
\hline Discounts & 0,051 & 0,720 & $-0,036$ & $-0,128$ & 0,057 & 0,113 & $-0,030$ \\
\hline Payment Process & 0,084 & 0,654 & 0,065 & $-0,016$ & 0,018 & 0,270 & $-0,039$ \\
\hline Balance inquiry & 0,019 & 0,604 & 0,117 & $-0,102$ & $-0,034$ & 0,264 & $-0,078$ \\
\hline Mobile application & 0,018 & 0,385 & 0,158 & $-0,073$ & $-0,007$ & 0,207 & $-0,085$ \\
\hline Telephone attention to the user & $-0,070$ & 0,367 & 0,139 & $-0,018$ & $-0,034$ & 0,291 & $-0,066$ \\
\hline Bike Design & 0,200 & 0,037 & 0,070 & 0,619 & 0,075 & 0,001 & $-0,080$ \\
\hline Ease of use & 0,208 & 0,029 & 0,099 & 0,739 & 0,066 & 0,014 & $-0,093$ \\
\hline Comfort & 0,275 & 0,018 & 0,091 & 0,697 & 0,062 & 0,076 & 0,018 \\
\hline Pedaling assistance & 0,287 & $-0,054$ & 0,079 & 0,444 & $-0,026$ & $-0,035$ & $-0,057$ \\
\hline Bicycle maintenance & 0,672 & 0,136 & 0,010 & 0,048 & 0,143 & $-0,127$ & $-0,041$ \\
\hline Extension of the current network of stations & 0,358 & 0,014 & 0,063 & 0,201 & 0,205 & $-0,149$ & $-0,019$ \\
\hline Distance between stations & 0,389 & $-0,072$ & 0,113 & 0,310 & 0,163 & $-0,104$ & 0,032 \\
\hline Functioning of the totem & 0,705 & 0,005 & $-0,017$ & 0,014 & 0,097 & $-0,102$ & 0,067 \\
\hline How the anchors work & 0,699 & 0,084 & $-0,041$ & 0,031 & 0,069 & $-0,153$ & 0,017 \\
\hline Availability to park the bicycle & 0,518 & 0,006 & 0,223 & 0,290 & 0,069 & $-0,187$ & $-0,001$ \\
\hline Availability of bicycles & 0,635 & 0,028 & 0,085 & 0,110 & 0,067 & $-0,192$ & 0,024 \\
\hline
\end{tabular}




\begin{tabular}{|c|c|c|c|c|c|c|c|}
\hline Payment Process & 0,398 & $-0,125$ & 0,230 & 0,305 & 0,070 & 0,195 & $-0,069$ \\
\hline Balance inquiry & 0,461 & $-0,110$ & 0,212 & 0,298 & 0,063 & 0,184 & $-0,084$ \\
\hline Mobile application & 0,461 & $-0,005$ & 0,014 & 0,081 & 0,129 & 0,143 & $-0,027$ \\
\hline Telephone attention to the user & 0,406 & $-0,084$ & 0,126 & 0,077 & 0,075 & 0,079 & 0,008 \\
\hline $\begin{array}{l}\text { I have experience in cycling (e.g. my own bike) through } \\
\text { the centre of Madrid }\end{array}$ & 0,013 & 0,127 & 0,061 & 0,070 & $-0,066$ & 0,026 & 0,706 \\
\hline $\begin{array}{l}\text { Before using BiciMAD I had already gone to the center } \\
\text { of Madrid on my own bicycle. }\end{array}$ & 0,027 & 0,065 & 0,036 & 0,040 & $-0,027$ & $-0,046$ & 0,704 \\
\hline $\begin{array}{l}\text { more responsible in } \\
\text { ters }\end{array}$ & 0,098 & 0,273 & 0,524 & $-0,035$ & $-0,083$ & $-0,018$ & 0,150 \\
\hline des of transport & 0,021 & 0,040 & 0,568 & 0,070 & $-0,100$ & $-0,022$ & 0,087 \\
\hline BiciMAD is cheaper than other modes of transport & 0,073 & $-0,054$ & 0,494 & 0,085 & 0,064 & 0,108 & $-0,031$ \\
\hline $\begin{array}{l}\text { With BiciMAD I get to my destination faster than } \\
\text { before }\end{array}$ & & $-0,018$ & 0,640 & 0,120 & 0,047 & 0,142 & $-0,033$ \\
\hline $\begin{array}{l}\text { The BiciMAD network corresponds to my usual and/or } \\
\text { occasional journeys }\end{array}$ & 0,071 & 0,055 & 0,426 & 0,178 & 0,153 & 0,099 & 0,002 \\
\hline Using & 0,101 & 0,138 & 0,659 & 0,090 & 0,075 & 0,117 & 0,199 \\
\hline e of the solutions to calm the & 0,079 & 0,040 & 0,454 & 0,007 & $-0,009$ & 0,132 & 0,082 \\
\hline I easily find an avai & & 0,089 & 0,240 & 0,122 & 0,148 & $-0,145$ & 0,060 \\
\hline Removing and parking the bike is easy for me & 0,510 & 0,064 & 0,060 & 0,102 & 0,079 & $-0,130$ & 0,068 \\
\hline $\begin{array}{l}\text { nfortable for me (adjust saddle } \\
\text { tc.) }\end{array}$ & & $-0,007$ & 0,209 & 0,485 & 0,166 & 0,059 & 0,092 \\
\hline $\begin{array}{l}\text { On a bicycle of BiciMAD I can climb the slopes of } \\
\text { Madrid easily }\end{array}$ & 0,145 & $-0,129$ & 0,312 & 0,384 & $-0,022$ & 0,056 & 0,124 \\
\hline BiciMAD bikes are easy to handle & 0,187 & $-0,107$ & 0,308 & 0,512 & $-0,017$ & 0,101 & 0,060 \\
\hline Operating on the totem screen of the stations is simple & 0,522 & $-0,006$ & 0,111 & 0,136 & 0,032 & 0,173 & 0,117 \\
\hline $\begin{array}{l}\text { I find it easy to keep track of my available balance on } \\
\text { BiciMAD }\end{array}$ & & $-0,118$ & 0,183 & 0,206 & 0,008 & 0,132 & 0,126 \\
\hline em to be happy using BiciMAD & 0,576 & 0,005 & 0,301 & 0,164 & $-0,019$ & $-0,066$ & $-0,031$ \\
\hline BiciMAD promotes the use of the bic & 0,161 & 0,002 & 0,593 & 0,300 & $-0,057$ & 0,033 & $-0,087$ \\
\hline I recommend BiciMAD & 0,280 & $-0,031$ & 0,629 & 0,274 & 0,037 & 0,058 & $-0,066$ \\
\hline
\end{tabular}

The factor loadings are presented in Table 5 in order to facilitate factor labeling, the dominant items, shaded, were defined as those with an absolute value of the loading greater than 0.35 .

To choose the optimal number of factors the author used L. Ricolfi's procedure as described in his unpublished material from the course "Methodology for Psychological and Social Research," (2002) where the number of factors is calculated as the best compromise between adaptation and efficiency of the solution. Adaptation is computed through the percentage of cells of the correlation matrix where the difference between observed and reproduced correlations is less than 0.05 . Efficiency is then described as the ratio between the real case containing a certain number of degrees of freedom (where saved parameters are the difference between the number of input data and the number of degrees of freedom) and the ideal solution in which only 1 degree of freedom is left. 
The interpretation of the meaning of the factors rely on their supporting questions scored by the respondents. Thus, the first factor (F1) has been labelled "Satisfaction with system operation". The next factor (F2) "Importance given to technological adequateness" which is clearly linked to technophile behavior, the third one (F3) is labelled "Green Values". The next three factors were labelled "Satisfaction with the shared bike" (F4), "Satisfaction with BiciMAD system" (F5), and "Importance given to system operation" (F6). Finally, the last two factors (F7) and (F8) describe "Previous user experience with biking" and "Satisfaction with the tariff". Those factors are confirmed through confirmatory factor analysis, then contrasted, associated to user characteristics (e.g. age, gender, household size, income or employment status) and introduced into the structural relation model. The analysis of Table 5 results shows the explanatory power of the seven identified latent variables and the questions of the survey that support the loading factors of each of them.

\subsection{Model estimation results}

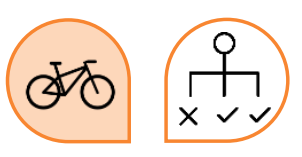

The commercial software M-Plus was used for the model estimation. The parameters were estimated simultaneously by using Maximum Likelihood with Huber-White covariance adjustment (Yuan and Bentler, 2000). Standard errors were calculated by adopting the White's sandwich-based method that produces robust statistics in the presence of non-normality of the indicators and the categorical variables (White, 1980; Bentler, 1989; Browne and Cudeck, 1992).

The estimation results are presented in Table 6 which shows the measurement equations of the confirmatory factor analysis that corresponds to exploratory factor analysis presented in Table 5 in the previous section. In this study the factor structure is revealed by exploratory factor analysis and it is used as part of the model structure with confirmatory factor analysis, which enhances the structural validity of the proposed model. The CFI value, which indicates the goodness-of-fit of the confirmatory factor analysis, is 0.826 , showing excellent data fit. The model including the set of measurement and structural equations fits properly.

The statistical model confirms the general behavioral framework and the research hypotheses for the case study of Madrid. Table 6 shows the relationship between the latent constructs and the 
respondents characteristics that are deemed relevant by the model. Most importantly, we focus on the effect of the various latent constructs on the frequency of use of bikeshare, as well as on the willingness to renew the yearly subscription.

Table 6. Structural Eq. relating LV to Bikeshare use and intention to renew subscription

\begin{tabular}{|c|c|c|c|}
\hline Latent Constructs & Explanatory / mediator variable & Est. & C.R. \\
\hline \multirow{2}{*}{$\begin{array}{l}\text { Satisfaction with the operation } \\
\text { (F1) }\end{array}$} & Importance of operation (F6) & -0.530 & -7.467 \\
\hline & Environmental responsibility (F3) & 1.161 & 9.140 \\
\hline \multirow{2}{*}{$\begin{array}{l}\text { Satisfaction with the vehicle } \\
\text { (bike) (F4) }\end{array}$} & Environmental responsibility (F3) & 1.213 & 7.008 \\
\hline & $\begin{array}{l}\text { Importance of tech ease/ Non-Technophile } \\
\text { (F2) }\end{array}$ & -0.470 & -5.750 \\
\hline \multirow{2}{*}{$\begin{array}{l}\text { Satisfaction with urban } \\
\text { infrastructure (F5) }\end{array}$} & Environmental responsibility (F3) & 0.094 & 3.924 \\
\hline & Previous Biking Exp (F7) & -0.214 & 2.580 \\
\hline Importance of operation (F6) & Female & 0.246 & 3.069 \\
\hline Dependent Variables & Explanatory / mediator variable & Est. & C.R. \\
\hline \multirow{3}{*}{ Frequent User } & Satisfaction with the operation (F1) & 0.428 & 6.304 \\
\hline & Satisfaction with the vehicle (bike) (F4) & 0.401 & 4.584 \\
\hline & Satisfaction with urban infrastructure (F5) & 0.160 & 1.837 \\
\hline \multirow{2}{*}{$\begin{array}{l}\text { Satisfaction with the tariff } \\
\text { (Willingness To Pay) (F8) }\end{array}$} & Satisfied with the operation (F1) & 0.775 & 2.580 \\
\hline & Frequent User & 0.068 & 0.000 \\
\hline \multirow[b]{2}{*}{ Renewing subscription } & Frequent User & -0.346 & -3.975 \\
\hline & $\begin{array}{l}\text { Satisfaction with the tariff (Willingness To } \\
\text { Pay) (F8) }\end{array}$ & 0.428 & 6.304 \\
\hline
\end{tabular}

C.R. =Est./S.e.

Ratio between chi-square and degrees of freedom $=2.32$ which are good (27).

RMSEA stands at 0.059. CFI stands at 0.826, which are reasonable according to Loehlin et al. (21).

The model statistically confirms $\mathrm{H} 1$ with the relations of the user satisfaction with the system, user satisfaction with the bike characteristics and user satisfaction with the urban infrastructure for biking being significant for the frequent use of bikeshare. The statistical model also confirms $\mathrm{H} 2$, with green values directly informing all three levels of satisfaction. The statistical model partially confirms $\mathrm{H} 3$, as the importance that the user sets on technology informs satisfaction with the bikes but not the general satisfaction with the system.

The correlation patterns on Table 6 partially confirms $\mathrm{H} 4$, with previous biking experience being correlated with satisfaction with urban infrastructure for biking but not with satisfaction regarding the 
bikes. The model also confirms $\mathrm{H} 5$ with covariates like age, income, familiarity with biking or access to a private bike having an impact on being a frequent user of BiciMAD.

Finally, the analysis also showed that the satisfaction with the tariff is positively and significantly correlated to the Intention to renew the subscription dependent variable, also and more surprisingly, the model has shown that being a frequent user of the system is negatively correlated with the intention to renew the subscription. These results and the weights among interrelated factors are explained below and represented in Figure 23.

Figure 23. Bikeshare model results: relation among variables and latent variables

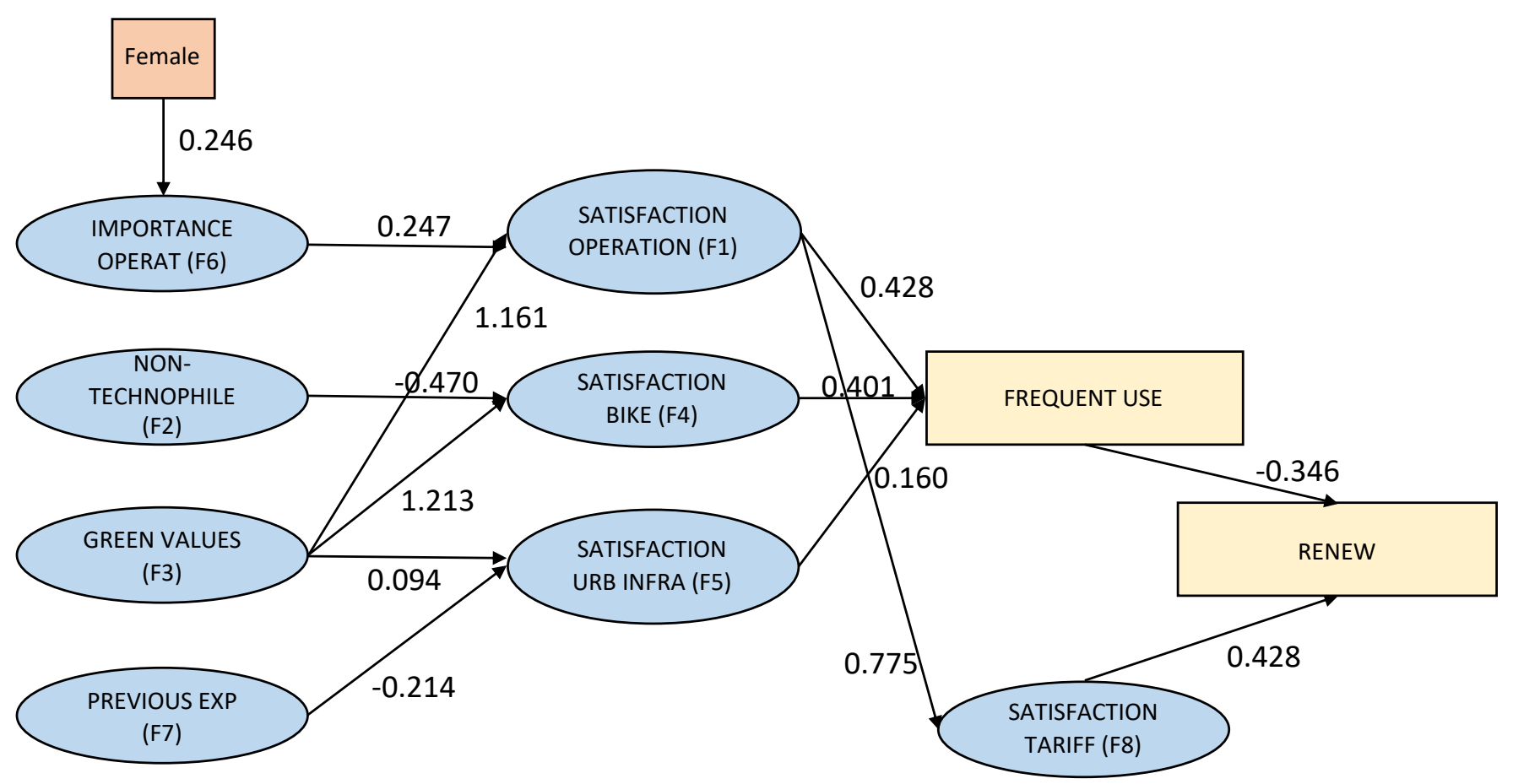

The analysis of the model obtained in the experiment shows that:

(i) The frequent use of bikeshare system in Madrid is correlated with the user's satisfaction with the operation and the vehicle, and to a lesser extent, with the urban biking infrastructure;

(ii) Green user values have a generalized positive impact on the perception that the users have of the system and therefore on the use that they make of it;

(iii) Being non-technophile has a negative correlation with user bike satisfaction, suggesting that technophilia acts as a driver to enhance a frequent usage of the system 
(iv) Finally, satisfaction with the system's tariff positively informs the intention of the user to renew his subscription, while frequently using bikeshare works reversely. This could be explained by one of the systems objectives, which was to try to transfer users from other modes to the decision to buy a private bicycle by increasing the presence of bikes in the streets of Madrid and by providing a first contact of Madrid's citizens with the biking experience.

These results are reproduced in Chapter 11. 
Behavioral factors underlying the adoption of smart mobility solutions

(This page has been intentionally left blank) 


\section{BEHAVIORAL MODEL FOR THE ADOPTION OF A MULTIMODAL TRANSIT APP 5}

\subsection{Overview of "Mi Transporte" APP}

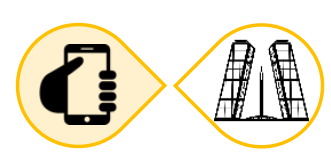

"Mi transporte" is a mobile application -available on iOS and on Android marketplaces- that gathers on a single channel both static and real time information on all the public transport modes available in the city of Madrid.

It has a remarked multimodal dimension, as it combines information about the transport supply offered by 40 different public transport operators in the Madrid Metropolitan Area and Madrid City. The app improves the communication of the information on the transport network to the final users, helping them to find the closest stop, providing information on the next train/bus arriving to that stop, as well as informing about any disruption on their trip, etc.

\footnotetext{
${ }^{5}$ The research included in this chapter has been published in 2018: Velazquez, G., Kaplan, S. and Monzon, A. (2018) 'Ex - ante and ex - post evaluation of a new transit information app : modelling use intentions and actual use', Transportation Research Record: Journal of the Transportation Research Board.
} 
Figure 24. Mi Transporte outlook. Configuration and Map screens.

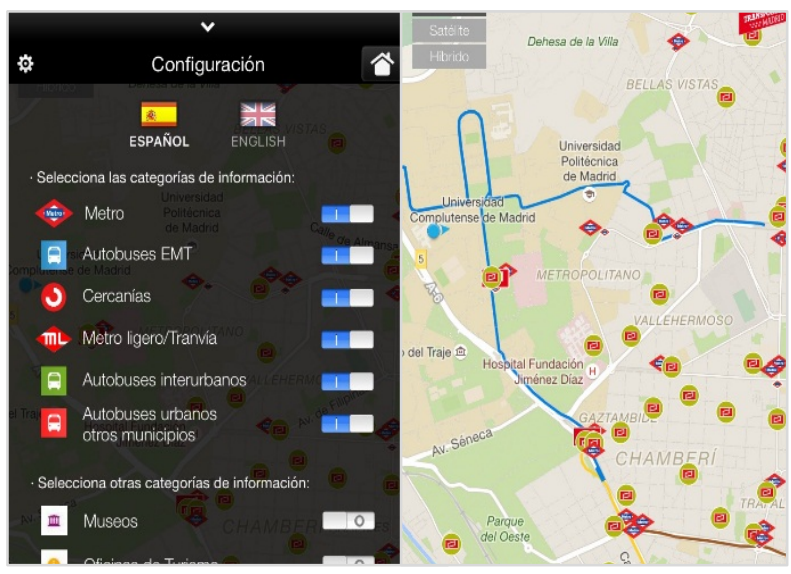

The main innovations of the new "Mi transporte" app are that it allows public transport users to obtain customized and automated information. Users can configure automatic alerts and programmed information searches that are delivered to them in the time and form that they select.

\subsection{Hypothesized behavioral framework}

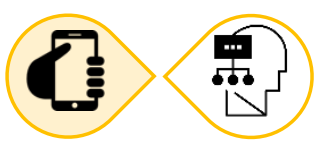

For the purposes of this work we hypothesize that the use of the app is related to the willingness-topay for the app and the interest in trying it. This interest is motivated by personal technology affinity (technophilia), time saving skills, environmental responsibility, perceived importance of the level-ofservice (LOS) and satisfaction with interchanges (the study was performed in one main interchange station), information search needs on transit, bicycle and car, and expectations regarding the benefits of the app. All of these elements were addressed in the questionnaire through specific sets of items.

The proposed behavioral framework is based on the Extended Technology Acceptance Model (ETAM), adapted to the context of transit use and mobile app use. In the ETAM, the demonstrability of the results and the output quality explain the perceived technology usefulness of the app which is expressed in terms of time and monetary savings. Subjective norms have not been considered as the usage of the app is not visible for other users. User experience or familiarity has been considered 
through the previous usage of mobility apps and the familiarity with technological devices. The construct of job relevance in the ETAM is a contextual variable and hence irrelevant in the current app use context. Hence, the proposed model framework enables to explore the following hypotheses:

H1: app use is related to the willingness-to-pay for the app and the intention to use it in the future.

H2: user's expectations, technophilia, and previous use of transport apps explain the intention to adopt the app.

H3: the search functionalities of the app, the LOS importance, information about side-modes and time saving skills explain the user's expectations.

H4: gender, age and smartphone use explain user's technophilia.

H5: trip type (frequency, duration, reason of trip) and smartphone use are related to time saving skills.

Figure 25. Hypothesized behavioral model for the adoption of a Multimodal Transit APP

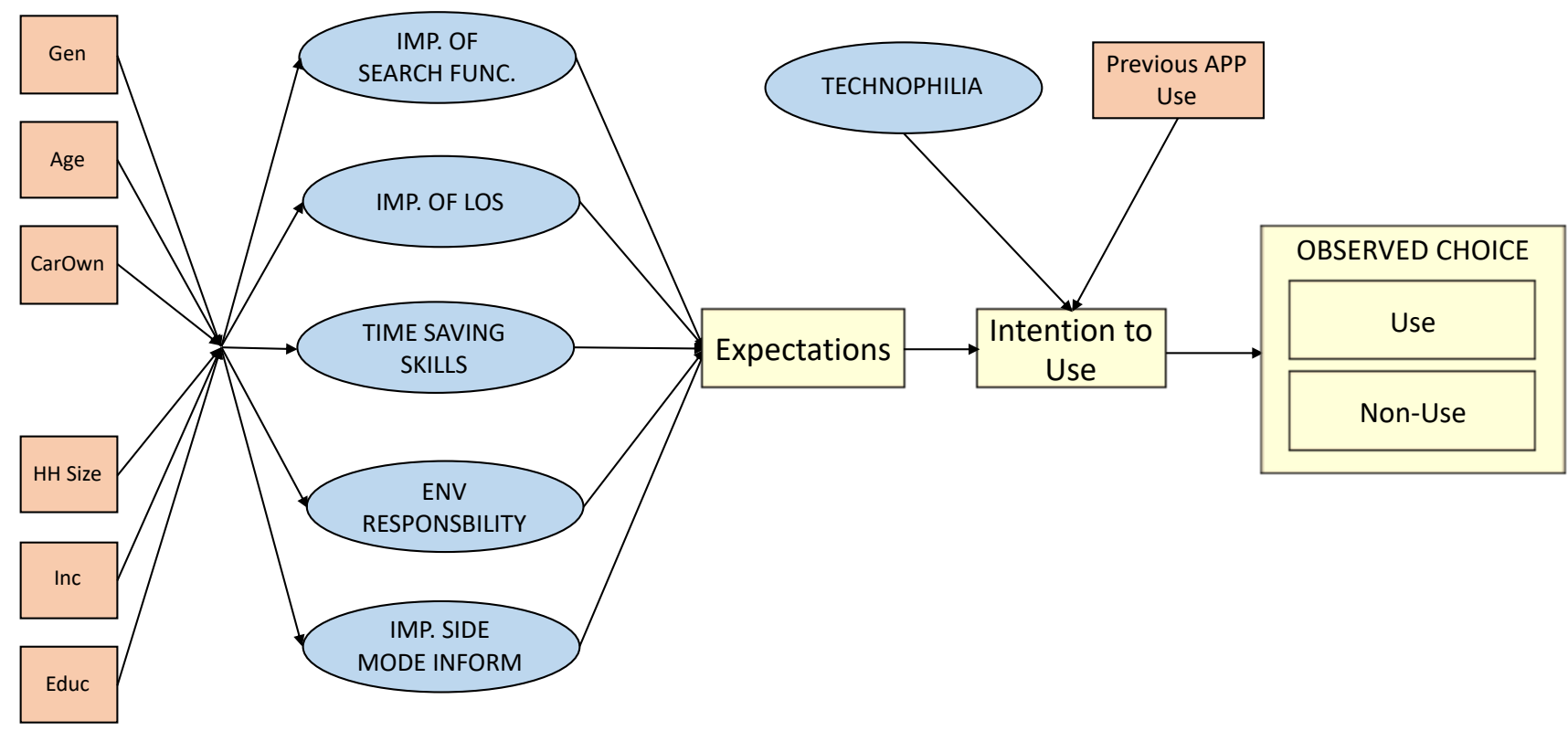




\subsection{Description of the experiment design and execution}

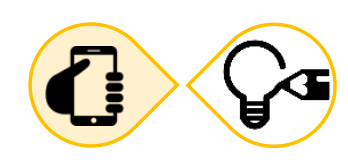

With the aim of analysing the adequateness of the app to the user's demands and expectations, as well as to the actual adoption of the solution and its impact on urban mobility, an experiment was developed by TRANSYT-UPM in the framework of the OPTICITIES FP7 European project.

The experiment was conceived as a panel study, consisting of three survey waves. A sample of potential users of the APP -that is, PT users- was obtained for the first wave. Users were then surveyed before the implementation of the new APP, right after the implementation of the APP and after three months of use. In these survey waves different items addressing the measurement of the aforementioned behavioral latent constructs were included. Also information on the adoption of the APP as their main PT information APP was gathered, in order to use it as dependent variable in the model. The required sample, for a universe of around 4,000,000 public transport users, and a $5 \%$ of error was estimated to have a size of 385 .

Survey design and administration

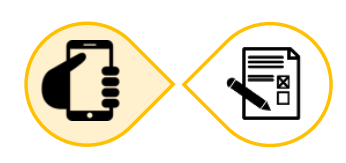

The surveying methodology was the combined personal intercept and online survey procedure as described in chapter 4.1. The questionnaire was designed on the online platform SurveyMonkey and consisted of a set of items addressed at observing the users characteristics in the areas of travel behavior, technological skills and predisposition to adopt both new technological solutions in general and mobile apps in particular. It was completed by a set of questions on the users' preferences for a transportation mobile app, as well as on their willingness to pay for such an application. It is worth 
mentioning that the survey was quite exhaustive by design, taking about $25-30$ minutes to be completed. In each surveying phase, a pilot questionnaire was previously administered to survey development experts and frequent users of mobility apps, who then provided feedback both on the quality of the addressed items and on the survey structure.

For the initial survey, data collection lasted for one week, engaging four surveyors who spent each fifteen hours on the matter. As it has been mentioned, in order to obtain a representative sample of transit users (potential app users) we applied a mix survey methodology based on a personal intercept short interview combined with a web-based survey, technique tested by Hernandez et al. (2017). More than 2,000 public transport users of different ages, using different transportation modes and at different days of the week and hours of the day were intercepted asked some questions and required to fill in the online survey. Those completing the web questionnaire entered a prize draw as incentive. They were intercepted in Avenida de America, one of the main interchange stations of the city that combines four subway lines (one circular line and three others), eleven urban bus lines, and twelve suburban bus lines, as well as park and ride facilities, with a demand of approximately 170,000 travelers per day.

Figure 26. Location of the Avenida de America interchange station within Madrid city

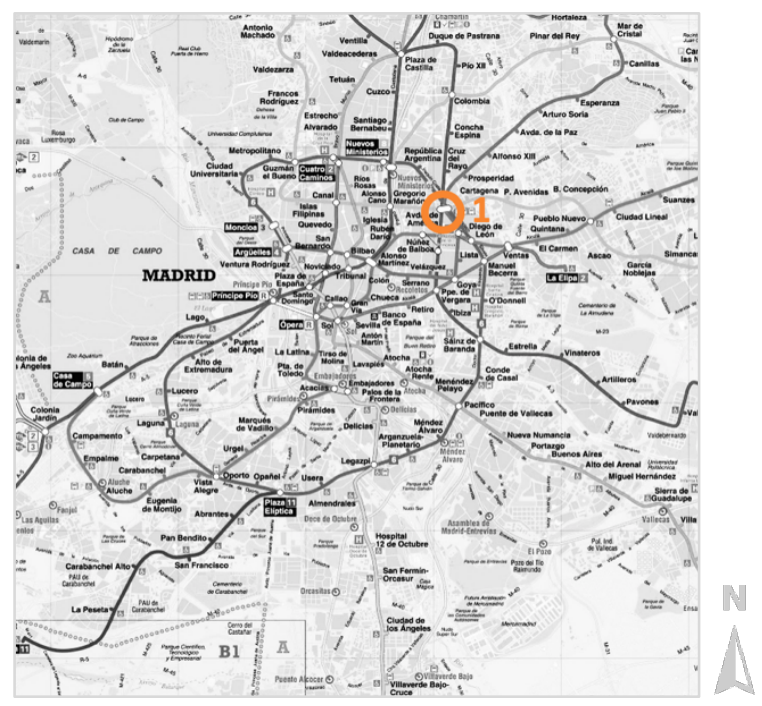

A total of 599 answers were obtained, out of which 386 were answers to the 40 questions presented, with more than 120 variables measured. This indicates a response rate of $19.3 \%$ complete answers to the questionnaire. This volume of successful response allowed the use of a representative sample. All the respondents provided contact details to be used in the following surveying waves in order to proceed with subsequent phases of the study. 
The complete study lasted for one year as a panel, in which the same sample was contacted and asked to fill new questions. Each wave included an incentive (12€ in PT trips for the first 100 respondents) being the first survey the longest (second wave 5 minutes, third wave 15 minutes). The dropout ratio was quite high along the panel with this methodology; out of the initial 386 respondents only 152 made it through the three stages of the panel.

Figure 27. Panel Survey Evolution through the three waves (Mi Transporte)

\begin{tabular}{|c|c|c|c|c|}
\hline & & 152 & & \\
\hline 386 & & 2. In-itinere (month 1) & & \\
\hline 1. Ex-ante (before) & & - Installation problems? & & 153 \\
\hline - Travelers' needs & & - Easy get used? & & 3. Ex-post (month 6) \\
\hline - Previous mobility profile & & - First impression & & - Changes mobility profile \\
\hline $\begin{array}{l}\text { - APP expectations } \\
\text { - Willingness to pay }\end{array}$ & 152 & Actual use: $33 \%$ & 130 & $\begin{array}{l}\text { - App's use and assessment } \\
\text { - Willingness to pay }\end{array}$ \\
\hline Intention to use: $56 \%$ & & & & Actual use: $34 \%$ \\
\hline
\end{tabular}

23

Wave 1 (ex-ante) selected the users distributed by the different sample categories, before the app "Mi Transporte" was launched. Wave 2 was carried out one month after the app was put in use. That means that users had started to get used to it and to realize its utility. Finally, the 3rd wave intended to capture changes in travel behavior and the assessment of the value added by the app.

The data collection campaign was launched with the initial survey in February-March 2015. Items in the questionnaires were focused on five aspects: (i) use of Public Transit, (ii) use of technological devices, (iii) Perceptions on PT and on PT apps, (iv) willingness-to-pay for an app with certain characteristics (those to be introduced) and characteristic rating (WTP) and (v) user socioeconomic characteristics. It was a panel survey conducted in three waves. The survey constituted mainly of questions associated to the Theory of Planned Behavior that states that attitudes toward behavior, subjective norms, and perceived behavioral control, together shape an individual's behavioral intentions and behaviors (Ajzen, 1991). Further elements of the online survey and the survey methodology have been based on the practice of social research (Williams and Babbie, 2006).

The questions were rated on a 5-point scale from "strongly disagree" to "strongly agree". The questionnaire design including both positively and negatively phrased items, reverse-scoring is employed as the standard procedure in data analysis in order to combine the negatively and positively phrased items. The following table shows the surveyed items besides the sociodemographic covariates and the dependent variables of intention to adopt, APP use, and willingness to pay for the system. 
Table 7. Survey items included in Mi Transporte research study questionnaire

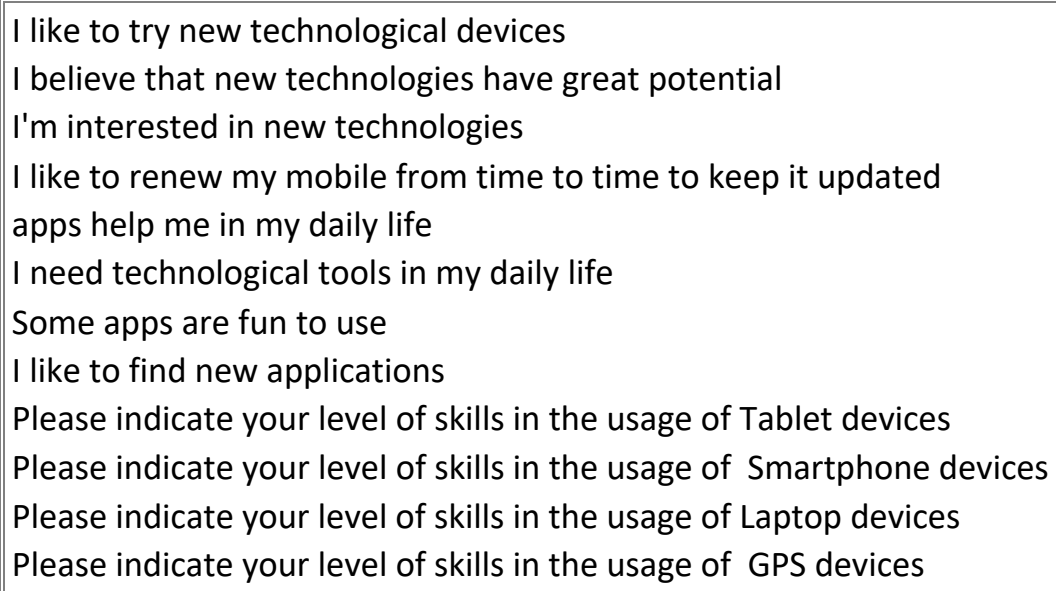

My most frequent trip takes too much time

I feel like I waste my time on the way

I would use public transport more often if there was real-time service information

I would use public transport more often if the service was better

The impact of transport on the environment is a real problem in Madrid

I feel as part of my responsibilities to reduce the emission of pollutants that potentiate the greenhouse effect It's important to search for the name of the stop It's important to find the nearest stop of a chosen line

It's important to find the nearest stop of a chosen mode of public transport

It's important to find the nearest public transport stop

It's important to find the nearest BiciMAD station

It's important being able to search for nearby BiciMAD stations according to occupancy level

It's important being able to find deterrent parking facilities (and information on public transport services there)

It's important to be able to search for parking facilities according to occupancy level

If the app allows me to save travel time, I intend to use it in my daily trips

If the app can increase the predictability of my daily trips, I will use it

If the app allows me to save money, I intend to use it

If the app allows me to plan my trips better, I intend to use it

Using the app will allow me to save some travel time

Thanks to the app I will get to my destination more calmly

Thanks to the app I will improve the regularity in my times of displacement

Thanks to the app I will reduce the impact of my travels on the environment

I think using the app will make it easier for me to change my transport habits

I think the app will be easy to use
Time

Flexibility

Predictability

Security

Comfort

Pleasure

Capability to carry items 


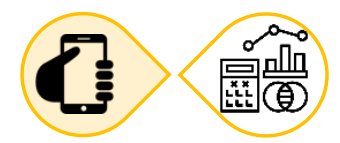

According to the methodology presented in Chapter 4, the statistical model employed for this study was Structural Equation Modelling. In this study, simillarly to that of the BiciMAD case, the SEM contains three sets of equations: (i) a set of measurement equations (eq. 1); (ii) a set of structural equations (eq. 2) linking the latent constructs to socio-economic characteristics, routine use of car and transit, PT subscription, car ownership and transit information search with emphasis on real-time information; a set of structural equations (eq. 3) relating app use indicators to the latent constructs and information search.

(1) $I_{r n}=Z_{l n}^{*} \alpha_{r}+v_{r n}$ and $v_{n} \sim N\left(0, \Sigma_{v}\right)$ for $r=1, \ldots, R$

(2) $Z_{l n}^{*}=X_{l n} \beta_{l}+\omega_{l n} \quad$ and $\omega_{n} \sim N\left(0, \Sigma_{\omega}\right) \quad$ for $l=1, \ldots, L$

(3) $Y_{k n}^{*}=Z_{k l n}^{*} \gamma_{k Z}+T \gamma_{k T} \xi_{m n}$ and $\xi_{n} \sim N\left(0, \sigma_{\xi}^{2}\right)$ for $k=1, \ldots, K$

where $I_{r n}$ is the value of an indicator $r$ of the latent construct $Z^{*}{ }_{1 n}$ as perceived by respondent $n, Z^{*}{ }_{1 n}$ is the value of latent construct $I$ for respondent $n, X_{I n}$ is a vector of the respondents individual characteristics (i.e., socio-economic characteristics, travel habits, place of residence, and travel information sources). $Y_{k n}^{*}$ is a vector of $k$ independent variables, namely the respondents intention to use the APP. $T_{k l n}$ is a vector of app information search possibilities (e.g., by stop, route, to arrive on time etc.). The error terms follow a normal distribution with respective covariance matrices. The estimated parameter vectors are $\alpha_{r}, b_{l}, \gamma_{z}$, and $\gamma_{T}$.

The modelling of the adoption of Mi Transporte is then conceived through a series of declared ordered variables, that are used to build de latent constructs and then introduced in the SEM model; a set of observed binary, ordered and categorical variables, that are used as covariates on both latent constructs and the dependent variables; and the binary dependent variables of "intention to use" and "use-nonuse". 


\subsection{Sample description}

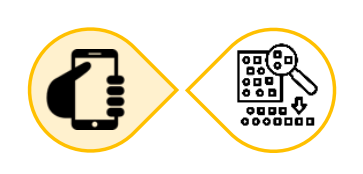

The survey involved a total of 200 women and 186 men. It was stratified in three age groups: young (18-30, 24\%), adults (30 to 45 years, $51 \%$ ) and senior travelers (50-70 years, 26\%). It is worth mentioning that the most limiting group to be targeted in order to achieve a representative sample were senior travelers, as they are less adroit in the use of technology. The travel behavior of respondents was collected through dedicated survey questions related to their most frequent trip. The results showed that a great share of intermodal trips characterizes the sample as expected, with the combinations of Bus-Metro and Metro-Bus accounting for more than $63 \%$ of multimodal trips.

The general characteristics of the obtained sample are:

Gender:

$(51,8 \%)$ women, $(48,2 \%)$ men.

Age groups:

(24\%) 15-30, (51\%) 30-50, (26\%) >50.

Level of studies:

(3\%) low, (40\%) medium, (57\%) high.

Users with disabilities:

(2\%).

Public transportation users: $\quad(78 \%)$ monthly pass, $(2 \%)$ yearly pass, $(20 \%)$ no subscr.

Driver's licence: $\quad$ (70\%) yes, $\quad(30 \%)$ no.

In order to know to what extent the users were comfortable with the use of different technological tools, they were asked about both their current IT device usage and their proficiency level in the use of each of the more broadly extended devices: PC, Smartphone, Tablet and GPS. The results, included in Table 8, show that technological penetration rates are high among public transport users in Madrid. Some $78 \%$ use personal computers and up to $86 \%$ declared a proficiency level; almost $84 \%$ are users of smartphones with the same rate stating a good or very good proficiency use level. 
Table 8. Technological capabilities of the sample by age, \% of device ownership

\begin{tabular}{||l|c|c|c|c||}
\cline { 2 - 5 } \multicolumn{1}{c|}{} & $\begin{array}{c}15-30 \\
\text { year old }\end{array}$ & $\begin{array}{c}30-50 \\
\text { year old }\end{array}$ & $\begin{array}{c}50-65 \\
\text { year old }\end{array}$ & Average \\
\hline \hline Smartphone & $89.3 \%$ & $82.9 \%$ & $73.3 \%$ & $83.7 \%$ \\
PC & $80.3 \%$ & $76.3 \%$ & $76.0 \%$ & $78.0 \%$ \\
Tablet & $44.0 \%$ & $49.3 \%$ & $32.0 \%$ & $43.8 \%$ \\
GPS & $20.1 \%$ & $27.6 \%$ & $26.7 \%$ & $24.4 \%$ \\
\hline
\end{tabular}

\section{PREFERENCES ON APP FEATURES}

Users were queried on desired capabilities for the application. Several questions on desired features were raised in which the user had to rank capabilities either by selecting his or her three most desired capabilities or by ranking among a series of options split by static information, real time information, information regarding special events in the network and search options and other in-app services.

The main sets of information that users desire to receive through the app are:

\section{Static information}

Schedules and timetables of the different transportation modes (selected among the three most desired static information services by $70 \%$ of users), then routing information between any two points (61\%), visualizing a map with public transportation stops on it $(41 \%)$, checking information on an specific stop (address, stop number, etc.) (39\%) and being able to check graphically the itinerary of a line (37\%).

\section{Real time information}

Checking information on the closest public transportation stops in real time (selected among the three most desired real time information services by $87 \%$ of users), routing information from the users real time location (74\%), visualizing in real time the closest public transportation lines (69\%), real time information on the closest public transportation services (65\%), visualization of the user location on the map (59\%).

\section{Special events information}

Suggestions of public transportation alternatives when the user is planning his/her route (selected among the three most desired services related to events by $66 \%$ of users), information on lines and stops affected by the event (62\%), alternative route suggestions when the user is affected by an event (54\%), real time information on events that may affect the user's trip (50\%). 


\section{Search options}

Users want the application to let them filter by closest stop (important or very important for $80 \%$ of users), filter by closest stop of a given transportation mode (ex. Bus) (79\%), filter by public transport stop name $(73 \%)$, search by closest stop of a given line $(74 \%)$ and, with less significance, search by public transportation stop code (49\%).

\section{In-app services}

Information on the user's transportation card: balance, credit recharge points and card information points were selected among the three most desired services by 63 percent of the users. Guidance information: The main desired means to receive guidance information are plain map indications, arrow movement through a map, or through panoramic image strings, being considered as more important than camera visualization or radar indications. Payments through the app: selected among the three most desired services by 37 percent of the users. Point Of Interest (POI) information: selected among the three most desired services by 27 percent of the users.

\section{App customization}

The main desired features were: saving favourite stops and lines ( $73 \%$ of users selected it among their three most desirable features), activating alerts on events affecting any of the user's favourite stops/lines (70\%), and personalized information on trip optimization (55\%).The possibility of changing the appearance of the app (colours, theme, font size, etc.) was desired by more than $50 \%$ of the surveyed users, and considered as not necessary by $24 \%$ of them.

\subsection{Behavioral factors identification}

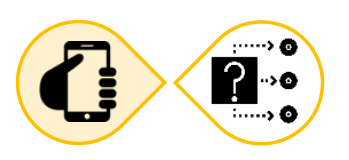

The data analysis included exploratory and confirmatory factor analysis followed by a structural equation model to empirically validate the framework. The objective of exploratory factor analysis is to identify a set of latent constructs underlying a set of measured variables in a situation without apriori hypotheses, while confirmatory factor analysis is to test whether the data fit a hypothesized measurement model. The exploratory factor analysis served to extract the latent constructs among 
variables. Tests of internal consistency and sample adequacy constituted the necessary preliminary conditions for conducting factor analysis and obtaining meaningful results.

The items obtained in the survey demonstrate good internal consistency (Cronbach's alpha $=0.876$ ) and good sampling adequacy according to Kaiser-Meyer-Olkin measure (KMO = 0.881). The Spearman correlation matrix shows the existence of correlations without multi-collinearity. The result of the Bartlett's test of sphericity rejects the null hypothesis that the correlation matrix is an identity matrix $(p=0.000)$. Exploratory principal axis factor analysis with varimax rotation (Kaiser normalization) produced six or seven factors according to the Scree plot. The existence of a factor that contained information on environmental concerns was deemed interesting for the analysis and therefore seven factors were taken into account for the modelling. The interpretation of the meaning of the factors rely on their supporting questions scored by the respondents. Thus, the first factor (F1) has been labelled "Technophile". The next factor (F2) "Expectations regarding the app", the third one (F3) is labelled "app search functionalities". The next three factors were labelled "Level Of Service (LOS) importance" (F4), "Side-mode information" (F5), and "Time saving skills" (F6). Finally the last factor (F7) grouped "Environmental responsibility" items. Then, those factors are confirmed by confirmatory factor analysis, then contrasted, associated to user characteristics (e.g. age, gender, trip length and type, principal mode and smartphone use) and introduced into the structural relation model. The analysis of the Table 9 results shows the explanatory power of the seven identified latent variables and the questions of the survey that support the loading factors of each of them.

Table 9. Output of rotated factor analysis (exploratory) for the mobile APP study

$\begin{array}{lllllll}\mathrm{F} 1 & \mathrm{~F} 2 & \mathrm{~F} 3 & \mathrm{~F} 4 & \mathrm{~F} 5 & \mathrm{~F} 6 & \mathrm{~F} 7\end{array}$

I like to try new technological devices

I believe that new technologies have great potential

I'm interested in new technologies

I like to renew my mobile from time to time to keep it updated

apps help me in my daily life

I need technological tools in my daily life

Some apps are fun to use

I like to find new applications

Please indicate your level of skills in the usage of Tablet devices

Please indicate your level of skills in the usage of Smartphone devices

Please indicate your level of skills in the usage of Laptop devices

Please indicate your level of skills in the usage of GPS devices

$$
\text { Time }
$$

\begin{tabular}{|l|l|l|l|l|l|l||}
.766 & .154 & .195 & .099 & -.023 & .119 & .027 \\
.664 & .115 & .252 & .074 & -.120 & -.017 & .053 \\
.802 & .153 & .194 & .044 & -.024 & .095 & .027 \\
.572 & .128 & -.045 & .050 & .093 & -.033 & .117 \\
.720 & .238 & .068 & .032 & .086 & .016 & .048 \\
.703 & .088 & .008 & -.073 & .076 & .057 & .043 \\
.674 & .151 & .102 & .138 & .011 & .006 & .117 \\
.773 & .195 & .076 & .100 & -.007 & .041 & .099 \\
.580 & .131 & .257 & .026 & .093 & .294 & -.325 \\
.610 & .087 & .198 & .089 & .034 & .202 & -.264 \\
.517 & .128 & .297 & -.019 & .054 & .295 & -.294 \\
.517 & .011 & .153 & .062 & .252 & .248 & -.198 \\
.135 & -.018 & .005 & .601 & .078 & .202 & -.132 \\
\hline
\end{tabular}




\begin{tabular}{|c|c|c|c|c|c|c|c|c|}
\hline \multirow{7}{*}{\begin{tabular}{||l} 
Please indicate the importance of each of the \\
following criteria for your MOST FREQUENT TRIP.
\end{tabular}} & Flexibility & .111 & . 103 & .122 & .727 & -.005 & -.059 & .117 \\
\hline & Predictability & .147 & .035 & .103 & .570 & -.113 & .120 & .025 \\
\hline & Safety & -.004 & .127 & .069 & .540 & -.064 & -.025 & -.022 \\
\hline & Security & -.014 & .061 & .068 & .593 & -.071 & -.066 & -.066 \\
\hline & Comfort & .025 & .120 & .039 & .674 & .098 & .073 & .033 \\
\hline & Pleasure & -.074 & .159 & -.052 & .654 & .118 & -.145 & .160 \\
\hline & Capability to carry items & .071 & .047 & .064 & .569 & .067 & -.020 & .269 \\
\hline My most frequent trip takes too much time & & .090 & -.064 & .096 & .045 & -.009 & .681 & .017 \\
\hline I feel like I waste my time on the way & & .049 & -.042 & -.016 & -.081 & .019 & .694 & -.101 \\
\hline $\begin{array}{l}\text { I would use public transport more often if } t \\
\text { information }\end{array}$ & here was real-time service & .136 & .151 & -.076 & .119 & -.050 & .510 & .361 \\
\hline I would use public transport more often if the serv & ice was better & .080 & .027 & -.089 & .116 & .042 & .714 & .264 \\
\hline The impact of transport on the environment is a re & eal problem in Madrid & -.018 & .015 & .123 & .014 & .027 & .238 & .681 \\
\hline $\begin{array}{l}\text { I feel as part of my responsibilities to reduce the } \\
\text { potentiate the greenhouse effect }\end{array}$ & emission of pollutants that & .000 & .082 & .000 & .123 & .068 & .058 & .786 \\
\hline It's important to search for the name of the stop & & .199 & .151 & .517 & .079 & -.045 & .084 & .033 \\
\hline It's important to find the nearest stop of a chosen & line & .113 & .202 & .723 & .073 & .082 & -.011 & .038 \\
\hline It's important to find the nearest stop of a chosen & mode of public transport & .139 & .106 & .800 & .052 & .081 & -.034 & .061 \\
\hline It's important to find the nearest public transport s & stop & .061 & .063 & .758 & .080 & .117 & .032 & -.005 \\
\hline It's important to find the nearest BiciMAD station & & .063 & .186 & -.011 & .020 & .790 & -.013 & .103 \\
\hline $\begin{array}{l}\text { It's important being able to search for nearby Bi } \\
\text { occupancy level }\end{array}$ & ciMAD stations according to & .075 & .194 & -.010 & .015 & .789 & -.063 & .073 \\
\hline $\begin{array}{l}\text { It's important being able to find deterrent parking } \\
\text { public transport services there) }\end{array}$ & facilities (and information on & .111 & .067 & .116 & -.009 & .802 & .009 & .008 \\
\hline $\begin{array}{l}\text { It's important to be able to search for parking facil } \\
\text { level }\end{array}$ & lities according to occupancy & .121 & .018 & .097 & .049 & .795 & .033 & -.003 \\
\hline If the app allows me to save travel time, I intend tc & use it in my daily trips & .316 & .595 & .445 & .113 & -.036 & .103 & .005 \\
\hline If the app can increase the predictability of my dai & ly trips, I will use it & .270 & .574 & .438 & .169 & -.080 & .039 & -.052 \\
\hline If the app allows me to save money, I intend to use & & .302 & .569 & .475 & -.022 & -.102 & .100 & -.041 \\
\hline If the app allows me to plan my trips better, I inter & nd to use it & .291 & .565 & .432 & .036 & -.039 & -.034 & -.031 \\
\hline Using the app will allow me to save some travel tin & & .143 & .788 & .100 & .119 & .022 & .012 & .013 \\
\hline Thanks to the app I will get to my destination more & e calmly & .145 & .800 & .060 & .038 & .128 & .002 & .037 \\
\hline Thanks to the app I will improve the regularity in $\mathrm{m}$ & ny times of displacement & .155 & .783 & .145 & .150 & .127 & -.055 & .009 \\
\hline Thanks to the app I will reduce the impact of my tr & avels on the environment & .012 & .593 & .049 & .003 & .269 & -.025 & .333 \\
\hline I think using the app will make it easier for me to $c$ & hange my transport habits & .200 & .691 & -.168 & .061 & .165 & .020 & .079 \\
\hline I think the app will be easy to use & & .319 & .538 & .186 & .158 & .012 & .064 & -.055 \\
\hline
\end{tabular}

The factor loadings are presented in the table. In order to facilitate factor labeling, the dominant items, shaded in bold, were defined as those with an absolute value of the loading greater than 0.50 . 


\subsection{Model estimation results}

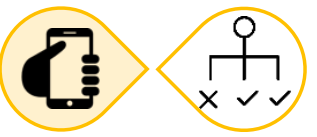

The commercial software M-Plus served for the model estimation. The parameters were estimated simultaneously by using Maximum Likelihood with Huber-White covariance adjustment (Yuan and Bentler, 2000). Standard errors were calculated by adopting the White's sandwich-based method that produces robust statistics in the presence of non-normality of the indicators and the categorical variables (White, 1980; Bentler, 1989; Browne and Cudeck, 1992).

The estimation results are presented in Table 10, which describes the measurement equations of the confirmatory factor analysis that corresponds to exploratory factor analysis presented in Table 9 in the previous section. In the same way as in the bikeshare study, in this study the factor structure is revealed by exploratory factor analysis and it is used as part of the model structure with confirmatory factor analysis, which enhances the structural validity of the proposed model. The CFI value, which indicates the goodness-of-fit of the confirmatory factor analysis, is 0.835 , showing excellent data fit. The model including the set of measurement and structural equations fits reasonably well.

The statistical model confirms the general behavioral framework and the research hypotheses for the case study of Madrid. Table 10 shows the relationship between the latent constructs and the respondents characteristics. Most importantly, we focus on the effect of the various latent constructs on the intention to use the real-time information app, as well as on the willingness to pay and the actual app use. The model statistically confirms $\mathrm{H} 1$ with the relation of willingness-to-pay for the app and the intention to use it being significant for its actual adoption.

The statistical model also confirms H2. With the user's expectations, the user's technophilia, and his previous use of transport mobile apps explaining the intention to adopt the app. The statistical model confirms H3. User's expectations are positively and significantly explained by search functionalities of the app, the LOS importance, information about side-modes and time saving skills.

The correlation patterns on Table 10 do confirm H4. With Gender and age negatively and significantly correlated (male and younger are more technophile) with the technophile factor and smartphone use positively and significantly correlated with the technophile factor (F1). The model also confirms H5 with the importance of Time Saving Skills positively and significantly related to the frequency and 
duration of the trip, as well as to the use of smartphone, while negatively and significantly related to the most frequent trip taking place inside the City Centre.

Table 10. Structural equations relating latent factors to app use intention and adoption

\begin{tabular}{|c|c|c|c|}
\hline Latent Constructs & Explanatory / mediator variable & Est. & C.R. \\
\hline Side-mode information (F5) & Environmental responsibility (F7) & 0.873 & 2.954 \\
\hline \multirow{4}{*}{ Expectations regarding the app (F2) } & App search functionalities (F3) & 1.213 & 7.008 \\
\hline & Los importance (F4) & 1.204 & 4.450 \\
\hline & Side-mode information (F5) & 0.094 & 3.924 \\
\hline & Time saving skills (F6) & 0.327 & 2.580 \\
\hline \multirow{3}{*}{ Technophile (F1) } & Age & -0.024 & -3.776 \\
\hline & Gender & -0.294 & -1.622 \\
\hline & Smartphone User & 1.495 & 5.911 \\
\hline \multirow{2}{*}{ LOS importance (F4) } & Age & 0.006 & 2.411 \\
\hline & Gender & 0.201 & 3.001 \\
\hline \multirow{4}{*}{ Time saving skills (F6) } & Smartphone User & 0.187 & 1.331 \\
\hline & Frequency of most frequent trip & 0.073 & 1.816 \\
\hline & Most Frequent Trip is long & 0.255 & 1.485 \\
\hline & Most Frequent Trip is Centre-Centre & -0.290 & -2.315 \\
\hline Dependent Variables & Explanatory / mediator variable & Est. & C.R. \\
\hline \multirow{3}{*}{ Intention to use the app } & Technophile (F1) & 0.847 & 3.371 \\
\hline & Expectations regarding the app (F2) & 1.104 & 4.088 \\
\hline & Previous app User & 0.944 & 2.126 \\
\hline Willingness To Pay (WTP) & $\begin{array}{l}\text { Willing to pay to save } 40 \% \text { or more of trip } \\
\text { time }\end{array}$ & 0.230 & 2.300 \\
\hline \multirow{2}{*}{ Use of the app } & Willingness to Pay (WTP) & 0.188 & 1.377 \\
\hline & Intention to use the app & 0.098 & 2.548 \\
\hline
\end{tabular}

C.R. = Est./s.e.

Ratio between chi-square and degrees of freedom $=2.42$ which are good (27).

RMSEA stands at 0.072 . CFI stands at 0.835 , which are reasonable according to Loehlin et al. (21).

Finally, the analysis also showed that the importance of Side-Mode information is positively and significantly correlated to the Environmental responsibility factor, and that the importance of the LOS is explained by Age and Gender (female and elder give more importance to LOS). These results and the weights among interrelated factors are explained below and represented in Figure 28. 
Figure 28. Multimodal APP model results: relation among variables and latent variables

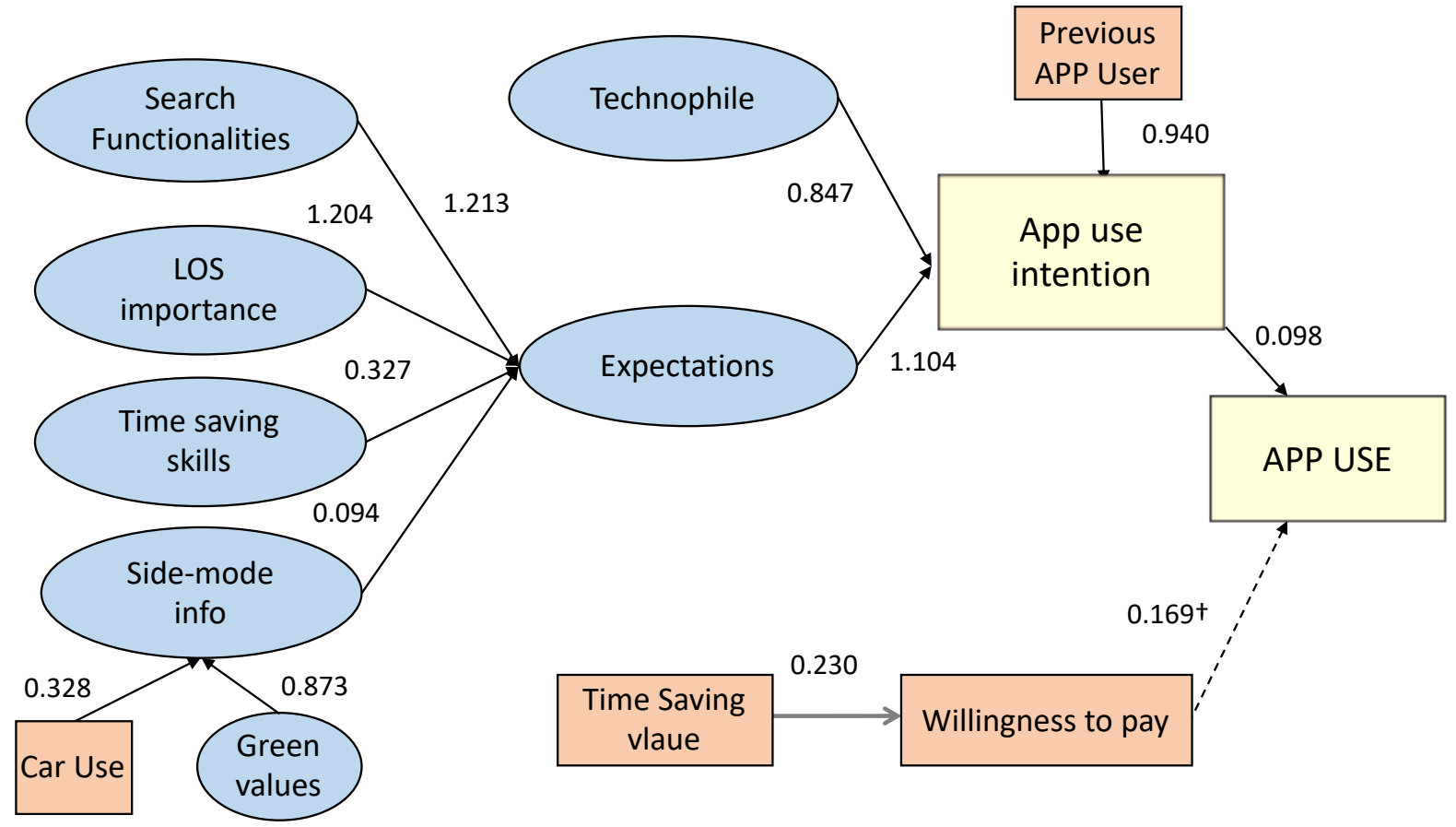

The analysis of the SEM shows that:

(i) The adoption of the app is correlated with the user's intention to adopt it and more strongly with the WTP;

(ii) While the intentions can be explained by various factors, the WTP is only related to the WTP to save time;

(iii) User's expectations, technophilia, and previous use of transport apps strongly explain the intention to adopt the app;

(iv) Search functionalities, the LOS importance, information about park-and-ride and bicycle and time saving skills explain the user's expectations;

(v) Gender, age and smartphone use explain user's technophilia;

(vi) Trip type, frequency, duration and smartphone use are related to time saving skills.

These results are reproduced in Chapter 11 . 


\section{BEHAVIORAL MODEL FOR THE ADOPTION OF CARSHARE 67}

\subsection{Overview of Carshare in Madrid}

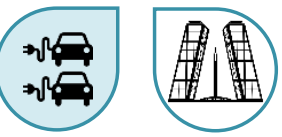

Madrid is among the pioneering cities in terms of the volume of carsharing vehicles and users in proportion to its population, as well as the rate of use of the system. The city currently has 6 different Carsharing service companies, two of which operate with the station model (Respiro and Bluemove) and four in free-float format (Car2Go, Emov, Zity and Wible). In total there are 2,500 vehicles of which $88 \%$ are electric ( $100 \%$ in the case of free-float). The city of Madrid has 4 free-float operators with a total of 2,100 fully electric vehicles. These vehicles can move and park without restrictions in the city and accumulate to date around 400,000 registered users.

\footnotetext{
${ }^{6}$ The research included in this chapter corresponds to the collaboration between UPM and UT Austin. During the stay of the author in 2017-18 Dr. Patricia Lavieri and Professor Chandra Bhat helped in the analysis of the survey and the modelling work. The ICLV model applied for the analysis of the survey was developed at the Centre for Transportation Research by Professor C. Bhat and his team.

${ }^{7}$ A previous stage of research of the present study was published in the proceeding of the XIII Congreso Internacional del Transporte, that took place in Gijon, Spain in 2018.
} 


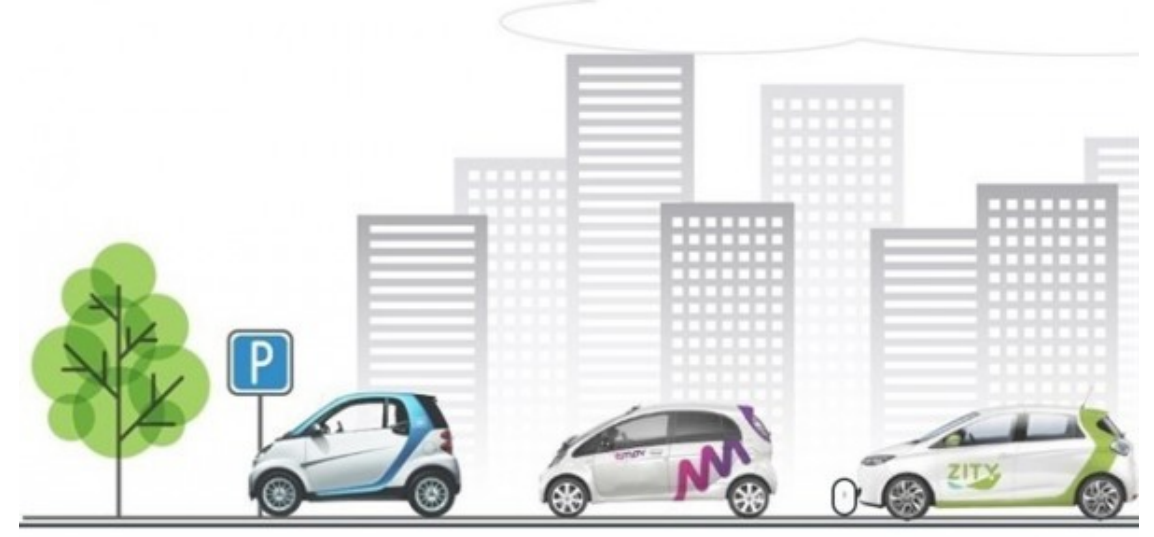

Even if there are different Carsharing systems operating in Madrid, they all share a similar business model. The user has to register through their website or smartphone app, providing his/ger license and payment data. Once he/she is registered, he can visualize all available cars around him/her, which can be prebooked through the app for a period of 20 minutes. Once near the car the user can open it with the app and start using it, parking it in whichever parking spot that is legally available. The charge is then made directly to the user's credit or debit card.

Figure 30. Area coverage for the three main existing carshare systems in Madrid

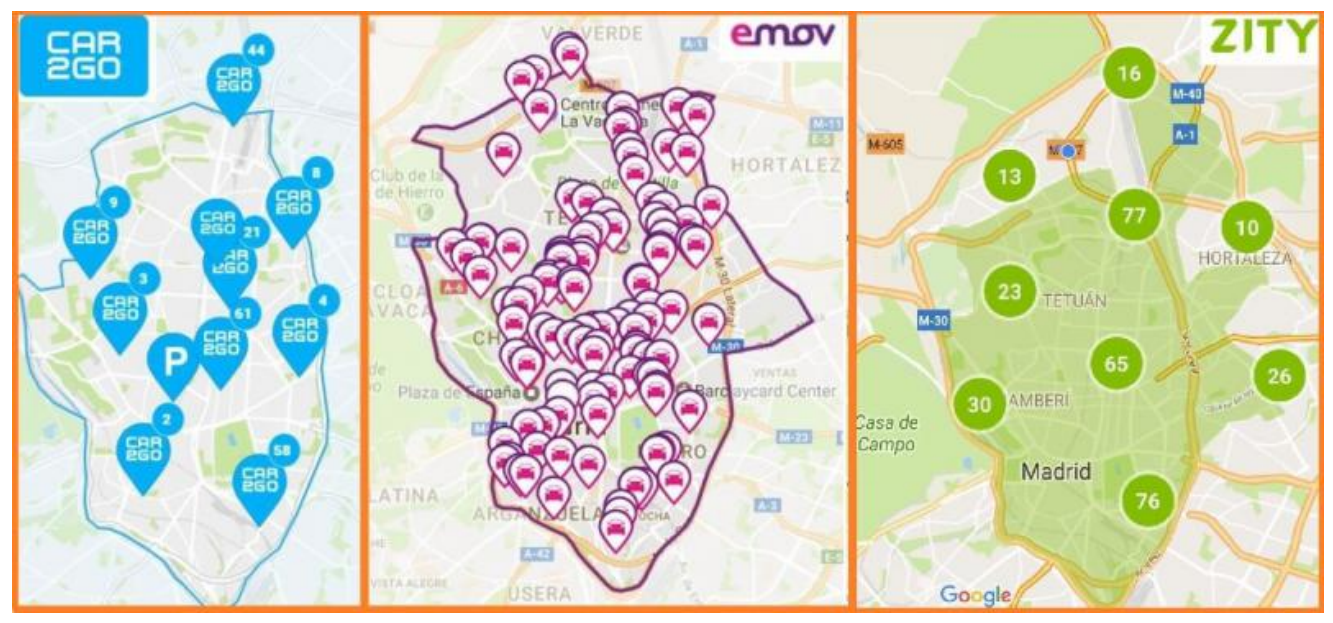

The different systems compete against each other by introducing differences in their prices, vehicles and offerings. Table 11 below summarizes the main differences in the services offered by the main six Carsharing companies in the city. 
Table 11. Offers characterization by different Carsharing services in Madrid

\begin{tabular}{|c|c|c|c|c|c|c|}
\hline & Vehicles & Seats & Rate & Initial fee & Area of operation & $\begin{array}{l}\text { Insurance } \\
\text { Franchise }\end{array}$ \\
\hline Car2Go & 500 & 2 & $0,21 € / \min$ & $9 €$ & First ring road & $500 €$ \\
\hline Emov & 600 & 4 & $0,23 € / \mathrm{min}$ & $9 €$ & $\begin{array}{l}\text { First ring road + Arturo } \\
\text { Soria neighbourhood }\end{array}$ & $500 €$ \\
\hline Zity & 500 & 5 & $0,26 € / \mathrm{min}$ & Free & $\begin{array}{l}\text { First ring road + Arturo } \\
\text { Soria neighbourhood }\end{array}$ & $50 €$ \\
\hline Wible & 500 & 5 & $0,24 € / \mathrm{min}$ & Free & $\begin{array}{l}\text { First ring road + Mirasierra, } \\
\text { Arturo Soria Sanchinarro } \\
\text { and Las Tablas } \\
\text { neighbourhoods }\end{array}$ & $99 €$ \\
\hline Respiro & 200 & 5 & $\begin{array}{c}\text { 2-6€/hour \& } \\
0,26-0,30 € \mathrm{~km}\end{array}$ & Free & Station-based & $500 €$ \\
\hline Bluemove & 200 & 5 & $\begin{array}{c}2 € / \text { hour \& } \\
0,25 € \mathrm{~km}\end{array}$ & Free & Station-based & $195 €$ \\
\hline
\end{tabular}

\subsection{Hypothesized behavioral framework}

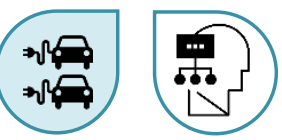

The methodological procedure for the study started with the development of hypotheses that enlarged the state of the art with regard to the behavioral framework for the adoption of Carsharing services. The survey was then designed to gather the relevant information on a representative sample of potential users of Madrid's Carsharing scheme taking into account the needs of the model. Finally, the hypothesized behavioral model structure is tested and validated through the application of an Integrated Choice and Latent Variable model, which allows to establish a general framework for any interrelationship between latent variables to be specified. Furthermore, it also enables for latent variables to be predicted through observed explanatory variables (Temme et al. 2008).

On top of the already studied relations of age, income and car ownership with Carsharing use, we hypothesize that the choice of whether to use a Carsharing scheme is related to the latent constructs of privacy concerns of the users, their social responsibility and to social norms. Carsharing systems 
keep track of all the trips that the user makes, as well as information on dynamic parameters of the trip like accelerations, decelerations, consumptions, speed or GPS track. This information is only to be used by the Carsharing companies for operational improvements, as well as for proof of misuse of the fleet or traffic laws breach. Hence, we hypothesize that the privacy concerns already proven for other technological advancements will also be present for Carsharing adoption and use. Also, as Carsharing systems in Madrid are electric and perceived as a more sustainable alternative to private cars, we hypothesize that community resilience attitude and environmental concerns (green values) positively impact both the adoption and the use of the free-float electric Carsharing systems in Madrid. Finally, as the talk about the system has been strong in the last two years and their presence in the streets is notorious, we believe that some level of social norm may come into play on the current adoption and use of the system.

All of these elements were addressed in the questionnaire through specific sets of items adapted to the context of car share use. Hence, the proposed model framework enables to explore the following hypotheses:

H1: Privacy concerns have a negative impact on Carshare adoption and use levels.

H2: Community Resilience, Environmental concerns and familiarity with the Sharing Economy positively impact Carshare adoption and level of use.

H3: Elements already proven for other Carsharing models like income, age, education level or car use level also have a similar effect on the adoption of $100 \%$ electric free-float Carsharing systems.

H4: Covariates such as age, income, familiarity with transit or access to a private car will have an impact on frequency of use of Carsharing services. 


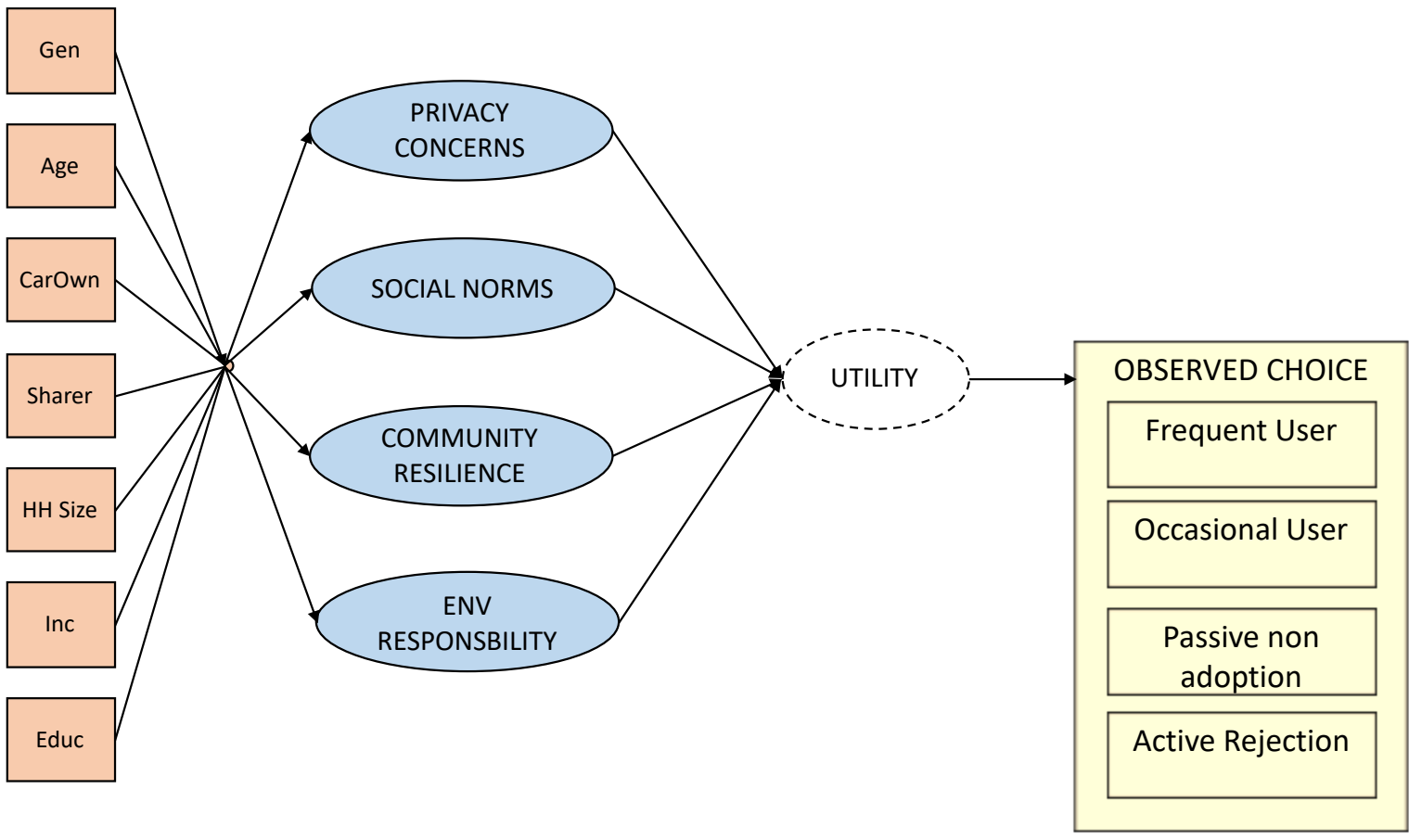

\subsection{Description of the experiment design and execution}

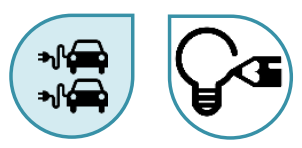

Data used for the analysis was obtained from a web-based survey conducted in October and November 2017 by the Transport Research Centre of the Universidad Politécnica de Madrid (TRANSyT-UPM). The full experiment included two waves of surveying; the first one centered around the use of Carsharing systems; the second one centered on the perceptions and expectations of the users on autonomous vehicles. 
Sample size was set to be above 700 answers in order to be able to apply a more complex model that allowed for a categorical dependent variable that could reflect different grades within the adoption or rejection of the Carsharing system.

The topics and items included in the questionnaire design were explicitly selected in order to elicit the elements present in the hypothesized behavioral model. Question items were designed following current state of the art on surveying for behavioral analysis with latent factors of privacy concerns (Hong and Thong, 2013) and community resilience (Leykin et al., 2013).

The answering options were designed taking into account the variable format needs of the ICLV mathematical model described in Section 9.3. below. The survey was structured in five different parts. The initial part contained questions covering the respondents' travel behavior, his/her most frequently used modes, driver's license availability, car ownership and current subscription to Carsharing systems. Answers were used to adapt the subsequent questions, focusing them on either Carshare use or private car use.

The second section of the survey contained questions on Carshare use or private car use for different trips, as well as inquiries on the reasons not to use Carshare and on general perceptions of the Carsharing systems operating in Madrid. The third part of the survey presented to the respondent questions aimed at capturing attitudinal variables, they were collected in a five point ordinal scale, following the widely acknowledged methodology described by Likert (1974). For questionnaire items containing statements related to perceptions of shared cars, social responsibility, community resilience and privacy, the scale ranged from (1) "I strongly disagree" to (5) "I strongly agree". Questions belonging to this section have been reproduced in Table 12.

The fourth part of the survey consisted of items containing affirmations related to driving behavior, with a scale ranging from (1) "Never" to (5) "Always". These answers have not been included in the present study and will be used in future research.Finally, the last section of the survey contained 
questions aimed at obtaining sociodemographic information of the respondent such as household size, income level, smartphone ownership or educational level.

Table 12. Survey items containing attitudinal questions

- I agree with my personal information being collected in order to improve the service.

- I agree to provide my bank details to speed up the payment

- I agree with my personal movements being analyzed in order to improve transportation planning

- I accept the companies to collect data on my driving style to improve road safety

- I accept that my personal data are shared with companies to receive offers and promotions

- I accept that my personal data be sold to lower the service

- I accept that my personal data are used to carry out mobility studies

- I always see people circulating in shared vehicles

- I always see shared vehicles parked on the street

- I always see shared vehicles parked near my house

- I always see shared vehicles parked near my work

- I think people want to try shared vehicles

- I know people who use shared vehicles

- I see ads promoting the shared vehicles

- People in Madrid can make mobility more sustainable

- People in Madrid are concerned about the welfare of others, people are supportive

- People in Madrid do what they can to improve the environment

- In Madrid, using shared vehicles is trendy

- Recently there is a lot of talk about shared vehicles

- When I use the shared car I feel that I am socially responsible

- When I use car sharing, I feel that I am doing my part in sustainability

- I think it's important to contribute to sustainability for others to do it too

Users were contacted through random mailing among members of two different institutions: (1) the staff and students of the Civil Engineering School of the Universidad Politécnica de Madrid, and (2) the staff and families in a public school located in different location within Madrid (see Figure 32). The survey took on average twelve minutes to be completed and respondents were asked to disseminate it among their peers and personal networks. Through this process, as well as through social media dissemination, a total of 959 complete answers to the survey were obtained. 
Figure 32. Location of the two institutions where the sample was obtained.

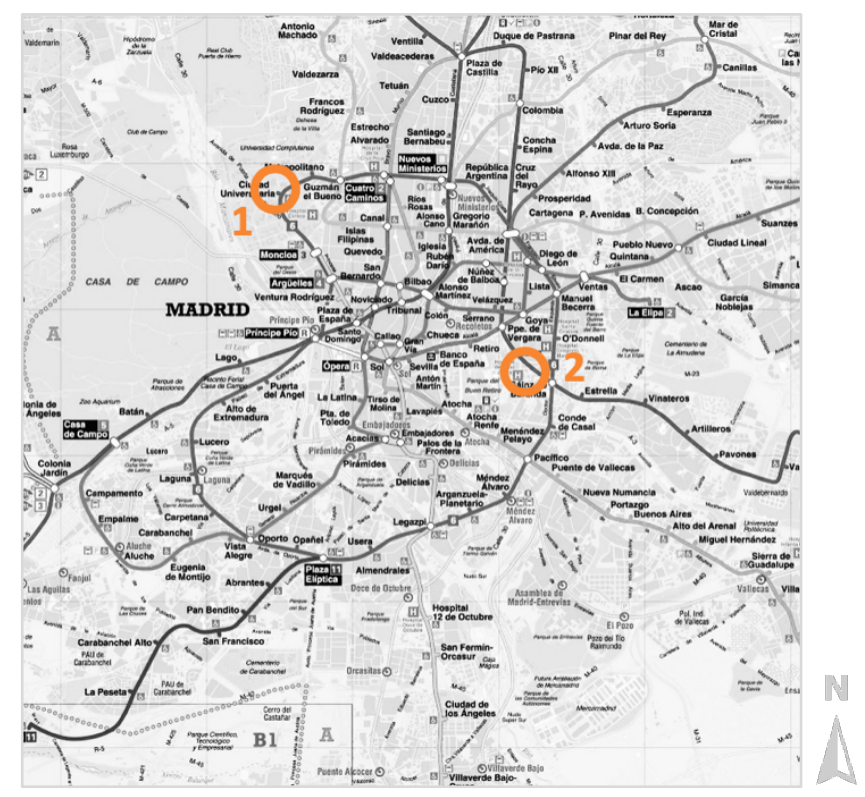

(1) Civil engineering school, UPM - (2) Public school SMP

Model Description

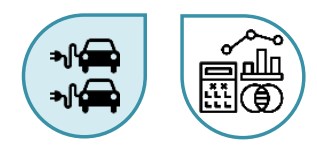

In this third study given the larger number of observations and the multinomial character of the estimated variable the ICLV model described by Bhat and Dubey (2014) was applied. The description of the model is reproduced in this section. The estimation approach follows Bhat and Dubey (2014).

There are three components to the model: (1) the latent variable structural equation model, (2) the latent variable measurement equation model, and (3) the choice model. These components are discussed in turn below. In the following presentation, we will use the index I for latent variables $(l=1,2, \ldots, L)$, and the index $i$ for alternatives $(i=1,2, \ldots, I)$. As appropriate and convenient, we will suppress the index $q$ for individuals $(q=1,2, \ldots, Q)$ in parts of the explanation.

\subsubsection{Latent Variable Structural Equation Model}

For the latent variable structural equation model, we will assume that the latent variable $z_{l}^{*}$ is a linear function of covariates as follows: 


$$
z_{l}^{*}=\boldsymbol{\alpha}_{l}^{\prime} \boldsymbol{w}+\eta_{l}
$$

where $\boldsymbol{w}$ is a $(\widetilde{D} \times 1)$ vector of observed covariates (not including a constant), $\boldsymbol{\alpha}_{\boldsymbol{l}}$ is a corresponding $(\widetilde{D} \times 1)$ vector of coefficients, and $\eta_{l}$ is a random error term assumed to be normally distributed. In our notation, the same exogenous vector $\boldsymbol{w}$ is used for all latent variables; however, this is in no way restrictive, since one may place the value of zero in the appropriate row of $\boldsymbol{\alpha}_{l}$ if a specific variable does not impact $z_{l}^{*}$. Also, since $z_{l}^{*}$ is latent, it will be convenient to impose the normalization discussed in Stapleton (1978) and used by Bolduc et al. (2005) by assuming that $\eta_{l}$ is standard normally distributed. Next, define the $(L \times \widetilde{D})$ matrix $\boldsymbol{\alpha}=\left(\boldsymbol{\alpha}_{1}, \boldsymbol{\alpha}_{2}, \ldots \boldsymbol{\alpha}_{L}\right)^{\prime}$, and the $(L \times 1)$ vectors $\boldsymbol{z}^{*}=\left(z_{1}^{*}, z_{2}^{*}, \ldots, z_{L}^{*}\right)^{\prime}$ and $\boldsymbol{\eta}=\left(\eta_{1}, \eta_{2}, \eta_{3}, \ldots, \eta_{L}\right)^{\prime}$. To allow correlation among the latent variables, $\boldsymbol{\eta}$ is assumed to be standard multivariate normally distributed: $\boldsymbol{\eta} \sim N\left[\mathbf{0}_{L}, \boldsymbol{\Gamma}\right]$, where $\boldsymbol{\Gamma}$ is a correlation matrix (as indicated earlier in Section 1, it is typical to impose the assumption that $\boldsymbol{\eta}$ is diagonal, but we do not do so to keep the specification general). In matrix form, Equation (1) may be written as:

$$
z^{*}=\alpha w+\eta
$$

\subsubsection{Latent Variable Measurement Equation Model}

All the indicator variables (that provide information on the latent variables) are ordinal in nature in our empirical context. In the general case, let there be $G$ ordinal indicator variables, and let $g$ be the index for the ordinal variables $(g=1,2, \ldots, G)$. Let the index for the ordinal outcome category for the $g^{\text {th }}$ ordinal variable be represented by $j_{g}$. For notational ease only, assume that the number of ordinal categories is the same across the ordinal indicator variables, so that $j_{g} \in\{1,2, \ldots, J\}$. Let $y_{g}^{*}$ be the latent underlying variable whose horizontal partitioning leads to the observed outcome for the $g^{\text {th }}$ ordinal indicator variable, and let the individual under consideration choose the $n_{g}{ }^{\text {th }}$ ordinal outcome category for the $g^{\text {th }}$ ordinal indicator variable. Then, in the usual ordered response formulation, we may write:

$$
y_{g}^{*}=\delta_{g}+\boldsymbol{d}_{g}^{\prime} z^{*}+\xi_{g}, \text { and } \psi_{g, n_{g}-1}<y_{g}^{*}<\psi_{g, n_{g}},
$$

where $\delta_{g}$ is a scalar constant, $\boldsymbol{d}_{\boldsymbol{g}}$ is an $(L \times 1)$ vector of latent variable loadings on the underlying variable for the $g^{\text {th }}$ indicator variable, and $\xi_{g}$ is a standard normally distributed measurement error 
term (the normalization on the error term is needed for identification, as in the usual ordered-response model; see (McKelvey and Zavoina, 1975).

Note also that, for each ordinal indicator variable, $\psi_{g, 0}<\psi_{g, 1}<\psi_{g, 2} \ldots<\psi_{g, j_{g}-1}<\psi_{g, j_{g}} ; \psi_{g, 0}=-\infty, \psi_{g, 1}=0$, and $\psi_{g, J_{g}}=+\infty$. For later use, let $\psi_{g}=\left(\psi_{g, 2}, \psi_{g, 3} \ldots, \psi_{g, J_{g}-1}\right)^{\prime}$ and $\boldsymbol{\psi}=\left(\psi_{1}^{\prime}, \psi_{2}^{\prime}, \ldots, \psi_{N}^{\prime}\right)^{\prime}$. Stack the $G$ underlying continuous variables $y_{g}^{*}$ into a $(G \times 1)$ vector $\boldsymbol{y}^{*}$ and the $G$ constants $\delta_{g}$ into a $(G \times 1)$ vector $\boldsymbol{\delta}$. Also, define the $(G \times L)$ matrix of latent variable loadings $\boldsymbol{d}=\left(\boldsymbol{d}_{1}, \boldsymbol{d}_{2}, \ldots, \boldsymbol{d}_{\boldsymbol{G}}\right)^{\prime}$, and let $\boldsymbol{\Sigma}$ be the correlation matrix of $\boldsymbol{\xi}=\left(\xi_{1}, \xi_{2}, \ldots, \xi_{G}\right)$. Stack the lower thresholds $\psi_{g, n_{g}-1}(g=1,2, \ldots, G)$ into a $(G \times 1)$ vector $\psi_{\text {low }}$ and the upper thresholds $\psi_{g, n_{g}}(g=1,2, \ldots, G)$ into another vector $\psi_{u p}$. Then, in matrix form, the measurement equation for the ordinal indicators may be written as:

$$
y^{*}=\delta+d z^{*}+\xi, \psi_{l o w}<y^{*}<\psi_{u p}
$$

\subsubsection{Choice Model}

Assume a typical random utility-maximizing model, and let $i$ be the index for alternatives $(i=1,2,3, \ldots$, I). Note that some alternatives may not be available for some individuals, but the modification to allow this is quite trivial. So, for presentation convenience, we will assume that all alternatives are available to all individuals. We also will assume fixed rather than random coefficients on the exogenous variables, though the consideration of normally distributed coefficients does not increase the computational complexity in our set-up (because of the normal kernel error term in the utilities, and the conjugate additive nature of the normal distribution). ${ }^{8}$ The utility for alternative $i$ is then written as:

$$
U_{i}=\boldsymbol{\beta}^{\prime} \boldsymbol{x}_{i}+\boldsymbol{\gamma}_{i}^{\prime}\left(\varphi_{i} z^{*}\right)+\varepsilon_{i}
$$

\footnotetext{
${ }^{8}$ One can also consider a skew-normal distribution for the coefficients that can accommodate asymmetric and non-normal (but unimodal) distributions. This will still enable the application of our proposed procedure, because the cumulative distribution of the skew-normal takes the form of the multivariate cumulative normal distribution (see Bhat and Sidharthan, 2012). Alternatively, one can accommodate non-normality in our set-up by considering a scale mixture of normals.
} 
where $\boldsymbol{x}_{i}$ is a $(D \times 1)$-column vector of exogenous attributes. $\boldsymbol{\beta}$ is a $(D \times 1)$-column vector of corresponding coefficients, $\boldsymbol{\varphi}_{i}$ is a $\left(N_{i} \times L\right)$-matrix of variables interacting with latent variables to influence the utility of alternative $i, \gamma_{i}$ is a $\left(N_{i} \times 1\right)$-column vector of coefficients capturing the effects of latent variables and its interaction effects with other exogenous variables, and $\varepsilon_{i}$ is a normal error term. The notation above is very general. Thus, if each of the latent variables impacts the utility of alternative $i$ purely through a constant shift in the utility function, $\varphi_{i}$ will be an identity matrix of size $L$, and each element of $\gamma_{i}$ will capture the effect of a latent variable on the constant specific to alternative $i$. Alternatively, if the first latent variable is the only one relevant for the utility of alternative $i$, and it affects the utility of alternative $i$ through both a constant shift as well as an exogenous variable, then $N_{i}=2$, and $\varphi_{i}$ will be a $(2 \times L)$-matrix, with the first row having a ' 1 ' in the first column and ' 0 ' entries elsewhere, and the second row having the exogenous variable value in the first column and ' 0 ' entries elsewhere. A whole range of other latent variable specifications may also be considered based on appropriately configuring the matrix $\varphi_{i}$.

To proceed further, let the variance-covariance matrix of the vertically stacked vector of errors $\boldsymbol{\varepsilon}\left[=\left(\varepsilon_{1}, \varepsilon_{2}, \ldots, \varepsilon_{I}\right)^{\prime}\right]$ be $\Lambda$. The choice model above may be written in a more compact form by defining the following vectors and matrices: $\boldsymbol{U}=\left(U_{1}, U_{2}, \ldots, U_{I}\right)^{\prime} \quad(I \times 1$ vector $)$, $\boldsymbol{x}=\left(\boldsymbol{x}_{1}, \boldsymbol{x}_{2}, \boldsymbol{x}_{3}, \ldots, \boldsymbol{x}_{I}\right)^{\prime}(I \times D$ matrix $)$, and $\boldsymbol{\varphi}=\left(\boldsymbol{\varphi}_{1}^{\prime}, \boldsymbol{\varphi}_{2}^{\prime}, \ldots, \boldsymbol{\varphi}_{I}^{\prime}\right)^{\prime}\left(\sum_{i=1}^{I} N_{i} \times L\right)$ matrix. Also, define the $\left(I \times \sum_{i=1}^{I} N_{i}\right)$ matrix $\gamma$, which is initially filled with all zero values. Then, position the $\left(1 \times N_{1}\right)$ row vector $\gamma_{1}^{\prime}$ in the first row to occupy columns 1 to $N_{1}$, position the $\left(1 \times N_{2}\right)$ row vector $\gamma_{2}^{\prime}$ in the second row to occupy columns $N_{1}+1$ to $N_{1}+N_{2}$, and so on until the $\left(1 \times N_{I}\right)$ row vector $\gamma_{I}^{\prime}$ is appropriately positioned. Then, in matrix form, Equation (5) may be written as :

$$
\boldsymbol{U}=\boldsymbol{x} \boldsymbol{\beta}+(\gamma \varphi) z^{*}+\varepsilon=\boldsymbol{x} \boldsymbol{\beta}+\lambda z^{*}+\varepsilon, \text { with } \lambda=\gamma \varphi
$$

Consider now that the individual under consideration chooses alternative $m$. Under the utility maximization paradigm, $U_{i}-U_{m}$ must be less than zero for all $i \neq m$, since the individual chose 
alternative $m$. Let $u_{i m}^{*}=U_{i}-U_{m}(i \neq m)$, and stack the latent utility differentials into a vector $\boldsymbol{u}^{*}=\left[\left(u_{1 m}^{*}, u_{2 m}^{*}, \ldots, u_{I m}^{*}\right)^{\prime} ; i \neq m\right]$.

In the context of the choice model formulation above, several important identification issues need to be addressed (in addition to the usual identification consideration that one of the alternatives has to be used as the base for each nominal variable when introducing alternative-specific constants and variables that do not vary across the $I$ alternatives). First, only the covariance matrix of the error differences is estimable. Taking the difference with respect to the first alternative, only the elements of the covariance matrix $\breve{\Lambda}$ of $\varsigma=\left(\varsigma_{2}, \varsigma_{3}, \ldots, \varsigma_{I}\right)$, where $\varsigma_{i}=\varepsilon_{i}-\varepsilon_{1} \quad(i \neq 1)$, are estimable. However, the condition that $\boldsymbol{u}^{*}<\boldsymbol{O}_{I-1}$ takes the difference against the alternative $m$ that is chosen. Thus, during estimation, the covariance matrix $\vec{\Lambda}$ (of the error differences taken with respect to alternative $m$ is desired). Since $m$ will vary across individuals, $\vec{\Lambda}$ will also vary across households. But all the $\vec{\Lambda}$ matrices must originate in the same covariance matrix $\Lambda$ for the original error term vector $\varepsilon$. To achieve this consistency, $\boldsymbol{\Lambda}$ is constructed from $\breve{\Lambda}$ by adding an additional row on top and an additional column to the left. All elements of this additional row and column are filled with values of zeros. Second, an additional scale normalization needs to be imposed on $\breve{\Lambda}$. For this, we normalize the first element of $\breve{\Lambda}$ to the value of one. Third, in MNP models, identification is tenuous when only individual-specific covariates are used. In particular, exclusion restrictions are needed in the form of at least one individual characteristic being excluded from each alternative's utility in addition to being excluded from a base alternative (but appearing in some other utilities). But these exclusion restrictions are not needed when there are alternative-specific variables.

\subsubsection{Model System identification and estimation}

As in all earlier ICLV models, we assume that the error vectors $\boldsymbol{\eta}, \bar{\xi}$, and $\varepsilon$ are independent of each other. Let $\boldsymbol{\theta}$ be the collection of parameters to be estimated: $\boldsymbol{\theta}=[\operatorname{Vech}(\boldsymbol{\alpha}), \operatorname{Vech}(\boldsymbol{\Gamma}), \breve{\boldsymbol{\delta}}, \operatorname{Vech}(\breve{\boldsymbol{d}}), \boldsymbol{\psi}, \operatorname{Vech}(\breve{\boldsymbol{\Sigma}}), \boldsymbol{\beta}, \operatorname{Vech}(\boldsymbol{\gamma}), \operatorname{Vech}(\breve{\boldsymbol{\Lambda}})]$, where $\operatorname{Vech}(\boldsymbol{\alpha})$, $\operatorname{Vech}(\breve{d})$, and $\operatorname{Vech}(\boldsymbol{\gamma})$ represent vectors of the elements of the $\boldsymbol{\alpha}, \breve{\boldsymbol{d}}$, and $\boldsymbol{\gamma}$, respectively, to be estimated, and $\operatorname{Vech}(\boldsymbol{\Gamma})$ represents the vector of the non-zero upper triangle elements of $\boldsymbol{\Gamma}$ (and similarly for other covariance matrices). The data for estimation include, for each individual, (1) the 
$\boldsymbol{x}, \boldsymbol{\varphi}$ and $\boldsymbol{w}$ covariate matrices, (2) The $(H \times 1)$-vector of continuous indicator variables, (3) the $n_{g}{ }^{\text {th }}$ outcome category for each of the $g$ ordinal indicator variables, and (4) the observed choice outcome $m$ (note that a particular empirical context may not have any continuous indicator variable, or may not have any ordinal indicator variable, but we will assume the presence of a combination of the two to reflect the general case).

The reduced form equations, obtained replacing the right side of Equation (1) for $z^{*}$ in Equations (3) and (6) form the following system:

$$
\begin{aligned}
& \breve{y}=\breve{\delta}+\breve{d} z^{*}+\breve{\xi}=\breve{\delta}+\breve{d}(\alpha w+\eta)+\breve{\xi}=\breve{\delta}+\breve{d} \alpha w+\breve{d} \eta+\breve{\xi} \\
& U=x \beta+\lambda z^{*}+\varepsilon=x \beta+\lambda(\alpha w+\eta)+\varepsilon=x \beta+\lambda \alpha w+\lambda \eta+\varepsilon
\end{aligned}
$$




\subsection{Sample description}

Table 13 presents a summary of the sample characteristics. Out of the total 959 adult respondents women constitute 47 percent of the sample. Age distribution shows that 49 percent of the sample is 29 years or younger, 34 percent are aged 30 to 44 years old and 20 percent are 45 years old or older. Smartphone ownership stands at 98 percent, which given the higher proportion of young respondents is in line with the last data on phone ownership in Spain (INE, 2017) that reports a 92 percent average penetration of Smartphone use in Spain.

\section{Table 13. Carshare Survey Sample Description Summary}

\begin{tabular}{|c|c|c|c|c|c|}
\hline Variable & Count & $\%$ & Variable & Count & $\%$ \\
\hline \multicolumn{3}{|l|}{ Age } & \multicolumn{3}{|l|}{ Gender } \\
\hline$<30$ & 442 & 46 & Male & 512 & 53 \\
\hline $30-44$ & 322 & 34 & Female & 445 & 47 \\
\hline$>44$ & 195 & 20 & Other & 2 & 0 \\
\hline \multicolumn{3}{|c|}{ Has used at least two other sharing services } & \multicolumn{3}{|l|}{ Has a PT Subscription } \\
\hline No & 485 & 50 & Yes & 504 & 53 \\
\hline Yes & 474 & 50 & No & 455 & 47 \\
\hline \multicolumn{3}{|l|}{ Has a valid driver's license } & \multicolumn{3}{|l|}{ Has a smartphone } \\
\hline Yes & 879 & 92 & Yes & 947 & 99 \\
\hline No & 80 & 8 & No & 12 & 1 \\
\hline \multicolumn{3}{|l|}{ Education level } & \multicolumn{3}{|l|}{ Carsharing Frequency } \\
\hline High school graduate & 67 & 7 & Never & 463 & 48 \\
\hline Some college & 106 & 11 & Sometimes & 312 & 33 \\
\hline Vocational/technical training & 22 & 2 & 1-3 days a week & 158 & 16 \\
\hline Bachelor degree & 388 & 41 & 4-5 days a week & 18 & 2 \\
\hline Graduate/post-graduate degree & 376 & 39 & Daily & 8 & 1 \\
\hline \multicolumn{3}{|l|}{ Annual household income } & \multicolumn{3}{|l|}{ Household Size } \\
\hline Under $\$ 15,000$ & 44 & 5 & 1 & 115 & 12 \\
\hline$\$ 15,000-\$ 29,999$ & 191 & 20 & 2 & 192 & 20 \\
\hline$\$ 30,000-\$ 59,999$ & 363 & 38 & 3 & 173 & 18 \\
\hline$\$ 60,000-\$ 79,999$ & 208 & 22 & 4 & 286 & 30 \\
\hline$\$ 80,000$ or more & 138 & 15 & 5 & 135 & 14 \\
\hline Prefer not to answer & 15 & - & $6+$ & 58 & 6 \\
\hline \multicolumn{3}{|l|}{ Car Accesibility } & \multicolumn{3}{|l|}{ Household vehicle count } \\
\hline I have my own car & 541 & 56 & 0 (no vehicles) & 92 & 10 \\
\hline I have access to car & 224 & 23 & 1 & 299 & 31 \\
\hline I have no access to a car & 112 & 12 & 2 & 369 & 38 \\
\hline I have no driver's license & 82 & 9 & $3+$ & 199 & 21 \\
\hline
\end{tabular}


The income distribution shows that 27 percent of the individuals reside in households earning $\$ 60,000$ or more per year. The sample is relatively well educated, with 41 percent of respondents having undertaken a bachelor degree and another 39 percent having undertaken higher education. Individual households account for only 12 percent of the sample while one out of every two households has four or more members.

Driver's license possession stands at 92 percent, reducing the sample considered for choice modelling to 874 answers. Regarding car accessibility 56 percent of the sample owns a car while another 23 percent of the sample has access to a car in their household. When asked about their mobility behavior users in the sample stated their weekly frequency for walking (Daily, 35 percent; Never, 4 percent), using transit (30 percent, 6 percent), driving their own car (29 percent; 17 percent), using their own motorbike ( 4 percent, 82 percent), biking ( 3 percent, 68 percent), and using Carshare (1 percent, 48 percent). It is remarkable that 44 percent of the sample is subscribed to at least one of the Carsharing systems operating in Madrid.

Table 14. Users vs. non-users of Carshare, for different levels of car access

\begin{tabular}{|l|c|c|c|}
\cline { 2 - 4 } \multicolumn{1}{c|}{} & Own car & Access to a car & No car access \\
\hline Carshare User & $46 \%$ & $52 \%$ & $48 \%$ \\
\hline Carshare Non User & $54 \%$ & $48 \%$ & $52 \%$ \\
\hline
\end{tabular}

Among those not subscribed to any Carsharing service the use of the private car stands on average at three to five days a week. The main purposes for which they use their private car are commuting, leisure-related trips and travelling to areas with poor transit accessibility. A summary of these data is presented in Table 15.

Table 15. Frequency of use of the private car by type of trip (Carshare non-users)

\begin{tabular}{|l|ccccc||}
\cline { 2 - 7 } \multicolumn{1}{c||}{} & Never & Rarely & Sometimes & Often & Always \\
\hline \hline To go to work / study center & $24 \%$ & $17 \%$ & $9 \%$ & $11 \%$ & $40 \%$ \\
\hline For leisure trips & $6 \%$ & $6 \%$ & $17 \%$ & $36 \%$ & $35 \%$ \\
\hline To go shopping & $15 \%$ & $15 \%$ & $19 \%$ & $25 \%$ & $26 \%$ \\
\hline To visit friends / family & $10 \%$ & $10 \%$ & $24 \%$ & $31 \%$ & $26 \%$ \\
\hline To go to the center of Madrid & $43 \%$ & $22 \%$ & $13 \%$ & $12 \%$ & $9 \%$ \\
\hline $\begin{array}{l}\text { To go to areas of Madrid without good access } \\
\text { with public transport / biking }\end{array}$ & $14 \%$ & $13 \%$ & $20 \%$ & $20 \%$ & $33 \%$ \\
\hline To go to work meetings & $36 \%$ & $15 \%$ & $15 \%$ & $13 \%$ & $21 \%$ \\
\hline To go out at night & $40 \%$ & $23 \%$ & $17 \%$ & $12 \%$ & $9 \%$ \\
\hline \hline
\end{tabular}


Asked about the reasons not to use Carshare, owning a car appears as the main reason, being important or very important to $63 \%$ of the sub-sample, followed by aversion to sharing (25\%) and by considering the service as costly (24\%). From these reasons not-to-use carshare, non-users were categorized into an "active rejection" category containing those for which the main reasons not to use carshare were linked to negative perceptions of the system while passive non-adoption contains, on the contrary, those non-users that state reasons like inconvenience or being users of an alternative mode.

Among those using Carshare the average use stands at 1-2 times a week, combining it with the use of transit, their private car or other modes the rest of the days. The main purposes for which they use Carshare are travelling to downtown where parking is expensive and scarce, travelling to areas with poor transit accessibility and going out at night. Regarding substitution, the surveyed users state that the trips that they now carry using Carshare were previously carried out using transit (45 percent), their private car $(25 \%)$ or taxi services (20 percent), with only 4 percent stating that the trips for which they use Carshare are mainly trips that they did not do before. A summary of these data is presented in Table 16.

Table 16. Frequency of use of Carshare by type of trip (Carshare users)

\begin{tabular}{|l|ccccc||}
\cline { 2 - 6 } \multicolumn{1}{c|}{} & Never & Rarely & Sometimes & Often & Always \\
\hline \hline To go to work / study center & $42 \%$ & $23 \%$ & $24 \%$ & $8 \%$ & $3 \%$ \\
\hline For leisure trips & $35 \%$ & $20 \%$ & $29 \%$ & $15 \%$ & $2 \%$ \\
\hline To go shopping & $50 \%$ & $21 \%$ & $19 \%$ & $8 \%$ & $1 \%$ \\
\hline To visit friends / family & $38 \%$ & $22 \%$ & $29 \%$ & $10 \%$ & $1 \%$ \\
\hline To go to the center of Madrid & $26 \%$ & $24 \%$ & $31 \%$ & $16 \%$ & $2 \%$ \\
\hline $\begin{array}{l}\text { To go to areas of Madrid without good access } \\
\text { with public transport / biking }\end{array}$ & $28 \%$ & $23 \%$ & $29 \%$ & $17 \%$ & $3 \%$ \\
\hline To go to work meetings & $66 \%$ & $13 \%$ & $14 \%$ & $6 \%$ & $1 \%$ \\
\hline To go out at night & $33 \%$ & $20 \%$ & $29 \%$ & $15 \%$ & $2 \%$ \\
\hline
\end{tabular}

Regarding familiarity with Carshare and with the sharing economy, one out of every two respondents has tried at least two other sharing schemes among a set of options presented to them including using shared bicycle systems, sharing an apartment, sleeping in a shared room in a hostel, using carpooling, using coworking spaces, or using services to exchange and reuse objects or clothes. These data allowed to introduce into the sample the attribute of being "sharer" or "non-sharer". 
Finally, according to the stated frequency of use of Carsharing services, users of the system were categorized into "occasional users" label used for those that make use the system occasionally and "frequent users" for those who state using it on a weekly basis.

Among the service characteristics, making reservations and using the cars are valued as easy by $90 \%$ of users, while availability and parking only by half of the respondents. The results, included in Table 17, show the overall distribution of the sample regarding their choice on Carshare adoption and use. We can see that the adult segment holds the largest percentage of frequent users (20 percent), while young respondents fall largely in the occasional user category (36 percent). We can also see that young respondents are more likely to consider the adoption of the service with only 29 percent being passively non-adopting it and almost 20 percent actively rejecting it.

Table 17. Choices of the sample by age group (Carshare)

\begin{tabular}{|c|c|c|c|c|}
\cline { 2 - 5 } \multicolumn{1}{c|}{} & $\begin{array}{c}\text { Passive Non- } \\
\text { Adoption }\end{array}$ & Active Reject & Occasional User & $\begin{array}{c}\text { Frequent } \\
\text { User }\end{array}$ \\
\hline \hline Young & $29 \%$ & $19 \%$ & $36 \%$ & $16 \%$ \\
\hline Adult & $41 \%$ & $12 \%$ & $27 \%$ & $20 \%$ \\
\hline Senior & $47 \%$ & $11 \%$ & $29 \%$ & $12 \%$ \\
\hline
\end{tabular}

The sample hence contained a 52 per cent of Carshare users, with representative socio-demographic characteristics for the population of Madrid and different frequencies in the use that they make of the service. Analysis has shown that most Carshare users utilize the service on an occasional basis and for trips related to leisure, visiting friends and relatives or going downtown where parking is scarce and expensive.

As for non-Carshare users, it has been observed that over 50 per cent of them use their private car to commute or to complement the PT network compared to about 11 per cent of Carshare users. It has been observed that Carsharing systems are direct competitors of both the private car and PT, as well as of other mobility services like ride-sourcing. 


\subsection{Behavioral factors identification}

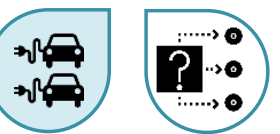

Exploratory factor Analysis

The data analysis for this study, as in the two earlier models, included exploratory and confirmatory factor analysis. The objective of the exploratory factor analysis is to identify latent constructs underlying a set of measured variables either to provide insights on latent construct structure or to validate a-priori hypotheses on underlying data structures, while confirmatory factor analysis is to test whether the data fit a hypothesized latent variable measurement model. The exploratory factor analysis, executed with the commercial software SPSS, served to verify the latent constructs existing among surveyed variables. Tests of internal consistency and sample adequacy constituted the necessary preliminary conditions for conducting factor analysis and obtaining meaningful results.

The items obtained in the survey demonstrate good internal consistency (Cronbach's alpha $=0.806$ ) and good sampling adequacy according to Kaiser-Meyer-Olkin measure ( $K M O=0.827)$. The Spearman correlation matrix shows the existence of correlations without multi-collinearity. The result of the Bartlett's test of sphericity rejects the null hypothesis that the correlation matrix is an identity matrix $(p=0.000)$. Exploratory principal axis factor analysis with varimax rotation (Kaiser normalization) produced 7-9 factors according to the Scree plot. The existence of different factors for the constructs of environmental concerns, community resilience perceptions and social norms was deemed interesting for the analysis and therefore eight factors were taken into account for the modelling. The labelling and interpretation of the factors relied on their supporting questions scored by the respondents. Thus, the first factor (F1) has been labelled "privacy concerns". The next factors are identified with social norms (F2) with community resilience values (F3) and with environmental responsibility (F4). The analysis of results presented in Table 18 shows the explanatory power of the 
four identified latent variables and the questions of the survey that support the loading factors of each of them.

Table 18. Output of the rotated factor analysis (exploratory), for the Carshare study.

\begin{tabular}{|c|c|c|c|c|}
\hline & $\mathrm{F} 1$ & $\mathrm{~F} 2$ & F3 & $\mathrm{F} 4$ \\
\hline $\begin{array}{l}\text { I agree with my personal information being collected in order to improve the } \\
\text { service. }\end{array}$ & 0.73 & & & \\
\hline I agree to provide my bank details to speed up the payment & 0.57 & & & \\
\hline $\begin{array}{l}\text { I agree with my personal movements being analyzed in order to improve } \\
\text { transportation planning }\end{array}$ & 0.87 & & & \\
\hline I accept the companies to collect data on my driving style to improve road safety & 0.86 & & & \\
\hline $\begin{array}{l}\text { I accept that my personal data are shared with companies to receive offers and } \\
\text { promotions }\end{array}$ & 0.38 & & & \\
\hline I accept that my personal data be sold to lower the service & 0.43 & & & \\
\hline I accept that my personal data are used to carry out mobility studies & 0.80 & & & \\
\hline I always see people circulating in shared vehicles & & 0.82 & & \\
\hline I always see shared vehicles parked on the street & & 0.79 & & \\
\hline I always see shared vehicles parked near my house & & 0.53 & & \\
\hline I always see shared vehicles parked near my work & & 0.48 & & \\
\hline I think people want to try shared vehicles & & 0.83 & & \\
\hline I know people who use shared vehicles & & 0.73 & & \\
\hline I see ads promoting the shared vehicles & & 0.36 & & \\
\hline People in Madrid can make mobility more sustainable & & & 0.56 & \\
\hline $\begin{array}{l}\text { People in Madrid are concerned about the welfare of others, people are } \\
\text { supportive }\end{array}$ & & & 0.56 & \\
\hline People in Madrid do what they can to improve the environment & & & 0.46 & \\
\hline In Madrid, using shared vehicles is trendy & & 0.60 & & \\
\hline Recently there is a lot of talk about shared vehicles & & 0.55 & & \\
\hline When I use the shared car I feel that I am socially responsible & & & & 0.95 \\
\hline When I use car sharing, I feel that I am doing my part in sustainability & & & & 0.98 \\
\hline I think it's important to contribute to sustainability for others to do so too & & & & 0.43 \\
\hline
\end{tabular}

These obtained factors were then tested in a confirmatory factor analysis whose results are presented in Table 19. Factors were contrasted with user characteristics (e.g. age, gender, income, car access) and introduced into the measurement equation model described in Section 9.3. 


\subsection{Model estimation results}

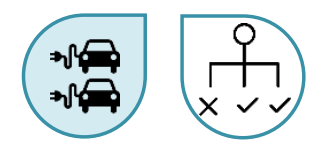

The model estimation was executed with the commecial software Gauss. The estimation converged providing as a first result the output of the confirmatory factor analysis estimation that is displayed on Table 19 below. On it we can see that the loadings of the different variables on the latent factors.

Table 19. Confirmatory Factor Analysis results (Carshare)

\begin{tabular}{||l|lrr||}
\cline { 2 - 4 } \multicolumn{1}{c|}{} & Parameter & Estimate & Est./s.e. \\
\hline F1 & PRIVSERV & 1 & 999 \\
& PRIVPAYM & 0.842 & 26.258 \\
& PRIVPLAN & 1.136 & 42.456 \\
& PRIVSFTY & 1.064 & 38.373 \\
& PRIVPROM & 0.783 & 19.115 \\
& PRIVSOLD & 0.808 & 19.317 \\
& PRIVRSCH & 1.032 & 36.891 \\
\hline \hline F2 & CSHVPEOP & 1 & 999 \\
& CSHVSTRT & 0.883 & 31.428 \\
& CSHVHOME & 0.638 & 20.112 \\
& CSHVWORK & 0.553 & 15.637 \\
& CSHVINT & 0.994 & 38.833 \\
& CSHVLIKE & 0.844 & 26.794 \\
& CSHVADV & 0.491 & 13.106 \\
& POPCSH2 & 0.939 & 33.038 \\
& POPCSH3 & 0.933 & 33.78 \\
\hline \hline F3 & COMSUSTM & 1 & 999 \\
& COMSOLID & 1.298 & 21.362 \\
& COMENV & 1.176 & 26.402 \\
\hline \hline F4 & FEELSOCR & 1 & 999 \\
& FEELSUST & 1.963 & 15.741 \\
& IMPSUST & 1.112 & 13.893 \\
\hline
\end{tabular}

Regarding the model estimation results, Table 20 presents the determinants of all the exogenous variables introduced in the model that have statistically significant impact on the four different latent variables previously defined and included in the model. Those variables that were only marginally statistically significant have been removed from the list and those intercepts not statistically significant have been marked as "--“ on the table. The model estimation process was guided by prior research, intuitiveness, and parsimony considerations.

We can see that Gender is related to environmental consciousness, with females being more conscious than men. Individuals aged 18 to 23 seem to have less environmental consciousness as well as those 
in large households, with each extra individual in the household reducing the likelihood for the individual to be environmentally aware when making mobility decisions. This can be linked to the general complexity of carrying children in those more sustainable modes.

Regarding Community Resilience only educational level comes out as statistically significant, with lesser educational levels (less than bachelor's) being less prone to care about community resilience. On social norms, being in the younger percentiles appears as statistically significant to be concerned about them.

With regard to Privacy concerns, age appears like a clear factor with individuals being less concerned about data sharing the younger that they are. Also educational level appears as relevant with higher educational levels affecting positively the openness to share personal and mobility data.

Table 20. Determinants of latent variables (Carshare)

\begin{tabular}{|c|c|c|c|c|c|c|c|c|}
\hline \multirow{3}{*}{ Variables (base category) } & \multicolumn{8}{|c|}{ Structural Equations Model Component Results } \\
\hline & \multicolumn{2}{|c|}{$\begin{array}{l}\text { Openness to } \\
\text { data sharing }\end{array}$} & \multicolumn{2}{|c|}{$\begin{array}{l}\text { Social norms for } \\
\text { car sharing }\end{array}$} & \multicolumn{2}{|c|}{$\begin{array}{l}\text { Community } \\
\text { resilience }\end{array}$} & \multicolumn{2}{|c|}{$\begin{array}{l}\text { Environmental } \\
\text { consciousness }\end{array}$} \\
\hline & Coeff. & t-stat & Coeff. & t-stat & Coeff. & t-stat & Coeff. & t-stat \\
\hline \multicolumn{9}{|l|}{ Gender (male) } \\
\hline Female & -- & -- & -- & -- & -- & -- & 0.167 & 2.06 \\
\hline \multicolumn{9}{|l|}{ Age ( $\geq 40$ years) } \\
\hline 18 to 23 & 0.393 & 3.93 & 0.510 & 4.96 & -- & -- & -0.266 & -2.39 \\
\hline 24 to 29 & 0.393 & 3.93 & 0.510 & 4.96 & -- & -- & -- & -- \\
\hline 30 to 39 & 0.275 & 2.05 & 0.510 & 4.96 & -- & -- & -- & -- \\
\hline \multicolumn{9}{|l|}{ Education (graduate degree) } \\
\hline Less than bachelor's degree & -0.335 & -2.18 & -- & -- & -0.247 & -1.96 & -- & -- \\
\hline Bachelor's degree & -0.191 & -2.33 & -- & -- & -- & -- & -- & -- \\
\hline \multicolumn{9}{|c|}{ Household income (>€4,000 per month) } \\
\hline$<€ 2,000$ per month & -0.217 & -2.31 & -0.233 & -3.11 & -- & -- & -- & -- \\
\hline$€ 2,000$ to $€ 4,000$ per month & -- & -- & -0.233 & -3.11 & -- & -- & -- & -- \\
\hline $\begin{array}{l}\text { Household size (effect of each } \\
\text { additional person) }\end{array}$ & -- & -- & -- & -- & -- & -- & -0.072 & -2.47 \\
\hline \multicolumn{9}{|c|}{ Correlations between latent variables } \\
\hline Openness to data sharing & 1.000 & $\mathrm{n} / \mathrm{a}$ & & & & & & \\
\hline Social norm & 0.281 & 5.54 & 1.000 & $\mathrm{n} / \mathrm{a}$ & & & & \\
\hline Community resilience & 0.116 & 2.20 & 0.160 & 2.67 & 1.000 & $\mathrm{n} / \mathrm{a}$ & & \\
\hline Environmental consciousness & 0.194 & 4.13 & 0.217 & 4.20 & 0.162 & 3.21 & 1.000 & $\mathrm{n} / \mathrm{a}$ \\
\hline
\end{tabular}

"--" not statistically significant at the $90 \%$ level of confidence: removed from the specification. "n/a" not applicable. 
Regarding the choice modelling the dependent variable is the decision to use Carshare, which has been split in four different categories: frequent user, user, active rejection and passive non-adoption. For modelling purposes passive non-adoption category has been taken as a base for comparison.

Exogenous covariates that appear as statistically significant are: gender, with females clearly more inclined towards the active rejection of Carshare; age, with adults (30-49) showing higher propensity to be frequent users of the service and level of education, with more propension of lower educational levels to actively reject the service.

It is worth highlighting the results obtained for vehicle ownership, that show that those who do not own a car are much more likely to be either frequent users of the service or active rejecters, much more positioned than the reference group of 'car available in the household'. It is also interesting how the familiarity with the sharing economy (having used at least three other shared services) clearly increases the likeliness of the user to be user or frequent user of the system.

Table 21. Measurement equation of use of shared services and choice model of Carsharing use

\begin{tabular}{|c|c|c|c|c|c|c|c|c|}
\hline \multirow{4}{*}{ Variables (base category) } & \multirow{3}{*}{\multicolumn{2}{|c|}{$\begin{array}{c}\text { Use of non- } \\
\text { transport shared } \\
\text { services } \\
\\
\text { (ordinal) }\end{array}$}} & \multicolumn{6}{|c|}{ Carshare use (base: passive non adoption) } \\
\hline & & & \multirow{2}{*}{\multicolumn{2}{|c|}{$\begin{array}{c}\text { REJECTION } \\
\text { Active rejection }\end{array}$}} & \multicolumn{4}{|c|}{ USE } \\
\hline & & & & & \multicolumn{2}{|c|}{ Occasional use } & \multicolumn{2}{|c|}{ Frequent use } \\
\hline & Coeff. & t-stat & Coeff. & t-stat & Coeff. & t-stat & Coeff. & t-stat \\
\hline \multicolumn{9}{|l|}{ Latent variables } \\
\hline Openness to data sharing & 0.412 & 6.77 & -- & -- & -- & -- & 0.281 & 2.30 \\
\hline Social norm & 0.378 & 4.61 & -- & -- & 0.410 & 3.83 & 0.551 & 2.42 \\
\hline Community resilience & 0.311 & 3.12 & -- & -- & -- & -- & -- & -- \\
\hline Environmental consciousness & 0.388 & 6.69 & -- & -- & -- & -- & -- & -- \\
\hline \multicolumn{9}{|l|}{ Gender (male) } \\
\hline Female & -- & -- & -0.281 & -7.11 & -0.291 & -6.65 & -0.347 & -8.99 \\
\hline \multicolumn{9}{|l|}{ Age ( $\geq 50$ years) } \\
\hline 18 to 29 & 0.589 & 4.63 & -- & -- & -- & -- & -- & -- \\
\hline 30 to 39 & 0.742 & 4.97 & -- & -- & -- & -- & 0.399 & 11.30 \\
\hline 40 to 49 & -- & -- & -- & -- & -- & -- & 0.399 & 11.30 \\
\hline \multicolumn{9}{|l|}{ Education (graduate degree) } \\
\hline Less than bachelor's degree & -- & -- & -0.239 & -4.92 & -0.284 & -5.27 & -- & -- \\
\hline Bachelor's degree & -- & -- & -0.162 & -7.29 & -- & -- & -- & -- \\
\hline \multicolumn{9}{|c|}{ Vehicle availability (car ownership) } \\
\hline $\begin{array}{l}\text { No vehicle available in the } \\
\text { household }\end{array}$ & -- & -- & 1.639 & 23.19 & 0.660 & 7.96 & 0.950 & 7.43 \\
\hline $\begin{array}{l}\text { Occasional car access without } \\
\text { ownership }\end{array}$ & -- & -- & 0.572 & 14.22 & 0.187 & 3.35 & 0.326 & 3.12 \\
\hline \multicolumn{9}{|l|}{ Sharer (< 3 services) } \\
\hline 3 or more services & $\mathrm{n} / \mathrm{a}$ & $\mathrm{n} / \mathrm{a}$ & -- & -- & 0.405 & 4.85 & 0.866 & 4.86 \\
\hline
\end{tabular}


Concerning the studied latent variables, results show that for the case of Madrid Community resilience and Environmental consciousness appears not to be statistically significant in a direct way with regard to the choice of Carshare use. On the other hand, Openness to data sharing (low privacy concerns) informs the tendency to be a frequent user and Social Norms inform the propensity to be occasional user or frequent user of electric Carshare.

In general, it was found that users of these services tend to be adults, male and well-educated. Visibility of the system appears to be good in general terms and the main barriers to their wider adoption are: availability, area coverage, and the need to have an operating smartphone at the time of starting and ending the short period rental. The sample shows a strong acceptance of the need to provide banking data for practical reasons while they strongly reject the use of their data to commercialize them and/or for promotional purposes.

Figure 33. Carshare model results: relation among variables and latent variables

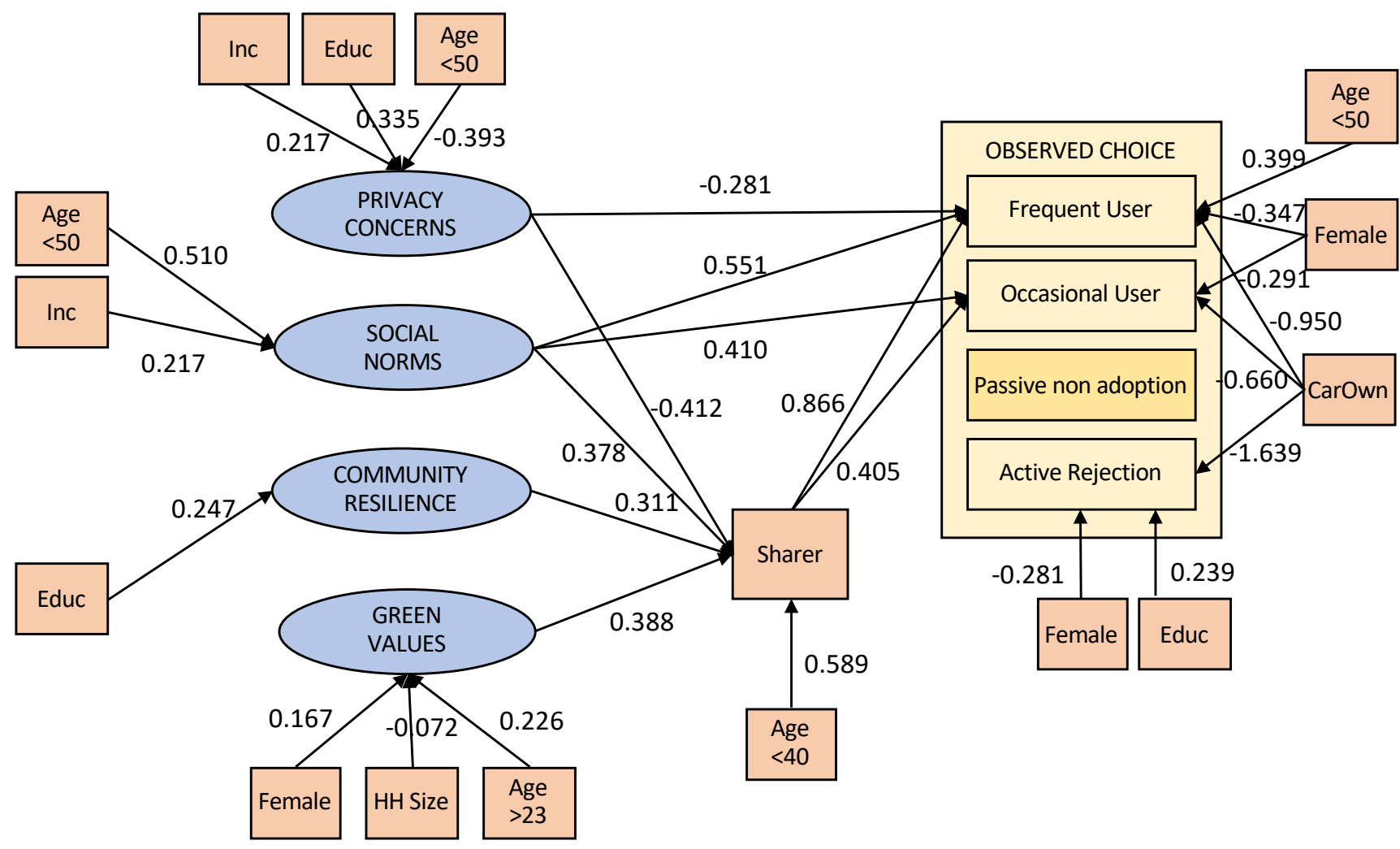

*Passive non-adoption colored grey as it is used as the base group for the estimation 
Results show that hypotheses 1,3 and 4 have been proven right while hypothesis 2 is partially rejected. From a behavioral perspective the privacy concerns of the user have a negative impact on Carshare adoption and usage levels. By contrast, it has been shown that social norms and familiarity with the Sharing Economy have a positive effect on both the adoption and use levels of Carshare services. The model results suggest that for the latent constructs of community resilience and environmental concerns a direct effect on the choice to adopt shared technologies has been observed, while no clear conclusion can be drawn for their effects on the level of use of the Carsharing service in particular.

Relations among variables which were already proven for other Carsharing models (e.g. Ullah et al. 2019) like those of income, age, education level or car use level on system adoption, also have a similar effect for the case of a $100 \%$ electric free-float Carsharing system. Also, the impact of the covariates of age, income, or access to a private car it has been shown on the frequency of use of the service. We identified derivative actions to enhance the adoption of these green technologies like the need for campaigns to (a) Increase the restrictions on the use of data that these services can develop, reducing privacy-sensitivity specially among adults. Visibility and area coverage are large for the case of Madrid, it is thus reasonable for social and community norms to have a strong impact. (b) The strengthening of community efficacy/ encouraging the creation of social norms is therefore another potential path to encourage adoption of the system. (c) Tackling car ownership. Finally, (d) a general encouragement of sharing economy and (e) exploiting the positive environmental effects of these systems by improving their image, come in finally as the last two recommendations.

Also, the gradual change in socio-demographics is likely to change the average adoption and use levels of Carshare in Madrid. The results in this study expand the body of knowledge by introducing the effect of familiarity with the sharing economy and privacy concerns on the adoption and the level of use of a free-float $100 \%$ electric carsharing system. The results also reveal the convenience of introducing complementary policies that discourage the substitution of PT trips by Carshare, like keeping PT priority lanes away from carshare users.

General perceptions of the sample include that current difficulties to carry children in them or to find a parking spot are an issue as well as reliability on the availability of vehicles when you need them. The latter could be solved in the future with the arrival of self-driving vehicles which would enable the possibility of picking the user up no matter when and where. In the meantime the introduction of specific Carshare parking policies in areas with scarce parking space could strongly encourage the use of Carshare.

These results are reproduced in Chapter 11. 


\section{DISCUSSION \& CROSS-SOLUTION ANALYSIS}

This chapter summarizes the main results obtained for the three studied solutions. It points out the main similarities and differences across the three solutions, and consequently across the technologies that have been object of analysis. A small table at the end of each block presents the main results of the different models with regard to the factors included in them. An additional table at the end of the section summarizes the results for the three solutions in order to ease the comparison of results. for each of the studied relations if it has been found significant $(\sqrt{ })$, non-significant $(\boldsymbol{K})$ or if the hypothesis has been only partially accepted $(\sim)$. Elements not included in each study are filled in grey.

\section{BIKESHARE}

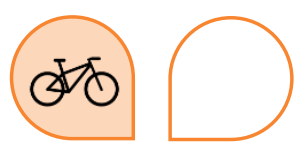

The analysis for the Bikeshare smart solution tested the statistical relevance of system characteristics and of the latent constructs of Green Values and Technophilia in order to predict satisfaction with BiciMAD (system, bike characterisctics and infrastructure) and bikeshare use. Satisfaction with the tariff was also considered in the model, combining it with the frequent use of the system in order to predict the intention to renew the subscription by the user.

The model statistically confirmed the first hypothesis formulated, with the relations of the user satisfaction with the system, user satisfaction with the bike characteristics and user satisfaction with the urban infrastructure for biking being significant for the frequent use of bikeshare. 
The model also confirmed the second research hypothesis, showing that users with green values tend to have higher levels of satisfaction regarding the bike characteristics, the urban biking infrastructure and BiciMAD system itself. This is consistent with previous research on bike use and proves that relation as valid for the specific case of an electrically assisted pedelec system like BiciMAD.

The statistical model partially confirms the third hypothesis, as the importance that the user sets on technology explains the user satisfaction with the bikes but not the user general satisfaction with the system. The correlation patterns on Table 6 partially confirm the fourth hypothesis, with previous biking experience being correlated with satisfaction with urban infrastructure for biking but not with satisfaction regarding the bikes. The model also confirms H5 with covariates like age, income, familiarity with biking or access to a private bike having an impact on being a frequent user of BiciMAD. Finally, the analysis also showed that the satisfaction with the tariff is positively and significantly correlated to the Intention to renew the subscription dependent variable. Also -and surprisingly- the model has shown that being a frequent user of the system is negatively correlated with the intention to renew the subscription. These result may appear as counter intuitive at first but recent studies, like the one by Castillo-Manzano et al. (2015) have shown a relation between biking familiarity -and bikeshare acting as the lever of this familiarity- and the willingness to buy a private bike. This could explain this switch from frequent use to not-renewing, as users may decide to buy their own bikes after the contribution of BiciMAD to promote active travel and to improve cycling culture, results that are in line with previous research by Munckacsy et al. (2017).

Results and the weights among interrelated factors are explained below and represented in Figure 23.

\begin{tabular}{|c|c|c|}
\hline & & $\begin{array}{c}\text { BIKESHARE } \\
\text { MODEL }\end{array}$ \\
\hline \multirow{7}{*}{$\begin{array}{l}\text { Addressed } \\
\text { Items }\end{array}$} & \multirow{7}{*}{$\begin{array}{l}\text { Green Values } \\
\text { Social Norms } \\
\text { Technophilia } \\
\text { Privacy/Safety } \\
\text { Willingness to pay } \\
\text { Service Quality } \\
\text { Socio Demographic }\end{array}$} & $\checkmark$ \\
\hline & & \\
\hline & & $\checkmark$ \\
\hline & & \\
\hline & & $\checkmark$ \\
\hline & & $\checkmark$ \\
\hline & & $\sim$ \\
\hline
\end{tabular}


In the study on Mi Transporte APP, we focus on the effect of the various latent constructs on the intention to use a real-time multimodal information app, as well as on the willingness to pay and the actual app adoption. The model has statistically confirmed $\mathrm{H} 1$ with the relation of willingness-to-pay for the app and the intention to use it being significant for its actual adoption. The statistical model also confirms H2. User's expectations, the user's technophilia, and her/his previous use of transport mobile apps explain the intention to adopt the app. The statistical model confirms H3. User's expectations are positively and significantly explained by search functionalities of the app, the LOS importance, information about side-modes and time saving skills. The correlation patterns do confirm H4. Gender and age appear as negatively and significantly correlated with the technophile factor (male and younger are more technophile) while smartphone use is positively and significantly correlated with the technophile factor. The model also confirms $\mathrm{H} 5$ with the importance of Time Saving Skills positively and significantly related to the frequency and duration of the trip, as well as to the use of smartphone, while negatively and significantly related to the most frequent trip taking place inside the City Centre. Finally, the analysis also showed that the importance of Side-Mode information is positively and significantly correlated to the Environmental responsibility factor, and that the importance of the LOS is explained by Age and Gender (female and elder give more importance to LOS). The effects of the different tested variables on the adoption of the system are presented in a simple way in the following table:

\begin{tabular}{|c|c|c|}
\hline & & $\begin{array}{c}\text { MULTIMODAL APP } \\
\text { MODEL }\end{array}$ \\
\hline \multirow{7}{*}{$\begin{array}{l}\text { Addressed } \\
\text { Items }\end{array}$} & \multirow{7}{*}{$\begin{array}{l}\text { Green Values } \\
\text { Social Norms } \\
\text { Technophilia } \\
\text { Privacy/Safety } \\
\text { Willingness to pay } \\
\text { Service Quality } \\
\text { Socio Demographic }\end{array}$} & $\checkmark$ \\
\hline & & \\
\hline & & $\checkmark$ \\
\hline & & \\
\hline & & $\sim$ \\
\hline & & $\checkmark$ \\
\hline & & $\checkmark$ \\
\hline
\end{tabular}

CARSHARE 


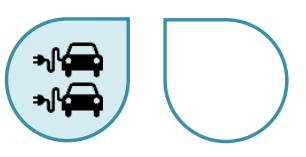

For the case of carshare, Table 20 presents the determinants of all the exogenous variables introduced in the model that have proven to be statistically significant on the four different latent variables previously defined and included in the model.

We can see that Gender is related to Green Values, with females being more conscious than men. Individuals aged 18 to 23 seem to have less environmental consciousness as well as those in large households, with each extra individual in the household reducing the likeliness for the individual to be environmentally aware when making mobility decisions. This can be linked to the general complexity of carrying children in those more sustainable modes.

Regarding Community Resilience only the educational level variable comes out as statistically significant, with lesser educational levels (less than bachelor's) being less prone to care about community resilience. On Social norms, being in the younger percentiles appears as statistically significant to be concerned about them.

With regard to Privacy concerns, age appears like a clear factor with individuals being less concerned about data sharing the younger that they are. Also, educational level appears as relevant with higher educational levels affecting positively the openness to share personal and mobility data.

On the adoption of the carsharing system, the results regarding the variables derived from the model are presented in a simple way in the following table:

\begin{tabular}{|c|c|c|}
\hline & & $\begin{array}{c}\text { CARSHARE } \\
\text { MODEL }\end{array}$ \\
\hline \multirow{7}{*}{$\begin{array}{l}\text { Addressed } \\
\text { Items }\end{array}$} & \multirow{7}{*}{$\begin{array}{l}\text { Green Values } \\
\text { Soc.Norms/Comm } \\
\text { Res } \\
\text { Technophilia } \\
\text { Privacy/Safety } \\
\text { Willingness to pay } \\
\text { Service Quality } \\
\text { Socio Demographic }\end{array}$} & $x$ \\
\hline & & $\sim$ \\
\hline & & \\
\hline & & $\checkmark$ \\
\hline & & \\
\hline & & \\
\hline & & $\checkmark$ \\
\hline
\end{tabular}


Table 22 summarizes the results that have been obtained for the three solutions, showing for each of the studied relations if it has been found significant $(\checkmark)$, non-significant $(\checkmark)$ or if the hypothesis has been only partially accepted $(\sim)$. Elements not included in each study are filled in grey.

Table 22. Comparison of results in the three solutions

\begin{tabular}{|c|c|c|c|c|}
\hline & & $\begin{array}{l}\text { BIKESHARE } \\
\text { MODEL }\end{array}$ & $\begin{array}{l}\text { MULTIMODAL APP } \\
\text { MODEL }\end{array}$ & $\begin{array}{l}\text { CARSHARE } \\
\text { MODEL }\end{array}$ \\
\hline \multirow{7}{*}{$\begin{array}{l}\text { Addressed } \\
\text { Items }\end{array}$} & Green Values & $\checkmark$ & $\checkmark$ & $x$ \\
\hline & Social Norms/Comm & & & $\sim$ \\
\hline & Technophilia & $\checkmark$ & $\checkmark$ & $\checkmark$ \\
\hline & Privacy/Safety & & & $\checkmark$ \\
\hline & Willingness to pay & $\checkmark$ & $\sim$ & \\
\hline & Service Quality & $\checkmark$ & $\checkmark$ & \\
\hline & Socio Demographic & $\sim$ & $\checkmark$ & $\checkmark$ \\
\hline
\end{tabular}

We can see that:

- Green Values have been found to inform the adoption of the bikeshare and the transit app solutions. This is coherent with previous research on bikesharing, and transit app use. However, they do not show statistical significance in the modelling of the adoption of shared electric vehicles. This could be explained by a lower perception of the sustainability that this system adds to the urban mobility system. Even if cars are $100 \%$ electric, they still generate emissions for their fabrication and the production of the electricity used to move them, as well as keep contributing to road congestion.

- The previous idea is in line with the partial conclusion on Social Norms influencing the adoption of carshare. It seems reasonable that carshare adopters do so more out of convenience than out of a personal propension towards social good, given that the perception of the system is 
for it to be sustainable but to a lesser extent than transit and bike solutions. Also, due to surveying limitations social norms were not tested in the models developed for the first two smart solutions, not being able to establish a comparison either between solutions or between social norms impacts and green values impacts.

- Technophilia has been proven to positively inform the adoption of all three solutions, as the effects for carshare adoption have already been tested in other studies (Lavieri et al. 2017b, autonomous carshare). The results are less conclusive in the case of bikeshare as the relation of the LV related to technology has an indirect relation with the decision to adopt though its effects on the perceived quality of the system and of the bikes.

- Privacy Concerns are tested in the Carshare model, proving to act as a strong barrier to adoption of these technologies. Users state that providing their payment information and the possibility that the service company sells their information are the main drivers of this rejection.

- Willingness to pay is also searched in the two first studies finding that it positively informs the adoption of the systems. However, for the case of the multimodal APP in which alternative free options exist, the prevalence of willingness to pay in the sample is very low.

- Service quality or the perceived level of service is tested in the bikeshare and multimodal app studies, proving to have a direct influence in the decision to adopt and the level of use of the services.

- Finally, in line with many other research works, the three analysis show different effects of sociodemographic characteristics on both the different latent variables and the adoption of the different solutions. We address the reader to the different sections, graphs and tables in which these relations are shown and described. 
PART IV-CONCLUSIONS 
Behavioral factors underlying the adoption of smart mobility solutions

(This page has been intentionally left blank) 


\section{CONCLUSIONS AND FUTURE RESEARCH}

\subsection{Conclusions}

The global objective of this thesis is to better understand how behavioral factors influence the decision of the citizens to adopt Smart Mobility solutions, as a necessary step to develop policies for enhancing their adoption, and thus, for achieving a more sustainable urban mobility. Consequently, this study has undertaken a research methodology aimed at analyzing the effects that different behavioral factors have on the adoption of three different smart mobility solutions. The analyzed solutions cover the three primary blocks of passenger mobility that take part in the city of Madrid, each of which accounts for approximately one third of its modal share: active modes, public transportation and the private car.

The work, which is thoroughly described in the present document, has developed its specific research method structured in three research experiments, centered on each one of the selected solutions. These experiments, despite executed in an independent way, hold a common logic in their procedures, and the behavioral constructs analyzed. These experiments were carried out in the years 2015, 2016 and 2017 and have contributed to the research objective by testing the effects of different latent constructs on both the decision to adopt and the level of use of three innovative smart mobility solutions.

Some commonalities and some differences amongst the factors driving adoption have been observed. This is helpful in order to derive different policies (see Section 11.2) for the enhancement of the adoption of smart mobility solutions linked to different transportation modes.

In line with the state of the art, one of the departing hypotheses in the development of this work has been that smart mobility solutions have commonalities, in behavioral terms, with other ICTs and of course with other more traditional transport modes. Hence, for results to be as useful as possible, the behavioral latent variables that were included in the study were selected from a state-of-the-art list 
which includes variables from both classical studies on mobility behavior and studies on technology solutions adoption.

The following pages reflect the hypotheses for each of the solutions, as well as their interpretation in the light of model outputs. Specific conclusions are then developed for each of the smart solutions analyzed. Finally, answers are given to the research questions that motivated this thesis. 


\subsubsection{BIKESHARE}

We have modelled the adoption of an electric pedelec public Bikesharing system. To do so we have gathered 442 answers to an online survey containing items on travel behavior, biking experience, technological skills, perceptions of the user on biking, sustainability issues and urban mobility, level of use of bikeshare and desire to renew his/her subscription to the system. A group of hypotheses (below) has been developed and introduced in a SEM model, obtaining the following results:

H1: Bikeshare use is related to the user satisfaction with the system, user satisfaction with the bike characteristics and user satisfaction with the urban biking infrastructure.

H2: User green values informs all three levels of satisfaction.

H3: Importance given to technology influences satisfaction with the bikes and with the system.

H4: Previous biking experience informs satisfaction with the bikes and with urban infrastructure for biking.

H5: Covariates like age, income, familiarity with biking or access to a private bike will have an impact on frequency of use of BiciMAD services.

The model statistically confirms $\mathrm{H} 1$, that bikeshare use is related to user satisfaction with the system, user satisfaction with the bike and user satisfaction with the urban infrastructure. The statistical model also confirms $\mathrm{H} 2$, with green values directly informing all three levels of user satisfaction. The statistical model partially confirms $\mathrm{H} 3$, suggesting the importance that the user sets on technology informs satisfaction with the bikes but not the general satisfaction with the system. The correlation patterns on Table 6 partially confirms $\mathrm{H} 4$, with previous biking experience being correlated with satisfaction with urban infrastructure for biking but not with satisfaction regarding the bikes. The model has not proven $\mathrm{H} 5$ referring to covariates like age, income, familiarity with biking or access to a private bike having an impact on being a frequent user of BiciMAD. Only gender has appeared to have an effect on the importance that the user gives to the quality of the service. 
The main conclusions for bikeshare smart mobility solution can be summarized in:

(i) The frequent use of bikeshare system in Madrid is correlated with the user's satisfaction with the operation and the vehicle, and to a lesser extent, with the urban biking infrastructure;

(ii) Green user values have a generally positive impact on the perception that the users have of the system and therefore their use of it;

(iii) Being non-technophile has a negative correlation with user bike satisfaction, suggesting that technophilia acts as a driver to enhance a frequent usage of the system. This finding is in line with past studies regarding adoption of ICT-based transportation solutions like ridesource (Lavieri et al. 2017);

(iv) Finally, satisfaction with the system's tariff positively informs the intention of the user to renew his/her subscription, while frequently using bikeshare works reversely. This could be explained by one of the systems objectives, which was to try to transfer users from other modes to biking. Previous research carried out by Rondinella (2015) found that familiarity with biking improves the perception of the system. Hence, the system could be enhancing the decision to buy a private bicycle by increasing the presence of bikes in the streets of Madrid and by providing a first contact of Madrid's citizens with the biking experience. 


\subsubsection{MULTIMODALAPP}

We have modelled the adoption of a multimodal real-time information-transit-app. To do so we have gathered 386 answers to an online survey containing items on travel behavior, technological skills and predisposition to adopt both new technological solutions in general and mobile apps in particular. Also, a set of questions on the users' preferences for a transportation mobile app, their perceptions of mobility and sustainability issues, as well as on their willingness-to-pay for a multimodal application were included. A group of hypotheses (below) have been developed and introduced in a SEM model, obtaining the following results:

H1: app use is related to the willingness-to-pay for the app and the intention to use it in the future.

H2: user's expectations, technophilia, and previous use of transport apps explain the intention to adopt the app.

H3: the search functionalities of the app, the LOS importance, information about sidemodes and time saving skills explain the user's expectations.

H4: gender, age and smartphone use explain user's technophilia.

H5: trip characteristics (frequency, duration, reason of trip) and smartphone use are related to time saving skills.

The model statistically confirms $\mathrm{H} 1$, that willingness-to-pay for the app and the intention to use it being significant for its actual adoption. The statistical model also confirms $\mathrm{H} 2$, with the user's expectations, the user's technophilia, and his/her previous use of transport mobile apps explaining the intention to adopt the app. The statistical model confirms H3. User's expectations are positively and significantly explained by search functionalities of the app, the LOS importance, information about side modes and time-saving skills. The correlation patterns do confirm $\mathrm{H} 4$, with gender and age negatively and significantly correlated with the technophile factor (male and younger are more technophile) and smartphone use positively and significantly correlated with the technophile factor (F1). The model also confirms $\mathrm{H} 5$ with the importance of time-saving skills positively and significantly related to the 
frequency and duration of the trip. Conversely, the use of smartphones is negatively and significantly related to the most frequent trip taking place inside the City Centre.

The main conclusions for the multimodal real time information APP smart mobility solution can be summarized in:

(i) The adoption of the app is correlated with the user's intention to adopt it and more strongly with the WTP;

(ii) While the intentions can be explained by various factors, the WTP is only related to the WTP to save time;

(iii) User's expectations, technophilia, and previous use of transport apps strongly explain the intention to adopt the app;

(iv) Search functionalities, the LOS importance, information about park-and-ride and bicycle and time-saving skills explain the user's expectations;

(v) Gender, age and smartphone use explain a user's technophilia,

(vi) Trip characteristics, frequency, duration and smartphone use are related to time-saving skills.

In general terms, the study shows that "Mi Transporte" app has achieved a relative success, as 35\% of the users that tested it are using it frequently for their most common trip and $48 \%$ of them stated that the app is now their main multimodal mobility app. The app has changed for the waiting time or route choice for $60 \%$. The general rating and user knowledge on the app improved during the experimentation period, with no severe reliability issues being reported.

The perceived level of service is a very important element, in line with results for other mobility solutions (Kaplan et al. 2014). The most important declared attributes are that the app is free, multimodal and provides information in real time. Willingness-to-pay for the app use was also addressed in the survey and results show that it remains low, and always linked to tangible time savings thanks to the use of the app, which aligns with our hypotheses given the existence of free alternatives such as Google maps or Waze. 


\subsubsection{CARSHARE}

We have modelled the adoption of a $100 \%$ electric Carsharing system. To do so we have gathered 959 answers to an online survey containing items on travel behavior, sharing experience, technological skills, perceptions of the user on sharing, sustainability and urban mobility and level of use of carshare. A group of hypotheses (below) have been developed and introduced in an Integrated Latent Variable and Choice model (ICLV), obtaining the following results:

H1: Privacy concerns have a negative impact on Carshare adoption and use levels.

H2: Community Resilience, Environmental concerns and familiarity with the Sharing Economy positively impact Carshare adoption and level of use.

H3: Elements already proven for other Carshare models like income, age, education level or car use level also have a similar effect on the adoption of $100 \%$ electric freefloat Carshare systems.

H4: Covariates such as age, income, familiarity with transit or access to a private car will have an impact on frequency of use of Carshare services.

Results show that hypotheses 1,3 and 4 have been proven right while hypothesis 2 is partially rejected. From a behavioral perspective the privacy concerns of the user has a negative impact on Carshare adoption and usage levels. On the other hand, it has been shown that social norms and familiarity with the Sharing Economy have a positive effect on both the adoption and level of use of Carshare services. The model results suggest that for the latent constructs of community resilience and environmental concerns a direct effect on the choice to adopt the technology has been observed, while no clear conclusion can be drawn for their effects on the level of use of the service.

Model results show that, for the case of Madrid, Community Resilience and Environment Consciousness appear not to be statistically significant with regards to the choice to adopt and use the Carshare mode. On the other hand, openness to data sharing (low privacy concerns) informs the tendency to be a frequent user and social norms inform the propensity to be a user or frequent user of electric Carshare.

In general, it was found that users of these services tend to be adults, male and well-educated. Visibility of the system appears to be good in general terms and the main barriers to their wider adoption are: 
availability, area coverage, and the need to have an operating smartphone at the time of starting and ending the short period rental.

Recommendations based on the results discussed in this thesis include the need for campaigns to (a) exploit the positive environmental effects of these systems, thus improving their image; and (b) increase the restrictions on the use of data that these services can develop, reducing privacy-sensitivity especially among adults. Visibility and area coverage are large for the case of Madrid. It is thus reasonable for social and community norms to have a strong impact; (c) The strengthening of community efficacy/encouraging the creation of social norms is therefore another potential path to encourage adoption of the system. Finally, (d) tackling car ownership and (e) general encouragement of sharing economy come in as the last two recommendations.

Also, the gradual change in socio-demographics will change the average adoption and use levels of Carshare in Madrid. The results in this study expand the body of knowledge by introducing the effect of familiarity with the sharing economy and privacy concerns on the adoption and the level of use of a free-float $100 \%$ electric carsharing system. The results also reveal the convenience of introducing complementary policies that discourage the substitution of public transportation trips by Carshare.

General perceptions of the sample include that current difficulties to carry children in them or to find a parking spot are an issue as well as reliability on the availability of vehicles when you need them. The latter could be solved in the future with the arrival of self-driving vehicles which would enable the possibility of picking the user up no matter when and where, but in the meantime the introduction of specific Carshare parking policies in areas with scarce parking space could strongly encourage the use of Carshare. 


\subsubsection{ANSWER TO RESEARCH QUESTIONS}

Seeing all the previous results and conclusions, we can finally answer the research questions of the thesis.

The first of the research questions was:

The actual use of transport modes is explained by a number of behavioral factors: green values, social norms and attitudes.

RQ1 - Are the behavioral factors for the adoption and use of smart mobility solutions similar to those relevant for explaining the use of transport modes?

Results have shown that transport-related behavioral factors like green values or system quality perception relate to the user's choice to adopt and use smart mobility solutions. Green values has been found statistically significant for both Bikeshare and the multimodal transportation APP, while for the case of Carshare the relationship was not demonstrated. The effect of social norms has not been deemed fully statistically significant in the only case study in which they were included as an item (Carshare).

We can conclude that we now better understand how behavioral constructs like green values, quality perception, communitarian attitudes or social norms, which had been studied for traditional transport modes, inform and influence the choice to adopt and use innovative smart mobility services.

Green values and social norms act as positive drivers of adoption of smart sustainable solution in all cases and should therefore be taken into account as psychological motivations that can help reinforce the use of these systems.

Quality of service perception positively informs the usage level of the systems in the form of a higher perceived ease of use, leading to higher frequency of use. On the other hand, barriers embedded in the attributes of the solutions impede their adoption. Adoption intention is hence associated not only with psychological motivations but also with functional considerations in relation with transportation. These findings are in line with those of Kaplan et al. (2017) regarding the level of use of transit in the Netherlands. 
The second research question was:

The actual use of ICT-based tools depends on a number of attitudinal factors: technophilia, privacy concerns, etc.

RQ2 - Are the attitudinal factors for the adoption and use of smart mobility solutions similar to those relevant for explaining the use of ICT-based tools?

Results show that technology-related behavioral factors like technophilia or privacy concerns do influence the users' choice to adopt and use smart mobility solutions.

Technophilia has been proven statistically significant for the three technologies and positively informs the adoption of two of them (bikeshare and multimodal app) with the third being present in the literature. We can extend the conclusion to state that technophiles are an important target group of these smart mobility solutions. They can play a significant role through early adoption of the systems in promoting the use of this new generation of travel information system, thus contributing to a rapid increase in demand.

However, and as stated by Kaplan et al. (2014), the system attributes and functionalities should be aligned to the needs of both technophiles and technophobes. "On one hand, the entry threshold for unwilling users should be lowered (e.g. easy and understandable feature design) and on the other hand, tech-lovers should be appealed (e.g. providing the possibility of participatory design)". It is also notable that technophiles have stronger presence among younger groups of population which can be observed in order to accommodate implementation strategies.

Privacy concerns on the other hand were only included in the study on carshare and demonstrated to have a negative impact on the decision of the users to use and adopt innovative and technology-based smart mobility solutions.

We have hence analyzed the effect of two main behavioral factors linked in previous research studies to the adoption and use of technology, proving them to be relevant for the adoption of smart mobility technologies, technophilia and user privacy concerns. Adoption intention for smart mobility solutions is hence associated with psychological motivations and barriers related to technology.

The third research question was: 
RQ3 - Are there differences in the behavioral and attitudinal factors that explain the adoption and use of different smart mobility solutions?

From the results we can conclude that there are differences in the effects that some of these factors develop over the adoption and use levels of different smart mobility solutions.

Technophilia is found to inform all three different solutions, while green values appear to inform the smart mobility solutions more linked to green modes (biking and PT). Social norms and privacy concerns have been found significant in the only study in which they were included, but to reinforce this conclusion further research should be developed in the future.

Finally, sociodemographic variables do have an effect on the decisions to adopt and the levels of use of the different technologies. However, these effects are diverse, with the only general conclusions in this regard being that users with a stronger appeal to use smart multimodal solutions tend to be male, high-technophile and well educated, with previous experience in similar services or in the traditional alternative for the smart solutions (biking, transit use, or sharing services). This affirmation should be tested however for the potential bias introduced by the area of operation of the systems within the city of Madrid. For further detail on the socioeconomic variables effects on smart solutions adoption we suggest the reader to refer to the different studies in sections 7,8 and 9 of the thesis.

We can conclude that the formulated hypotheses have been validated, with latent constructs of traditional transport behavior studies and latent constructs from the technology field being proven as relevant for the adoption and use of smart mobility technologies.

Through the work developed we have expanded the body of knowledge on this matter. The obtained results provide researchers and practitioners with a better understanding of the adoption and use of smart mobility technologies, showing that both functional and psychological factors affect adoption intention and level of use.

The work sheds light on potential elements to be considered for their implementation, which can lead to better strategies for the enhancement of the adoption of sustainable transportation option by citizens, thus, achieving the greatest impact on sustainability. These results can also guide efforts to better understand the demand for other smart mobility solutions in the future. 
Behavioral factors underlying the adoption of smart mobility solutions 


\subsection{Policy recommendations}

The arrival of Smart Mobility solutions to our cities is today more of a reality than a future possibility. These technologies are increasing their presence by the hour in multiple cities worldwide, generally provided by private firms, with some of the companies that manage them providing their services at a global scale.

Nevertheless, the role of the public administration and policy measures is essential in both the proper functioning of these systems, and their eventual generalized adoption. As it was introduced in the beginning of this work, both considerations are necessary for them to deploy their advantages.

The first one is necessary in order to ensure that the deployment of these technological solutions does not generate new, extra challenges for the city. In this sense, we have seen the conflicts that ridehailing solutions are bringing worldwide, the banning of shared scooters in Madrid, Valencia or Barcelona due to their indiscriminate parking that tampered accessibility or the general described risk of exclusion of either the poor or the non-tech-savvy.

The second one is desirable for them to achieve their wider potential and to effectively tackle challenges that our cities face. Sharing systems are able to reduce the need for private car fleets, parking space and ease the renewal and maintenance of the vehicles, as well as the application of other policy measures. Transit apps, in line with any other real-time information system improve transit ridership and multimodality, both desired objectives for European cities according to the European Commission. Finally, bikesharing services enhance the use and adoption of biking as a modal option for the users, which in return brings closer the solution to many other challenges: traffic calming, emission reduction, health improvement, social cohesion, friendliness of the public space, etc.

Based on the specific results of this work, we can see that behavioral traits present in the population as well as system configuration and perception characteristics are relevant in the users' choice to adopt and use these solutions, thus potentially contributing to a more sustainable mobility.

Concerning specific policy measures to enhance the adoption of smart mobility solutions that can be derived from this work:

- Green values have been proven to have a positive impact on active mode and transit smart mobility solution adoption. A policy recommendation associated with this finding would be to strengthen this trait through awareness-raising campaigns and educational programs. 
- Privacy concerns, at least in one case, have been proven to have a negative effect on the adoption and use of smart mobility solutions. In this sense, the promotion of user confidence in these systems appears as an option. Some other policy measures that could be derived have to do with (i) providing these systems with a clear and strong data privacy regulation and (ii) making visible in the eyes of the users that such regulation exists and is enforced by the authorities.

- Technophilia has been found to positively inform the adoption of all three solutions. We can also see this more as a barrier than as an advantage, in the sense that the technological features of the system are affecting the non-technophile user's decision to adopt it. Making the systems design as understandable and accessible as possible would increase adoption of smart mobility solutions.

- Finally, system features and design appear as relevant in all the systems. It is therefore recommended to test and pilot the technologies before the overall launching of the system, as well as relying in best practices from other similar cities. The public action towards the introduction of these solutions should be accompanied by a robust communication strategy to understand citizens' travel needs and expectations, underline the positive effects for sustainability that these solutions have and clarify the need for change in their travel behavior.

These implementation policies can be understood as complementary to other measures that are strongly encouraged such as slowing down traffic speed for bikeshare (Romanillos et al. 2019), an adequate design of charging stations with regard to access distance, and charging opportunities as studied by Gimenez et al. (2014) for electric vehicles. 


\subsection{Limitations and Future research}

Findings and conclusions of this dissertation have improved the understanding of the different behavioral and attitudinal factors that influence the adoption of smart mobility services. Through the analysis of the three solutions the relations of constructs like technophilia, privacy concerns, green values or social norms with active, transit and car modes are further explained.

However, there is a number of topics that have not been addressed in this work due to methodological or scope limitations. In methodological terms, there is a limitation corresponding to the choice to use survey data for research. The selected surveying method brings the limitations of random sampling in terms of representativity for the first two studies, and that of self-selection in the carsharing study. The limitation on the number of items to be included in the study is a remarkable limitation of this work, as further questions or addressing more complex issues may bring lower response rates. Another limitation is using declared inputs for the modelling. Also, the available datasets had to be treated and cleaned thoroughly to generate the adequate variables for the models used in the analysis to converge. This process can lead to the introduction of a certain bias as well as limits the number of variables to be used. The development of improved models or more powerful software tools could help to simultaneously analyze more complex relationships between variables.

The work here presented could be complemented by introducing the analysis of the items marked in grey in the general table of searched elements per survey (Table 3), e.g. helping to understand the effects of variables like privacy concerns on other smart mobility technologies.

Another research line that could strengthen the obtained results would be developing studies on similar smart solutions in different cities or regions, as well as by similar analysis of different smart mobility solutions such as shared motorbikes, shared scooters, ride-hailing services or in the close future, autonomous vehicle fleets. Furthermore, jointly analyzing choice between smart mobility options and traditional variants has been proven feasible (Choudhury et al. 2018) and can provide insights on the future choice modelling of such combinations of technologies.

Future studies could also complement the use of declared variables with real data coming from the systems (so called big data) that according to Chen et al. (2016) and Gutierrez-Puebla (2018) is likely to offer innovative insights on solutions related to ICT (as a complement to traditional data collection systems like surveys). In this regard, the standardized data collection on smart mobility solutions seems to be key not only for their management but for their promotion and improvement. 
According to the gurus on the matter, the final step down the road of smart mobility is set to be Mobility as a Service paired with integrated fare-calculation and payment processing.

Also, one key element down the road are fully autonomous electric vehicles; set to disrupt individual mobility. It appears as key, that before we integrate all modes in a single mobility services system, we better understand why and how we decide to use smart mobility systems.

In, it seems reasonable that in the introduction of such systems that substantially reduce human decision making on personal mobility, subjective elements such as perceived system fairness that have been described as relevant for transit use (Kaplan et al. 2014) and other technologies like toll systems (Gomez et al. 2017) play a relevant role that should be studied.

We have attempted to reduce potential biases (e.g., by using the appropriate statistical methods). Surveys have been designed and pre-tested carefully. We recognize, however, that findings can be subjected to hypothetical bias and cognitive incongruence. Also, certain biases inherent in survey research, such as self-selection, non-response and policy response bias, may remain. 


\section{REFERENCES}

- Ajzen, I. (1991) 'The theory of planned behavior', Orgnizational Behavior and Human Decision Processes, 50, pp. 179-211. doi: 10.1016/0749-5978(91)90020-T.

- Ajzen, I. and Fishbein, M. (1980) 'Understanding attitudes and predicting social behaviour'.

- Alawadhi, S. et al. (2012) 'Building Understanding of Smart City Initiatives', in. Springer, Berlin, Heidelberg, pp. 40-53. doi: 10.1007/978-3-642-33489-4_4.

- Andreas, S. (2000) 'Regularities in travel demand: an international perspective', Journal of Transportation and Statistics, 3, p. 1.

- Angelidou, M. (2014) 'Smart city policies: A spatial approach', Cities, 41, pp. S3-S11. doi: 10.1016/j.cities.2014.06.007.

- Ashok, K., Dillon, W. R. and Yuan, S. (2002) 'Extending Discrete Choice Models to Incorporate Attitudinal and Other Latent Variables', Journal of Marketing Research. Sage Publications, Inc., pp. 31-46. doi: 10.2307/1558582.

- Astroza, S., Garikapati, V. M., Bhat, C. R., Pendyala, R. M., Lavieri, P. S., and Dias, F. F. (2017) 'Analysis of the Impact of Technology Use on Multimodality and Activity Travel Characteristics', Transportation Research Record: Journal of the Transportation Research Board, 2666(1), pp. 1928. doi: 10.3141/2666-03.

- Bakogiannis, E. et al. (2014) 'Case studies and sustainable urban mobility research schemes: A communication channel among researchers and interdisciplinary community groups', International Journal of Service Science, Management and Engineering, 1(4), pp. 42-51.

- Barberan, A., de Abreu e Silva, J., and Monzon, A. (2017). 'Factors influencing bicycle use: a binary choice model with panel data'. Transportation Research Procedia, 27, 253-260. doi:10.1016/j.trpro.2017.12.097

- Bart, Y., Shankar, V., Sultan, F., \& Urban, G. L. (2005) 'Are the Drivers and Role of Online Trust the Same for All Web Sites and Consumers? A Large-Scale Exploratory Empirical Study', Journal of Marketing, 69(4), pp. 133-152. doi: 10.1509/jmkg.2005.69.4.133.

- Bentler, P. M. (1989) 'EQS 6 Structural Equations Program Manual'. Available at: http://84.89.132.1/ satorra/CourseSEMVienna2010/EQSManual.pdf (Accessed: 1 August 2017). 
- Bhat, C. R. and Dubey, S. K. (2014) 'A new estimation approach to integrate latent psychological constructs in choice modeling'. doi: 10.1016/j.trb.2014.04.011.

- Brakewood, C., Barbeau, S. and Watkins, K. (2014) 'An experiment evaluating the impacts of real-time transit information on bus riders in Tampa, Florida'. Available at: https://nacto.org/wp-content/uploads/2016/04/5-Brakewood-et-al_Evaluating-the-Impactsof-Real-Time-Transit-Information-in-Tampa-and-Atlanta_2014.pdf (Accessed: 13 July 2017).

- Brown, T. (2006) 'Confirmatory Factor Analysis for Applied Research, Methodology in the Social Sciences'.

- Browne, M. W. and Cudeck, R. (1992) 'Alternative Ways of Assessing Model Fit', Sociological Methods \& Research, 21(2), pp. 230-258. doi: 10.1177/0049124192021002005.

- Buttel, F. H. (1987) 'New Directions in Environmental Sociology', Annual Review of Sociology. Annual Reviews 4139 El Camino Way, P.O. Box 10139, Palo Alto, CA 94303-0139, USA, 13(1), pp. 465-488. doi: 10.1146/annurev.so.13.080187.002341.

- Caragliu, A., Del Bo, C. and Nijkamp, P. (2011) 'Smart Cities in Europe', Journal of Urban Technology. Routledge, 18(2), pp. 65-82. doi: 10.1080/10630732.2011.601117.

- Cardozo, O. D., Gutiérrez Puebla, J. and García Palomares, J. C. (2009) 'Influencia de la morfología urbana en la demanda de transporte público: análisis mediante sig y modelos de regresión múltiple' GeoFocus (Artículos), no 10, p. 82-102. ISSN: 1578-5157

- Castillo-Manzano, J., Castro-Nuño, M. and López-Valpuesta, L. (2015). 'Analyzing the transition from a public bicycle system to bicycle ownership: A complex relationship'. Transportation Research Part D: Transport and Environment, 38, pp.15-26.

- Chen, C. F. and Chao, W.-H. (2011) 'Habitual or reasoned? Using the theory of planned behavior, technology acceptance model, and habit to examine switching intentions toward public transit', Transportation Research Part F: Traffic Psychology and Behaviour, 14(2), pp. 128-137. doi: 10.1016/j.trf.2010.11.006.

- Chen, C., Ma, J., Susilo, Y., Liu, Y., and Wang, M. (2016). 'The promises of big data and small data for travel behavior (aka human mobility) analysis'. Transportation Research Part C: Emerging Technologies, 68, 285-299. doi:10.1016/j.trc.2016.04.005

- Chin, E., Felt, A. P., Sekar, V., and Wagner, D. (2012) 'Measuring user confidence in smartphone security and privacy', in Proceedings of the Eighth Symposium on Usable Privacy and Security SOUPS '12, p. 1. doi: 10.1145/2335356.2335358.

- Choo, S. and Mokhtarian, P. L. (2004) 'What type of vehicle do people drive? The role of attitude and lifestyle in influencing vehicle type choice'. doi: 10.1016/j.tra.2003.10.005.

- Choudhury, C. F., Yang, L., de Abreu e Silva, J., and Ben-Akiva, M. (2018). 'Modelling preferences for smart modes and services: A case study in Lisbon'. Transportation Research Part A: Policy and Practice, 115, 15-31. doi:10.1016/j.tra.2017.07.005

- Chourabi, H., Nam, T., Walker, S., Gil-Garcia, J. R., Mellouli, S., Nahon, K., ... Scholl, H. J. (2012) 'Understanding smart cities: An integrative framework', Proceedings of the Annual Hawaii International Conference on System Sciences, pp. 2289-2297. doi: 10.1109/HICSS.2012.615. 
- Cialdini, R. B. and Goldstein, N. J. (2004) 'SOCIAL INFLUENCE: Compliance and Conformity', Annu. Rev. Psychol, 55, pp. 591-621. doi: 10.1146/annurev.psych.55.090902.142015.

- Cialdini, R. B., Reno, R. R. and Kallgren, C. A. (1990) 'A focus theory of normative conduct: Recycling the concept of norms to reduce littering in public places.', Journal of Personality and Social Psychology, 58(6), pp. 1015-1026. doi: 10.1037/0022-3514.58.6.1015.

- Circella, G. (2017) 'The Multimodal Behavior of Millennials: Exploring Differences in Travel Choices between Young Adults and Gen Xers in California'. Available at: https://trid.trb.org/view/1439739 (Accessed: 2 May 2019).

- Comrey, A. L., Lee, H. B. and Lee, H. B. (2013) 'A First Course in Factor Analysis'. Psychology Press. doi: $10.4324 / 9781315827506$.

- Courtney, K. L. (2008) 'Privacyand SeniorWillingnesstoAdopt SmartHome Information Technology in Residential Care Facilities', MethodsInf, 47, pp. 76-81. doi: 10.3414/ME9104.

- Dantan, S., Bulteau, J. and Nicolaï, I. (2015) 'Hurried or risk-adverse travelers: who will pay more for multimodal information?', Procedia Engineering, 115, pp. 61-68. doi: 10.1016/j.proeng.2015.07.355.

- Dunlap, R. E., Van Liere, K. D., Mertig, A. G., and Jones, R. E. (2000) 'New Trends in Measuring Environmental Attitudes: Measuring Endorsement of the New Ecological Paradigm: A Revised NEP Scale', Journal of Social Issues. John Wiley \& Sons, Ltd (10.1111), 56(3), pp. 425-442. doi: 10.1111/0022-4537.00176.

- Dunlap, R. and Van Liere, K. (1984) 'Commitment to the Dominant Social Paradigm and Concern for Environmental Quality', Social Science Quarterly, 65. Available at: https://peec.stanford.edu/resources/readings/commitment-dominant-social-paradigm-andconcern-environmental-quality (Accessed: 2 May 2019).

- Dyrberg, M., Christensen, C., Anderson, M., Nielsen, O. and Prato C. (2015) 'Transfer attributes in route choice models for public transport passengers'. Available at:

http://transp-or.epfl.ch/heart/2015/abstracts/hEART_2015_submission_121.pdf (Accessed: 1 August 2017).

- Dziekan, K. and Kottenhoff, K. (2007) ‘Dynamic At-Stop Real-Time Information Displays for Public Transport: Effects on Customers', World Transit Research. Available at: http://www.worldtransitresearch.info/research/1954 (Accessed: 27 June 2017).

- Dunlap, R. \& Jones, R. (2002). 'Environmental Concern: Conceptual and Measurement Issues'. In Dunlap and Michelson (Ed), Handbook of Environmental Sociology (pp. 482-542). London: Greenwood Press.

- Eagly, A. and Chaiken, S. (1993) 'The psychology of attitudes.' Available at: https://psycnet.apa.org/record/1992-98849-000 (Accessed: 2 May 2019).

- EEA (2006) 'Urban Sprawl in Europe - The ignored challenge'. European Environmental Agency.

- Efthymiou, D., Antoniou, C. and Waddell, P. (2013) 'Factors affecting the adoption of vehicle sharing systems by young drivers', Transport Policy, 29, pp. 64-73. doi: 10.1016/j.tranpol.2013.04.009. 
- European Commission (2001) 'European transport policy for 2010: time to decide'. Available at: https://ec.europa.eu/transport/sites/transport/files/themes/strategies/doc/2001_white_pape r/lb_com_2001_0370_en.pdf (Accessed: 2 May 2019).

- European Commission (2011a) 'Cities of Tomorrow'. doi: 10.2776/41803.

- European Commission (2011b) 'Roadmap to a Single European Transport Area - Towards a competitive and resource efficient transport system'. Available at: https://eurlex.europa.eu/legal-content/EN/TXT/PDF/?uri=CELEX:52011DC0144\&from=EN (Accessed: 9 April 2019).

- European Commission (2017) 'Horizon 2020 Work Programme: Smart, green and integrated transport'. Available at:

http://ec.europa.eu/research/participants/data/ref/h2020/wp/2014_2015/main/h2020-

wp1415-transport_en.pdf (Accessed: 21 November 2017).

- European Environment Agency (2016), 'Towards clean and smart mobility Transport and environment in Europe' Accessed 05/05/2019. Available at:

https://www.eea.europa.eu/publications/signals-2016/download

- Fernandez-Anez, V., Velazquez, G., Perez-Prada, F., \& Monzón, A. (2018) 'Smart City Projects Assessment Matrix: Connecting Challenges and Actions in the Mediterranean Region', Journal of Urban Technology. Routledge, pp. 1-25. doi: 10.1080/10630732.2018.1498706.

- Fernández-Güell, J., Collado-Lara, M., Guzman, S. and Fernandez Anez, V. (2016) 'Incorporating a Systemic and Foresight Approach into Smart City Initiatives: The Case of Spanish Cities'. doi: 10.1080/10630732.2016.1164441.

- Fosgerau, M., Hjorth, K., Riff Brems, C. and Fukuda, D. (2008) 'Travel time variability Definition and valuation'. Available at: http://www.trafikdage.dk/td/papers/papers08/KatrineHjorth.pdf (Accessed: 27 June 2017).

- Giffinger, R., Fertner, C. and Kramar, H. (2007) 'Smart cities Ranking of European medium-sized cities'. Available at: www.srf.tuwien.ac.at (Accessed: 2 May 2019).

- Gimenez, D., Ribeiro, A., Gutierrez-Puebla, J. and Pais-Antunes, A. (2014) 'Charging-Stations for Electrical Vehicles: Analysis and Model to Identify the Most Convenient Locations'. In: de Sousa J., Rossi R. (eds) Computer-based Modelling and Optimization in Transportation. Advances in Intelligent Systems and Computing, vol 262. Springer, Cham https://doi.org/10.1007/978-3-31904630-3_8

- Glaeser, E. L. and Gottlieb, J. D. (2009) 'The Wealth of Cities: Agglomeration Economies and Spatial Equilibrium in the United States', Journal of Economic Literature, 47(4), pp. 983-1028. doi: 10.1257/jel.47.4.983.

- Golob, T. F. (2003) 'Structural Equation Modelling for Travel Behaviour Research', Published in Transportation Research Part B: Methodological, 37, pp. 1-25.

- Gomez, J., Papanikolaou, A. and Vassallo, J.M. 'Users' perceptions and willingness to pay in interurban toll roads: identifying differences across regions from a nationwide survey in Spain' Transportation (2017) 44: 449. https://doi.org/10.1007/s11116-015-9662-6 
- Goodwin, C. (1991) 'Privacy: Recognition of a Consumer Right', Journal of Public Policy \& Marketing, 10(1), pp. 149-166. doi: 10.1177/074391569101000111.

- de Groot, J. I. M. and Steg, L. (2009) 'Mean or green: which values can promote stable proenvironmental behavior?', Conservation Letters. John Wiley \& Sons, Ltd (10.1111), 2(2), pp. 6166. doi: 10.1111/j.1755-263X.2009.00048.x.

- Guagnano, G. A. (2001) 'Altruism and Market-Like Behavior: An Analysis of Willingness to Pay for Recycled Paper Products', Population and Environment. Kluwer Academic Publishers-Plenum Publishers, 22(4), pp. 425-438. doi: 10.1023/A:1006753823611.

- Gutierrez Puebla, J. (2013) 'Estructura económica de la ciudad de Madrid - Madrid y su entorno: estructura territorial, infraestructuras de transporte y relaciones funcionales' In Estructura económica de la ciudad de Madrid (pp. 57-86).

- Gutierrez Puebla, J. (2018) 'Big Data y nuevas geografías: la huella digital de las actividades humanas'. Documents d'anàlisi geogràfica, Vol. 64 Núm. 2, p. 195-217. DOI 10.5565/rev/dag.526

- Han, L. et al. (2017) 'The intention to adopt electric vehicles: Driven by functional and nonfunctional values', Transportation Research Part A: Policy and Practice. Pergamon, 103, pp. 185197. doi: 10.1016/J.TRA.2017.05.033.

- Helsper, E. (2009) 'The ageing internet: digital choice and exclusion among the elderly', Working with Older People, 13(4), pp. 28-33. doi: 10.1108/13663666200900068.

- Homem de Almeida Correia, G., de Abreu e Silva, J. and Viegas, J.M. (2013) 'Using latent attitudinal variables estimated through a structural equations model for understanding carpooling propensity, Transportation Planning and Technology', 36:6, 499-519, DOI: 10.1080/03081060.2013.830894

- Hong, W. and Thong, J. Y. L. (2013) 'INTERNET PRIVACY CONCERNS: AN INTEGRATED CONCEPTUALIZATION AND FOUR EMPIRICAL STUDIES', Forthcoming in MIS Quarterly, 37(1), pp. 275-298. Available at: http://ssrn.com/abstract=2229627 (Accessed: 23 January 2018).

- Hou, X. and Chen, X. (2013) 'Analysis of Urban Public Transit Information Requirements in China by Web-based Survey', Procedia - Social and Behavioral Sciences, 96, pp. 1522-1527. doi: 10.1016/j.sbspro.2013.08.173.

- Ibraeva, A. and Sousa, J. F. de (2014) 'Marketing of Public Transport and Public Transport Information Provision', Procedia - Social and Behavioral Sciences, 162, pp. 121-128. doi: 10.1016/j.sbspro.2014.12.192.

- INE (2017) 'Encuesta sobre Equipamiento y Uso de Tecnologías de Información y Comunicación en los Hogares., Notas de prensa'. Available at: http://www.ine.es/prensa/tich_2017.pdf (Accessed: 18 January 2018).

- International Telecommunications Union (2018) ICT Statistics. Available at: https://www.itu.int/en/ITU-D/Statistics/Pages/stat/default.aspx (Accessed 5 May 2019)

- J. Louviere, J. and Hensher, D. (1982) 'Design and Analysis of Simulated Choice or Allocation Experiments in Travel Choice Modelling', Transportation Research Record, 890, pp. 11-17. 
- Joireman, J. A. P. Lasane, Terell, Bennett, Jennifer, Richards, Diana, Solaimani, Salma (2001) 'Integrating social value orientation and the consideration of future consequences with in the extended norm activation model of proenvironmental behaviour', British Journal of Social Psychology. John Wiley \& Sons, Ltd (10.1111), 40(1), pp. 133-155. doi: 10.1348/014466601164731.

- Kaplan, S., Monteiro, M. M., Anderson, M., Nielsen, O. A., and Medeiros Dos Santos, E., (2017) 'The role of information systems in non-routine transit use of university students: Evidence from Brazil and Denmark', Transportation Research Part A: Policy and Practice, 95, pp. 34-48. doi: 10.1016/j.tra.2016.10.029.

- Kaplan, S., de Abreu e Silva, J. and Di Ciommo, F. (2014) 'The relationship between young people's transit use and their perceptions of equity concepts in transit service provision', Transport Policy, 36, pp. 79-87. doi: 10.1016/j.tranpol.2014.08.004.

- Kenyon, S. and Lyons, G. (2003) 'The value of integrated multimodal traveller information and its potential contribution to modal change', Transportation Research Part F: Traffic Psychology and Behaviour, 6(1), pp. 1-21. doi: 10.1016/S1369-8478(02)00035-9.

- Khattak, A.J., Yim, Y., and Prokopy, L.S. (2003) 'Willingness to pay for travel information'. Transp Res Part C 11: 137-159.

- Kormos, C., Gifford, R. and Brown, E. (2015) 'The Influence of Descriptive Social Norm Information on Sustainable Transportation Behavior', Environment and Behavior. SAGE PublicationsSage CA: Los Angeles, CA, 47(5), pp. 479-501. doi: 10.1177/0013916513520416.

- Kuhnimhof, T., Buehler, R. and Dargay, J. (2011) 'A New Generation', Transportation Research Record: Journal of the Transportation Research Board. SAGE PublicationsSage CA: Los Angeles, CA, 2230(1), pp. 58-67. doi: 10.3141/2230-07.

- Larose, R., Tsai, H. (2014). 'Completion rates and non-response error in online surveys: Comparing sweepstakes and pre-paid cash incentives in studies of online behavior'. Computers in Human Behavior. 34. 110-119. 10.1016/j.chb.2014.01.017.

- Lavieri, P., Dias, F., Ruiz-Juri, N., Kuhr, J., Bhat, C. (2017a) 'A MODEL OF RIDESOURCING DEMAND GENERATION AND DISTRIBUTION'. Available at:

http://www.caee.utexas.edu/prof/bhat/ABSTRACTS/Ridesourcing_paper.pdf (Accessed: 28 November 2017).

- Lavieri, P., Garikapati, V., Bhat, C., Pendyala, R., Astroza, S., Dias, F. (2017b) 'Modeling Individual Preferences for Ownership and Sharing of Autonomous Vehicle Technologies', Transportation Research Record: Journal of the Transportation Research Board, 2665(1), pp. 1-10. doi: 10.3141/2665-01.

- Leydesdorff, L. and Deakin, M. (2010) 'The Triple Helix Model and the Meta-Stabilization of Urban Technologies in Smart Cities'. Available at: http://arxiv.org/abs/1003.3344 (Accessed: 2 May 2019).

- Leykin, D., Lahad, Mooli, Cohen, Odeya, Goldberg, Avishay, Aharonson-Daniel, Limor (2013) 'Conjoint Community Resiliency Assessment Measure-28/10 Items (CCRAM28 and CCRAM10): A Self-report Tool for Assessing Community Resilience'. doi: 10.1007/s10464-013-9596-0. 
- Li, Z., Hensher, D. A. and Rose, J. M. (2010) 'Willingness to pay for travel time reliability in passenger transport: A review and some new empirical evidence', Transportation Research Part E: Logistics and Transportation Review, 46(3), pp. 384-403. doi: 10.1016/j.tre.2009.12.005.

- Likert, R. (1974) 'The method of constructing and attitude scale', Scaling: A sourcebook for behavioral scientists.

- Loehlin, J. C. and Beaujean, A. A. (no date) Latent variable models: an introduction to factor, path, and structural equation analysis. Available at:

https://books.google.es/books?hl=es\&lr=\&id=mCwIDwAAQBAJ\&oi=fnd\&pg=PP1\&dq=john+loe hlin+latent+variable+models\&ots=r9rXDSYop_\&sig=75gcCMXPhwXKyjigEJyGwKXfBbs\#v=onepa ge\&q=john loehlin latent variable models\&f=false (Accessed: 18 July 2017).

- Lombardi, P. Giordano, Silvia, Farouh, Hend, Yousef, Wael. (2012) 'Modelling the smart city performance', Innovation: The European Journal of Social Science Research. Taylor \& Francis Group, 25(2), pp. 137-149. doi: 10.1080/13511610.2012.660325.

- Lopez, Iria; Monzon, Andres (2018) 'Evaluating sustainability and innovation of mobility patterns in Spanish cities. Analysis by size and urban typology.' Sustainable Cities and Society, vol. 38. Págs: 684 - 696. ISSN: 2210-6707.

- Madrid City Council, (2011). 'Plan de calidad del aire de la ciudad de Madrid 2011-2015', Available at:

https://www.madrid.es/UnidadesDescentralizadas/Sostenibilidad/CalidadAire/Ficheros/PlanAi re\&CC_Eng.pdf. Accessed: 05/05/2019

- Madrid City Council, (2016). 'Protocolo para Episodios de Alta Contaminacion por NO2'.

- Martinussen, L. M. Sømhovd, Mikael, Møller, Mette, Siebler, Frank. (2015) ‘A Go/No-go approach to uncovering implicit attitudes towards safe and risky driving', Transportation Research Part F: Traffic Psychology and Behaviour. Pergamon, 30, pp. 74-83. doi: 10.1016/J.TRF.2015.02.005.

- McKelvey, R. D. and Zavoina, W. (1975) 'A statistical model for the analysis of ordinal level dependent variables', The Journal of Mathematical Sociology. Taylor \& Francis Group, 4(1), pp. 103-120. doi: 10.1080/0022250X.1975.9989847.

- Mehdizadeh Dastjerdi, A., Kaplan, S., de Abreu e Silva, J., Nielsen, O. A., \& Pereira, F. C. (2019). 'Factors driving the adoption of mobility-management travel app: a bayesian structural equation modelling analysis'. In Proceedings of the 98th Annual Meeting of the Transportation Research Board

- Mehdizadeh Dastjerdi, A., Kaplan, S., de Abreu e Silva, J., Nielsen, O. A., and Pereira, F. C. (2019). 'Participating in environmental loyalty program with a real-time multimodal travel app: User needs, environmental and privacy motivators.' Transportation Research Part D: Transport and Environment, 67, 223-243. doi:10.1016/j.trd.2018.11.013

- Milne, G. R. and Culnan, M. J. (2004) 'Strategies for reducing online privacy risks: Why consumers read (or don't read) online privacy notices', Journal of Interactive Marketing. John Wiley \& Sons, Ltd, 18(3), pp. 15-29. doi: 10.1002/dir.20009. 
- Molin, E. J. E. and Timmermans, H. J. P. (2006) 'Traveler expectations and willingness-to-pay for Web-enabled public transport information services', Transportation Research Part C: Emerging Technologies, 14(2), pp. 57-67. doi: 10.1016/j.trc.2006.05.003.

- Monzon, A. (2015) 'Smart Cities Concept and Challenges', Springer International Publishing Switzerland. SCITEPRESS, pp. 17-31. doi: 10.1007/978-3-642-33489-4_4.

- Monzon, A. (2016) Observatorio de la Movilidad Metropolitana. 'Informe 2014'.

- Monzon, A., Hernandez, S., Munckasy, A., Garcia, A., Velazquez, G., 2017. 'Improving mobility surveys quality and rate of responses at low cost by combining intercept and web questionnaire methods', 11th International Conference on Transport Survey Methods, Esterel, Canada.

- Monzon, A. and Bayart, C. (2018) 'Workshop Synthesis: Web-based surveys, new insight to address main challenges', Transportation Research Procedia. Elsevier, 32, pp. 167-173. doi: 10.1016/J.TRPRO.2018.10.030.

- Munckasy, Andras, (2017), 'User profiles and adoption attributes of innovative bike-sharing systems: the case of BiciMAD (Madrid)'. Doctoral thesis. Universidad Politécnica de Madrid

- Munkacsy, Andras; Monzon, Andres; (2017a) 'Impacts of Smart Configuration in PedelecSharing: Evidence from a Panel Survey in Madrid.' Journal of Advanced Transportation, vol. 2017. Pp: 1-11. ISSN: 0197-6729

- Munkácsy, A. and Monzón, A. (2017b) 'Potential User Profiles of Innovative Bike-Sharing Systems: The Case of BiciMAD (Madrid, Spain)', Asian Transport Studies, 4, pp. 621-638. doi: 10.11175/eastsats.4.621.

- Munkacsy, András; Monzón, Andrés (2018) 'Diffusion of bike sharing as an innovation vector in the city: the case of BiciMAD (Madrid)'. Journal of urban technology, vol. 25, no. 3. Pp: 1-26.

- Navarro, K. F., Gay, V., Golliard, L., Johnston, B., Leijdekkers, P., Vaughan, E., Williams, M.-A. (2013) 'SocialCycle: What can a mobile app do to encourage cycling?', Proceedings - Conference on Local Computer Networks, LCN, pp. 24-30. doi: 10.1109/LCNW.2013.6758494.

- Neirotti, P., De Marco, A., Cagliano, A. C., Mangano, G., \& Scorrano, F. (2014) 'Current trends in Smart City initiatives: Some stylised facts', Cities, 38, pp. 25-36. doi: 10.1016/j.cities.2013.12.010.

- Nijland, H., Van Meerkerk, J. and Hoen, A. (2015) 'Impact of Car Sharing on mobility and co 2 emissions pbl note'. Available at:

https://www.pbl.nl/sites/default/files/cms/publicaties/PBL_2015_Note Impact of car sharing_1842.pdf (Accessed: 2 May 2019).

- Nordlund, A. M. and Garvill, J. (2003) 'Effects of values, problem awareness, and personal norm on willingness to reduce personal car use', Journal of Environmental Psychology. Academic Press, 23(4), pp. 339-347. doi: 10.1016/\$0272-4944(03)00037-9.

- OECD. (2006) Territorial Reviews 'Competitive Cities in the Global Economy'. Available at: https://www.oecd.org/cfe/regional-policy/37839981.pdf (Accessed: 5 January 2019). 
- Pendleton, L. H. and Shonkwiler, J. S. (2001) 'Valuing Bundled Attributes: A Latent Characteristics Approach', Land Economics. University of Wisconsin Press, 77(1), pp. 118-129. doi: $10.2307 / 3146984$.

- Phelps, J., Nowak, G. and Ferrell, E. (2000) 'Privacy Concerns and Consumer Willingness to Provide Personal Information', Journal of Public Policy \& Marketing, 19(1), pp. 27-41. doi: 10.1509/jppm.19.1.27.16941.

- Prettenthaler, F. E. and Steininger, K. W. (1999) 'From ownership to service use lifestyle: the potential of car sharing', Ecological Economics. Elsevier, 28(3), pp. 443-453. doi: 10.1016/S09218009(98)00109-8.

- Pugesek, B. H., Tomer, A. and Eye, A. von. (2003) 'Structural equation modeling: applications in ecological and evolutionary biology'. Cambridge University Press.

- Rondinella, Gianni (2015). 'Considering cycling for commuting: the role of mode familiarity : an exploration on the (circular) relation between cycling behaviours and attitudes toward cycling in Vitoria-Gasteiz, Spain'. Doctoral Thesis. Universidad Politécnica de Madrid.

- PWC Public Sector Research Centre (2007) 'The road ahead for public service delivery'. Available at: www.psrc-pwc.com (Accessed: 2 May 2019).

- S Goldberger, A. (1972) 'Structural Equation Methods in Social Sciences', Econometrica, 40, pp. 979-1001. doi: 10.2307/1913851.

- Schultz, P. W., Gouveia, V. V., Cameron, L. D., Tankha, G., Schmuck, P., \& Franěk, M. (2005) 'Values and their Relationship to Environmental Concern and Conservation Behavior', Journal of Cross-Cultural Psychology. Sage PublicationsSage CA: Thousand Oaks, CA, 36(4), pp. 457-475. doi: $10.1177 / 0022022105275962$.

- Schwartz, S. H. (1977) 'Normative Influences on Altruism', Advances in Experimental Social Psychology. Academic Press, 10, pp. 221-279. doi: 10.1016/S0065-2601(08)60358-5.

- Sheng, Hong \& Nah, Fiona \& Siau, Keng. (2008) 'An Experimental Study on Ubiquitous Commerce Adoption: Impact of Personalization and Privacy Concerns', Journal of the Association for Information Systems, 9(6), pp. 344-376. Available at: https://search.proquest.com/docview/198899661/fulltextPDF/80F001AB234F4A83PQ/1?acco untid=7118 (Accessed: 23 January 2018).

- Skelley, T., Namoun, A. and Mehandjiev, N. (2013) 'The impact of a mobile information system on changing travel behaviour and improving travel experience', Lecture Notes in Computer Science (including subseries Lecture Notes in Artificial Intelligence and Lecture Notes in Bioinformatics), 8093 LNCS, pp. 233-247. doi: 10.1007/978-3-642-40276-0_18.

- Tellis, W. M. (1997) 'Introduction to Case Study', The Qualitative Report. Nova Southeastern University, School of Social and Systematic Studies, 3(2).

- Temme, D., Paulssen, M. and Dannewald, T. (2008) 'Incorporating Latent Variables into Discrete Choice Models - A Simultaneous Estimation Approach Using SEM Software', 1(2), pp. 220-237. Available at: https://www.statmodel.com/download/Temme.pdf (Accessed: 25 January 2018). 
- Thompson, B. (2007) 'Factor Analysis', in The Blackwell Encyclopedia of Sociology. Oxford, UK: John Wiley \& Sons, Ltd. doi: 10.1002/9781405165518.wbeosf003.

- Toledo, T. and Beinhaker, R. (2006) 'Evaluation of the Potential Benefits of Advanced Traveler Information Systems', Journal of Intelligent Transportation Systems, 10(4), pp. 173-183. doi: $10.1080 / 15472450600981033$.

- Trompet, M., Parasram, R. and Anderson, R. J. (2014) 'Benchmarking Disaggregate Customer Satisfaction Scores of Bus Operators in Different Cities and Countries', Transportation Research Record: Journal of the Transportation Research Board, 2351(1), pp. 14-22. doi: 10.3141/235102 .

- Udo, G. J. (2018) 'Information Management \&amp; Computer Security Privacy and security concerns as major barriers for e-commerce: a survey study', Computer Security Computer Security International Journal of Retail \&amp Distribution Management Iss. PT, 9(13), pp. 165174. Available at: https://doi.org/10.1108/EUM0000000005808 (Accessed: 23 January 2018).

- UITP (2014) Imperatives to shape extended mobility ecosystems of tomorrow The Future of Urban Mobility 2.0. Available at: https://www.uitp.org/sites/default/files/members/140124 Arthur D. Little \%26 UITP_Future of Urban Mobility 2 0_Full study.pdf (Accessed: 9 April 2019).

- Ullah I., Liu K., Vanduy T. (2019) 'Examining Travelers' Acceptance towards Car Sharing Systems-Peshawar City, Pakistan,' Sustainability, MDPI, Open Access Journal, vol. 11(3), pages 1-16, February.

- United Nations (2019) 'UN Open Data', Available at: http://data.un.org/, (Accessed: 5 may 2019)

- UN-Habitat III (2017) 'New Urban Agenda', in Conference on Housing and Sustainable Urban Development (Habitat III). doi: ISBN: 978-92-1-132757-1.

- Velazquez, G., Kaplan, S. and Monzon, A. (2018) 'Ex - ante and ex - post evaluation of a new transit information app : modelling use intentions and actual use', Transportation Research Record: Journal of the Transportation Research Board.

https://doi.org/10.1177/0361198118792753

- Vredin Johansson, M., Heldt, T. and Johansson, P. (2006) 'The effects of attitudes and personality traits on mode choice', Transportation Research Part A: Policy and Practice. Pergamon, 40(6), pp. 507-525. doi: 10.1016/J.TRA.2005.09.001.

- Van der Waard, J., Jorritsma, P. and Immers, B. (2013) 'New Drivers in Mobility; What Moves the Dutch in 2012?', Transport Reviews, 33(3), pp. 343-359. doi: 10.1080/01441647.2013.801046.

- Waygood, E. O. D., and Susilo, Y. O. (2015). Walking to school in Scotland: Do perceptions of neighbourhood quality matter? IATSS Research, 38(2), 125-129.

doi:10.1016/j.iatssr.2014.12.002

- Wesley Schultz, P. (2001) 'The structure of environmental concern: concern for self, other people, and the biosphere', Journal of Environmental Psychology. Academic Press, 21(4), pp. 327-339. doi: 10.1006/JEVP.2001.0227. 
- White, H. (1980) 'A Heteroskedasticity-Consistent Covariance Matrix Estimator and a Direct Test for Heteroskedasticity', Econometrica. The Econometric Society, 48(4), p. 817.

doi: $10.2307 / 1912934$.

- Williams, D. G. and Babbie, E. R. (2006) 'The Practice of Social Research.', Contemporary Sociology. 12th ed. Belmont CA ;London: Wadsworth Cengage, 5(2), p. 163. doi: $10.2307 / 2062956$.

- World Bank (2019) World Bank Open Data. Available at: https://data.worldbank.org/ (Accessed: 5 May 2019)

- World Economic Forum (2018), 'Global Agenda 2018'. Available at: https://www.weforum.org/agenda/2018/03/internet-minute-whatsapp-facebook-emails. (Accessed: 2 may 2019)

- World Economic Forum (2019), 'Global Risks Report 2019'. (Accessed: 05 May 2019) Available at: http://www3.weforum.org/docs/WEF_Global_Risks_Report_2019.pdf.

- Xu, H. and Gupta, S. (2009) 'The effects of privacy concerns and personal innovativeness on potential and experienced customers' adoption of location-based services', Electronic Markets. Springer-Verlag, 19(2-3), pp. 137-149. doi: 10.1007/s12525-009-0012-4.

- Yuan, K.-H. and Bentler, P. M. (2000) 'Inferences on Correlation Coefficients in Some Classes of Nonnormal Distributions', Journal of Multivariate Analysis, 72(2), pp. 230-248. doi: 10.1006/jmva.1999.1858.

- Zainal, Z. (2007) 'Case study as a research method', Jurnal Kemanusiaan bil, 9.

- Zhang, D., Schmöcker, J.-D., Fujii, S., and Yang, X. (2016) 'Social norms and public transport usage: empirical study from Shanghai', Transportation. Springer US, 43(5), pp. 869-888. doi: 10.1007/s11116-015-9625-y.

- Zheng, X.-P. (2007) 'Measurement of Optimal City Sizes in Japan: A Surplus Function Approach', Urban Studies. Sage PublicationsSage UK: London, England, 44(5-6), pp. 939-951. doi: 10.1080/00420980701318961.

- Zografos, K. G., Androutsopoulos, K. N. and Apospori, E. (2012) 'User Acceptance and Willingness to Pay for the Use of Multimodal Trip Planning Systems', Procedia -Social and Behavioral Sciences Transport Research Arena- Europe, 48, pp. 2405-2414.

doi: 10.1016/j.sbspro.2012.06.1211. 
Behavioral factors underlying the adoption of smart mobility solutions

(This page has been intentionally left blank) 
PART V - ANNEXES 
Behavioral factors underlying the adoption of smart mobility solutions

(This page has been intentionally left blank) 


\section{ANNEX I - SURVEYS}

I.a) BICIMAD SURVEY 9

${ }^{9}$ In order to save on space, only the third out of the three waves carried out for BiciMAD is here reproduced. It is the more complete of the three as it included new items on top of those included in the two initial ones. 
Behavioral factors underlying the adoption of smart mobility solutions

(This page has been intentionally left blank) 


\section{BIENVENIDO}

TRANSyT (Centro de Investigación del Transporte de la Universidad Politécnica de Madrid) está realizando una encuesta para estudiar la movilidad en Madrid y la opinión de los ciudadanos acerca del servicio público de bicicletas, BiciMAD.

\section{¡Su opinión es muy importante para nosotros!}

\section{Participará en el SORTEO DE DOS VALES REGALO POR VALOR DE $50 €$ DE UNA}

TIENDA DE ARTÍCULOS CICLISTAS entre las personas que rellenen la encuesta.

Al pulsar "Siguiente" accederá al cuestionario, que dura 10-12 minutos. El plazo para realizar la encuesta es de una semana desde la fecha en la que se le entregó la tarjeta.

Si tiene alguna duda, puede ponerse en contacto con nosotros en la siguiente dirección de correo electrónico: bicimad@caminos.upm.es

La encuesta es anónima y de carácter voluntario, respetándose todas las normas en materia de protección de datos personales.

\section{¡Muchas gracias por su colaboración!}




\section{NÚMERO DE ACCESO}

Por favor, introduzca el NÚMERO DE ACCESO* al cuestionario (código que aparece en la tarjeta que le fue entregada):

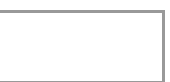

*EL CÓDIGO ES PERSONAL Y NO DEBE SER INTRODUCIDO POR MÁS DE UNA PERSONA(NO DA DERECHO A PREMIOS A MÁS DE UNA PERSONA).

*LE RECORDAMOS QUE TIENE QUE CONSERVAR LA TARJETAA LO LARGO DEL DESARROLLO DE LA ENCUESTA (SIN ELLA NO PODRÁ RECOGER EL PREMIO). 


\section{USTED Y LA BICICLETA}

En la primera sección del cuestionario encontrará preguntas acerca de su relación con la bicicleta como modo de transporte urbano. Estas preguntas se refieren al USO DE LA BICICLETA EN GENERAL y no específicamente a los desplazamientos realizados con una bicicleta pública (BiciMAD).

A1. ¿Cuántas bicicletas tiene a su disposición en su hogar (para uso propio o compartido)?
Ninguna
1
2
3 o más 


\section{USTED Y LA BICICLETA}

A11. ¿Qué tipo de bicicleta es la que tiene a su disposición? (Puede marcar más de una.)

\section{Plegable}

\section{Urbana}

Montaña

Bicicleta de carretera

Bicicleta de cicloturismo

$\square$ Eléctrica

$\square$ Otra (especifique)

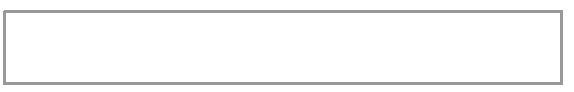

A12. ¿Con qué frecuencia usa su bicicleta?

\begin{tabular}{|c|c|c|c|c|c|c|}
\hline & A diario & $\begin{array}{c}\text { Varias } \\
\text { veces por } \\
\text { semana }\end{array}$ & $\begin{array}{l}\text { Una vez a } \\
\text { la semana }\end{array}$ & $\begin{array}{l}\text { Una vez o } \\
\text { varias } \\
\text { veces al } \\
\text { mes }\end{array}$ & $\begin{array}{l}\text { Alguna } \\
\text { vez }\end{array}$ & Nunca \\
\hline \multicolumn{7}{|l|}{$\begin{array}{l}\text { Desplazamiento al } \\
\text { trabajo/centro de estudios }\end{array}$} \\
\hline \multicolumn{7}{|l|}{ Ir de compras } \\
\hline Hacer pequeños recados & O & 0 & 0 & & 0 & O \\
\hline \multicolumn{7}{|l|}{ Visitar amigos o familiares } \\
\hline $\begin{array}{l}\text { Por ocio (por ejemplo, dar un } \\
\text { paseo en bicicleta) }\end{array}$ & 0 & & & 0 & 0 & O \\
\hline \multicolumn{7}{|l|}{ Salir de noche } \\
\hline Otros viajes & 0 & 0 & 0 & 0 & 0 & 0 \\
\hline
\end{tabular}




\section{USTED YLA BICICLETA}

A13. ¿Qué experiencia tiene montando en bicicleta?
Muy poca
Poca
Media
Bastante
Mucha

A14. ¿Con qué regularidad hace ejercicio?

Nunca

Alguna vez

Una o varias veces al mes

Una vez a la semana

Varias veces por semana

A diario 
A2. Valore la IMPORTANCIA de los factores en el USO DE LA BICICLETA EN GENERAL para usted (no específicamente en Madrid).

Emplee, por favor, una escala de 1 a 5 , donde 1 significa nada importante y 5 muy importante.

\begin{tabular}{|c|c|c|c|c|c|}
\hline & $\begin{array}{l}1 \text { - Nada } \\
\text { importante }\end{array}$ & 2 & 3 & 4 & $\begin{array}{l}5 \text { - Muy } \\
\text { importante }\end{array}$ \\
\hline Clima & 0 & 0 & O & 0 & 0 \\
\hline Orografía & & O & & & \\
\hline Peligro de accidentes & O & 0 & O & 0 & 0 \\
\hline
\end{tabular}

Precio: más barata que otros medios de transporte

Es buena para el medioambiente

Su flexibilidad y poder aparcar en cualquier parte

Es divertida y va con mi estilo de vida 
A3. Valore la IMPORTANCIA de las siguientes infraestructuras para el USO DE LA BICICLETA EN GENERAL para usted (no específicamente en Madrid).

Emplee, por favor, una escala de 1 a 5, donde 1 significa nada importante y 5 muy importante.

$$
\begin{gathered}
1 \text { - Nada } \\
\text { importante }
\end{gathered}
$$$$
5 \text { - Muy }
$$

$2 \quad 3$

4 importante

Carriles bici separados del tráfico motorizado y peatonal

Carriles compartidos con el tráfico motorizado (con límite de velocidad de $30 \mathrm{~km} / \mathrm{h})$

Aparcamientos seguros en la vía pública

Acceso y aparcamiento en los centros comerciales, culturales y otros establecimientos públicos

Aparcamientos y duchas en el lugar de trabajo/estudio

Acceso con bicicleta al transporte público 
A4. ¿Cuál es su nivel de SATISFACCIÓN (cómo lo valora) con la infraestructura y el servicio relacionado con la movilidad ciclista EN MADRID?

Emplee, por favor, una escala de 1 a 5, donde 1 significa que está totalmente insatisfecho y 5 que está totalmente satisfecho.

$1-$ $5-$

Totalmente Totalmente insatisfecho 3 satisfecho

Carriles bici separados del tráfico motorizado y peatonal

Carriles compartidos con el tráfico motorizado (con límite de velocidad de $30 \mathrm{~km} / \mathrm{h}$ )

Aparcamientos seguros en la vía pública (destinados a bicicletas normales, NO BiciMAD)

Acceso y aparcamiento en los centros comerciales, culturales y otros establecimientos públicos (No BiciMAD)

Aparcamientos y duchas en el lugar de trabajo/estudio

Acceso con bicicleta al transporte público 
A5. ¿Cuál es su modo de transporte habitual en los siguientes viajes?

En caso de varios modos de transporte, marque el que considera el modo más relevante.

andar público coche moto bicicleta
Desplazamiento al
trabajo/centro de estudios
Ir de compras
Hacer pequeños recados
Visitar amigos o familiares
Por ocio (por ejemplo, dar un
paseo en bicicleta)
Salir de noche
Otros viajes




\section{USTED Y BICIMAD}

En esta sección encontrará preguntas acerca de su opinión sobre BiciMAD, el servicio público de bicicleta eléctrica de Madrid.

\section{B1. ¿Es Usted usuario de BiciMAD?}

Soy usuario abonado de BiciMAD

Soy usuario ocasional (no abonado) de BiciMAD

\section{No he probado BiciMAD nunca}




\section{USTED Y BICIMAD}

B131. ¿Por qué no ha probado BiciMAD? (Puede marcar varias respuestas.)

Uso mi propia bicicleta

Las estaciones no coinciden con mis trayectos habituales/ocasionales

La cuota anual me parece cara

La tarifa por cada uso me parece cara

No hay carril bici en mis trayectos habituales/ocasionales

Los carriles bici segregados y/o no segregados que existen en mis trayectos son inadecuados para mí

El tráfico motorizado es peligroso y/o demasiado rápido

Me desplazo más rápido en otros modos de transporte

La bicicleta de BiciMAD me parece difícil de manejar

La bicicleta de BiciMAD me parece incómoda

Otro (especifique) 
B132. ¿Utilizaría las bicicletas de BiciMAD, si...?

Por favor, emplee una escala de 1 a 5 , donde 1 significa que está totalmente en desacuerdo y 5 que está totalmente de acuerdo.

$1-$

Totalmente

en Totalmente

desacuerdo 2

3

4 de acuerdo

...la cuota anual fuera más barata

...la primera media hora de uso para inscritos fuera gratuita

...estuviera disponible en otras zonas de la ciudad

...hubiera más carriles bici en el centro

...los carriles bici segregados y no segregados le dieran más confianza, fueran más seguros, etc.

...la velocidad máxima de coches se redujera a $30 \mathrm{~km} / \mathrm{h}$ en el centro

...las bicicletas de BiciMAD fueran más

sencillas de usar

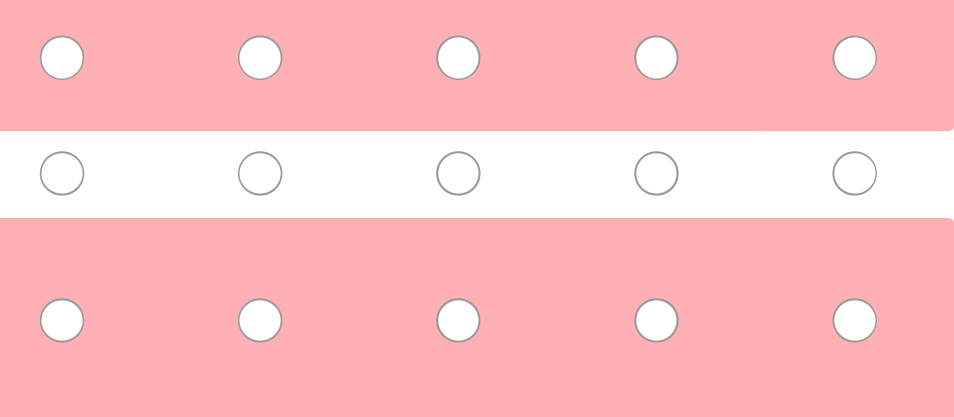




\section{USTED Y BICIMAD}

B121. ¿Antes de usar una bicicleta de BiciMAD, había probado otro sistema de bicicletas públicas?

\section{Sí}

No

B122. ¿Cuándo fue la primera vez que usó una bicicleta de BiciMAD?
Año
Mes

Año y

mes
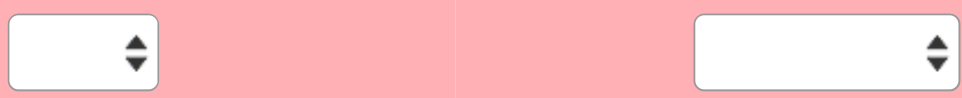

B123. ¿Por qué utiliza BiciMAD? (Puede marcar varios.)

Porque me parece más rápida que otros modos de transporte

Porque me parece más económica que otros modos de transporte

Porque me parece más ecológica que otros modos de transporte

Para hacer deporte

Porque me lo paso bien yendo en bici

Porque se puede aparcar fácilmente en el centro

Otro (especifique)

B124. ¿Con qué tipo de tarjeta utiliza el servicio como usuario ocasional? Puede marcar varios.

De 1 día

De 3 días

De 5 días

Con el abono de un amigo o familiar 
B125. ¿Estuvo abonado anteriormente a BiciMAD?

Sí

No 


\section{USTED Y BICIMAD}

B126. ¿Por qué no utiliza BiciMAD más veces? (Puede marcar varios.)

Generalmente uso mi propia bicicleta

Las estaciones no coinciden con mis trayectos habituales

Dificultades de encontrar una bicicleta libre (o un espacio para dejarla) en mis trayectos habituales

La cuota anual me parece cara

La tarifa por cada uso me parece caro

No hay carril bici en mis trayectos habituales

Los carriles bici segregados y/o no segregados que existen en mis trayectos son inadecuados para mí

El tráfico motorizado es peligroso y/o demasiado rápido

Me desplazo más rápido en otros modos de transporte

Las bicicletas son difíciles da manejar

Las bicicletas son incómodas

Otro (especifique)

B127. ¿Se plantea inscribirse como abonado en el próximo año?

Sí

No 


\section{USTED Y BICIMAD}

B111. ¿Desde cuándo está abonado al sistema BiciMAD?

Año

Mes

Inicio $\rightarrow$

B112. ¿Antes de usar una bicicleta de BiciMAD, había probado algún otro sistema de bicicletas públicas?

\section{Sí \\ No}

B113. ¿Probó BiciMAD antes de inscribirse como abonado anual? (Por ej. como usuario ocasional, con la tarjeta de un amigo, etc.)

\section{Sí \\ No}

B114. ¿Se plantea renovar su abono para próximo(s) año(s)?

\section{Sí}

\section{No}




\section{USTED Y BICIMAD}

B115. ¿Por qué utiliza BiciMAD? (Puede marcar varios.)

Porque me parece más rápida que otros modos de transporte

Porque me parece más económica que otros modos de transporte

Porque me parece más ecológica que otros modos de transporte

Para hacer deporte

Porque me lo paso bien yendo en bici

$\square$ Porque se puede aparcar fácilmente en el centro

$\square$ Otro (especifique) 


\section{USTED Y BICIMAD}

B2. ¿Si no estuviese BiciMAD, en qué medio de transporte realizaría el viaje que actualmente hace en bicicleta pública (el viaje que realiza más veces con BiciMAD)?

\section{No haría esta ruta}

Andando

Metro

Autobús

Coche

Moto

\section{Bicicleta}

Otro (especifique) 


\section{USTED Y BICIMAD}

B31. ¿Con qué frecuencia y qué motivo usa BiciMAD?

\begin{tabular}{|c|c|c|c|c|c|c|}
\hline & A diario & $\begin{array}{l}\text { Algunas } \\
\text { veces por } \\
\text { semana }\end{array}$ & $\begin{array}{l}\text { Una vez a } \\
\text { la semana }\end{array}$ & $\begin{array}{l}\text { Una vez o } \\
\text { algunas } \\
\text { veces al } \\
\text { mes }\end{array}$ & $\begin{array}{l}\text { Alguna } \\
\text { vez }\end{array}$ & Nunca \\
\hline \multicolumn{7}{|l|}{$\begin{array}{l}\text { Desplazamiento al } \\
\text { trabajo/centro de estudios }\end{array}$} \\
\hline \multicolumn{7}{|l|}{ Ir de compras } \\
\hline Hacer pequeños recados & $\cap$ & O & O & & O & O \\
\hline \multicolumn{7}{|l|}{ Visitar a amigos o familiares } \\
\hline $\begin{array}{l}\text { Por ocio (por ejemplo, dar un } \\
\text { paseo en bicicleta) }\end{array}$ & & & & & & \\
\hline \multicolumn{7}{|l|}{ Salir de noche } \\
\hline Otros viajes & 0 & 0 & 0 & 0 & 0 & 0 \\
\hline
\end{tabular}


B32. ¿Cuál es la duración máxima del trayecto que está dispuesto a recorrer con BiciMAD según el motivo del viaje?

\section{Duración máxima del trayecto}

\section{Desplazamiento al \\ trabajo/centro de \\ estudios}

Ir de compras

Hacer pequeños

recados

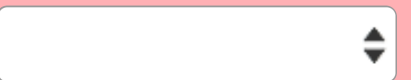

$\checkmark$

Visitar a amigos o

familiares

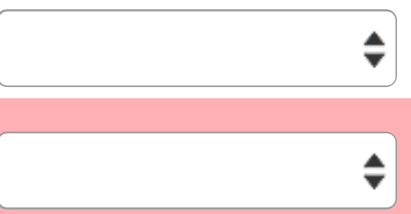

Por ocio (por

ejemplo, dar un

$\checkmark$

paseo en bicicleta)

Salir de noche

Otros viajes

B33. ¿A cuántos minutos caminando de su domicilio se encuentra la estación de BiciMAD más cercana? 
B4. ¿En comparación con su situación antes de usar BiciMAD, cuáles son sus hábitos de viaje actuales?

Responda, por favor, si actualmente viaja más o menos que antes de usar BiciMAD.

Mucho

$\begin{array}{ccccc}\text { menos que } & & \text { No hay } & & \text { Mucho más } \\ \text { antes } & \text { Menos } & \text { cambio } & \text { Más } & \text { que antes }\end{array}$

Viajes en transporte público

Viajes en coche

Viajes en moto

Viajes en bicicleta (propia)

Viajes andando

Número total de viajes

Duración total de sus desplazamientos

Distancia total de sus viajes 
B51. ¿Hasta qué punto son IMPORTANTES para usted en el USO DE LA BICICLETA PÚBLICA EN GENERAL los siguientes atributos?

Emplee, por favor, una escala de 1 a 5 , donde 1 significa nada importante y 5 muy importante.

\begin{tabular}{|c|c|c|c|c|c|}
\hline & $\begin{array}{l}1 \text { - Nada } \\
\text { importante }\end{array}$ & 2 & 3 & 4 & $\begin{array}{c}5 \text { - } \\
\text { Muy importante }\end{array}$ \\
\hline Diseño de la bicicleta & O & O & O & O & 0 \\
\hline Facilidad de uso & & & & & \\
\hline Comodidad & O & O & O & 0 & O \\
\hline Asistencia al pedaleo & 0 & & O & & O \\
\hline Mantenimiento de las bicicletas & 0 & O & 0 & O & O \\
\hline
\end{tabular}

Extensión de la red actual de estaciones

Distancia entre estaciones

Funcionamiento del tótem

Funcionamiento de los anclajes

Disponibilidad para aparcar la bicicleta

Disponibilidad para coger una bicicleta

Cuota anual

Tarifa para inscritos

Tarifa para usuarios ocasionales

Descuentos

Proceso de pago

Consulta del saldo

Aplicación móvil

Atención telefónica al usuario 
B52. ¿Cuál es su nivel de SATISFACCIÓN (cómo lo valora) con cada una de las siguientes características de BiciMAD?

Por favor, emplee una escala de 1 a 5, donde 1 significa que está totalmente insatisfecho con la característica y 5 que está muy satisfecho.

$1-$

Totalmente Totalmente insatisfecho 3 4 satisfecho

Diseño de la bicicleta

Facilidad de uso

Comodidad

Asistencia al pedaleo

Mantenimiento de las bicicletas

Extensión de la red actual de estaciones

Distancia entre estaciones

Funcionamiento del tótem

Funcionamiento de los anclajes

Disponibilidad para aparcar la bicicleta

Disponibilidad de bicicletas

Cuota anual (25€ para residentes, $15 €$ para titulares del Abono Transportes)

Tarifa para inscritos $(0,5 €$ la primera media hora, $0,6 €$ las siguientes fracciones de $30 \mathrm{~min}$.)

Tarifa para usuarios ocasionales ( $2 €$ la primera hora, $4 €$ las siguientes fracciones de $60 \mathrm{~min}$.) 


\begin{tabular}{|c|c|c|c|c|c|}
\hline & $\begin{array}{c}1 \text { - } \\
\text { Totalmente } \\
\text { insatisfecho }\end{array}$ & 2 & 3 & 4 & $\begin{array}{c}5 \text { - } \\
\text { Totalmente } \\
\text { satisfecho }\end{array}$ \\
\hline \multicolumn{6}{|c|}{$\begin{array}{l}\text { Descuentos }(0,1 € \text { por coger la bicicleta } \\
\text { de una estación saturada y } 0,1 € \text { por } \\
\text { reserva de anclaje o dejar la bicicleta } \\
\text { en una estación con baja ocupación })\end{array}$} \\
\hline \multicolumn{6}{|l|}{ Proceso de pago } \\
\hline Consulta del saldo & O & & O & & 0 \\
\hline \multicolumn{6}{|l|}{ Aplicación móvil } \\
\hline Atención telefónica al usuario & 0 & O & O & O & O \\
\hline
\end{tabular}

B53. ¿Cuál es su nivel de SATISFACCIÓN GENERAL (cómo lo valora) con el servicio de bicicleta pública que presta BiciMAD?

Por favor, emplee una escala de 1 a 5, donde 1 significa que está totalmente insatisfecho con la característica y 5 que está muy satisfecho.

1 - Totalmente insatisfecho

Satisfacción

general con

BiciMAD
5 - Totalmente satisfecho 
B6. La siguiente sección contiene algunas afirmaciones acerca de BiciMAD. Por favor, indique su opinión.

Por favor, emplee una escala de 1 a 5, donde 1 significa que está totalmente en desacuerdo con la afirmación y 5 que está totalmente de acuerdo.

$1-$

Totalmente en desacuerdo
5

- Totalmente de acuerdo

Probar una bicicleta de BiciMAD me ayudó a tomar la decisión de usar (o no usar) el servicio

Tengo experiencia en ir en bicicleta (por ej. mi propia bici) por el centro de Madrid

Antes de usar BiciMAD ya había ido alguna vez al centro de Madrid en mi propia bicicleta

Usando la bici pública me siento más responsable en lo medioambiental y social

BiciMAD es más ecológico que otros modos de transporte

BiciMAD es más económico que otros modos de transporte

Con BiciMAD llego a mi destino más rápido que antes

BiciMAD, para mí, es una forma de moverme y practicar deporte a la vez

La red de BiciMAD corresponde a mis trayectos habituales $\mathrm{y} / \mathrm{u}$ ocasionales

Usar BiciMAD va con mi estilo de vida

La bicicleta pública es una de las soluciones para calmar el tráfico en el centro de Madrid 
1 -

5

Totalmente en

desacuerdo

2

- Totalmente de acuerdo

Los descuentos aplicados (reservar anclaje, retirar una bicicleta de una estación saturada, etc.) racionalizan el uso del sistema BiciMAD

Encuentro fácilmente una bicicleta disponible o un anclaje para aparcarla

Retirar y aparcar la bici en el anclaje de BiciMAD es sencillo para mí

Las bicicletas de BiciMAD son cómodas para mí (ajustar altura del sillín, peso de la bici, etc.)

En una bicicleta de BiciMAD puedo subir las cuestas de Madrid tranquilamente

Las bicicletas de BiciMAD son fáciles de manejar

Operar en la pantalla del tótem de las estaciones de BiciMAD es sencillo

Me resulta fácil llevar el control de mi saldo disponible en BiciMAD

La gente se interesa al verme usar BiciMAD

Otros usuarios parecen estar contentos al usar BiciMAD

BiciMAD fomenta el uso de la bicicleta en el centro de Madrid

Recomiendo BiciMAD a aquellos que quieran moverse por Madrid 
B133. ¿Hasta qué punto son IMPORTANTES para usted en el USO DE LA BICICLETA PÚBLICA EN GENERAL los siguientes atributos?

Emplee, por favor, una escala de 1 a 5, donde 1 significa nada importante y 5 muy importante.

\begin{tabular}{|c|c|c|c|c|c|}
\hline & $\begin{array}{l}1 \text { - Nada } \\
\text { importante }\end{array}$ & 2 & 3 & 4 & $\begin{array}{c}5- \\
\text { Muy importante }\end{array}$ \\
\hline Diseño de la bicicleta & O & O & O & 0 & 0 \\
\hline Facilidad de uso & & & & & \\
\hline Comodidad & O & O & O & 7 & O \\
\hline Asistencia al pedaleo & O & O & O & & O \\
\hline Mantenimiento de las bicicletas & 0 & 0 & 0 & O & 0 \\
\hline
\end{tabular}

Extensión de la red actual de estaciones

Distancia entre estaciones

Funcionamiento del tótem

Funcionamiento de los anclajes

Disponibilidad para aparcar la bicicleta

Disponibilidad para coger una bicicleta

Cuota anual

Tarifa para inscritos

Tarifa para usuarios ocasionales

Descuentos

Proceso de pago

Consulta del saldo

Aplicación móvil

Atención telefónica al usuario 


\section{USTED Y BICIMAD}

B134. ¿Cuál es su nivel de SATISFACCIÓN (cómo lo valora) con cada una de las siguientes características de BiciMAD?

Por favor, emplee una escala de 1 a 5, donde 1 significa que está totalmente insatisfecho con la característica y 5 que está muy satisfecho.

$1-$ $5-$

Totalmente Totalmente insatisfecho 3 satisfecho

Extensión de la red actual de estaciones

Distancia entre estaciones

Cuota anual (25€ para residentes, $15 €$ para titulares del Abono Transportes)

Tarifa para inscritos $(0,5 €$ la primera media hora, $0,6 €$ las siguientes fracciones de $30 \mathrm{~min}$.)

Tarifa para usuarios ocasionales ( $2 €$ la primera hora, $4 €$ las siguientes fracciones de $60 \mathrm{~min}$.)

Descuentos $(0,1 €$ por coger la bicicleta de una estación saturada y $0,1 €$ por reserva de anclaje o dejar la bicicleta en una estación con baja ocupación )

B135. ¿Cuál es su nivel de SATISFACCIÓN GENERAL (cómo lo valora) con el servicio de bicicleta pública que presta BiciMAD?

Por favor, emplee una escala de 1 a 5, donde 1 significa que está totalmente insatisfecho con la característica y 5 que está muy satisfecho.

$$
\begin{aligned}
& 1 \text { - Totalmente } \\
& \text { insatisfecho }
\end{aligned}
$$$$
2
$$$$
3
$$

5 - Totalmente satisfecho

Satisfacción general con

BiciMAD 


\section{DETALLES PERSONALES}

A continuación encontrará algunas preguntas personales. Le recordamos que los datos se emplearán exclusivamente para un estudio cientifico de forma anónima, respetando las leyes en materia de protección de datos.

C1. Género:

Hombre

Mujer

\section{C2. Edad:}

Año

Año de nacimieno

C3. Nivel de estudios alcanzado:

Sin estudios

Enseñanza primaria

Enseñanza secundaria

Bachillerato

Formación profesional

Grado/Licenciatura/Diplomatura

Máster

Doctorado

Otro (especifique) 


\section{DETALLES PERSONALES}

C4. ¿Cuál es su situación laboral?

Empleado

Autónomo

Desempleado

Jubilado

Estudiante

Ama/o de casa

Otro (especifique)

C5. ¿Usted tiene...?

Carnet de conducir

Acceso a coche

Acceso a motocicleta o ciclomotor

Abono de Transportes

Ninguna de las anteriores 


\section{DETALLES PERSONALES}

C6. Código postal de su domicilio o de su residencia habitual en Madrid: (si no aplica: "00000")

C7. El número de personas que conviven en su hogar (incl. usted):
1
2
3
4
5
Más

C8. Nivel de ingresos neto en su hogar al mes:

Menos o igual de $1.300 €$

$1.300-2.500 €$

Más de $2.500 €$ 
Aquí puede dejar sus comentarios sobre la movilidad ciclista y el servicio público de bicicleta de Madrid.

(Campo opcional. Si no tiene comentarios, pulse el botón Siguiente.) 


\section{FIN DEL CUESTIONARIO}

\section{¡Muchas gracias por su colaboración!}

Si desea participar en el sorteo y/o recibir información sobre los resultados de la encuesta directamente, por favor, escriba aquí su dirección de correo electrónico:

Confirmación del correo electrónico:

Número de teléfono (opcional, si quiere que se utilice este medio para avisarle del premio):

En la página web www.bicimad.transyt-projects.com la semana del 4 de julio de 2016 se indicará si su número de encuesta es el GANADOR. Si nos da alguna de las informaciones anteriores se lo comunicaremos personalmente.

Si tiene alguna duda, póngase en contacto con nosotros en la siguiente dirección de correo: bicimad@caminos.upm.es

Para finalizar el cuestionario, pulse el botón "Listo".

MUCHAS GRACIAS POR SU TIEMPO. 
I.b) MULTIMODAL APP SURVEY 
Behavioral factors underlying the adoption of smart mobility solutions

(This page has been intentionally left blank) 


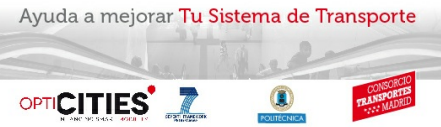

Bienvenido

Bienvenido y gracias por participar en la segunda fase del estudio de movilidad urbana del CRTM y UPM como socios del proyecto OPTICITIES. Este cuestionario está destinado a todos los participantes que hayan descargado, instalado e iniciado la aplicación "Mi Transporte" de CRTM en su dispositivo móvil.

Por favor, introduzca su número de acceso* al cuestionario. (Código que figura en el correo electrónico que le fue enviado con el enlace a este cuestionario.)

Al pulsar "Siguiente" accederá al cuestionario, que dura aproximadamente 8 minutos. Le pedimos que lo rellene con atención. No olvide que puede añadir sus comentarios al final del mismo. El cuestionario es anónimo, con fines de investigación y de mejora del servicio de transporte ofrecido por el CRTM, respetándose la normativa en materia de protección de datos. Le agradecemos su participación.

*EL CÓDIGO ES PERSONAL Y NO DEBE SER INTRODUCIDO POR MÁS DE UNA PERSONA (NO DA DERECHO A PREMIOS A MÁS DE UNA PERSONA) 


\section{La nueva aplicación}

EI CRTM ha subido a los mercados la aplicación "Mi Transporte" para dispositivos móviles que proporciona información sobre su posición y los servicios de transporte para mejorar la calidad de sus viajes en transporte público en la Comunidad de Madrid.

En esta fase del proyecto OPTICITIES Usted puede participar en un estudio consistente en probar la nueva aplicación durante un tiempo y darnos su opinión respondiendo a este breve cuestionario. Esto le dará derecho a participar en el sorteo de más premios.

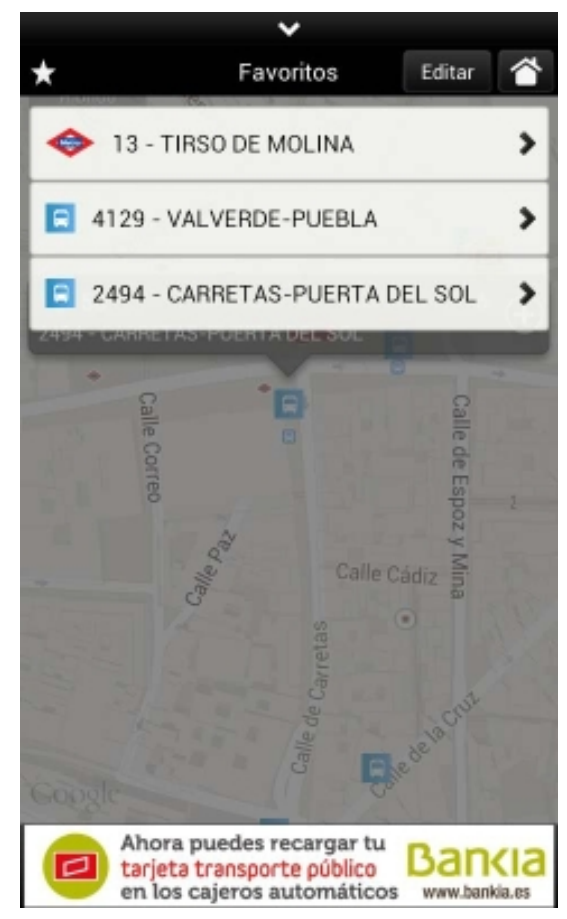




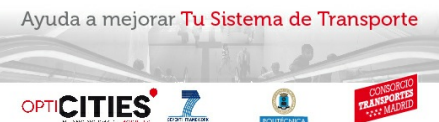

Descarga y uso de la aplicación

¿Hace cuánto descargó Usted la aplicación "Mi Transporte"?

Hoy

Hace menos de una semana

Hace más de una semana 


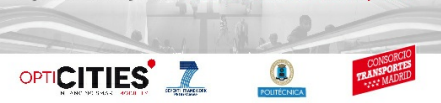

Dispositivo móvil

En esta pantalla encontrará preguntas acerca del dispositivo móvil en el cual ha descargado la aplicación.

Tipo de dispositivo móvil:

Teléfono inteligente

Tablet

Ambos, preferentemente teléfono inteligente

Ambos, preferentemente tablet

Sistema operativo del dispositivo móvil:

Android

iOS (por ejemplo iPhone, iPad)

Ambos

Marca (opcional) :

Modelo (opcional), por ejemplo: Galaxy S5, Nexus 5, Xperia Z3...: 


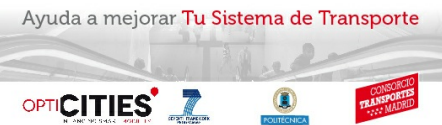

Instalación e iniciación

¿Hasta qué nivel está satisfecho conel proceso de instalación de la app?

Por favor, responda con su opinión utilizando la siguiente escala de 1 a 5, donde1 significa totalmente insatisfecho y 5 significa totalmente satisfecho.

1 -

Totalmente insatisfecho

Buscar la app en

la tienda en línea

Descargar la

aplicación en mi

dispositivo móvil

Instalación

Iniciación (primer

uso)

Configuración
5 -

4 Totalmente satisfecho

3

$\bigcirc$

○

O

0

.

P 
¿Hasta ahora cuántas veces ha utilizado "Mi Transporte" para consultas sobre sus viajes?

Ninguna

Una

Algunas veces

La empleo con frecuencia

¿En qué tipo de viajes ha utilizado o utiliza la aplicación? Puede marcar varios.

$\square$ Su viaje más frecuente (el viaje que realiza un mayor número de veces a lo largo de la semana)

$\square$ Sus viajes ocasionales (que realiza a menudo pero no es el más frecuente)

$\square$ Sus viajes no habituales (por ejemplo, en un barrio desconocido)

$\square$ En caso de incidencias (servicio de transporte público alterado, calle cortada, etc.)

$\square$ Otro (especifique) 


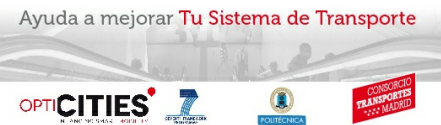

Diseño

Indique, por favor, hasta qué nivel está satisfecho con el diseño de la aplicación.

Por favor, responda con su opinión utilizando la siguiente escala de 1 a 5, donde1 significa totalmente insatisfecho y 5 significa totalmente satisfecho.

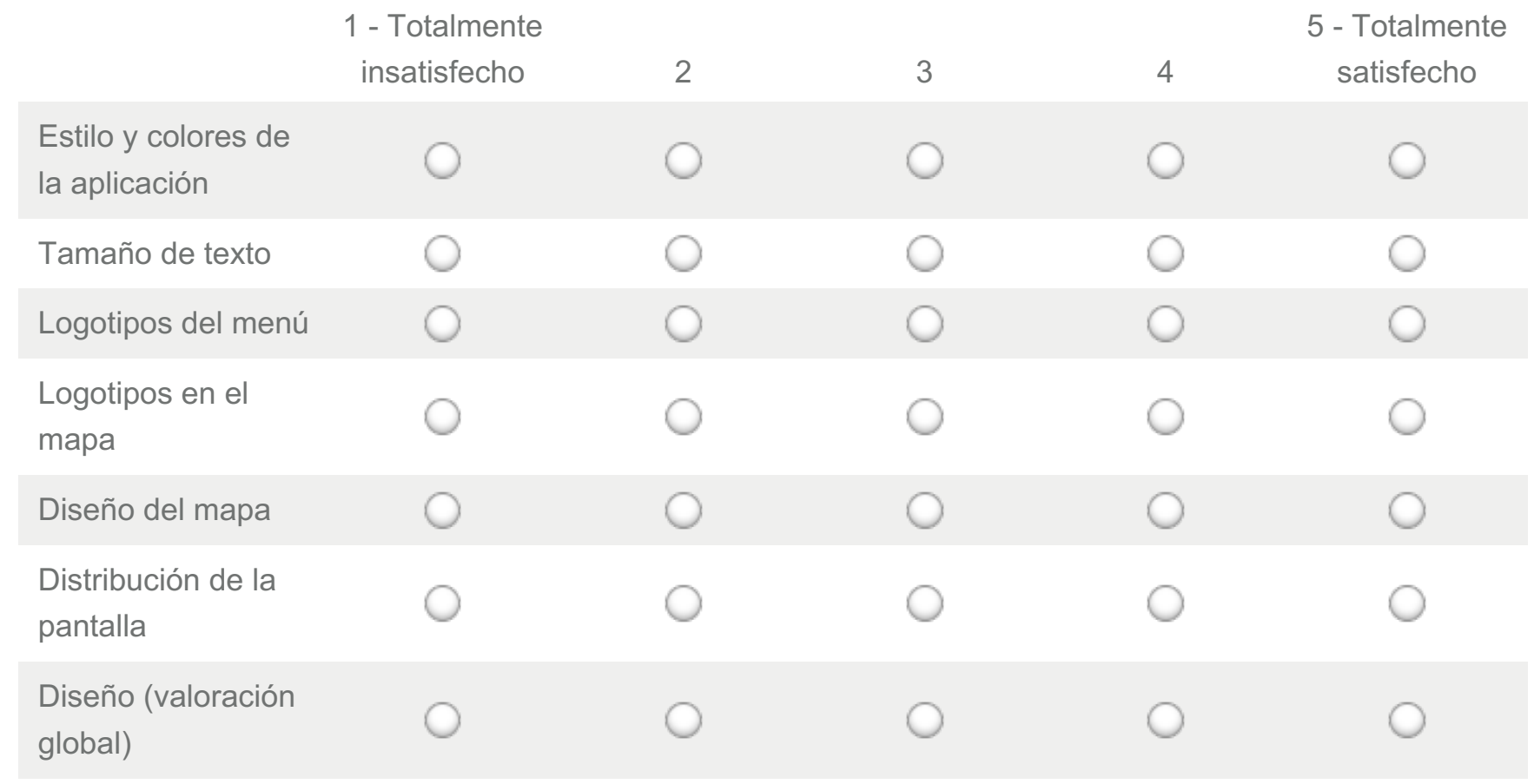




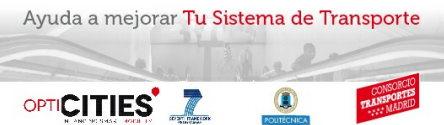

Funcionalidades de la aplicación

Indique, por favor, hasta qué nivel está satisfecho con las siguientes funcionalidades de la aplicación.

Por favor, responda con su opinión utilizando la siguiente escala de 1 a 5 , donde1 significa totalmente insatisfecho y 5 significa totalmente satisfecho.

1

- Totalmente insatisfecho
5

- Totalmente satisfecho

Visualización de su posición en tiempo real

Navegación por el mapa

Búsqueda de paradas/estaciones de toda la red

Visualización de las direcciones a seguir (hasta una parada cercana)

Guardar favoritos

Alertas sobre incidencias

Configurar alarmas en relación con sus paradas favoritas

Visualización de líneas de toda la red de transporte público

Visualización de rutas de toda la red de transporte público

Guía rápida del uso de la app 


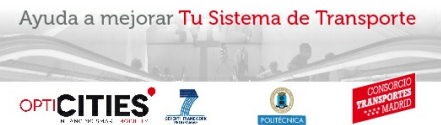

\section{Búsqueda}

Indique, por favor, hasta qué nivel está satisfecho con las siguientes opciones de búsqueda de paradas/estaciones cercanas.

Por favor, responda con su opinión utilizando la siguiente escala de 1 a 5 , donde1 significa totalmente insatisfecho y 5 significa totalmente satisfecho.

1

- Totalmente insatisfecho
5

- Totalmente satisfecho

Buscar por el nombre de la parada (por ejemplo, Princesa-Pza. España)

3

4

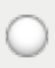

Boscar por el código de la parada (por ejemplo, "1750")

Buscar la parada de una línea elegida (por ejemplo, la línea 2 de la EMT)

Buscar la parada más cercana de un modo de transporte público elegido (por ejemplo, autobuses)

Buscar la parada de transporte público más cercana

Buscar una parada en el mapa (con la visualización de su posición en tiempo real)

Buscar una parada según las direcciones indicadas (radar, flechas, etc.) 


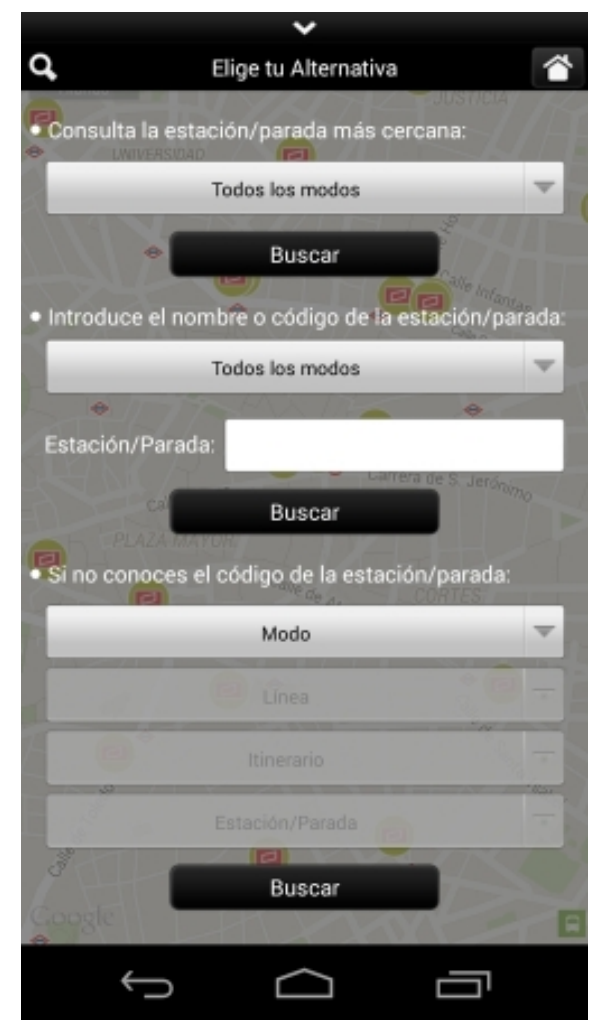


Ordene, por favor, las opciones de visualización de las direcciones a seguir hasta una parada/estación cercana.

Responda con su opinión ordenando las respuestas de 1 a 5 , donde1 significa la opción más útil y 5 la menos útil para Usted.

1.

Mapa

Carteles en realidad aumentada (a través de la cámara, Vs. la imagen en esta pantalla)

Flechas

Radar

Lista de paradas cercanas

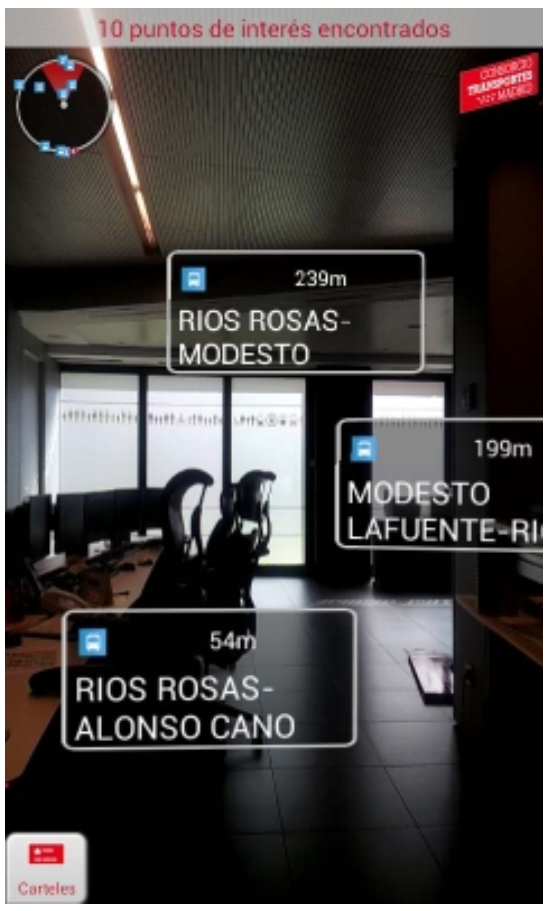

2.

3.

4. 5.

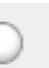

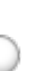




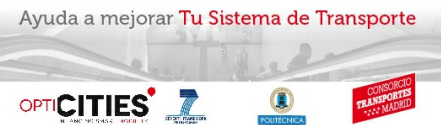

Utilidad de la aplicación

La siguiente sección contiene algunas declaraciones acerca de la aplicación. Por favor, indique su opinión según su parecer.

Emplee la siguiente escala de 1 a 5 en la que1 equivale a totalmente en desacuerdo y 5 a totalmente de acuerdo.

1 -

Totalmente

5 -

en

Totalmente

desacuerdo

2

3

de acuerdo

Utilizar la app me permite ahorrar cierto tiempo de viaje

Gracias a la app logro llegar a mi destino más calmadamente

Gracias a la app puedo mejorar la regularidad en mis tiempos de desplazamiento

Gracias a la app puedo reducir el impacto de mis viajes sobre el medio ambiente

Creo que utilizar la app facilitará que cambie mis hábitos de transporte

La app me permite ahorrar dinero

La app me permite planificar mejor mis viajes

La app es fácil de usar 


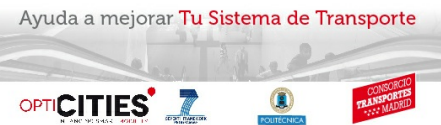

Atributos de la aplicación

Por favor, señale cuánto valora los siguientes atributos de la aplicación.

Responda con su opinión utilizando la siguiente escala de 1 a 5 , donde1 significa nada importante y 5 significa muy importante para Usted.

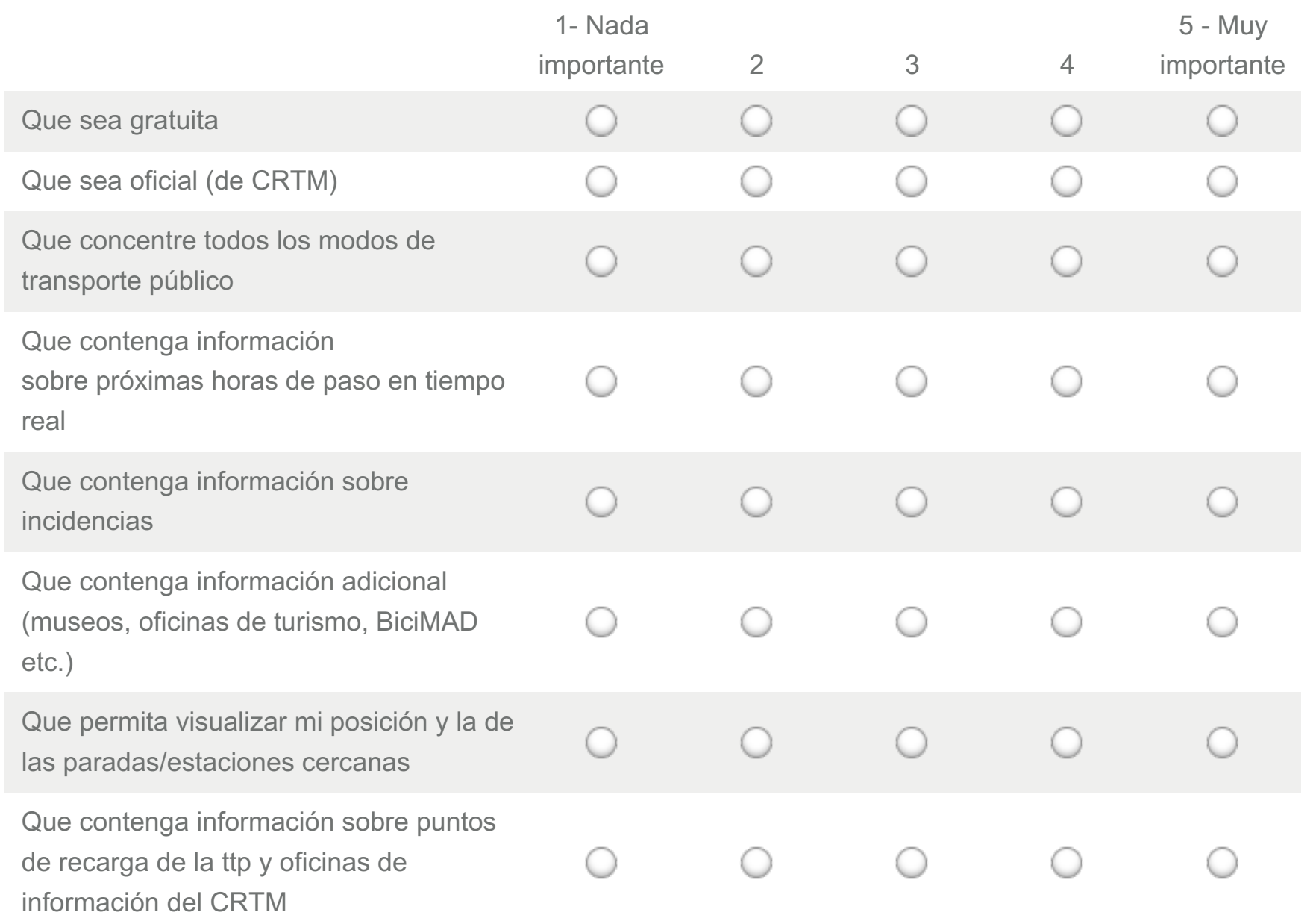


De la siguiente lista elijatodas las funcionalidades que le gustaría que la aplicación tuviese.

Alarmas de proximidad para informarle cuando se acerca a su destino durante su viaje

Planificador de ruta en tiempo real

Enviar sugerencias y avisos de incidentes a CRTM por los usuarios

Obtener sugerencias para optimizar sus viajes más frecuentes (en tiempo, número de trasbordos, etc.)

$\square$ Gamificación/juego (por ej. para mejorar sus hábitos de viaje reduciendo su huella energética)

$\square$ Consultar el saldo de su tarjeta de transporte público

$\square$ Información en tiempo real sobre las bicicletas y estaciones de BiciMAD

$\square$ Información en tiempo real sobre plazas de parking

$\square$ Horarios de apertura y cierre de estaciones e intercambiadores

$\square$ Información sobre precios de billetes

$\square$ Puntos de interés a lo largo de su ruta

$\square$ Posibilidad de pago desde la aplicación

$\square$ Compartir mis búsquedas y favoritos con mis amigos (Facebook, Whatsapp...)

$\square$ Rutas alternativas ante incidentes

Seguimiento de desplazamientos para darle información actualizada de interés durante su trayecto (guía turística, eventos culturales próximos....)

Guía de desplazamientos para hacer sus viajes más saludables, reducir huella de carbono, consumo energético...

Cruce de información con otras fuentes (calidad del aire, datos meteorológicos...)

$\square$ Otro (especifique) 


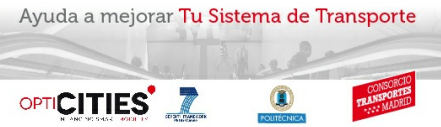

Valoración global y comentarios

Indique, por favor, su valoración global después del primer uso.

Por favor, responda con su opinión utilizando la siguiente escala de 1 a 5 , donde1 significa totalmente insatisfecho y 5 significa totalmente satisfecho.

5

1 - Totalmente

- Totalmente

insatisfecho

2

3

4 satisfecho

Valoración global de la aplicación "Mi Transporte"

Si lo desea, puede añadir comentarios sobre la aplicación: instalación, diseño, funcionalidades, etc. (opcional). 


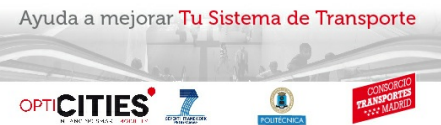

GRACIAS POR COMPLETAR EL CUESTIONARIO

Para completar el cuestionario, tiene que pulsar el botón "Listo"en la parte inferior de esta página.

En breve nos pondremos en contacto con Usted por correo electrónico (o teléfono) para facilitarle información sobre los premios.

Si quiere que le contactemos -en relación con los premios y la última fase del proyecto- a través de una dirección/número distinto del empleado para enviarle el enlace a este cuestionario, por favor, indíquelo a continuación (opcional).

Correo electrónico:

Teléfono:

Puede enviar cualquier pregunta u opinión adicional por correo electrónico aopticities@crtm.es.

IMUCHAS GRACIAS POR SU COLABORACIÓN, SU OPINIÓN NOS AYUDA A MEJORAR EL SISTEMA DE TRANSPORTE PÚBLICO! 
I.C) CARSHARE SURVEY 
Behavioral factors underlying the adoption of smart mobility solutions

(This page has been intentionally left blank) 


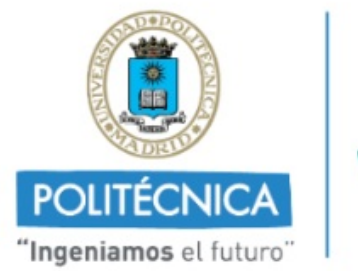

\section{TRANSYT}

ESTUDIO SOBRE EL VEHÍCULO COMPARTIDO EN MADRID

\section{Bienvenido}

Smartvision es un nuevo concepto de vehículo compartido: inteligente, conectado, autónomo, eléctrico y sin volante.

Ante la perspectiva de que este sistema pueda llegar a funcionar en Madrid, el Centro de Investigación del Transporte de la UPM (TRANSyT) está realizando un estudio con el objetivo de analizar el uso de los vehículos compartidos actualmente en funcionando en Madrid.

Tomado de smart vision EQ fortwo. Presentado en la feria del Automovil 2017 en Frankfurt

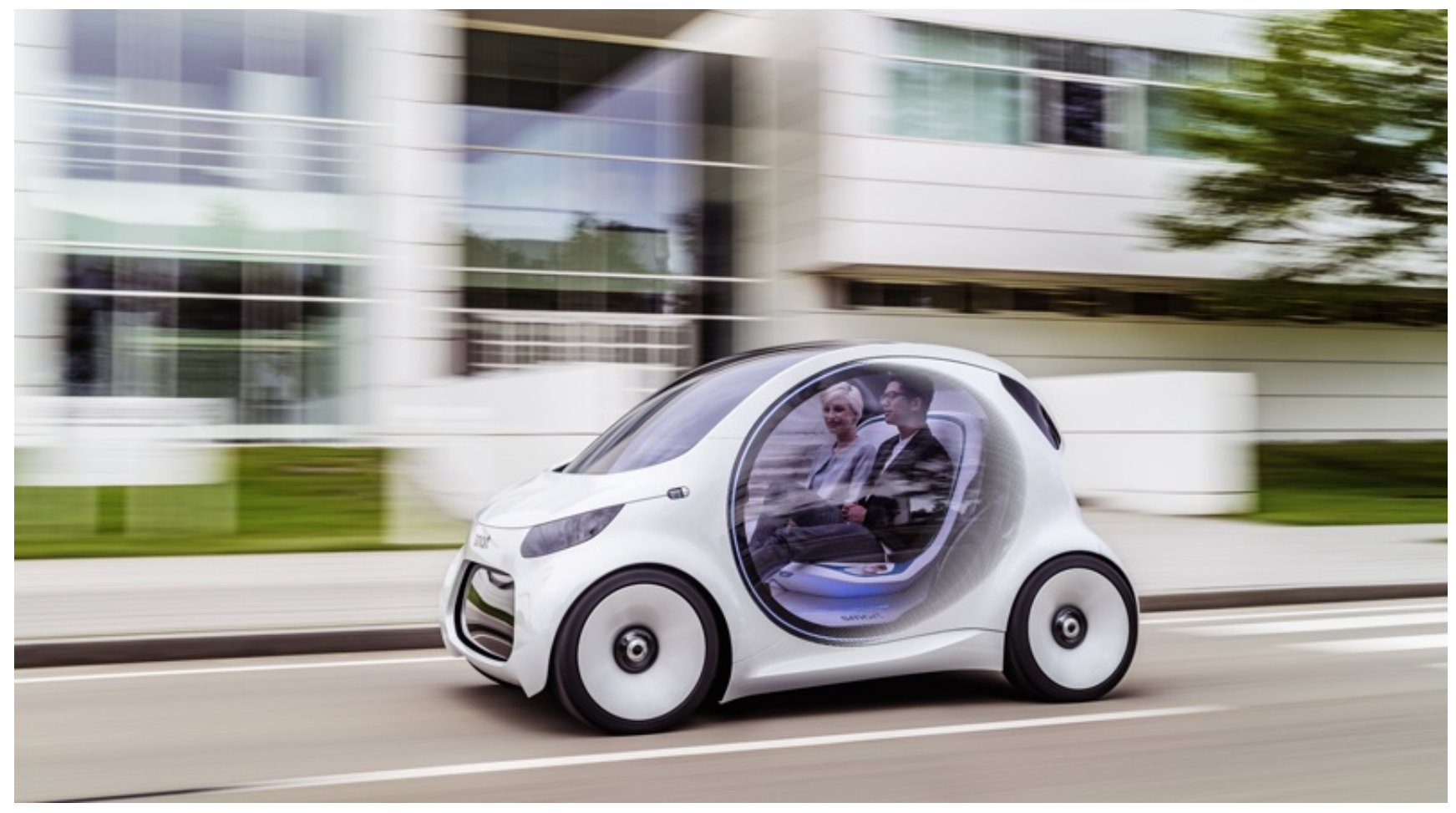



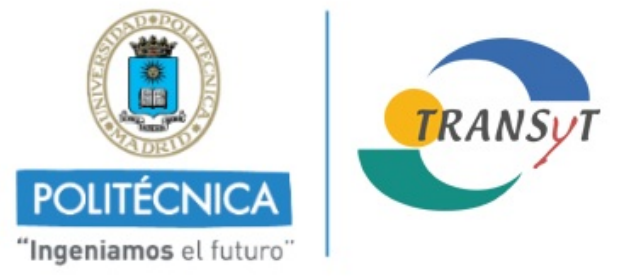

\section{ESTUDIO SOBRE EL VEHÍCULO COMPARTIDO EN MADRID}

\section{Bienvenido}

IMPORTANTE: En el presente estudio se entiende como "vehículo compartido" el modelo de Car2Go, Emov, Bluemove o Respiro, y no el de "viajes compartidos" como Blablacar o Amovens.

La encuesta se completa en 10-12 minutos. Para agradecerle su participación, con su respuesta entrará en el SORTEO DE CAJAS SMARTBOX:

\section{1 x Desconecta tres días/Noche romántica/Opera/Cena Gourmet (99.9€) $3 \times$ Spa para dos (39.9€)/Pura adrenalina (44.9€)

$$
7 \text { x Vino y Tapas (19.9€) }
$$

¡Su opinión es muy importante para nuestro estudio!

¡Muchas gracias por su colaboración!

La encuesta es anónima y de carácter voluntario, respetándose todas las normas en materia de protección de datos personales. Si tiene alguna duda, puede ponerse en contacto con nosotros en la siguiente dirección de correo electrónico: g.velazquez@upm.es
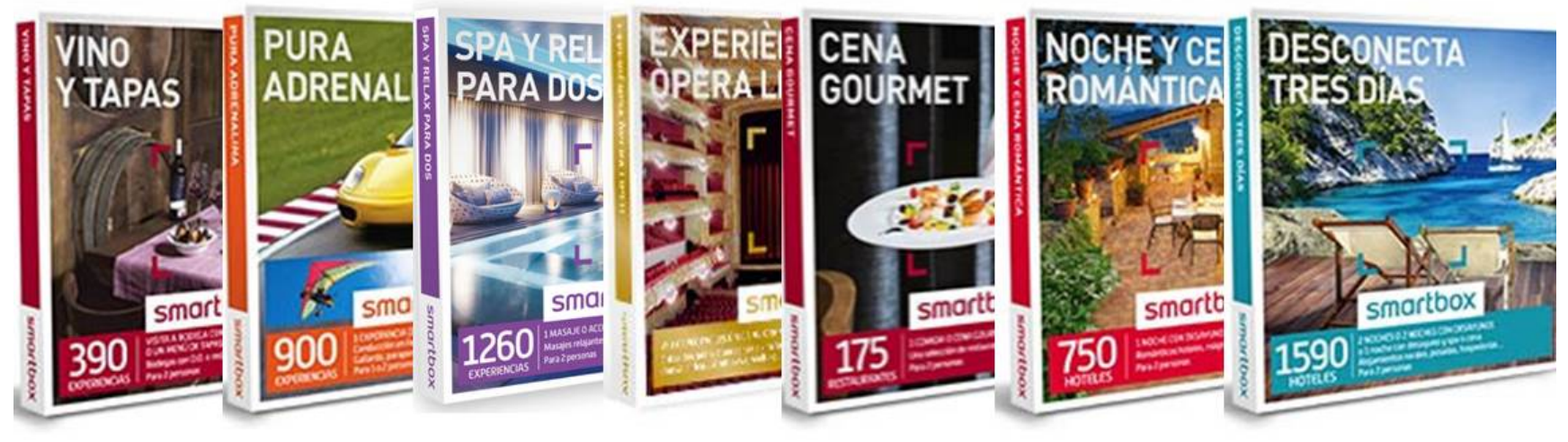


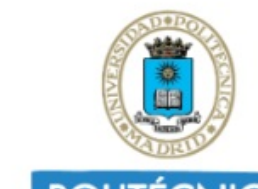

\section{POLITÉCNICA}

\section{TRANSYT}

"Ingeniamos el futuro"

\section{ESTUDIO SOBRE EL VEHÍCULO COMPARTIDO EN} MADRID

\section{Datos de movilidad urbana}

* 1. ¿Dispone de Vehículo Propio?

Tengo mi propio vehículo

Tengo acceso a un vehículo en mi hogar

No tengo acceso a vehículo particular, pero si carnet

No tengo carnet de conducir

* 2. ¿Qué modos de transporte empleas a lo largo de la semana?

Coche privado
Coche Compartido
Moto compartida
Transporte Público (Metro-Bus-Cercanías)
Bicicleta privada
Bicicleta Compartida
Andar (trayectos de más de 10 minutos)


* 3. Por favor indique de cuales de los siguientes sistemas de vehículo compartido es usted usuario (Respuesta múltiple)

$\square$ Car2Go

Emov

$\square$ Respiro

$\square$ Bluemove

$\square$ Ninguno 


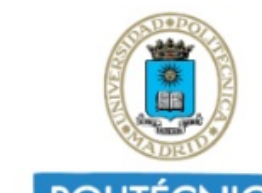

\section{POLITÉCNICA}

\section{TRANSYT}

"Ingeniamos el futuro"

\section{ESTUDIO SOBRE EL VEHÍCULO COMPARTIDO EN} MADRID

\section{Propósito de viaje}

* 4. ¿Con qué frecuencia emplea el vehículo compartido para sus diferentes viajes?

Con

Nunca Raramente Aveces frecuencia Siempre

Para ir a trabajar/centro de estudio

Para viajes de ocio

Para ir de compras

Para visitar a amigos/familiares

Para ir al centro de Madrid

Para ir a zonas de Madrid sin buen acceso con Transporte

Público/bicimad

Para ir a reuniones de trabajo

Para salir de noche

* 5. Los trayectos que realiza en vehículo compartido antes los realizaba principalmente:

Andando

En bicicleta

En coche particular

En transporte público

En taxi

En moto

Son viajes que no realizaba antes 


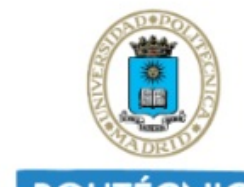

\section{POLITÉCNICA}

\section{TRANSYT}

"Ingeniamos el futuro"

\section{ESTUDIO SOBRE EL VEHÍCULO COMPARTIDO EN} MADRID

\section{Experiencia con los vehículos compartidos}

*6. ¿Cuál es tu experiencia con los vehículos compartidos?

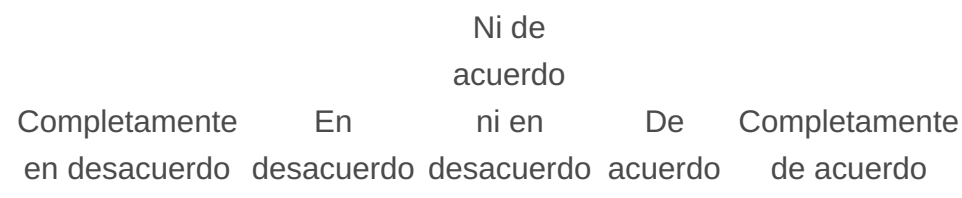

Sé reconocer las marcas de los vehículos compartidos en la calle

Sé los precios de uso de los vehículos compartidos

Sé los términos de uso de los vehículos compartidos

Sé la cobertura del seguro de los vehículos

compartidos

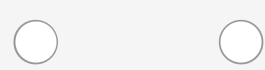

O

$\bigcirc$
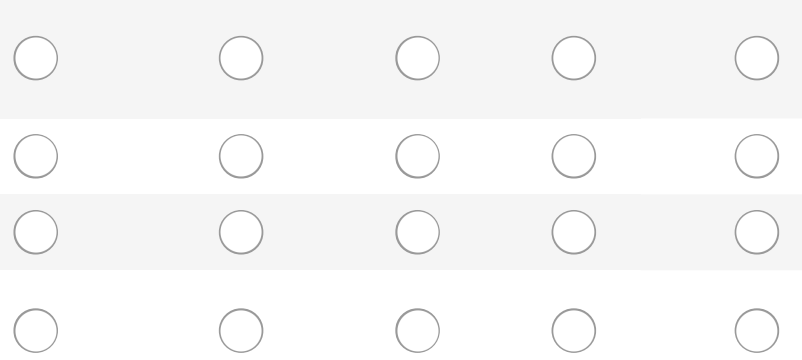

* 7. ¿Qué piensas sobre el uso de los vehículos compartidos?

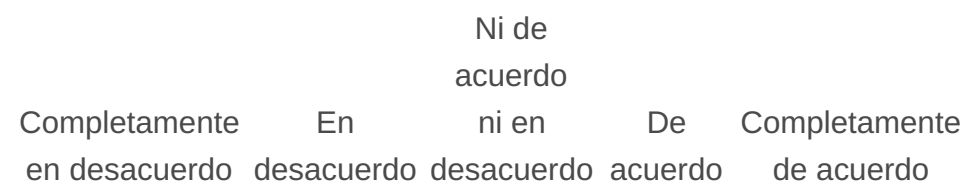

Los vehículos compartidos son fáciles de reservar

Los vehículos compartidos son fáciles de encontrar

Los vehículos compartidos son fáciles de aparcar
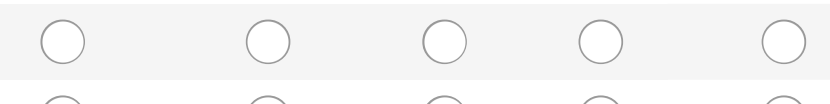

Los vehículos compartidos son fáciles de utilizar

(arranque, apagado, cierre...) 


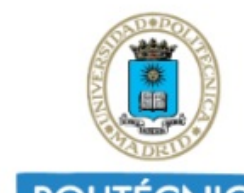

\section{POLITÉCNICA}

\section{TRANSYT}

"Ingeniamos el futuro"

\section{ESTUDIO SOBRE EL VEHÍCULO COMPARTIDO EN} MADRID

\section{Propósito de viaje}

* 8. ¿Con qué frecuencia emplea el coche PRIVADO para sus diferentes viajes?

Con

Nunca Raramente Aveces frecuencia Siempre

Para ir a trabajar/centro de estudio

Para viajes de ocio

Para ir de compras

Para visitar a amigos/familiares

Para ir al centro de Madrid

Para ir a zonas de Madrid sin buen acceso con Transporte

Público/bicimad

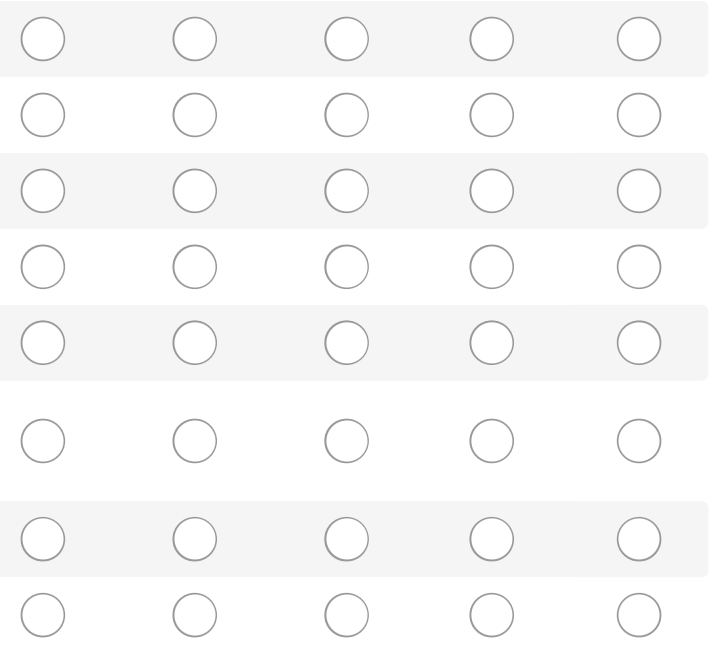

Para ir a reuniones de trabajo

Para salir de noche

* 9. ¿Cuales de los siguientes son tus motivos para no usar el coche compartido?

No tengo tiempo para ir a darme de alta
No quiero facilitar mis datos bancarios
No se puede probar sin compromiso
No me compensa el precio
No estoy tranquilo conduciendo vehículos ajenos
No me convence la política de seguro
Tengo mi propio vehículo




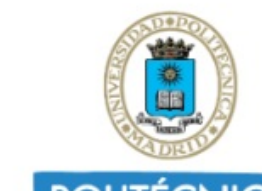

\section{POLITÉCNICA}

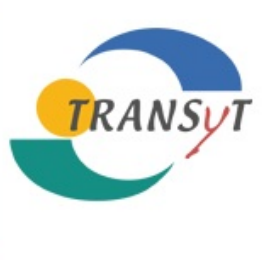

\section{ESTUDIO SOBRE EL VEHÍCULO COMPARTIDO EN MADRID}

\section{Experiencia con los vehículos compartidos}

* 10. ¿Cuál es tu experiencia con los vehículos compartidos?

Nide
acuerdo
Completamente En ni en De Completamente
en desacuerdo desacuerdo desacuerdo acuerdo

He probado un sistema de vehículos compartidos

He estudiado la posibilidad de utilizar vehículos compartidos

He descargado alguna APP de vehículos compartidos

He accedido el sitio web de sistemas de vehículo compartido

Sé reconocer las marcas de los vehículos compartidos en la calle

Sé los precios de uso de los vehículos compartidos

Sé los términos de uso de los vehículos compartidos

Sé la cobertura del seguro de los vehículos

compartidos
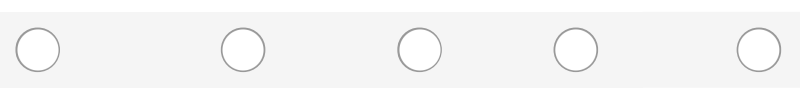


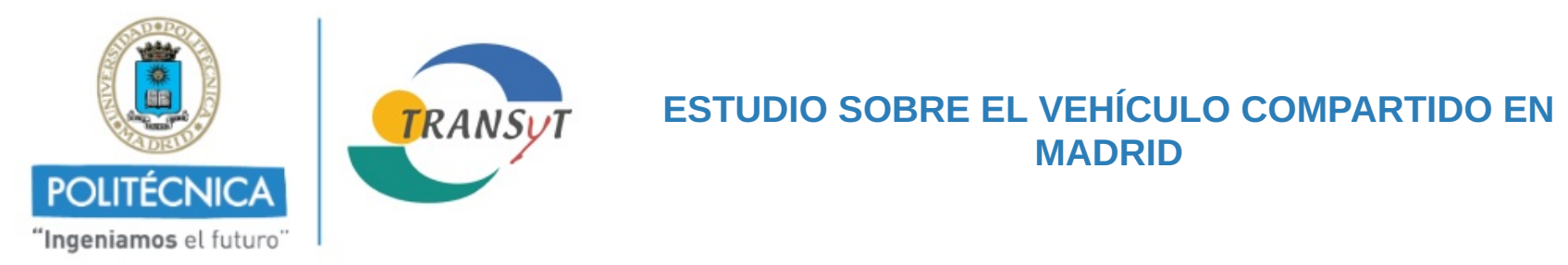

Imagen de los vehículos compartidos

* 11. ¿Qué piensas sobre la visibilidad e imagen de los vehículos compartidos?

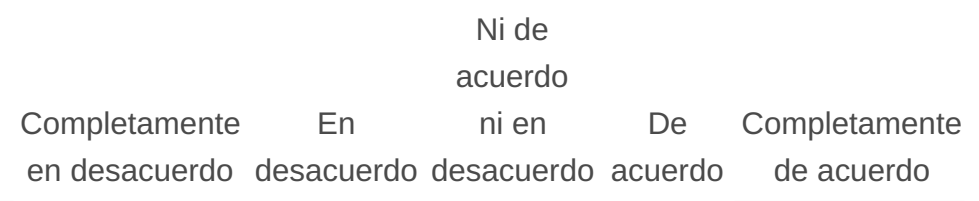

\begin{abstract}
Siempre veo gente circulando en vehículos compartidos
\end{abstract}

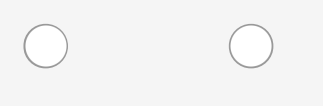

Siempre veo vehículos compartidos aparcados en la calle

Siempre veo vehículos compartidos aparcados cerca de mi casa

Siempre veo vehículos compartidos aparcados cerca de mi trabajo

Parece que a mucha gente le interesa usar vehículos compartidos

Conozco gente que utiliza vehículos compartidos

Veo anuncios promocionando los vehículos compartidos 


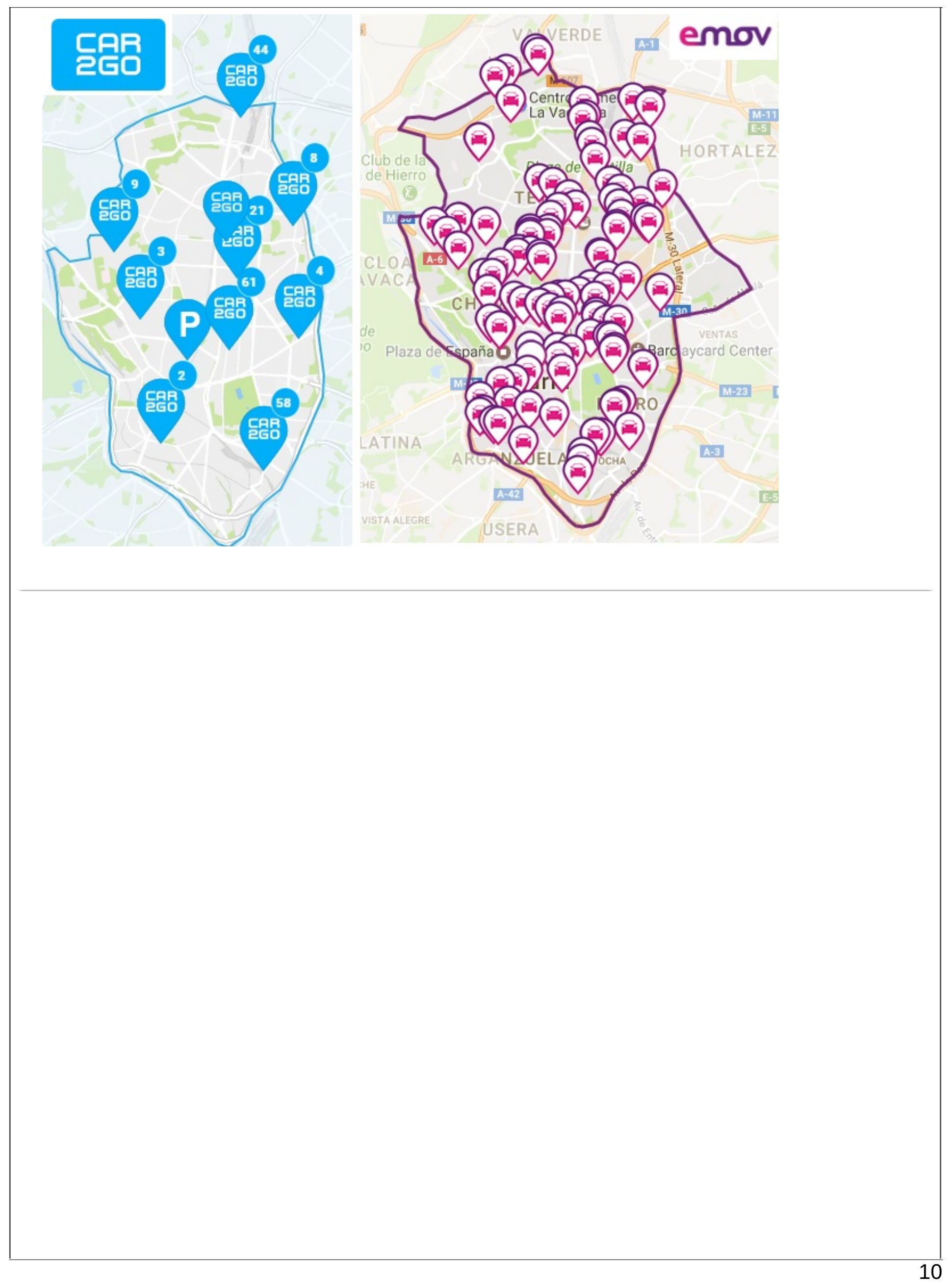




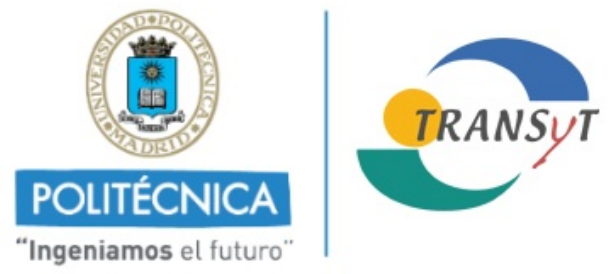

\section{ESTUDIO SOBRE EL VEHÍCULO COMPARTIDO EN MADRID}

\section{Opiniones personales}

\section{En esta parte de la encuesta encontrará preguntas dirigidas a conocer susopiniones personales sobre los vehículos compartidos. Por favor responda empleando las escalas facilitadas.}

* 12. ¿Qué piensas sobre la utilidad de los vehículos compartidos?

Nide
acuerdo
$\begin{aligned} & \text { Completamente En ni en De Completamente } \\ & \text { en desacuerdo desacuerdo desacuerdo acuerdo }\end{aligned}$

Los vehículos compartidos son más sostenibles que los vehículos privados

Los vehículos compartidos son más prácticos que los coches privados

Los vehículos compartidos tienen una flota más actualizada

Los vehículos compartidos son más baratos que el coche privado

Los vehículos compartidos te limitan menos que el coche privado

Los vehículos compartidos son más flexibles que el transporte público

Los vehículos compartidos son más cómodos que otros modos 


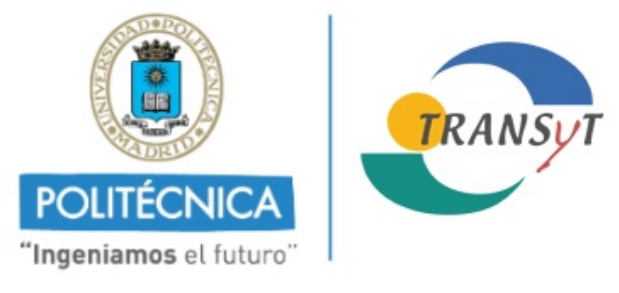

\section{ESTUDIO SOBRE EL VEHÍCULO COMPARTIDO EN MADRID}

\section{Dificultades de uso}

* 13. ¿Cuáles son tus contras a la hora de utilizar vehículos compartidos?

$\begin{array}{ccc} & \text { Nide } \\ \text { acuerdo } & \\ \text { Completamente En } \quad \text { ni en De } & \text { Completamente } \\ \text { en desacuerdo desacuerdo desacuerdo acuerdo } & \text { de acuerdo }\end{array}$

En el vehículo compartido no puedo dejar mis cosas

(gafas, documentos, caramelos...)

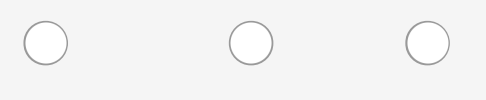

El vehículo compartido puede no estar disponible cuando lo necesite

En el vehículo compartido no puedo fumar

El vehículo compartido puede estar sucio

El vehículo compartido puede estar dañado

El vehículo compartido puede estar sin batería

El vehículo compartido requiere tener el móvil con batería e internet

El vehículo compartido no cubre suficiente zona

El vehículo compartido es demasiado caro 
* 14. ¿Qué opinas de la recogida de datos por las empresas de vehículos compartidos?

\begin{tabular}{ccccc}
\multicolumn{3}{c}{ Ni de } & & \\
Totalmente & acuerdo ni & Totalmente \\
en & En & en & De & de \\
desacuerdo desacuerdo desacuerdo & acuerdo & Acuerdo
\end{tabular}

Acepto que se recopile información personal sobre mí para mejorar el servicio.

Acepto facilitar mis datos bancarios para acelerar el pago

Acepto que se analicen mis movimientos personales para mejorar la planificación de transporte

Acepto que puedan recoger datos sobre mi estilo de conducción para mejorar la seguridad vial

Acepto que mis datos personales se compartan con empresas para recibir ofertas y promociones
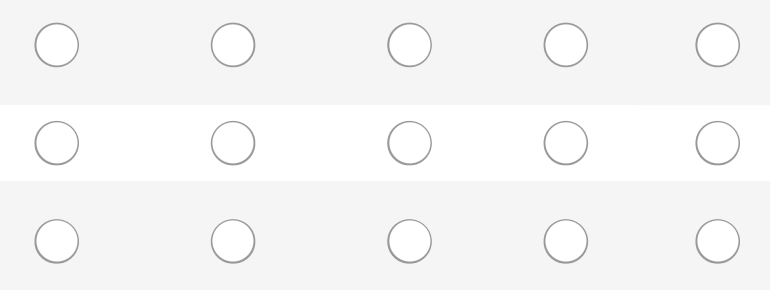

Acepto que mis datos personales sean vendidos para abaratar el servicio

Acepto que mis datos personales sean empleados para realizar estudios de movilidad 


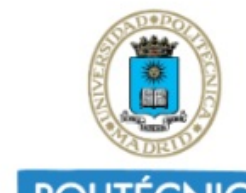

\section{POLITÉCNICA}

\section{TRANSYT}

"Ingeniamos el futuro"

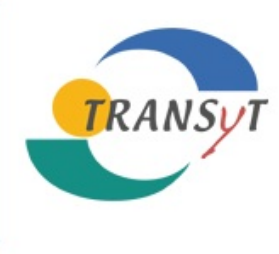

\section{ESTUDIO SOBRE EL VEHÍCULO COMPARTIDO EN} MADRID

\section{Eficiencia colectiva}

\section{* 15. ¿Qué piensa sobre la conciencia social de Madrid?}

Ni de acuerdo ni

$\begin{array}{lcccc}\text { Completamente } & \text { En } & \text { en } & \text { De } & \text { Completamente } \\ \text { en desacuerdo desacuerdo desacuerdo acuerdo } & \text { de Acuerdo }\end{array}$

Creo que las personas en Madrid son capaces de hacer la movilidad más sostenible

Creo que a las personas de Madrid les preocupa el bienestar de los demás, la gente es solidaria

Creo que las personas en Madrid hacen lo que pueden para mejorar el medio ambiente

Creo que entre todos se puede hacer de Madrid una ciudad de cero emisiones

Creo que cuanta más gente utilice los vehículos compartidos, más gente los probará

Creo que el fenómeno de usar vehículos compartidos está de moda en Madrid

Creo que últimamente se habla mucho de los vehículos compartidos

Cuando uso el coche compartido siento que soy socialmente responsable

Cuando uso el coche compartido siento que cumplo con mi parte en la sostenibilidad

Creo que es importante contribuir con mi parte a la sostenibilidad para que todo el mundo lo haga
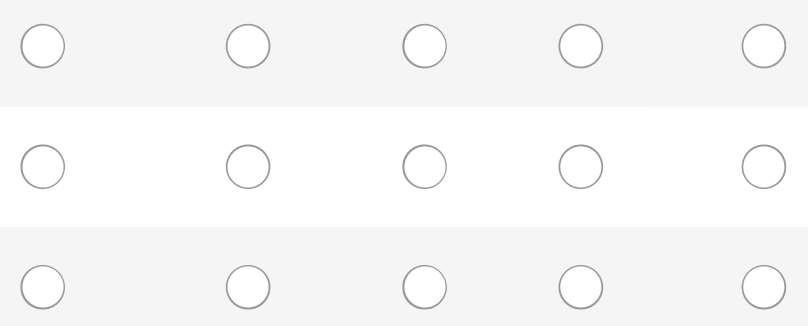

\section{a}

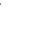
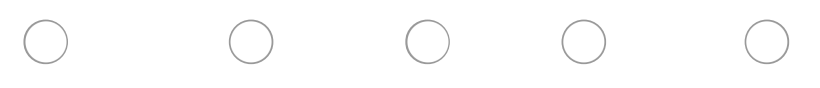


\section{POLITÉCNICA}

"Ingeniamos el futuro"

\section{Estilo de Conducción}

En esta parte queremos conocer su estilo de conducción para entender la utilidad que podría tener la mejora de la circulación gracias a los vehículos compartidos.

Le recordamos que la encuesta es anónima y le pedimos que responda con sinceridad empleando la escala proporcionada Nunca-Siempre.

\section{* 16. Velocidad}

Por favor indique con qué frecuencia se producen las siguientes situaciones mientras conduce

Nunca

Disfrutar la sensación de conducir al límite

Sentir que el

coche pide velocidad

Conducir un poco por encima del

máximo permitido

Pegarse a otros

vehículos

Acelerar cuando

tratan de adelantarle
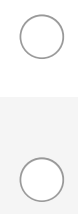

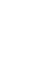

Raramente

$A$ veces

Con frecuencia

Siempre
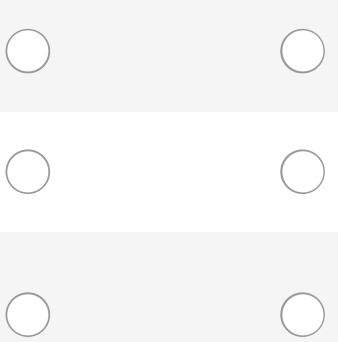
* 17. Nivel de atención

Por favor indique con qué frecuencia se producen las siguientes situaciones mientras conduce

$\begin{array}{lllll}\text { Nunca } & \text { Raramente } & \text { A veces frecuencia Siempre }\end{array}$

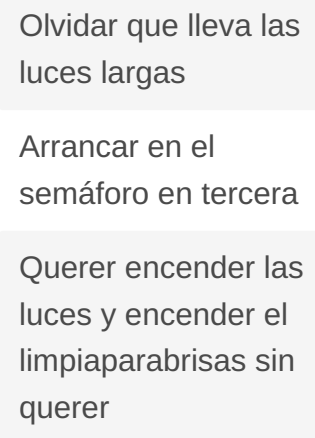

Olvidar que lleva las

luces largas

Arrancar en el

semáforo en tercera

Querer encender las

luces y encender el

limpiaparabrisas sin

querer

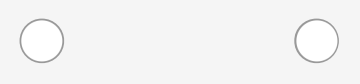

Olvidar planear su ruta

conforme al tráfico

Casi chocar por no

estimar bien el

espacio

Por ir distraído, tener

que frenar

bruscamente

Por ir distraído, tomar

una calle equivocada

No advertir que un

peatón estaba

cruzando

Por ir siguiendo el

tráfico, pasar un

semáforo en rojo 
* 18. Interacción con otros usuarios

Por favor indique con qué frecuencia se producen las siguientes situaciones mientras conduce

Intentar conducir con
precaución
Actuar pensando que
mejor prevenir que
curar
En cedas al paso y
rotondas esperar con
paciencia
Conducir pendiente de
las maniobras de otros
En caso de duda dejar
pasar a los demás

\section{* 19. Estrés al volante}

Por favor indique con qué frecuencia se producen las siguientes situaciones mientras conduce

$\begin{array}{llll}\text { Nunca } & \text { Raramente } & \text { A veces frecuencia }\end{array}$

Sentirse estresado
mientas conduzco
Sentirse nervioso
mientras conduzco
Ponerse impaciente
en atascos

Sentirse estresado cerca de bicis o buses

00

\section{* 20. Aprovechamiento del viaje al conducir}

Por favor indique con qué frecuencia se producen las siguientes situaciones mientras conduce

Escuchar radio/música
Pensar en otras cosas
Hablar por teléfono
Comer algo
Arreglarse antes de entorno
llegar




\section{POLITÉCNICA}

TRANSYT

“Ingeniamos el futuro"

\section{ESTUDIO SOBRE EL VEHÍCULO COMPARTIDO EN} MADRID

\section{Algunos datos sobre usted}

Por último necesitamos conocer algunos datos.

Le recordamos que todos los datos serán tratados anónimamente y con el fin exclusivo del presente estudio.

* 21. ¿Qué edad tiene usted?

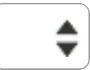

* 22. Género

Hombre

Mujer

Otro

* 23. Nivel de estudios

Enseñanza obligatoria

Formación Profesional

Bachillerato

Grado Universitario/Licenciatura/Diplomatura

Posgrado 
24. Por favor indique el nivel de renta de su hogar

Menos de $1.000 € /$ mes

$1.000-2.000 € /$ mes

2.000-4.000€/mes

4.000-6.000€/mes

más de $6.000 € /$ mes

* 25. Por favor indique el número de miembros de su hogar

\section{$\rightarrow$}

* 26. Por favor indique el número de vehículos de que dispone su hogar

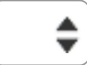

* 27. ¿Dispone usted de abono de transporte?

$\mathrm{Si}$

No

* 28. ¿Dispone usted de Smartphone?

$\mathrm{Si}$

No

* 29. Por favor indique si es usted usuario de los siguientes sistemas (Respuesta múltiple)

$\square$ Ecooltra

Muving

$\square$ Obike

$\square$ BiciMAD

$\square$ Ninguno 
* 30. Por último: ¿Ha utilizado alguna vez este tipo de servicios? (Respuesta múltiple)

Airbnb

Compartir piso

BiciMAD

Hostales con habitación compartida

Blablacar

Espacios de coworking

Compartir despacho

— Intercambio de objetos/muebles/ropa (Wallapop...)

Ninguna

31. El sorteo se realizará el 10 de Diciembre de 2017

Si desea participar en el sorteo así como ser informado de la segunda fase del estudio centrada en el vehículo autónomo, introduzca aquí su email de contacto: 


\section{POLITÉCNICA}

\section{ESTUDIO SOBRE EL VEHÍCULO COMPARTIDO EN}

MADRID

\section{Fin}

\section{Las respuestas se enviarán cuando pulse "Listo" ¡Gracias por su colaboración!}

Si lo desea le invitamos a compartir esta encuesta con su círculo mediante el siguiente enlace:

https://es.surveymonkey.com/r/CARMAD 
Behavioral factors underlying the adoption of smart mobility solutions

(This page has been intentionally left blank) 


\section{ANNEX $\|$ - RESEARCH ACTIVITIES THAT SUPPORTED THE THESIS}

Throughout the development process of this doctoral thesis, different research projects and research activities have been developed by the candidate. This section presents the most relevant ones, briefly describing their context and their contribution to the global work carried out in the thesis.

All these initial research works fueled the definition of my personal research trajectory that subsequently derived in this Thesis.

\section{ASCIMER PROJECT}

\section{ASCIMER \\ ASSESSING SMART CITY INITIATIVES \\ FOR THE MEDITERRANEAN REGION}

ASCIMER (Assessing Smart City Initiatives in the MEditerranean Region) was a three-year research project, funded by the EIB Institute under its EIBURS programme. The project addressed a tender to develop a general methodology to assess smart city projects with a particular application to the Southern Mediterranean Region. The project was framed within the H2020 R\&D EU initiative of smart cities (http://www.eiburs-ascimer.transyt-projects.com/).

The overall goal was to develop a comprehensive framework to help public and private stakeholders to make informed decisions about Smart City investment strategies and to build skills to evaluate and prioritize these kinds of projects, including solving difficulties regarding deployment and transferability. The project will address the following objectives:

- To define the Smart City concept and to understand how it can contribute to meeting urban development priorities.

- To develop a methodology to assess and prioritize Smart City projects.

- To develop guidelines to implement and manage Smart City Projects. 
- $\quad$ To Characterize Mediterranean City challenges and to develop a transferability strategy of Smart City projects. This objective will be part of the other three above.

\section{OPTICITIES PROJECT}

\section{OPTICITIES}

OPTICITIES was a three year research project aimed at Optimising Citizen Mobility and Freight Management in Urban Environments, funded by the European Commission under its 7th research framework programme. (http://www.opticities.com/)

The project consisted in the testing of different innovative technologies linked to citizen mobility and freight transport in the cities of Madrid, Lyon, Gothenburg, Wroclaw, Torino and Birmingham. The Universidad Politécnica de Madrid was involved in the Madrid pilot.

TRANSYT-UPM, the transport research centre was in charge of the design and execution of the experimentation plan of the two new technologies presented in the pilot; a public transport multimodal mobile app for the end user and a decision support tool for the transport operator in Madrid region (CRTM).

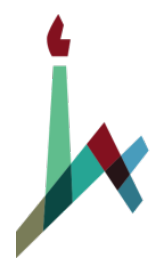

The research stay at the Hebrew university of Jerusalem, under the supervision of Professor Sigal Kaplan was focused on the study of factors related to the use and adoption of new intelligent transport services. The worthiness of this analysis lies in the understanding of potential design and policy elements that can lead towards the adoption of these solutions which are deemed as key for making cities more sustainable. 
The work was based on the data obtained from the survey carried out in OPTICITIES for a new public transport mobility APP in Madrid. Work was centred in the application of statistical analysis techniques (SEM modelling) with the advice of experienced researchers from the University of Tel Aviv and Jerusalem (Israel) and the exchange of experiences from previous cases of analysis carried out with such techniques. The used softwares were MPlus and SPSS. As an outcome came the better understanding of the factors more related to perception and intention to use mobility apps by different groups and consequently to address the implications on transport policy.

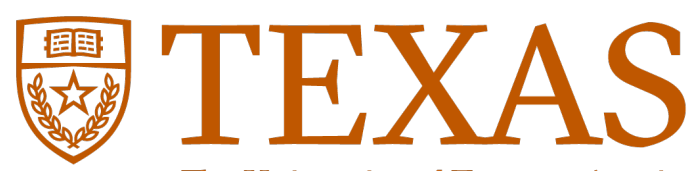

The University of Texas at Austin

The research stay at the University of Texas at Austin, under the supervision of Dr. Chandra Bhat, was carried out at the Transportation Research Center of the University of Texas at Austin. The Center has a recognized international prestige within the transportation research field and more specifically within studies for behavioral modelling in transportation.

In general, the stay has allowed me to know one of the most important American universities in the state of Texas, which is also one of the top valued internationally in the field of Civil Engineering. During the stay I had the chance of increasing my knowledge on data analysis software, studies on autonomous vehicles and long distance travel in the USA as well as on discrete choice models and behavioral models. From where I obtained useful insights to further develop my work. Applied this new knowledge to the improvement and updating of the user behavior models of the transport network of Madrid.

The work carried out during the stay can be summarized in the following points:

- Analysis of different evaluation systems and criteria for intelligent urban mobility technologies used in Europe and the United States.

- Review of different models to analyze the adoption of smart urban mobility solutions and their impact on transport behavior (SEM, ICLV, ...).

- Develop and validate a model for the case study of the shared electric vehicle. With the case study of the city of Madrid.

- Write a scientific paper based on the results obtained. 